Inert Electrodes Program

\title{
Results from a Pilot Cell Test of Cermet Anodes
}

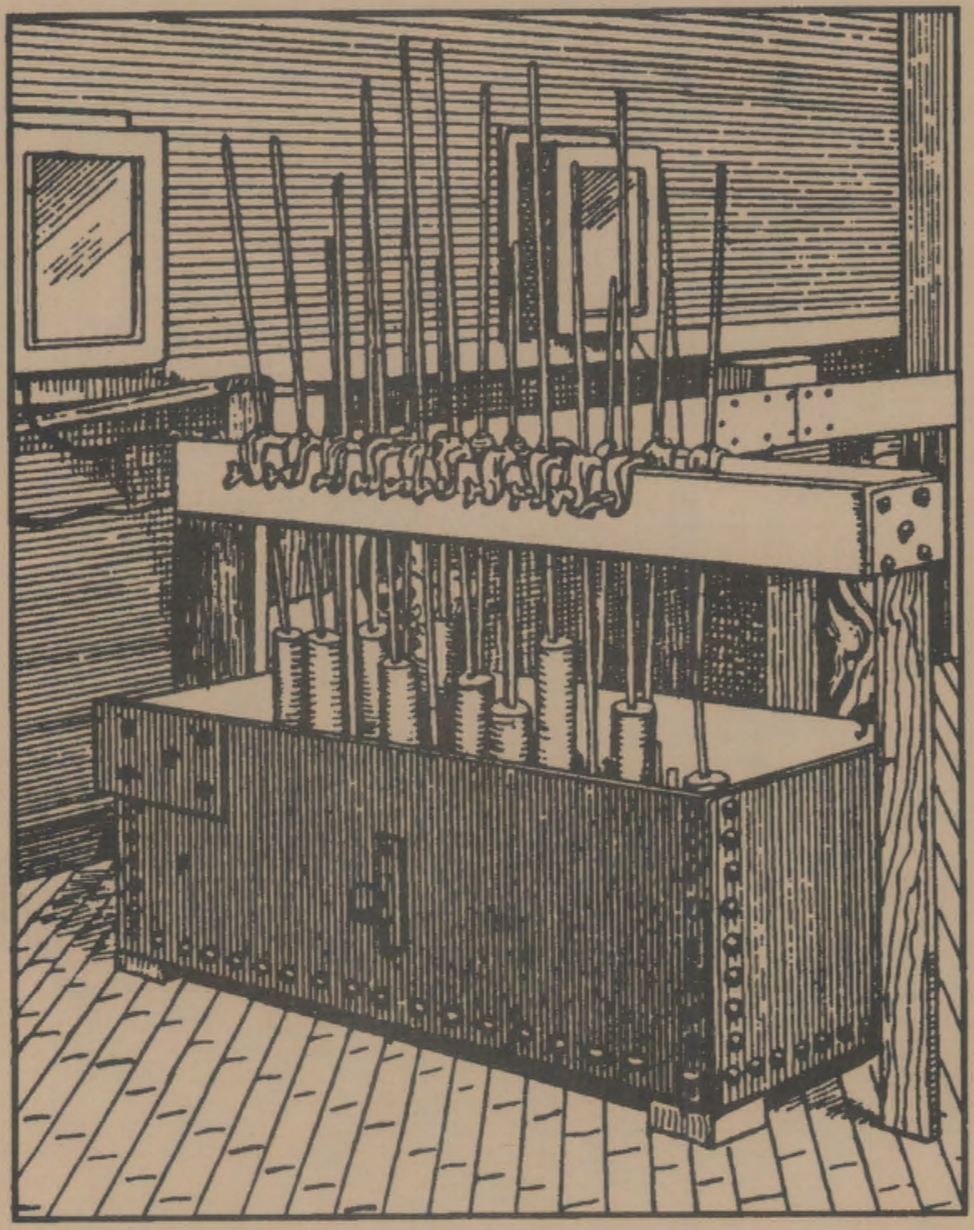

August 1992

Work Supported by the U.S. Department of Energy under Contract DE-AC06-76RLO 1830

Pacific Northwest Laboratory Operated for the U.S. Department of Energy by Battelle Memorial Institute 


\section{DISCLAIMER}

This report was prepared as an account of work sponsored by an agency of the United States Government. Neither the United States Government nor any agency thereof, nor Battelle Memorial Institute, nor any of their employees, makes any warranty, expressed or implied, or assumes any legal liability or responsibility for the accuracy, completeness, or usefulness of any information, apparatus, product, or process disclosed, or represents that its use would not infringe privately owned rights. Reference herein to any specific commercial product, process, or service by trade name, trademark, manufacturer, or otherwise does not necessarily constitute or imply its endorsement, recommendation, or favoring by the United States Government or any agency thereof, or Battelle Memorial Institute. The views and opinions of authors expressed herein do not necessarily state or reflect those of the United States Government or any agency thereof.

\section{PACIFIC NORTHWEST LABORATORY operated by \\ BATTELLE MEMORIAL INSTITUTE for the UNITED STATES DEPARTMENT OF ENERGY under Contract DE-ACO6-76RLO 1830}

Printed in the United States of America

Available to DOE and DOE contractors from the

Office of Scientific and Technical Information, P.O. Box 62, Oak Ridge, TN 37831; prices available from (615) 576-8401. FTS 626-8401.

Available to the public from the National Technical Information Service, U.S. Department of Commerce, 5285 Port Royal Rd., Springfield, VA 22161. 
PNL -8269

UC -313

Inert Electrodes Program

RESULTS FROM A PILOT CELL TEST OF CERMET ANODES

C. F. Windisch Jr.

D. M. Strachan

C. H. Henager Jr.

E. N. Greenwell

T. R. Alcorn ${ }^{(a)}$

August 1992

Prepared for

the U.S. Department of Energy

under Contract DE-ACO6-76RLO 1830

Pacific Northwest Laboratory

Richland, Washington 99352

(a) Reynolds Metals Company, Manufacturing Technology Laboratory, Muscle Shoats, Alabama. 


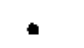

* Pe 


\section{$\underline{\text { SUMMARY }}$}

The pilot cell test of the cermet anodes was completed in August 1991 at the Reynolds Metals Company Manufacturing Technology Laboratory, Muscle Shoals, Alabama. During this test 13 cermet anodes were evaluated. The longest time any one anode was tested was $314 \mathrm{~h}$ (13.1 days). During the pilot cell test, all of the anodes corroded severely as measured by both impurities in the aluminum metal and post-test analyses of the anodes. The overall dimensions of the anodes did not change much but a reaction layer of significant thickness was observed. In addition, electrolyte components were observed deep within the anode and resulted in significant changes in the composition and properties of the anode material.

It is still unclear whether the cermet material evaluated in this work is the best choice for an "inert" anode. The negative results of the pilot cell test would appear to argue against using this material, but there were many deficiencies in the pilot cell test that may make this conclusion premature. These deficiencies primarily involved the failure to maintain optimal operating conditions, including alumina concentration at saturation, constant current and voltage conditions, constant anode-to-cathode distance (ACD), and constant temperature. Also, there were problems caused by the large carbon anode that was used simultaneously with the cermet anodes and mechanical fracture problems with both the anode connections and the cermet anodes themselves. In addition, the microstructure of the cermet anodes was not exactly the same as that tested previously in the laboratory; the ramifications of these differences are not certain.

Despite no ciear indication as to whether the cermet material would make a good candidate for an inert anode under more "ideal" conditions, the pilot cell test was successful in demonstrating that the performance of the anode is strongly influenced by either or both anode fabrication and operation. The results of this work indicate the variety of fabrication and operational considerations that need to be addressed carefully in any future testing of this or other candidate material. At the very least, this work establishes an experimental protocol for anode fabrication, cell operation, and post-test 
diagnostics that would seem to be required in future testing. The work also points to some important chemical and physiological changes in the cermet material that occur during electrolysis that should be kept in mind in future tests. These changes will probably occur to a greater or lesser extent during most operations with the cermet anodes; albeit it remains to be determined under what conditions of anode fabrication and cell operation the rates of these transformations can be reduced to acceptable values. 


\section{ACKNOWLEDGMENTS}

The authors wish to acknowledge the staff of the Pacific Northwest Laboratory (PNL) who assisted the authors in performing the pilot cell test, including L. R. Bunneli, S. M. Faber, and N. D. Stice. We recognize the valuable contributions that the Manufacturing Technology Laboratory of the Reynolds Metals Company provided to this work, including the assistance of their staff and the use of their pilot cell and other laboratory facilities. We are also grateful for the assistance by Dr. W. E. Haupin in making voltage measurements during the test and in providing his expertise as a consultant on this program. Technical assistance in the post-test analyses of the cermet anodes and pilot cell data was provided by various PNL staff including $R$. $R$. Adee, R. E. Bowey, J. E. Coleman, H. P. Foote, M. S. Good, J. L. Humason, D. E. McCready, K. H. Pool, N. T. Saenz, and S. 0. Slate. The authors also recognize the assistance of F. R. Huettig, program consultant, and G. L. Van Dillian, Ceramic Magnetics, Inc., who helped direct the fabrication of the cermet anodes. Also acknowledged are the assistance of D. K. Hilliard in performing the editorial review of the report and J. L. Brimhall who performed the technical review; the programmatic assistance provided by M. J. McMonigle, Office of Industrial Processes, U.S. Department of Energy (DOE), Washington, D.C.; the DOE Richland Field Office, DOE; and the programmatic support provided by the Office of Industrial Processes, DOE. 


\section{CONTENTS}

SUMMARY ...........................

ACKNOWLEDGMENTS .........................

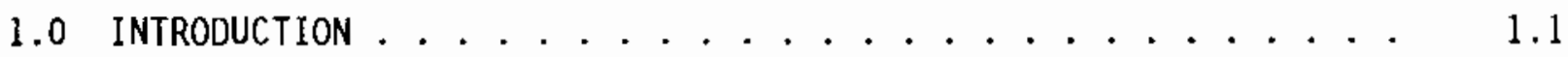

2.0 PILOT CELL DESIGN AND TEST PLAN . . . . . . . . . . 2.1

2.1 PILOT CELL DESIGN . . . . . . . . . . . . 2.1

2.2 PILOT CELL TEST PLAN . . . . . . . . . . . . 2.5

3.0 FABRICATION OF THE CERMET ANODES ................... 3.1

3.1 POWDER PRODUCTION . . . . . . . . . . . . . 3.1

3.2 ANODE PRODUCTIDN . . . . . . . . . . . . . . . . . 3.5

4.0 PILOT CELL OPERATION . . . . . . . . . . . . . . . 4.1

4.1 CELL START-UP AND BREAK-IN . . . . . . . . . . . 4.1

4.2 PReheating of CERMET ANODES . . . . . . . . . . . 4.5

4.3 CERMET ANODE OPERATION $\ldots \ldots \ldots \ldots \ldots$

4.3.1 Electrolyte Chemistry . . . . . . . . . 4.9

4.3 .2 Liquid Level Control ............ . 4.14

4.3.3 Anode Current Distribution . . . . . . . . 4.17

4.3.4 Operational Problems ............ 4.40

4.3.5 Bath and Metal Impurities ........... 4.43

5.0 POST-TEST ANALYSIS . . . . . . . . . . . . . 5.1

5.1 APPEARANCE AND DIMENSIONAL CHANGES ............. 5.1

5.1.1 Appearance Changes ............ . 5.1

5.1 .2 Dimensional Changes . . . . . . . . . . . 5.9

5.2 MicrostruCtURAL AND COMPOSItIONAL CHANGES . . . . . 5.17

5.2.1 Description of Core Sections......... 5.17 
5.2.2 Optical Microscopy of Core Sections:

Overall Perspective ........... 5.18

5.2.3 Reactions at the Bottom of the Anode . . . . . . 5.23

5.2.4 Reactions in the Center and Top of the Anode . . . 5.38

5.2.5 Reactions in the Wing Region ......... 5.43

5.2.6 Reactions in Other Anode Core Sections...... 5.45

5.2.7 Summary of Chemical Changes in the .......... . . . . . . . 5.45
Cermet Anode ....

5.3 PHYSICAL AND MECHANICAL PROPERTIES CHANGES . . . . . . 5.50

5.3 .1 Density ............... 5.50

5.3.2 Mechanical Properties ............ 5.51

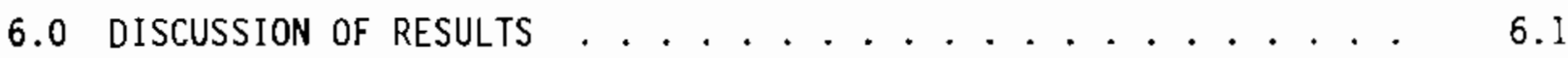

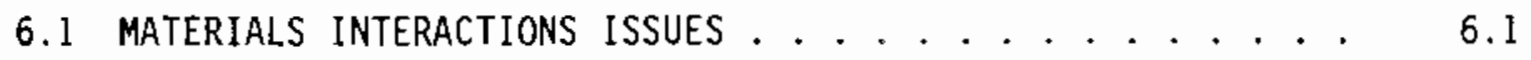

6.2 OPERATIONAL ISSUES . . . . . . . . . . . . 6.7

6.2.1 Cermet Anode Cracking and Stem Breakage . . . . . 6.8

6.2.2 0peration at Low Anode Current Density. . . . 6.8

6.2 .3 Operation at Alumina Saturation ....... 6.9

6.2.4 Cermet Anode Corrosion Rate ......... 6.9

7.0 CONCLUSIONS AND RECOMMENDATIONS ............... 7.1

8.0 REFERENCES . . . . . . . . . . . . . . . 8.1

APPENDIX A - BATH CONCENTRATION DATA . . . . . . . . . A.1

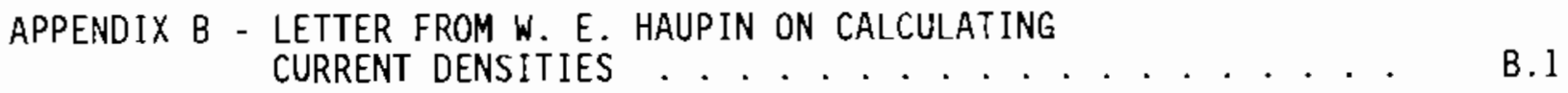

APPENDIX C - ANALYSIS OF NI ROD FRACTURE ........... C.I

APPENDIX D - METAL ANALYSIS RESULTS ............. D. . . .

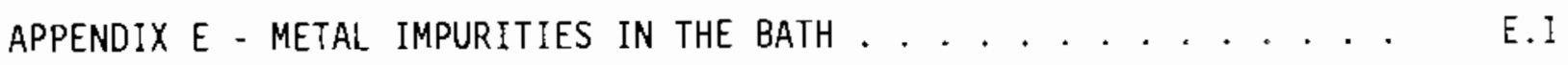




\section{FIGURES}

2.1 Photograph of the Pilot Cell ............. 2.1

2.2 Diagram of the Pilot Cell (Top View) . . . . . . . . 2.2

2.3 Diagram of the Pilot Cell (Side View) ......... 2.3

2.4 Schematic of the Six-Pack of Cermet Anodes Showing

Position Designations . . . . . . . . . . . 2.4

2.5 Photograph of the Cermet Anodes in the Pilot Cell ..... 2.5

2.6 Photograph of an Assembled Cermet Anode and Connector Rod . . . 2.6

2.7 Nominat Dimensions of the Cermet Anode . . . . . . . . . 2.7

2.8 Log Sheet for Recording Data During the Pilot Cell Test . . . . 2.8

3.1 Results from the X-ray Diffraction Scans of the XBAT

Series of Calcined Powders . . . . . . . . . . . . 3.2

3.2 As-Sintered Anode a) Top View, b) After Sectioning and Treating With a Dye Penetrant to Show the Depth of the Crack, c) Cross-Section Face After Treating With

Dye Penetrant . . . . . . . . . . . . . 3.7

3.3 Results from Dilatometer Measurements

on a Pressed, Green Ferrite Sample . . . . . . . . . 3.8

3.4 Close-up View of a Cross Section of a Pilot

Cell Anode Showing the Excellent Bonding . . . . . . . . . . 3.10

3.5 A Schematic of the U1trasound Device for Determining the Presence of Cracks in Pilot Cell Anodes ........ 3.10

3.6 Results from the Ultrasound Testing Showing the Existence of Cracks Within the Anode ............ 3.12

4.1 Cathode Temperature during Heatup . . . . . . . . . . 4.2

4.2 Current Versus Time for Graphite Anodes in Positions A and D.................... 4.3

4.3 Current Versus Time for Graphite Anodes in Positions B and E............... 4.3

4.4 Current Versus Time for Graphite Anodes in Positions $C$ and $F \ldots . . . . . . . . . .4 .4$ 
4.5 Current Imbalance on the Carbon Anodes . . . . . . . . . 4.5

4.6 Photograph of Cermet Anodes in the

Preheat Furnace .. . . . . . . . . . . . . . 4.6

4.7 Transferring a Cermet Anode to the Pilot Cell . . . . . . . . 4.7

4.8 Anode Bl after It Had Cracked during Transfer to the Pilot Cell ................... . . . 4.8

4.9 Bath Ratio Versus Time during the Pilot Cell Test . . . . . . 4.10

4.10 $\mathrm{CaF}_{2}$ Concentration Versus Time during the Pilot Cell Test.......................... 4.10

4.11 Temperature Versus Time during the Pilot Cel1 Test . . . . . 4.11

4.12 Diagram Showing Position of Alumina Sampling Points and One Set of Measurements (as Weight Percent) at These Points... . . . . . . . . . . . . 4.12

4.13 Weight Percent Alumina Versus Time during the Pilot Cell Test . . . . . . . . . . . . . . . . . 4.13

4.14 Percent of Alumina Saturation Versus Time during the Pilot Cell Test . . . . . . . . . . . . . 4.13

4.15 Effect of Temperature on Alumina Saturation under Pjlot Cell Conditions . . . . . . . . . . . . . . . . 4.14

4.16 Anode Immersion Versus Time during the Pilot Cell Test.... . 4.15

4.17 Bath Level Versus Time during the Pilot Cell Test . . . . . 4.15

4.18 Anode-to-Cathode Distance (ACD) Versus Time during the Pilot Cell Test .................... 4.16

4.19 Schematic of Anode Positions Showing Exchange Sequence for Individual Cermet Anodes . . . . . . . . . . . . . 4.18

4.20 Current Through Anodes in Position A Versus Time during the Pilot Cell Test. . . . . . . . . . . . . . . . 4.19

4.21 Current Through Anodes in Position B Versus Time during the Pilot Cell Test...............

4.22 Current Through Anodes in Position $C$ Versus Time during the Pilot Cell Test . . . . . . . . . . . . . . .

4.23 Current Through Anodes in Position D Versus Time during the Pilot Cell Test. 
4.24 Current Through Anodes in Position E Versus Time during the Pilot Cell Test .............. 4.21

4.25 Current Through Anodes in Position F Versus Time during Pilot Cell Test . . . . . . . . . . . . 4.21

4.26 Current Imbalance on the Cermet Anodes . . . . . . . . . . 4.22

4.27 Variation of Voltage with Time for the Cermet Anodes during the Pilot Cell Test.............. 4.23

4.28 Cathode Voltage Drop Versus Time during the Pilot Cell Test .................

4.29 Current Versus Voltage (iv) Scans for Anode in Position $C$ at Various Carbon Anode Currents . . . . . . . . .

4.30 Current Versus Voltage (iV) Scans for Various Anode Positions with Carbon Anode Current at $0.5 \mathrm{kA}$. . . . 4.25

4.31 8EMF as a Function of Current Through the Carbon Anode . . . . . 4.26

4.32 P1ot Showing Negligible Variation of 8EMF with Time during the Pilot Cell Test............... 4.28

4.33 Effect of Carbon Anode Voltage on the Cermet Anode Voltage ................. 4.28

4.34 Schematic of Voltage Probes Used in the Pilot Cel1 Test . . . 4.29

4.35 Voltage Probe Measurements . . . . . . . . . . . . 4.31

4.36 Schematic Showing Current Densities on Different Parts of a Cermet Anode . . . . . . . . . . . . . 4.32

4.37 Calculated BEMF from the Landau Model . . . . . . . . . . . . 4.34

4.38 Three-Dimensional Current Vector Field Calculated with PNL Model................. 4.37

4.39 Cross-Section of the Pilot Cell with Isopotential Lines . . . 4.38

4.40 Photograph Showing the Cryolite Cover on Top of the Cermet Anodes............... $4.4 \mathrm{I}$

4.41 Photograph Showing the "Packed" Alumina Sleeve . . . . . . . . . 4.42

4.42 Concentration of $\mathrm{Cu}$ in the Metal as a Function of Time during the Pilot Cell Test 
4.43 Concentration of $\mathrm{Fe}$ in the Metal as a Function of Time during the Pilot Cell ..................

4.44 Concentration of $\mathrm{Ni}$ in the Metal as a Function of Time during the Pilot Cell Test................

4.45 Concentration of $\mathrm{Cu}$ in the Bath as a Function of Time during the Pilot Cell Test...............

4.46 Concentration of $\mathrm{Fe}$ in the Bath as a Function of Time during the Pilot Cell Test ................

4.47 Concentration of $\mathrm{Ni}$ in the Bath as a Function of Time during the Pilot Cell Test...............

5.1 Photographs of Exterior and Interior of Anode Al after Testing in the Pilot Cell

5.2 Photographs of Exterior and Interior of Anode E2 after Testing in the Pilot Cell ...............

5.3 Photographs of Exterior and Interior of Anode Aux2 after Testing in the Pilot Cell ...............

5.4 Photographs of Exterior and Interior of Anode A2 after Testing in the Pilot Cell ..............

5.5 Photographs of Exterior and Interior of Anode $\mathrm{Cl}$ after Testing in the Pilot Cell . . . . . . . . . . . 5.6

5.6 Photographs of Exterior and Interior of Anode C2 after Testing in the Pilot Cell . . . . . . . . . . . . .

5.7 Photographs of Exterior and Interior of Anode D1 after Testing in the Pilot Cell

5.8 Photographs of Exterior and Interior of Anode D2 after Testing in the Pilot Cel?

5.9 Photographs of Exterior and Interior of Anode Auxl after Testing in the Pilot Cell

5.10 Photographs of Exterior and Interior of Anode E1 after Testing in the PiTot Cell

5.11 Photographs of Exterior and Interior of Anode Fl after Testing in the Pilot Cell . . . . . . . . . . . . .

5.12 Photographs of Exterior and Interior of Anode F2 after Testing in the Pilot Cell 
5.13 Schematic of Cermet Anode Showing Dimensions That Were Measured Before and/or After Testing in the

Pilot Cell .................. 5.14

5.14 Variation of Change in Inside Height Dimension with

A. $h$ for Cermet Anode during the Pilot Cell Test . . . . . . 5.14

5.15 Variation of Reaction Layer Thickness with A.h for

Cermet Anodes during the Pilot Cell Test . . . . . . . . . 5.15

5.16 Variation of Reaction Layer Thickness with A.h for

Cermet Anodes during the Pilot Cell Test . . . . . . . . 5.16

5.17 Schematic Showing Core Sections Removed from

Cermet Anodes for Analysis . . . . . . . . . . . 5.18

5.18 Low Magnification Photograph of F1-B ........... 5.19

5.19 Low Magnification Photograph of Fl-M . . . . . . . . 5.20

5.20 Low Magnification Photograph of FI-T .......... 5.21

5.21 Low Magnification Photograph of F1-W. . . . . . . . 5.22

5.22 "Dot" Map for the Element $\mathrm{Cu}$ in Fl-B.......... 5.24

5.23 "Dot" Map for the Element Fe in Fl-B . . . . . . . . . . 5.25

5.24 "Dot" Map for the Element $\mathrm{Ni}$ in F1-B . . . . . . . . . 5.26

5.25 "Dot" Map for the Element Al in F1-B . . . . . . . . . 5.27

5.26 "Dot" Map for the Element $F$ in F1-B Near
the Surface Region . . . . . . . . . . . . . . . 5.29

5.27 Variation of Al/Fe Intensity Ratio as a Function

5.28 Variation of $F / F e$ Intensity Ratio as a Function

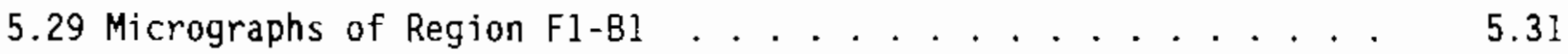

5.30 Variation of Al/Fe Ratio for the Ferrite Phase as a

Function of Distance (Log Scale) from the Bottom

of Anode Fl ................... . . 5.32

5.31 Micrographs of Region Fl-82 ............. 5.33

5.32 Micrographs of Region Fl-B3 ............. 5.33 
5.33 Micrographs of Region F1-B4 ............ 5.34

5.34 Micrographs of Region F1-B5 . . . . . . . . . . 5.34

5.35 Composition of Alloy Phase as a Function of

Distance from the Bottom of Anode F1 .......... 5.36

$5.36 \mathrm{Ni} / \mathrm{Cu}$ Ratio in the Alloy Phase as a Function

of Distance from the Bottom of Tested Anodes . . . . . . . . 5.37

5.37 Composition of the NiO Phase as a Function of

Distance from the Bottom of Anode F1 . . . . . . . . 5.37

5.38 Micrographs of Region F1-M1 . . . . . . . . . . 5.38

5.39 Micrographs of Region Fl-Tl ............ . 5.39

5.40 Composition of the Fluoride Phase as a Function of

Distance from the Botton of Anode Fl . . . . . . . . . 5.40

5.41 Schematic Showing Summary of XRD Results on Vertical

Core Section from Anode F1 . . . . . . . . . . . . . . 5.42

5.42 Micrographs of Region FI-T2 . . . . . . . . . . . 5.43

5.43 Micrographs of Region Fl-Wl . . . . . . . . . . 5.44

5.44 Composition of Alloy Phase as a Function of

Position in the Wing Region ............ 5.44

5.45 Low Magnification Photograph of Core Section from Anode C2 (Bottom Region) ............. . 5.46

5.46 Low Magnification Photograph of Core Section

from Anode C2 (Middle Region) ............ 5.47

5.47 Low Magnification Photographs of Core Section

from Anode C2 (Top Region) . . . . . . . . . . . . 5.48

5.48 Cherron-Notch Bars . . . . . . . . . . . 5.52

5.49 Stress-Strain Curve for (a) Control Anode and (b) Anode Fl .................... 5.55

5.50 Variation of Fracture Stress as a Function of Temperature . . $\quad 5.56$

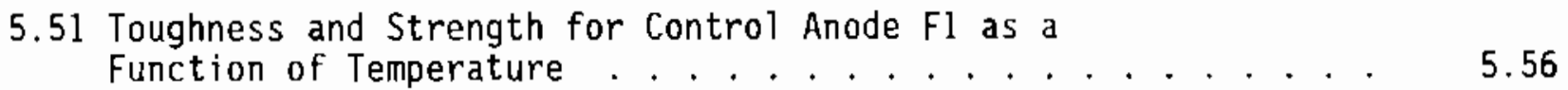

5.52 Toughness and Strength for Anode F1 as a . . . . . . . . . . . . . 5.57
Function of Temperature . . . . . 
5.53 Fracture Morphology below the DBTT $\left(20^{\circ} \mathrm{C}\right) \ldots \ldots . . . . .58$

5.54 Fracture Morphology at the DBTT . . . . . . . . . . 5.59

5.55 Comparison of Fraction Toughness Values ........ 5.61

5.56 Comparison of Thermal Shock Values . . . . . . . . 5.62

5.57 Micrograph of Fracture Surface Showing Presence of

Aluminum Fluoride Phase at the Grain Boundaries . . . . . . 5.64 


\section{TABLES}

3.1 Composition of Powders Produced at Ceramic Magnetics and Analyzed at Rutgers University ............ 3.3

3.2 Results from Pressing and Sintering Experiments with XBAT Powders ...................... 3.4

3.3 Initial Sintering Schedule for the Pilot Cell Test Anodes . . 3.6

3.4 Description of the Test Anodes That Were Sent to PNL . . . . 3.9

3.5 Composition of Tested and Control Anode Materials . . . . . 3.13

4.1 The Lives of the Cermet Anodes . . . . . . . . . . . . . 4.22

4.2 Extrapolated BEMF Values ................ . . 4.27

4.3 Conductivities of Cel1 Components . . . . . . . . . . 4.35

4.4 Chronological Listing of Stem Failures . . . . . . . . . 4.41

4.5 Impurities in the Bath Additives . . . . . . . . . 4.45

5.1 Results of Wet Lab Analysis of FI-B . . . . . . . . . 5.28

5.2 Densities of Cermet Anodes . . . . . . . . . . . . . . 5.50

5.3 Test Matrix for Mechanical Properties Testing . . . . . . . 5.53

5.4 Materials Parameters for Various Ceramics and Cermets . . . . 5.60

6.1 Reactions with $\mathrm{Al}_{2} \mathrm{O}_{3}$ at $1300 \mathrm{~K} \ldots \ldots 6.3$

6.2 Reactions with $\mathrm{AlF}_{3}$ at $1300 \mathrm{~K} \ldots . . . . . . . .6 .3$ 


\subsection{INTRODUCTION}

The Inert Electrodes Program is being conducted at the Pacific Northwest Laboratory (PNL) ${ }^{(a)}$ for the U.S. Department of Energy (DOE), Office of Industrial Processes (0IP). The goal of the program is to develop long-lasting, energy-efficient anodes and ancillary equipment for Hall-Heroult cells used to produce aluminum metal. Emphas is has been placed on the development of anodes made from a ceramic/metal composite consisting of $\mathrm{NiO}$ and $\mathrm{NiFe}_{2} \mathrm{O}_{4}$ and a $\mathrm{Cu} / \mathrm{Ni}$ metal phase. Laboratory tests (Strachan et a1. 1989) have shown that this composition corrodes at a low enough rate to make it an attractive alternative to the consumable carbon anodes currently used in commercial smelting operations. Before aluminum companies would consider using the cermet anodes, however, it is necessary to demonstrate operational success on a longer scale. In particular, acceptable performance had to be shown in a larger, self-heated ce11. Toward this end, Reynolds Metals Company (RMC) was subcontracted by PNL in Fiscal Year 1988 for use of the "pilot cell" at their Manufacturing Technology Laboratory (MTL) in Muscle Shoals, Alabama. The pilot cell was subsequently modified to allow testing of cermet anodes as described in Section 2.0 of this report. A preliminary "prototype anode test" was also performed by RMC and PNL in a large laboratory cell at the MTL in March 1989 to determine certain operating conditions for the cermet anodes before running the pilot ce11 test.

The cermet anodes that were tested in the pilot cell were manufactured by Ceramic Magnetics, Inc. (CMI), Fairfield, New Jersey. The staff of PNL worked closely with those at CMI between October 1989 and August 1991 to scale up both the manufacture of the cermet powder and the fabrication of the cermet anodes themselves. The results of this fabrication effort are discussed in Section 3.0 of this report. In June 1991, a test plan for the pilot cell test was finalized (Windisch et al. 1991a) after a series of meetings with PNL, RMC, DOE staff, program consultants, and DOE-selected advisors. In July 1991, 13 cermet anodes were delivered to the MTL for testing in the pilot cell. The

(a) Operated for the U.S. Department of Energy by Battelle Memorial Institute under Contract DE-AC06-76RLO 1830. 
pilot cell test was initiated on August 1, 1991. The test was conducted jointly by the staff at PNL and RMC, assisting each other in evaluating all of the 13 anodes between August 1 and August 30, 1991. During that test, some operational difficulties were encountered and the pilot cell test procedures had to be modified extensively. Discussion of the operation of the pilot cell test and these difficulties is presented in Section 4.0. The 1ongest any cermet anode was tested in the pilot cell was 13.1 days. After the test was completed, the anodes were returned to PNL for many post-test analyses. The results of these post-test analyses are discussed in Section 5.0.

Additional cermet anodes were delivered to the MTL in September 1991 and these were used in cooperation with Eltech Research Corporation (ERC), Fairport, ohio, in a second phase of the pilot cell test, conducted during September and October 1991. These anodes were returned to ERC for evaluation. The results from these analyses will be reported in a separate ERC report. The staff at PNL, RMC, and ERC have all interacted closely in comparing their data and results from the pilot cell test so that a clear and consistent consensus could be developed regarding the performance of the cermet anode material.

In addition to post-test analytical data, other data were collected during the pilot cell test including temperature, electrolyte and aluminum metal composition, anode-to-cathode distance (ACD), and anode immersion. The pilot cell was heavily instrumented so that current and voltage signals could be collected from numerous positions around the cell. Some of the signal data are discussed in this report. Other studies of current and voltage data from the pilot cell test were performed as part of the Sensors Development Program at PNL. The objective of the sensors studies was to determine whether digital signal analysis (DSA) methods could be used to relate process noise to alumina concentration. The results of the DSA analysis were published separately in two PNL reports (Williford and Windisch 1992; Windisch.1992).

In summary, the primary objective of the pilot cell test was to evaluate the "inertness" of cermet anodes as nonconsumable substitutes for carbon in a pilot reduction cell. If the material could be shown to corrode or wear at acceptably low rates in this test, it was hoped that industry would become 
sufficiently interested in the material and the inert-anode alternative to proceed with the next step in transferring the technology to commercial cells. other issues related to inert anode performance and operation (separate from corrosion issues), such as mechanical properties (e.g., thermal cracking), pilot cell peculiarities (e.g., uniqueness of voltage characteristics), and control of bath chemistry (e.g., alumina concentration), were considered important, but secondary, in this first pilot cell test. This point is important since serious problems associated with these secondary issues were encountered in this test and the problems with the secondary issues may well have affected the material performance relative to the primary objective. Consequently, shortcomings of the material and technology as they relate to these secondary issues should not be construed as a "failure" for the material or a lack of relevancy of the test. Many of these shortcomings were, in fact, anticipated; however, in light of the primary objective of the work and for the sake of expediency, it was decided to proceed with the test and address the secondary issues more fully at a later time. 


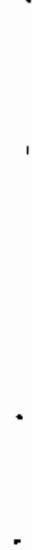




\subsection{PILOT CELL DESIGN AND TEST PLAN}

\subsection{PILOT CELL DESIGN}

The pilot reduction cell at MTL, shown in Figure 2.1, is a small, selfheated cell with the capacity for two industrial-size carbon anodes. Schematics of the pilot cell design are shown in Figures 2.2 and 2.3. Key features of this design include the following:

- Two 15.5-inch $\times 21.5$-inch anodes located 4 inches apart, centered over two standard amorphous cathode blocks.

- Sidewall construction consisting of rammed carbon, prebake carbon blocks, and TR-19 vermiculite insulation to minimize heat losses.

- Alumina feed through a point feed system located between the two anodes.

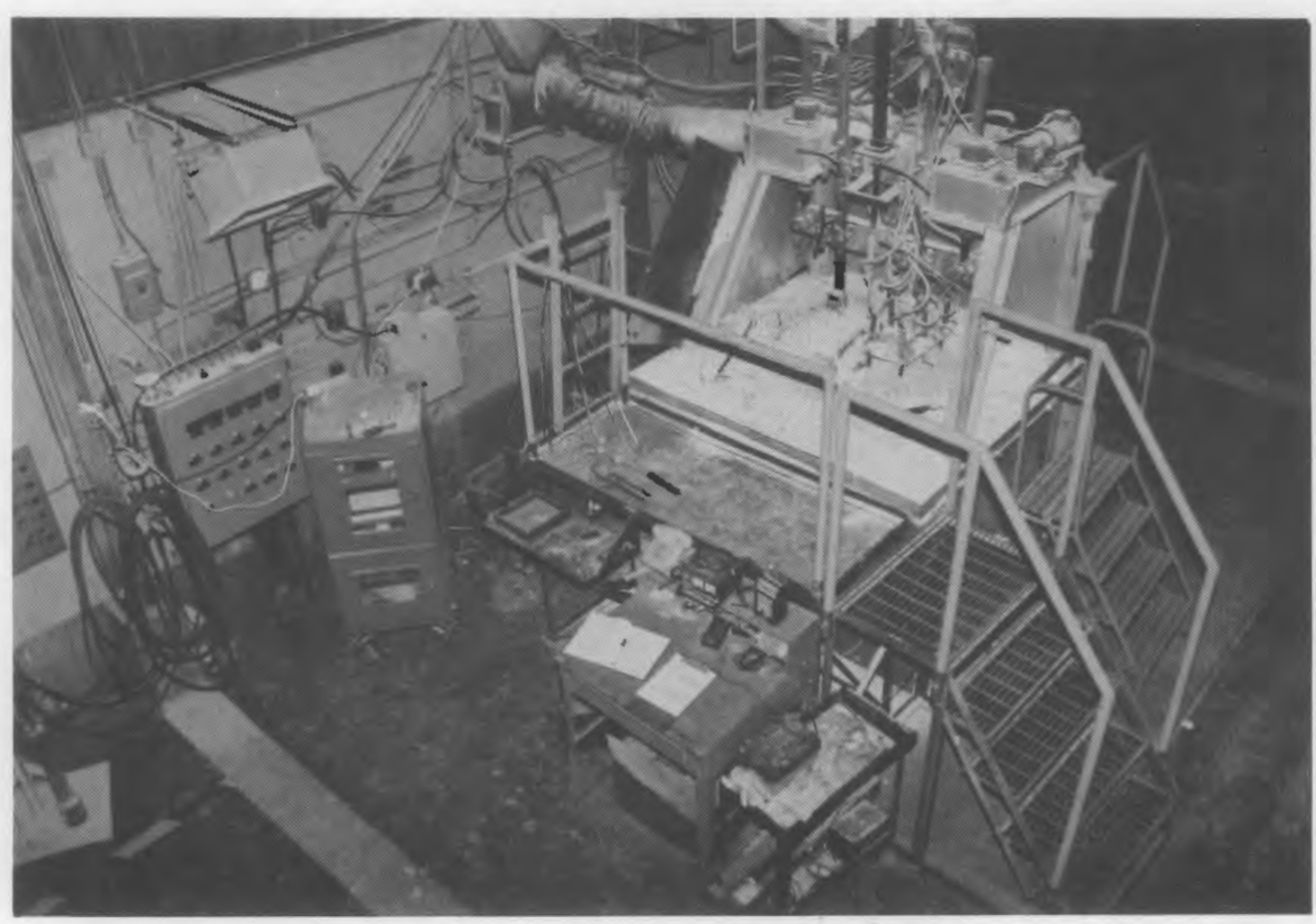

FIGURE 2.1. Photograph of the Pilot Cell 
NORTH

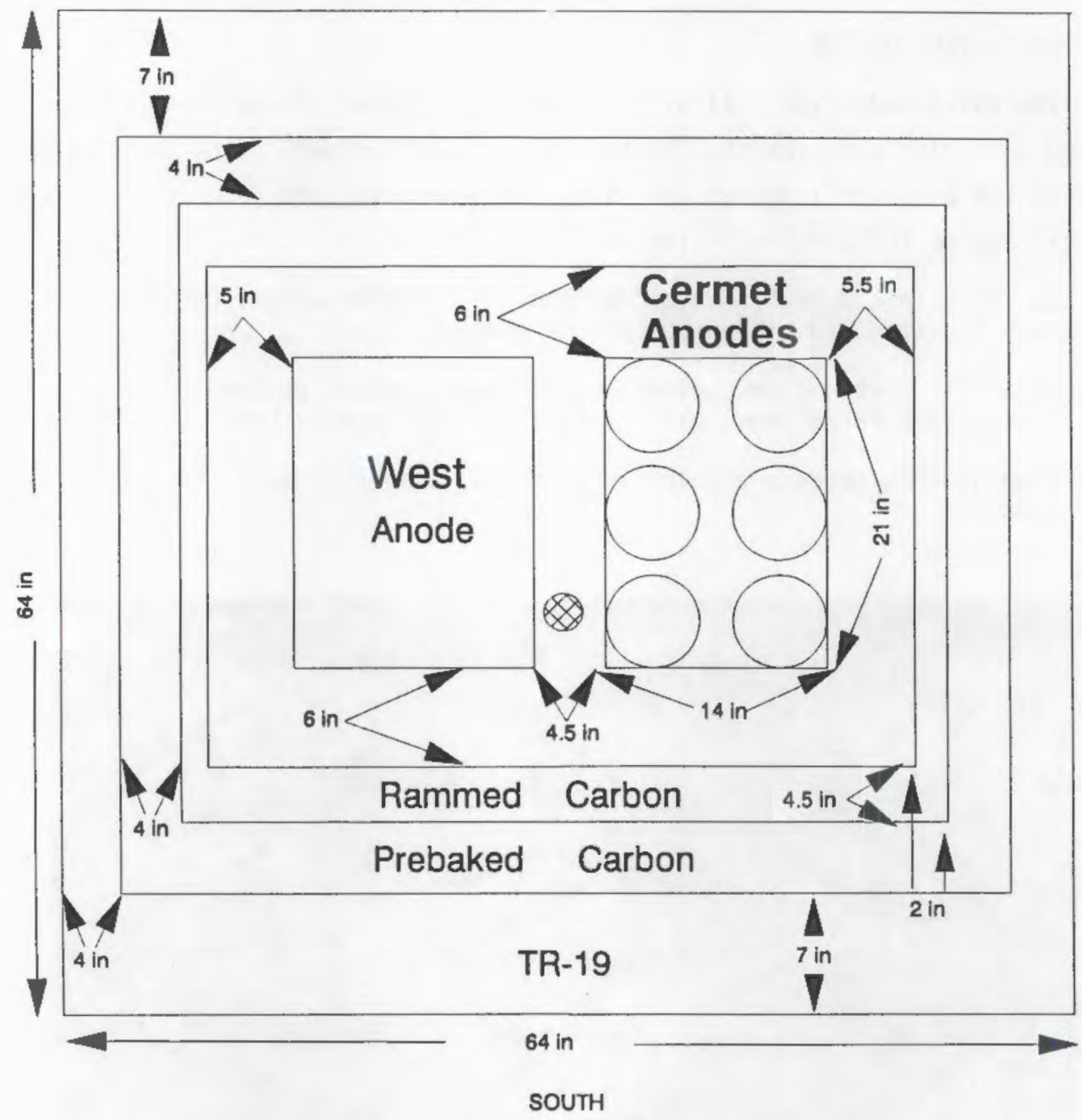

FIGURE 2.2. Diagram of the Pilot Cell (Top View)

- A cel1 cavity 44-inch x 33-inch and 17-inch deep. A 5-inch gap exists between the edge of the anode on two sides and a 6 -inch gap on the other sides. Metal tapping was normally done using a vacuum crucible between the two anodes.

Special modifications were made to the cell to accommodate the testing of the cermet anodes. One of the carbon anodes (east anode) was replaced by a 


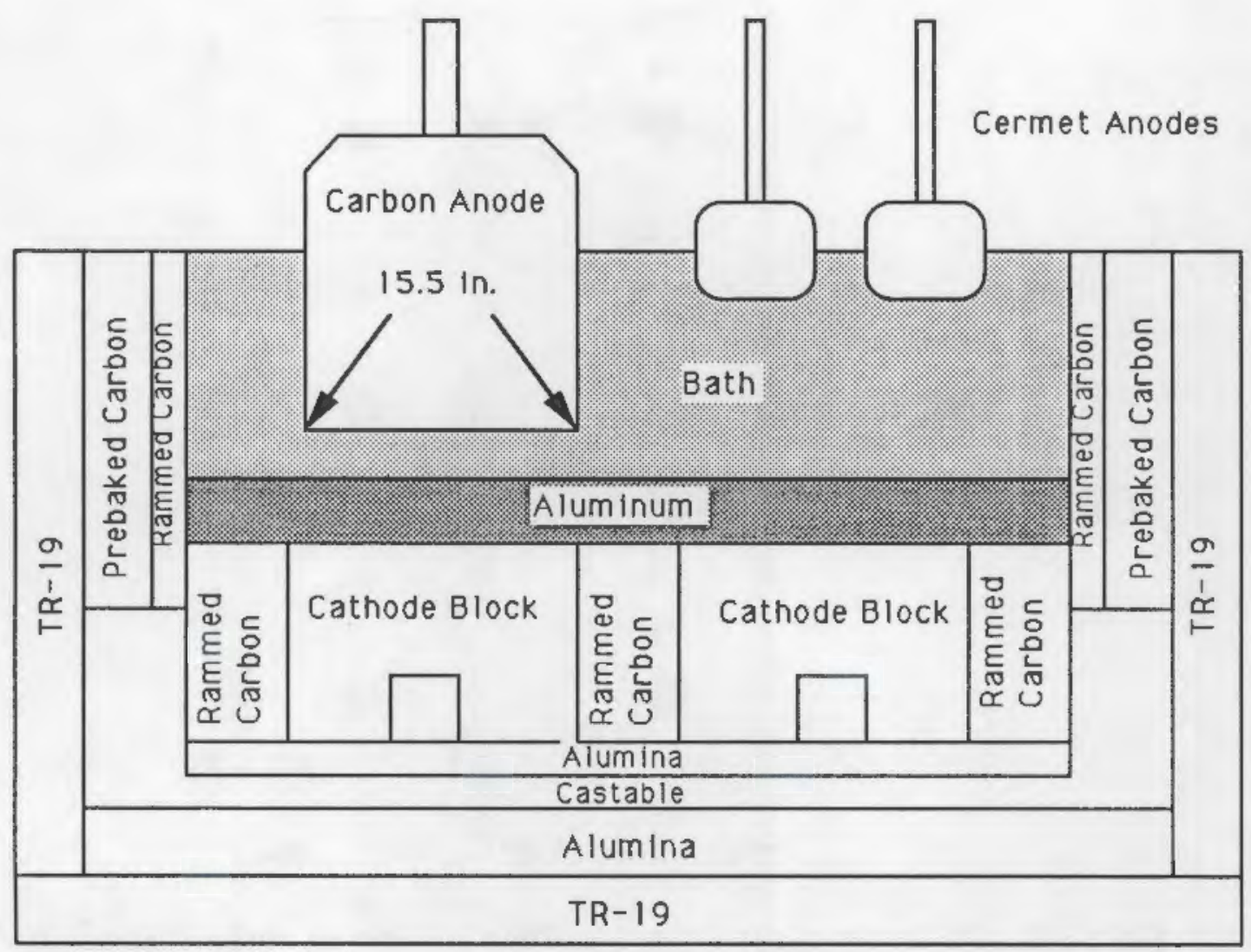

\section{FIGURE 2.3. Diagram of the Pilot Cell (Side View)}

cermet anode cluster consisting of six cermet anodes in a 2-by-3 arrangement as shown in Figures 2.4 and 2.5. The cermet anode positions were identified as $A$ through $F$ as shown in Figure 2.4. The holder system allowed for removal and adjustment of each anode individually. Current was supplied to the anode cluster by means of cables connected to the top of each stem. Current was monitored to each cermet anode by means of a calibrated current shunt located near the top of the superstructure. The shunts were calibrated at $100 \mathrm{mV}$ being equal to $500 \mathrm{~A}$. Each of the anodes was electrically isolated from the adjacent carbon anode, allowing individual control of current or voltage of the carbon anode and cermet anode cluster. This allowed operation of the carbon anode to provide sufficient heat for maintaining a proper thermal balance in the cell. 


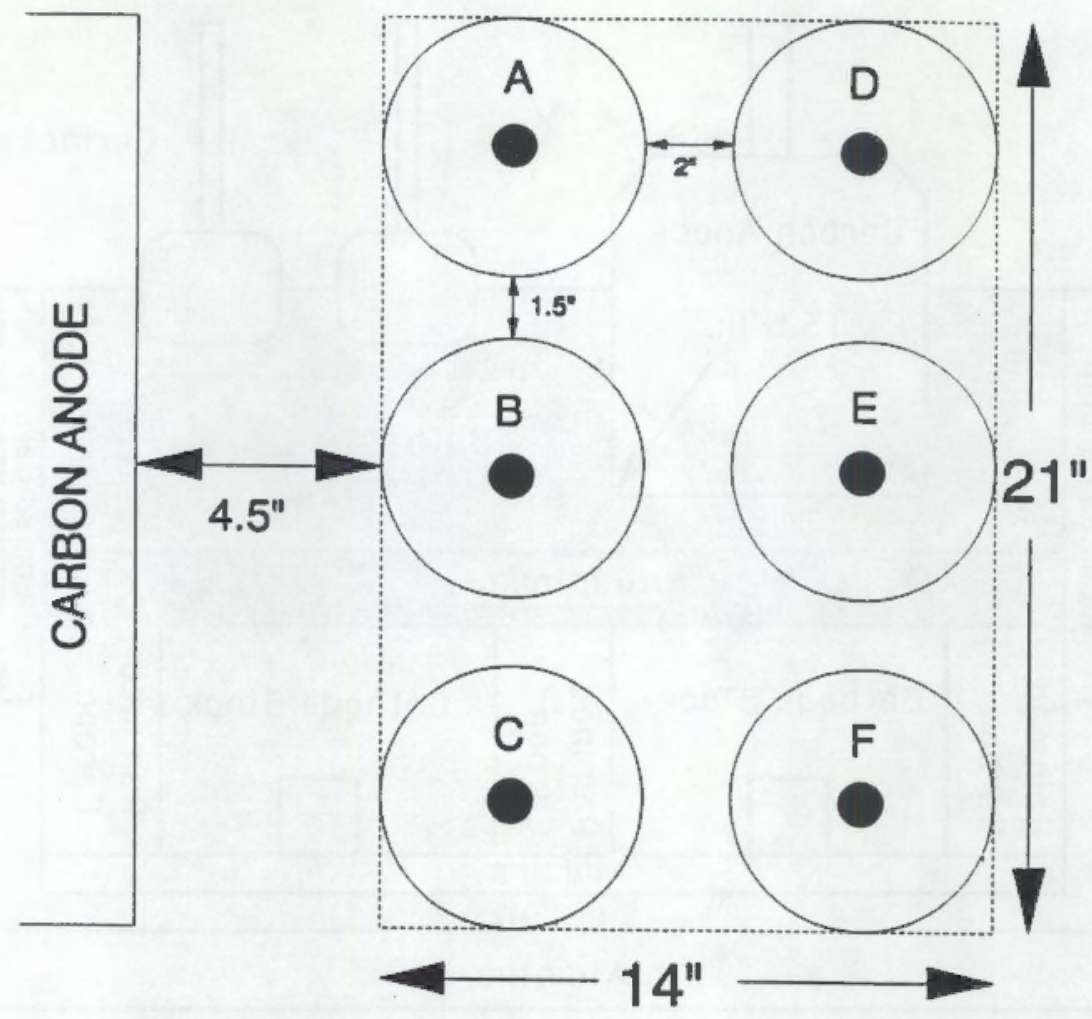

FIGURE 2.4. Schematic of the Six-Pack of Cermet Anodes Showing Position Designations

The cermet anodes were of the type $\mathrm{NiO}-\mathrm{NiFe}_{2} \mathrm{O}_{4}-\mathrm{Cu}$ and were manufactured at CMI. (Issues related to fabrication of the anodes are discussed in Section 3.0.) Each of the cermet anodes had the shape shown in the photograph in Figure 2.6 and had the nominal dimensions shown in the schematic of the crosssection shown in Figure 2.7. The anodes were roughly cylindrical with an additional 1-in. lip or "wing" on the top edge. All edges of the anode were rounded. A 18-inch-long, 1-inch-diameter $\mathrm{Ni}$ connector rod was screwed into the center of each cermet anode. A 1.25-in. diameter alumina sleeve was placed over the rod, extending 3 inches up from the top of the cermet anode. Both the alumina sleeve and the 1-in. lip on the anode were meant to protect the rod-anode junction from attack by electrolyte vapors.

Platinum wires were also connected to the top of the anodes and the bottom of the stems to help determine voltage drops. Most of these wires were too fragile and did not survive installation of the anodes in the cell, 


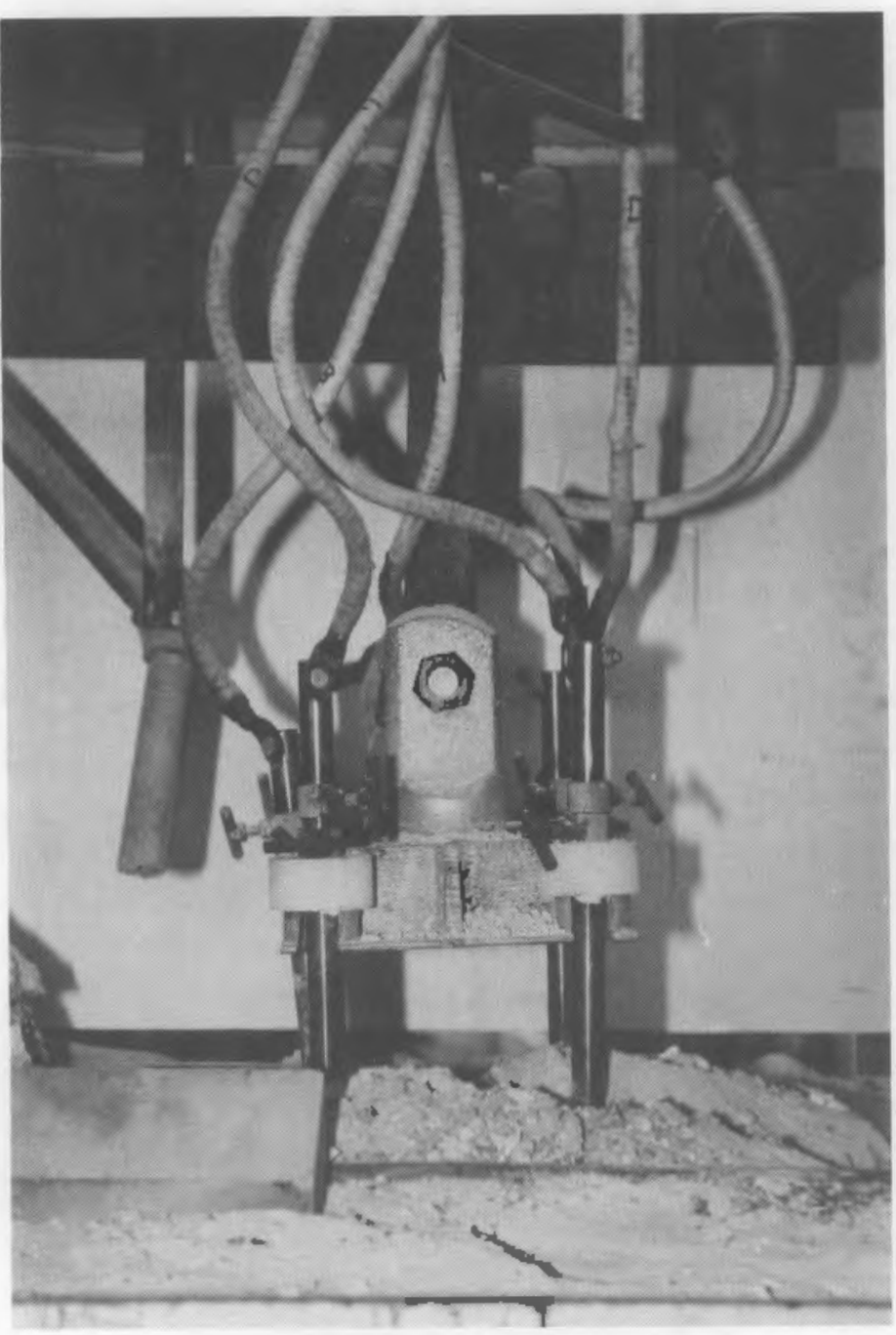

FIGURE 2.5. Photograph of the Cermet Anodes in the Pilot Cell

however, so only a few measurements were made with them. Additional wires were connected to the top of the stems to provide routine voltage drop measurements to the data acquisition system. These connections worked well as they were remote from the crust of the cell and were connected after the cermet anodes were installed.

\subsection{PILOT CELL TEST PLAN}

The pilot cell test was to be performed in accordance with the procedures developed during a series, of meetings involving PNL, RMC, DOE staff, 


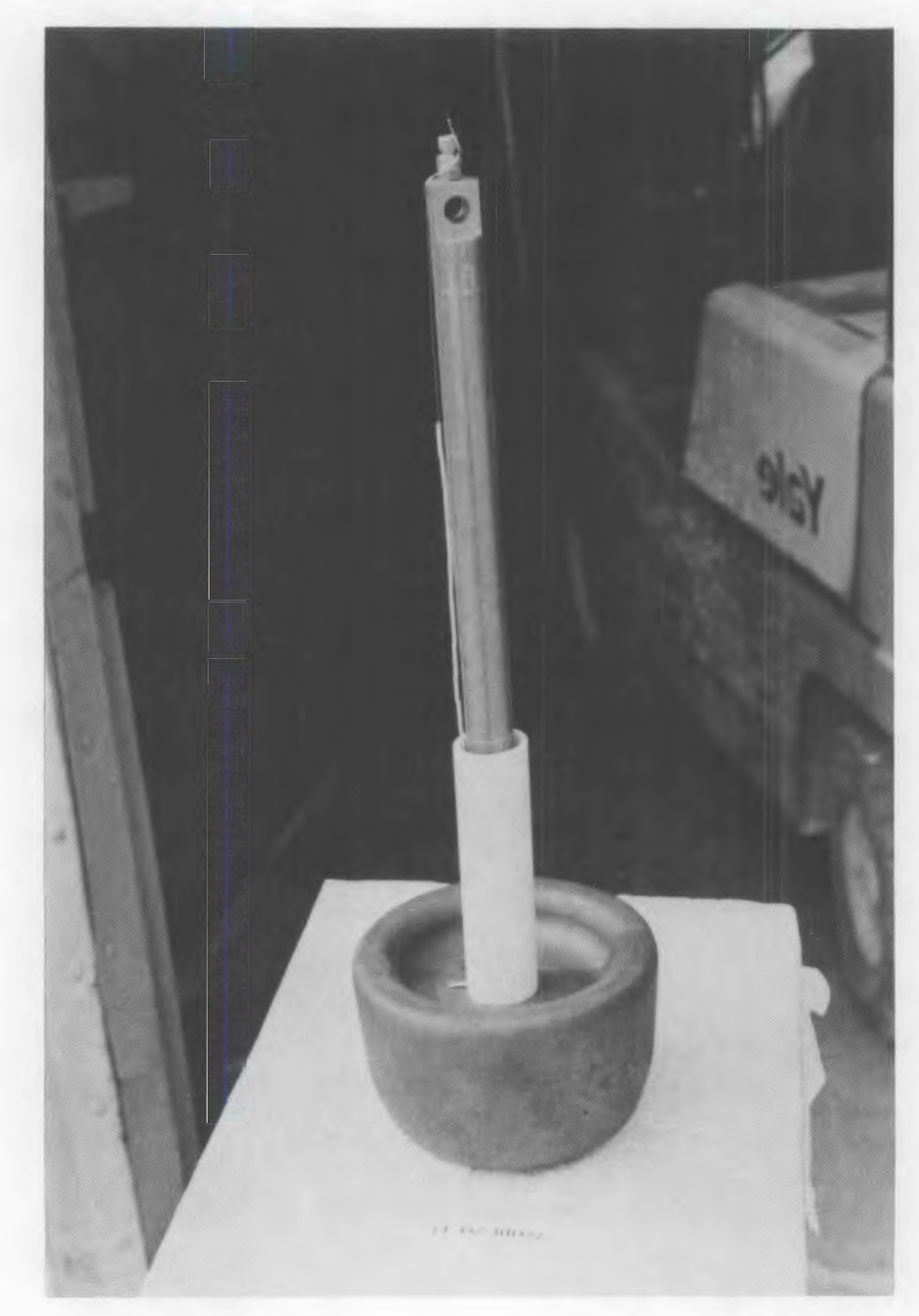

FIGURE 2.6. Photograph of an Assembled Cermet Anode and Connector Rod

program consultants, and DOE-selected advisors. These procedures were discussed in detail in Windisch et a1. (199la). Due to operational problems encountered during the pilat cell test, in particular cracking of the anodes and failure of the $\mathrm{Ni}$ connector rods, the procedures had to be modified significantly. These problems and the specific changes employed to address them are discussed in Section 4.0 .

In general, data collection procedures were not significantly affected by the operational problems discussed in Section 4.0. Current and voltage data, bath temperature, anode immersion and anode-to-cathode distance (ACD), 


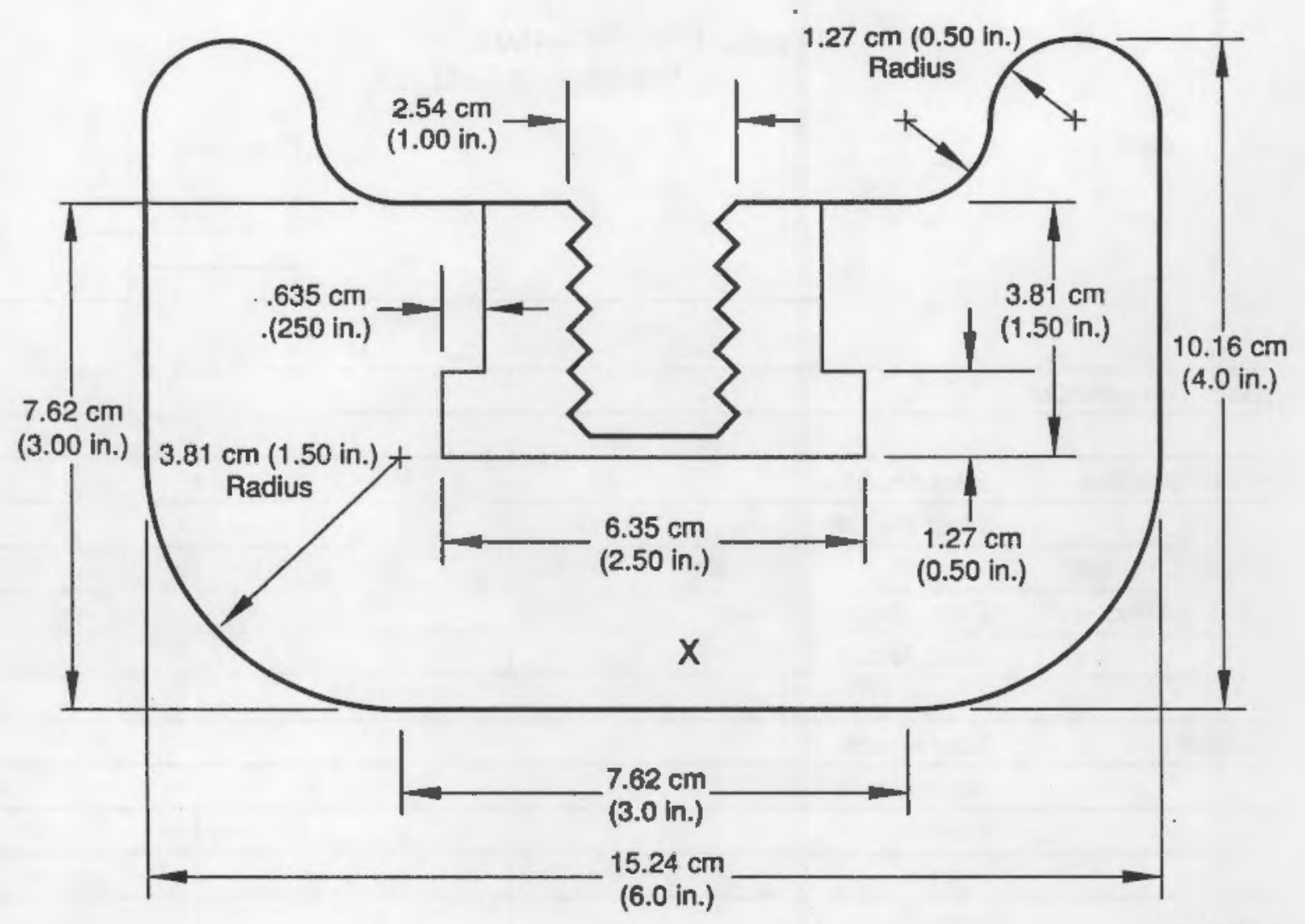

R9203085.1

FIGURE 2.7. Nominal Dimensions of the Cermet Anode (Inverted "T" around screw connection corresponds to a "core-material" that was added in earlier configurations. See Section 3.2.)

and samples of bath and metal were all taken as scheduled to monitor performance of the anodes and control the cell operation. These items were recorded on a $\log$ sheet during each of the three daily shifts as shown in Figure 2.8. In addition, the current through each cermet anode, the total current through the cermet anode cluster, and the voltages across the east (cermet cluster) and west (carbon) anodes were logged every 30 seconds with a Dianachart data acquisition system and a personal computer. Non-routine data and activities were recorded in log books. 


\section{Pilot Reduction Cell \\ Inert Anode Test}

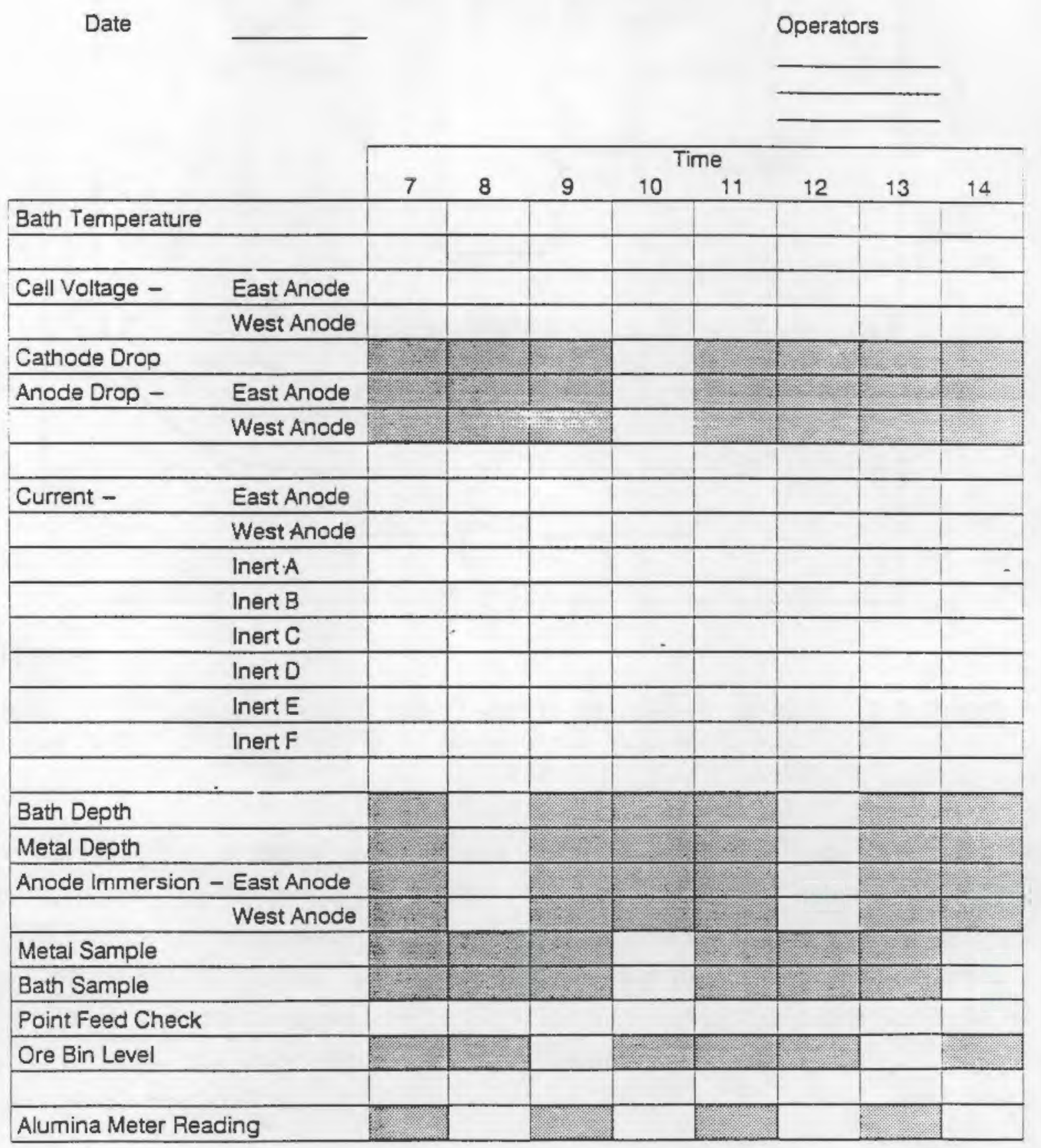

Comments:

FIGURE 2.8. Log Sheet for Recording Data During the Pilot Cell Test 


\subsection{FABRICATION OF THE CERMET ANODES}

A set of 26 anodes were needed for use in both the PNL and ERC portions of the pilot cell test. These anodes were produced at CMI with the initial pressing and sintering conditions used previously at PNL (Hart et al. 1987). The powder from which these anodes were produced was also made at CMI. In this section, the production of the powder will be reviewed briefly and then the efforts leading to the successful production of the anodes will be chronicled.

\subsection{POWDER PRODUCTION}

Although the production of the ceramic precursor powder has been discussed el sewhere (Windisch et al. 1991b), some of the characterization results were not available. Therefore, the production of the ceramic powder from which the pilot cell anodes were fabricated is discussed here briefly.

A large, approximately $1000-\mathrm{kg}$ batch of powder containing hematite $\left(\mathrm{Fe}_{2} \mathrm{O}_{3}\right.$, Pfizer Pigments, Inc., Easton, New Jersey) and high purity, green nickel oxide (NiO, Novamet, Wyckoff, New Jersey) was mixed wet $\left(\mathrm{H}_{2} \mathrm{O}\right)$ in a steel ball mill for $2 \mathrm{~h}$ to $4 \mathrm{~h}$. This powder was dried at room temperature in large flat pans. Eight $50-\mathrm{kg}$ batches of powder were calcined at different conditions to attain a fully reacted and sinterable powder. Initially, the calcining was not performed at sufficiently high temperatures so that the main constituents were basically unreacted $\mathrm{Fe}_{2} \mathrm{O}_{3}$ and $\mathrm{NiO}$. As the temperature and time at temperature were increased from $800^{\circ} \mathrm{C}$ for $2 \mathrm{~h}$ to $980^{\circ} \mathrm{C}$ for $6 \mathrm{~h}$, the amount of these materials decreased in favor of the desired compounds, $\mathrm{NiFe}_{2} \mathrm{O}_{4}$ and NiO. These results are summarized in Figure 3.1. Batch eight (XBAT-8) contained no detectable $\mathrm{Fe}_{2} \mathrm{O}_{3}$.

In addition to performing $x$-ray analyses, a chemical analysis was also performed on the mixed $\mathrm{Fe}_{2} \mathrm{O}_{3}$ and $\mathrm{NiO}$ to determine the composition of this powder that served as the source for all of the calcining trials and the anodes. The results from this analysis showed that the composition of the powder closely matched the specified composition. At PNL, a powder sample was randomly selected from a larger batch of powder, dissolved in $6 \mathrm{M} \mathrm{HCl}$, which was 


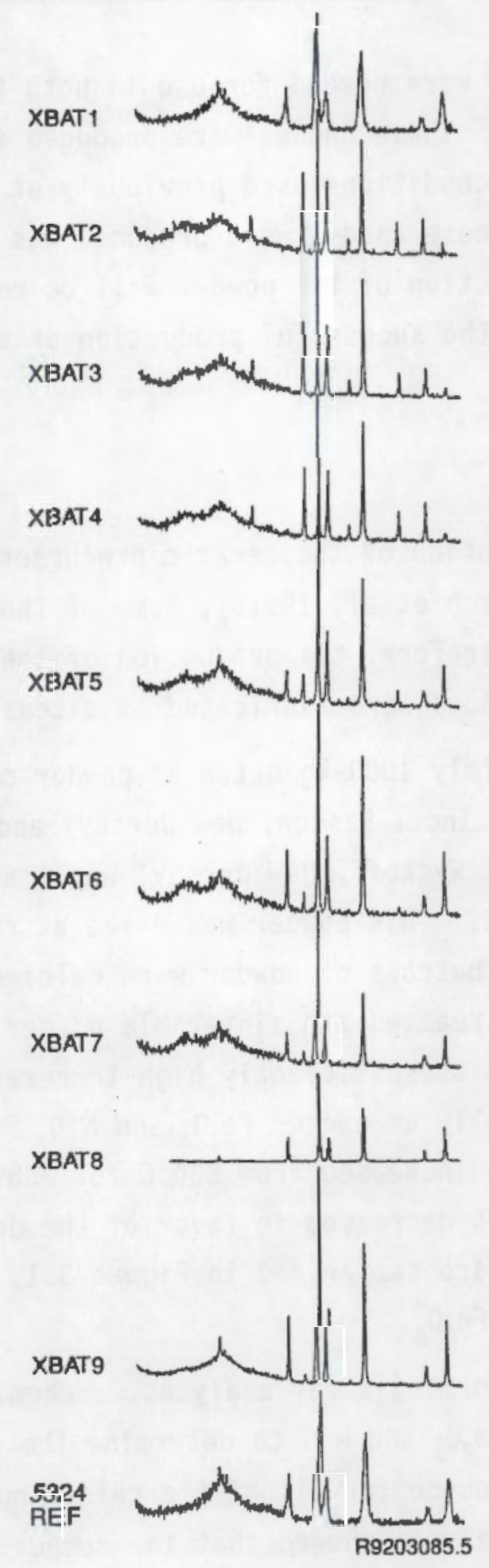

FIGURE 3.1. Results from the X-ray Diffraction Scans of the XBAT Series of Calcined Powders 
then analyzed using an inductively coupled plasma (ICP) spectrometer. An analysis of each calcined powder batch was also provided by CMI. These analyses match closely the desired composition shown as "5324" in Table 3.1. The notation "5324" was devised by Alcoa Laboratories (Weyland et a1. 1986) and is used here to refer to the composition that serves as a "reference" material.

During the course of obtaining the correct calcining conditions for the precursor powder, small pellets of the calcine were pressed and sintered. Even when the calcine contained substantial quantity of unreacted $\mathrm{Fe}_{2} \mathrm{O}_{3}$, the powder sintered well and a pellet of desired density was usually obtained. The results from several of these sintering tests are summarized in Table 3.2.

One of the problems identified early in the program was the low consolidation pressures available at CMI. The maximum pressure that could be attained at CMI was $91 \mathrm{MPa}$ (13 kpsi). This is substantially lower than the $140 \mathrm{MPa}(20 \mathrm{kpsi})$ used in the laboratory studies at PNL. This low consolidation pressure led to approximately $0.1 \mathrm{~g} / \mathrm{cm}^{3}$ lower density (see Table 3.2 ). Although the powders from XBAT-5 through XBAT- 8 yielded the same sintered

IABLE 3.1. Composition of Powders Produced at Ceramic Magnetics and Analyzed at Rutgers University

\begin{tabular}{|c|c|c|}
\hline \multirow[b]{2}{*}{ Batch Number } & \multicolumn{2}{|c|}{ Assay, mass $\%$} \\
\hline & $\begin{array}{l}\text { Iron as } \\
\mathrm{Fe}_{2} \mathrm{O}_{3} \\
\end{array}$ & $\begin{array}{c}\text { Nickel as } \\
\mathrm{NiO} \\
\end{array}$ \\
\hline ХВАТ - 2 & 46.8 & 53.3 \\
\hline XBAT - 3 & 46.8 & 53.3 \\
\hline XBAT - 4 & 46.8 & 53.3 \\
\hline ХВАТ - 5 & 46.8 & 53.5 \\
\hline XBAT- 6 & 46.8 & 53.5 \\
\hline ХВАТ - 7 & 46.8 & 53.5 \\
\hline XBAT -8 & 46.8 & 53.5 \\
\hline XBAT-9 & 46.8 & 53.5 \\
\hline XBAT-3 (PNL) & 48.4 & 51.5 \\
\hline "5324" & 48.5 & 51.7 \\
\hline
\end{tabular}


TABLE 3.2. Results from Pressing and Sintering Experiments with XBAT Powders

\begin{tabular}{|c|c|c|}
\hline \multirow[b]{3}{*}{ Material } & \multicolumn{2}{|c|}{ Sintered Densities, $\mathrm{g} / \mathrm{cm}^{3}$} \\
\hline & \multicolumn{2}{|c|}{ Consolidation Pressure, $\mathrm{MPa}$ (kpsi) } \\
\hline & $91 \mathrm{MPa}$ (13 kpsi) & $140 \mathrm{MPa}(20 \mathrm{kpsi})$ \\
\hline "5324" Powder & 5.60 & 5.70 \\
\hline ХВАT-9 & 5.47 & 5.62 \\
\hline XBAT -8 & -- & 5.72 \\
\hline ХВАT -7 & -- & 5.78 \\
\hline$" 5324 "+17 \% \mathrm{Cu}$ & 6.05 & 6.11 \\
\hline XBAT-9 $+17 \% \mathrm{Cu}$ & 5.94 & 5.99 \\
\hline XВAT- $8+17 \% \mathrm{Cu}$ & -- & 6.05 \\
\hline XВAT $-7+17 \% \mathrm{Cu}$ & -- & 6.06 \\
\hline Lab Anode ("5324" + $17 \% \mathrm{Cu})$ & -- & 5.97 \\
\hline Test Anode (XBAT-9+17\% Cu) & 5.85 & -- \\
\hline
\end{tabular}

densities as the "5324" powder after pressing at $140 \mathrm{MPa}$ and sintering, when XBAT-9 was similarly pressed and sintered, the final density was about $0.1 \mathrm{~g} / \mathrm{cm}^{3}$ lower. Therefore, the densities of the pilot cell anodes were about $0.2 \mathrm{~g} / \mathrm{cm}^{3}$ lower than the densities of anodes that had been tested in the lab and the prototype anode used in the large laboratory-scale test (Strachan et al. 1990). If $6.1 \mathrm{~g} / \mathrm{cm}^{3}$ is considered the theoretical density for the cermet, then the anodes were approximately $95 \%$ dense.

Each $25-\mathrm{kg}$ batch of powder was also spray dried. Early batches of the powder were spray dried to an agglomerate particle size of $8 \mu \mathrm{m}$. It was noted in small test batches taken from each $25-\mathrm{kg}$ test batch that this powder did not blend well with Cu metal. The final batch of powder was spray dried to a particle size of $20 \mu \mathrm{m}$. The particle sizes of $20 \mu \mathrm{m}$ and $50 \mu \mathrm{m}$ represented the mean agglomerate size. The actual powder making up these agglomerates was probably in the range of $1 \mu \mathrm{m}$ to $5 \mu \mathrm{m}$.

Finally, a large batch of powder $(500 \mathrm{~kg})$ was calcined (XBAT-9). Since the batch size and furnace used in the trial calcinings were small, the conditions necessary to calcine a $500-\mathrm{kg}$ batch of powder were changed slightly. Whether this change or simply the difference in calcining a larger batch of 
powder made the difference, the resulting powder had a trace of hematite and did not sinter to as high a density as the powder from XBAT-8. The resulting sintered density from the XBAT-9 powder was approximately $0.1 \mathrm{~g} / \mathrm{cm}^{3}$ lower than that obtained from XBAT-8. The exact cause of this is uncertain at this time, but one explanation is that portions of the powder were at the calcining temperature longer than other portions. This could possibly have been corrected by longer ball milling or use of a different furnace/furnace design so that uniform calcining occurred. The effect of this lower density on the performance of the anode material is not known but could have provided increased access by the electrolyte to the interior of the anode along grain boundaries.

\subsection{ANODE PRODUCTION}

Using the spray-dried powder described above mixed with 17 mass\% $\mathrm{Cu}$ metal (Alamo Supply Co., Houston, Texas), 13 test anodes $^{(a)}$ were fabricated. The initial sintering schedule for these anodes is shown in Table 3.3. From the experience in constructing laboratory anodes, shrinkage of the material from the as-pressed green anode to final sintered anode was well known; about $17 \% 1$ inear shrinkage occurs on sintering. Therefore, after a couple of trials, an isostatic press mold was designed from which a near net-shape anode was obtained after sintering. The target anode dimensions were shown in Figure 2.7. To accommodate the $\mathrm{Ni}$ rod that was to be used to support the anodes and provide an electrical connection, a metal-rich core material had been developed (Strachan et a1. 1989). This core was constructed of $50 \%$ cermet powder and $50 \%$ of an alloy that was $65 \% \mathrm{Cu}$ and $35 \% \mathrm{Ni}$. The core material, when sintered, provided a good electrical bond between the $\mathrm{Ni}$ rod and the cermet anode body and a reasonable transition between the coefficient of thermal expansion of the cermet and the $\mathrm{Ni}$ rod. The shape of this core was

(a) The test anodes were preliminary anodes with the same dimensions as those used in the pilot cell test. These anodes were made to determine the optimum fabrication conditions and the specifics of the electrical connection scheme that worked best, prior to making the anodes actually used in the pilot cell test. 
TABLE 3.3. Initial Sintering Schedule for the Pilot-Cell Test Anodes

\begin{tabular}{lcr}
$\begin{array}{l}\text { Temperature } \\
\text { Range, }{ }^{\circ} \mathrm{C}\end{array}$ & $\begin{array}{c}\text { Rate, } \\
{ }^{\circ} \mathrm{C} / \mathrm{h}\end{array}$ & $\begin{array}{c}\text { Time, } \\
\mathrm{h}\end{array}$ \\
\cline { 4 - 4 } 25 to 650 & 15 & 40 \\
650 to 1070 & 50 & 8 \\
Hold at 1070 & -- & 4 \\
1070 to 1200 & 30 & 4 \\
Hold at 1200 & -- & 8 \\
Cool & 50 & 24 \\
Total Time & & 88
\end{tabular}

designed to prevent the core from pulling free from the anode body during use in the event a crack developed between the two materials.

The first anode delivered to PNL had a circumferential crack (Figure 3.2). From the shape and orientation, it was concluded that this crack developed as a result of differential contraction of the core and anode materials. This differential contraction caused the cermet to be placed in tension - a situation in which most ceramic materials do not perform well.

In an attempt to understand this cracking phenomenon, the dilatometric properties were measured. The results from this measurement are summarized in Figure 3.3. Although the two materials consolidate at different rates, this is not expected to cause severe stresses in the material. Even if stresses were induced from this behavior, the stresses would have been annealed during the heat treatment at about $1250^{\circ} \mathrm{C}$. However, the slope of the curves shown in Figure 3.3 indicate that on cooling the core material shrinks about $1 \%$ faster than the cermet material.

Before describing the set of tests that led to the final sintering conditions, one sintering condition should be described. While this is almost anecdotal, the information may be important for later studies. One anodesized cylinder was produced using the powder described above but without spray 

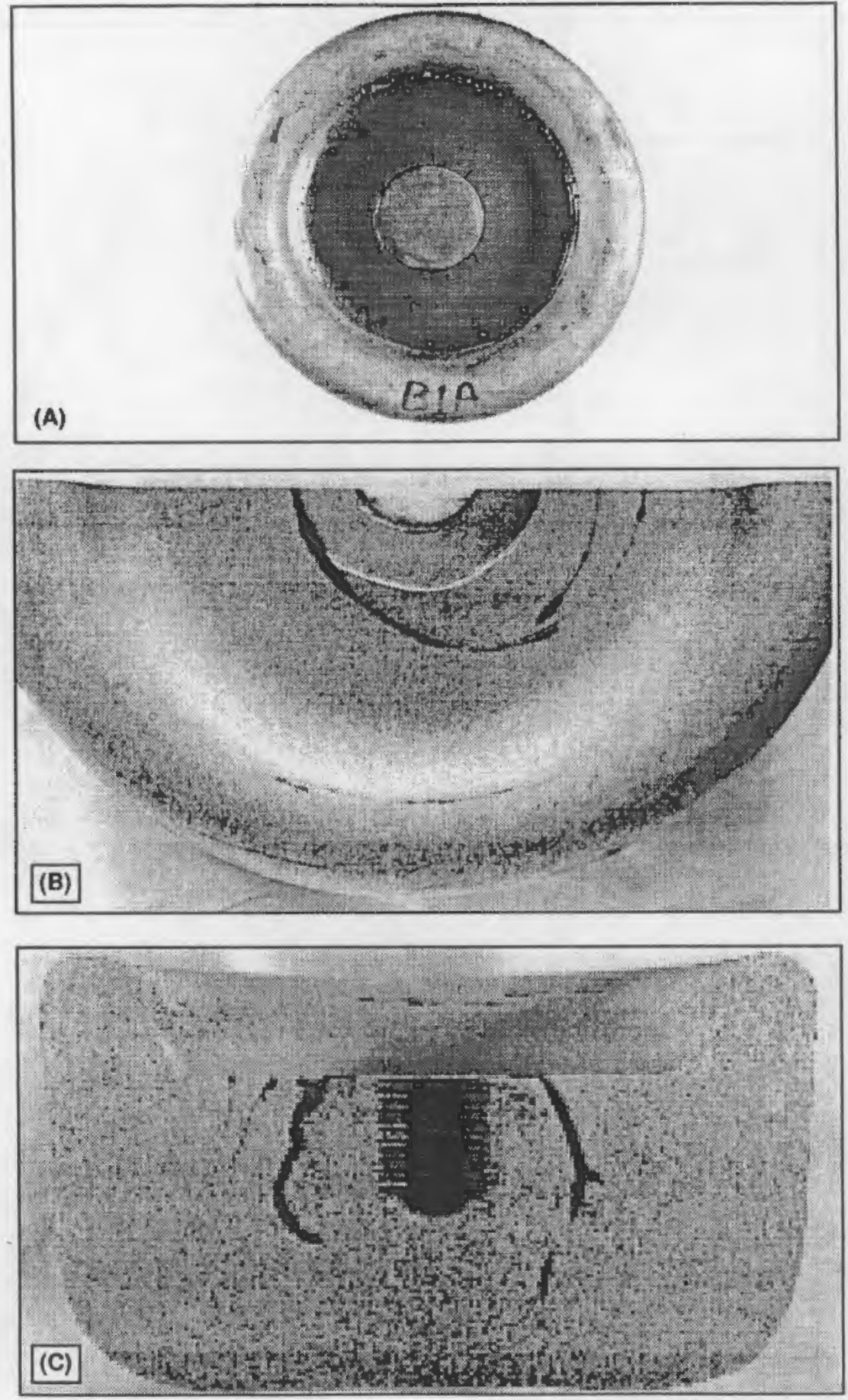

R9203085.6

FIGURE 3.2. As-Sintered Anode a) Top View, b) After Sectioning and Treating With a Dye Penetrant to Show the Depth of the Crack, c) CrossSection Face After Treating With Dye Penetrant 


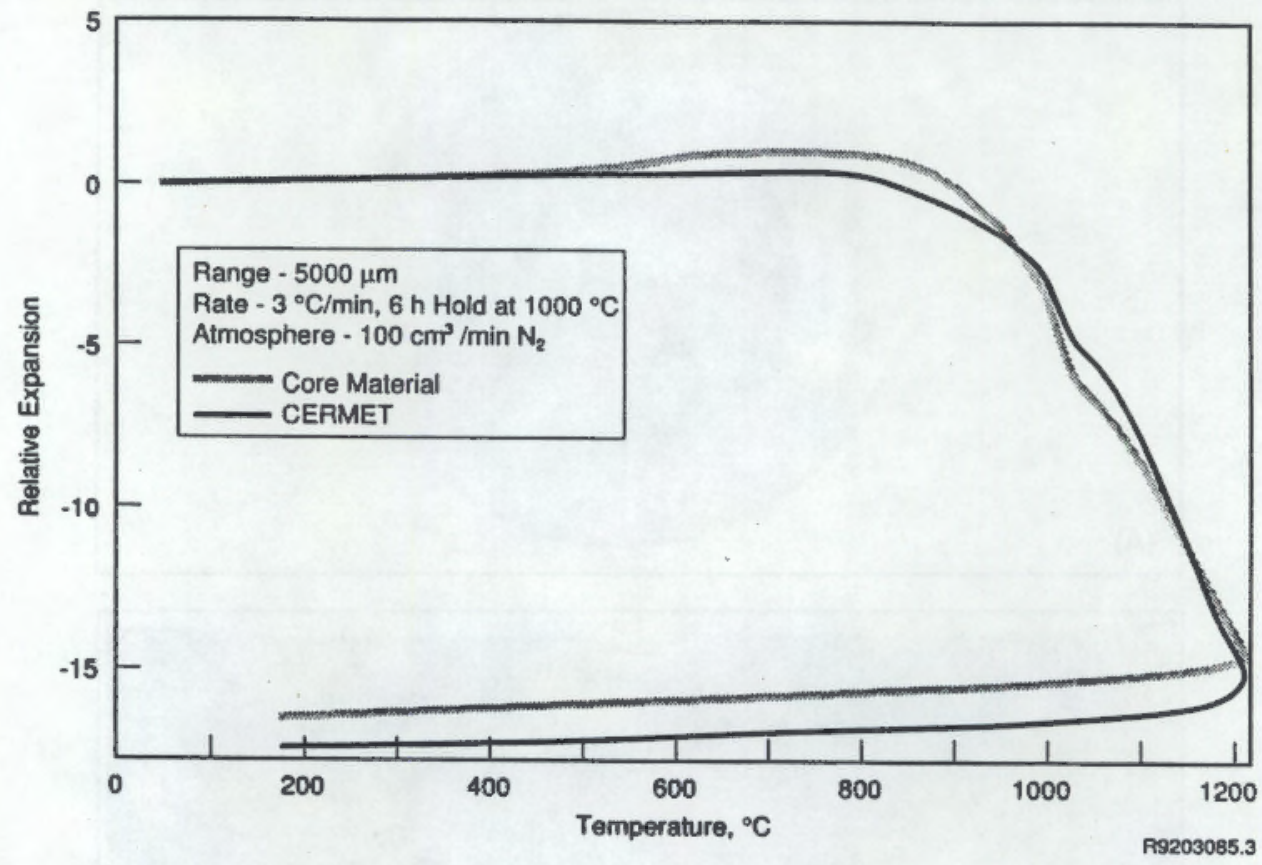

FIGURE 3.3. Results from Dilatometer Measurements on a Pressed, Green Ferrite Sample

drying and without an organic binder. This material sintered we11, but most of the Cu bled from the material, forming a pool at the bottom.

When the cermet material is formulated, only pure $\mathrm{Cu}$ is used. However, examination of the metal phase in the cermet shows it to be about $65 \%$ to $85 \% \mathrm{Cu}$ and the remainder $\mathrm{Ni}$. It had lang been suspected that the organic caused reduction of the NiO with subsequent alloying between the $\mathrm{Cu}$ and the $\mathrm{Ni}$. If an organic sintering aid is to be excluded, the sintering conditions will need to be changed, possibly including a slightly reducing atmosphere.

A series of anodes were produced with the intent that sintering conditions and/or a modification of the core design might yield anodes without cracks. The data on those anodes are summarized in Table 3.4. In the end, it was decided to leave out the core and machine the threads (needed to attach the $\mathrm{Ni}$ rod) directly into the cermet material.

In Table 3.4, the "inverted " $T$ " refers to the cross section shape of the core material that was stepped to be wider at the base than at the top. 
TABLE 3.4. Description of the Test Anodes That Were Sent to PNL

Code

B1

B1A

B2

B2A

B4

B4A

C1

Description

Standard anode configuration with a $65 \% \mathrm{Cu} / 35 \% \mathrm{Ni}$ core of smaller diameter, but inverted "T" shape.

Same as B1, but without the inverted "T" shape to the core.

Standard anode configuration with a $12.2 \mathrm{~mm}$ ( 0.5 inch) hole drilled in the cermet/metal core at the green stage. Same as B2, but without the inverted " $T$ " shape to the core.

Same as B1, but constructed using the "5324" ferrite powder.

Same as B4, but without the inverted "T" shape core.

Standard configuration, but the core was made by gradually increasing the amount of cermet phase in the core material from $50 \%$ at the inner most portion to $85 \%$ in the outer most.

This was done to prevent the anode from dropping from the core material during use if a crack developed between. the core and the cermet anode material. From the shape of the cracks, it was initially thought that the shape of the core may have been, in some way, causing the cracks; even the anodes with the straight cores cracked. More surprising was the fact that the anode constructed with the "5324" powder also cracked. This result suggests that even the prototype anode used in the laboratory cell test (Strachan et al. 1990) was probably also cracked. In all cases, where a core material was used, excellent bonding occurred between the cermet and core materials (Figure 3.4).

The fact that these cracks were small indicated that detection using $x$-ray radiography would not be successful. At PNL, the Applied Physics Center specializes in nondestructive testing. This group had equipment set up and available to examine these anodes and determine if these cracks could be seen. By immersing the anode in a tank of water on an aluminum pedestal, the entire anode could be scanned using ultrasound. A schematic of the experimental device for scanning the anodes is shown in Figure 3.5. U1trasound is focussed on the anode and the reflected sound is detected. The anode is rotated through $360^{\circ}$ with "scans" being taken as frequently as every $1 \mathrm{~mm}$. If no 


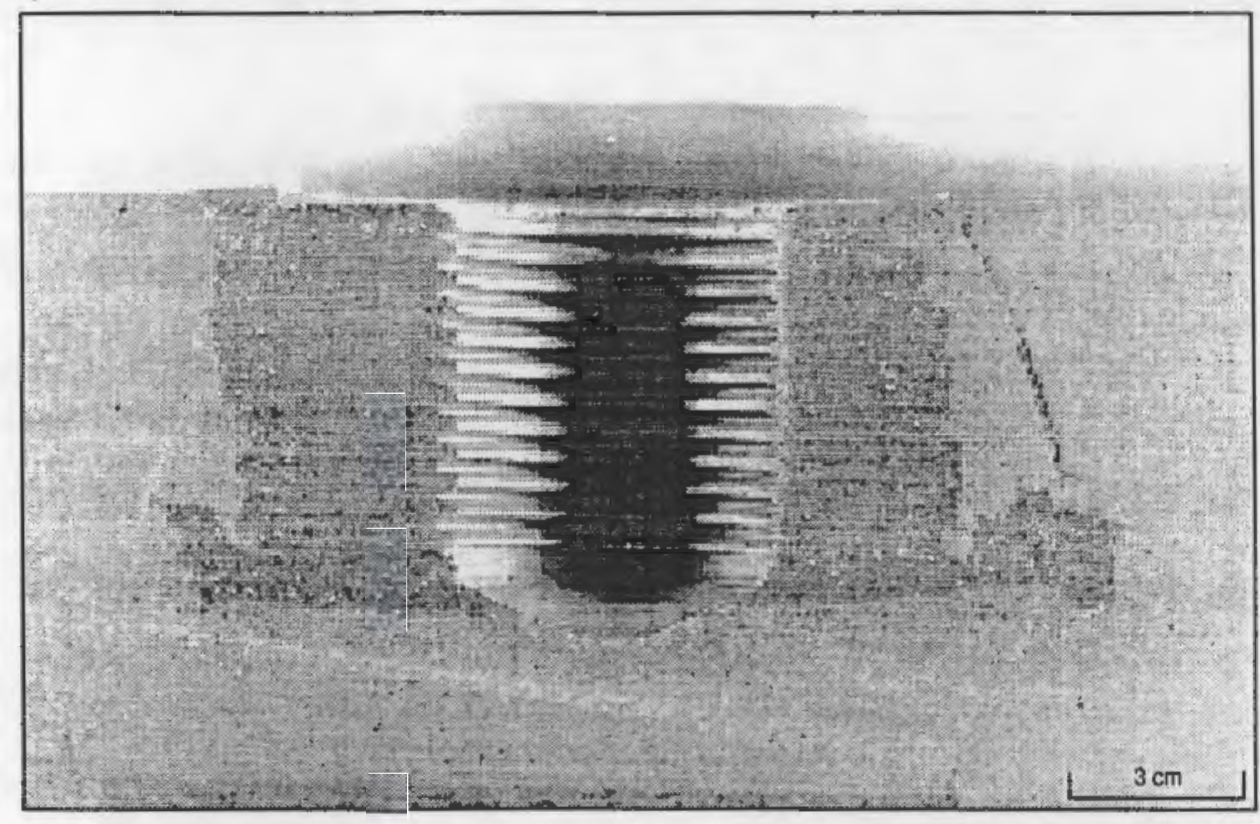

ค9203085.4

FIGURE 3.4. Close-up View of a Cross Section of a Pilot Cell Anode Showing the Excellent Bonding

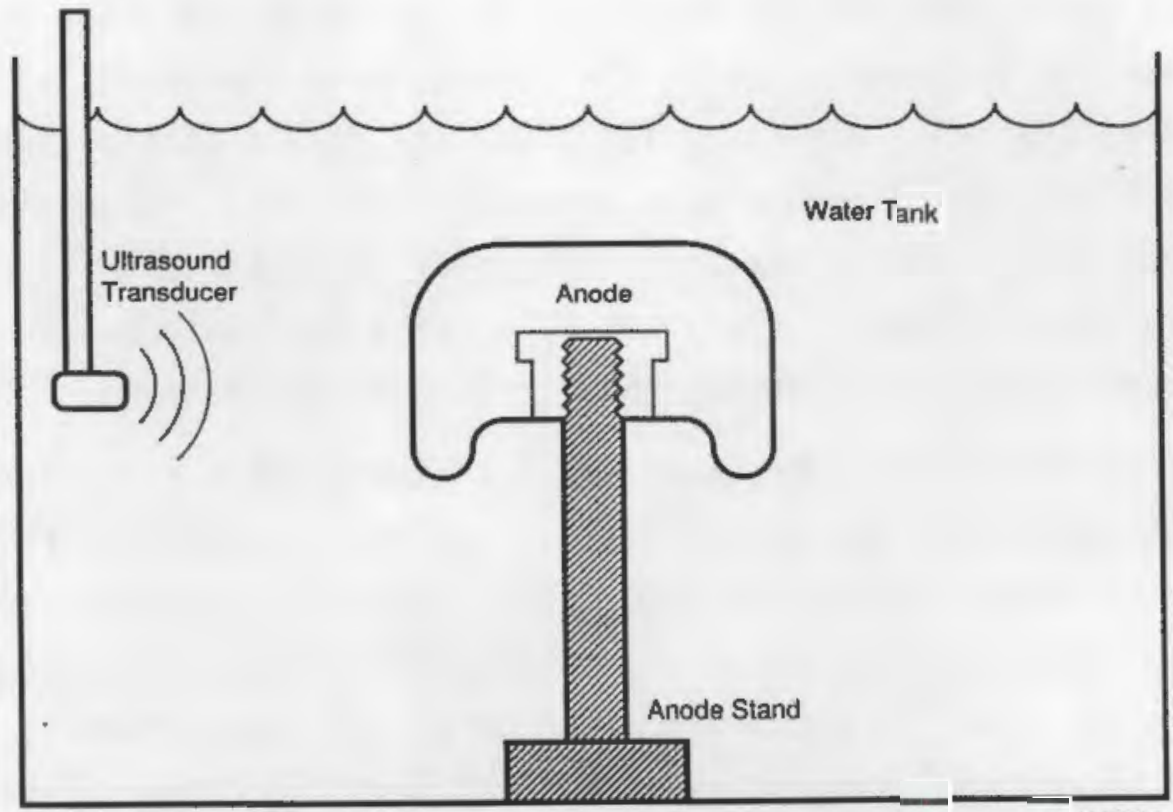

R9203085.2

FIGURE 3.5. A Schematic of the U1trasound Device for Determining the Presence of Cracks in Pilot Cell Anodes 
crack or defect exists in the material, the sound is not reflected until it reaches the other side of the anode. The sound will not penetrate beyond a crack, so the intensity of the reflected sound is more intense from a crack. By measuring the time it takes for the sound wave to pass through the water and then into the anode, the depth of the crack from the surface can be measured. For more accuracy, the speed of sound in the cermet material was measured using a solid piece of a sectioned anode of known thickness. An example of the "picture" of the crack in a cracked anode is shown in Figure 3.6. In this figure three views are shown. One view is shown as a cross section. The next view is a circumferential view at the depth of the most intense signal from the crack. In the third view, the crack is viewed from the bottom of a sectioned anode. In these views, the crack is represented by the darkest area. Confirmation of the depth and geometry of the crack was obtained by sectioning the anode and examining the crack.

Since it appeared that the core material was causing the cracking in the cermet anodes, two test anodes without any core material were produced. These anodes contained no cracks that were visible, and none were found upon examination using ultrasound. These two anodes were heated to $1000^{\circ} \mathrm{C}$ at about $50^{\circ} \mathrm{C} / \mathrm{h}$. The anodes remained heated for about $12 \mathrm{~h}$. After slow cooling, both anodes appeared to crack after removal from the furnace at a temperature of about $50^{\circ} \mathrm{C}$ to $70^{\circ} \mathrm{C}$. This performance was deemed acceptable and the remainder of the anodes were pressed and sintered. Two of the next 13 anodes were nondestructively tested for cracks; none were found.

Before and after use, the composition of the anodes was checked. Samples were selected from the middle of the anode. The samples were ground into a fine powder and a weighed portion of the powder was dissolved in $6 \mathrm{M} \mathrm{HCl}$. After the ferrite material was dissolved, the remaining portion, namely the $\mathrm{Cu}$, was dissolved by adding a couple of drops of concentrated $\mathrm{HNO}_{3}$ to the $\mathrm{HCl}$. This solution was diluted to a known volume and analyzed using ICP. The results of these analyses are summarized in Table 3.5. The composition is essentially identical to that of anodes prepared at PNL ("5324") and extremely close to theoretical based on starting material composition. 

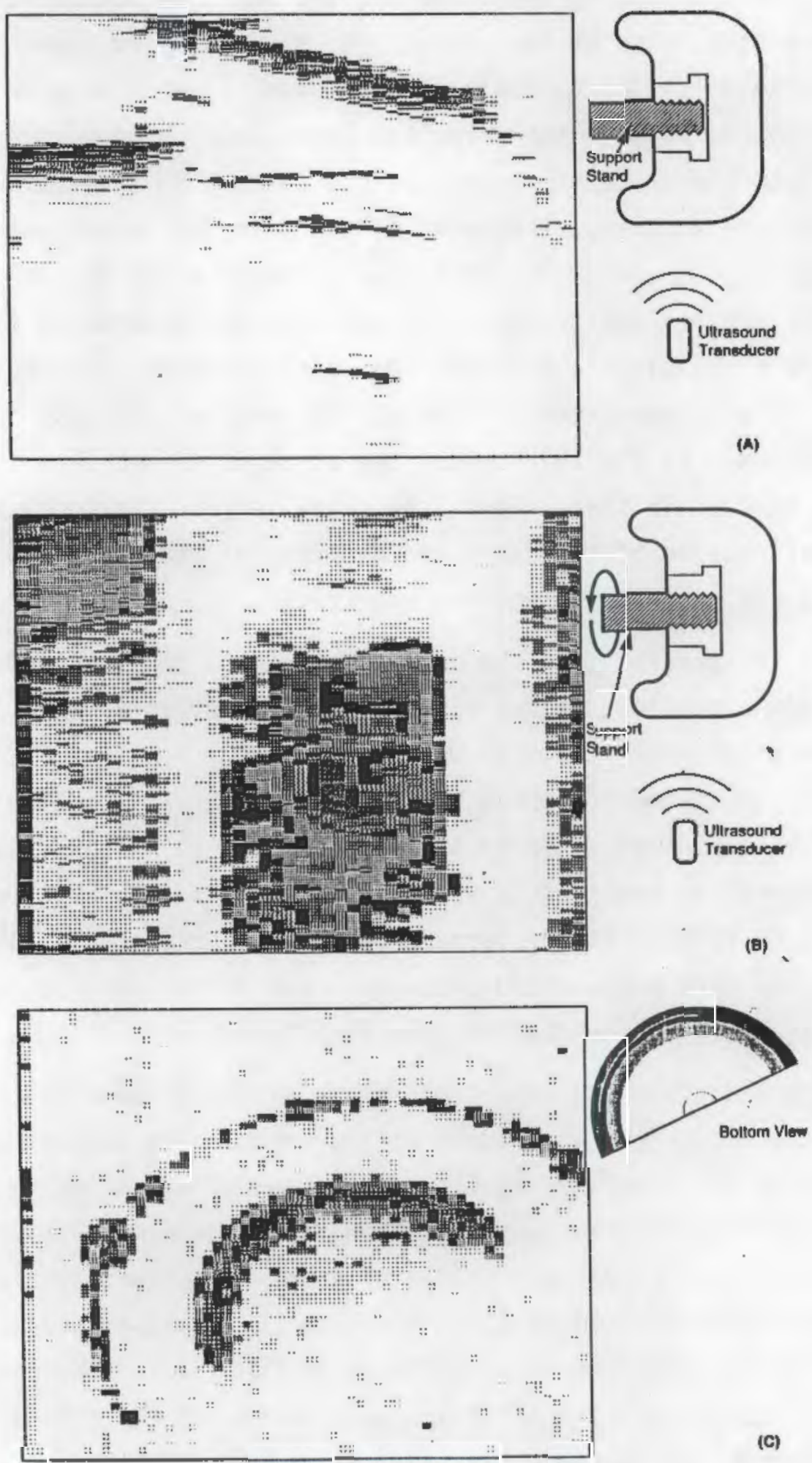

(C)

FIGURE 3.6. Results from the Ultrasound Testing Showing the Existence of Cracks Within the Anode. Three Views of the Anode are Presented. 
IABLE 3.5. Composition of Tested and Control Anode Materials

\begin{tabular}{|c|c|c|c|}
\hline \multirow[b]{2}{*}{ Material } & \multicolumn{3}{|c|}{ Composition, Mass \% } \\
\hline & $\mathrm{Cu}$ & $\mathrm{Ni}$ & $\mathrm{Fe}$ \\
\hline "5324" & 16.8 & 32.0 & 28.1 \\
\hline $\begin{array}{l}\text { Control (CMI } \\
\text { Fabricated) }\end{array}$ & 16.2 & 32.0 & 27.4 \\
\hline $\begin{array}{l}\text { Tested (CMI } \\
\text { Fabricated) }\end{array}$ & 16.6 & 31.3 & 26.7 \\
\hline Theoretical & 17.0 & 33.7 & 28.0 \\
\hline
\end{tabular}


$+$ 


\subsection{PILOT CELL OPERATION}

\subsection{CELL START-UP AND BREAK-IN}

The MTL pilot reduction cell began operation on August 1, 1991. The start-up procedure was similar to that used in past operations of the pilot cell and essentially consisted of the following steps:

1. The cathode bottom was covered with aluminum buttons (400 $1 \mathrm{~b})$ before beginning a gas prebake.

2. Heat was applied with a gas torch for $32 \mathrm{~h}$ to melt the aluminum.

3. Two (2) preheated carbon anodes were installed. Current at $5.6 \mathrm{kA}$ was passed through the cell for the next $24 \mathrm{~h}$.

4. Cryolite was then melted in the cell by raising the anodes to arcing conditions and placing solid cryolite around the anodes. The reclaimed cryolite used for this purpose typically has a bath ratio of 1.7 with small amounts of $\mathrm{LiF}, \mathrm{MgF}_{2}$, and $\mathrm{CaF}_{2}$. Within two hours of beginning this step, 3 inches of liquid bath had been achieved. This operation occurred on August 3.

5. Several days were then allowed to achieve chemical and thermal stability before replacing the standard carbon anode with the graphite anode cluster. This replacement occurred on August 5. Figure 4.1 shows key cathode temperatures during heat-up and initial operation.

Before operation with the cermet anodes, a cluster of similar sized anodes made of graphite was installed. These anodes were 6 inches in diameter and 8 inches high with a 1 -inch diameter 304 stainless steel stem threaded into the anode. The purpose of installing the graphite anode cluster in the cell was to provide time to ensure proper operation of the data collection systems and allow individual changeout to the cermet anodes. The graphite cluster was installed as a unit on August 5, 1992 at 3:10 pm. The anodes had been preheated using a gas torch. An initial problem was found to exist due to high electrical noise on the data acquisition system arising primarily from the ac rectifier signals. The signals were subsequently improved by instal1ing filters in the data acquisition circuits.

Figures 4.2 through 4.4 show the current versus time for each of the graphite anodes from August 7-9. All of the graphite anodes were to be 


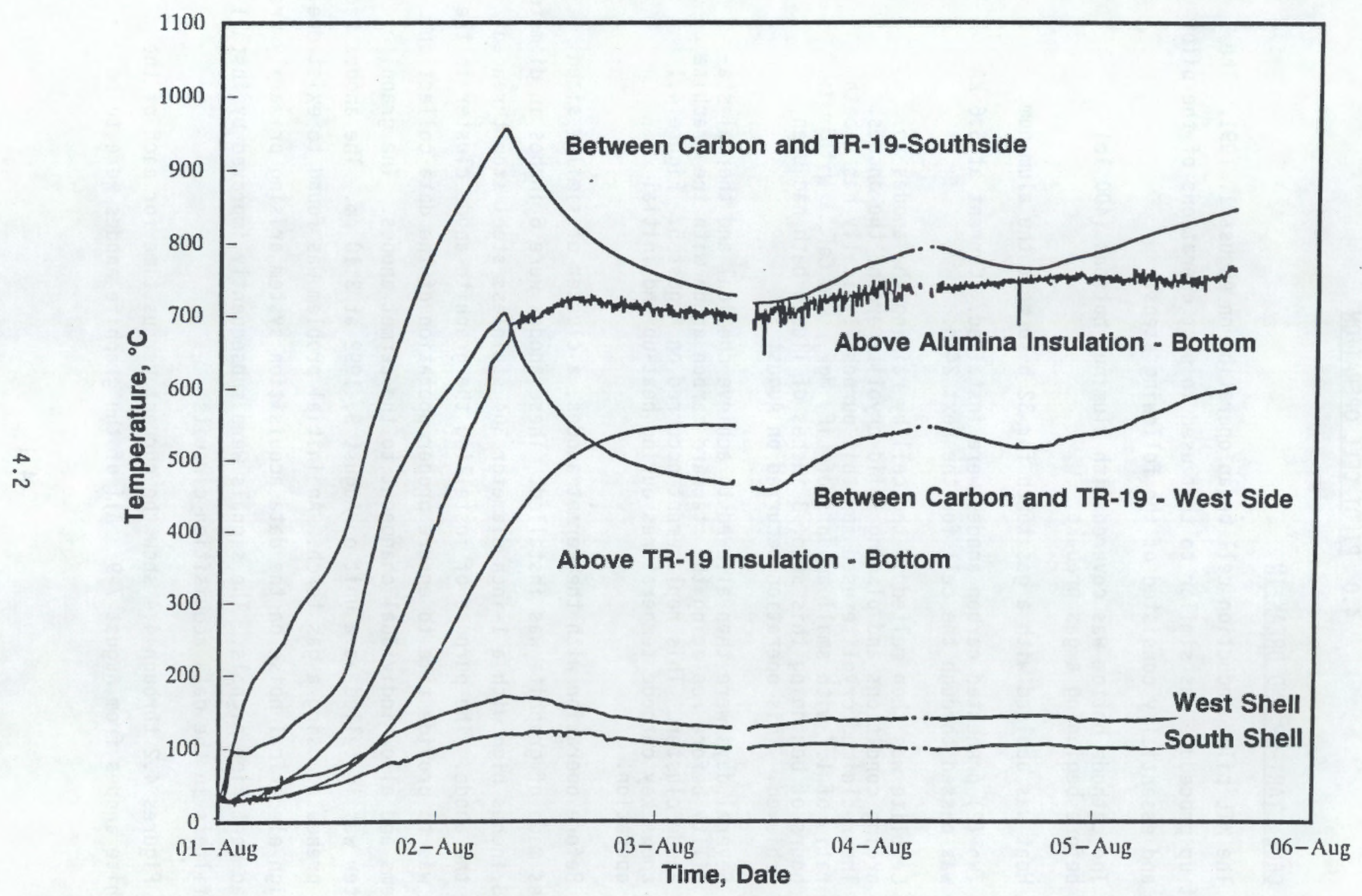

FIGURE 4.1. Cathode Temperature during Heatup 


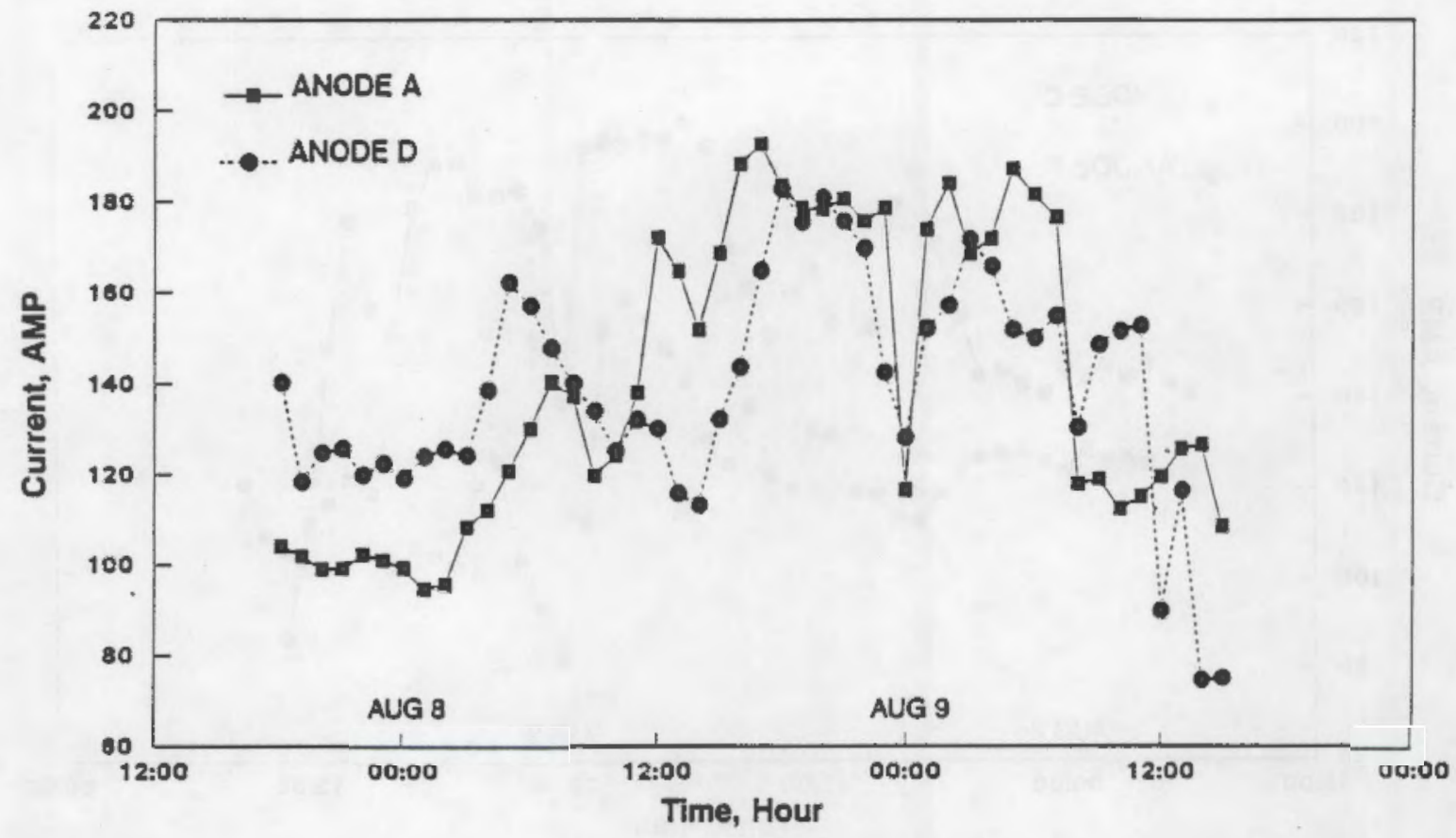

FIGURE 4.2. Current Versus Time for Graphite Anodes in Positions A and D

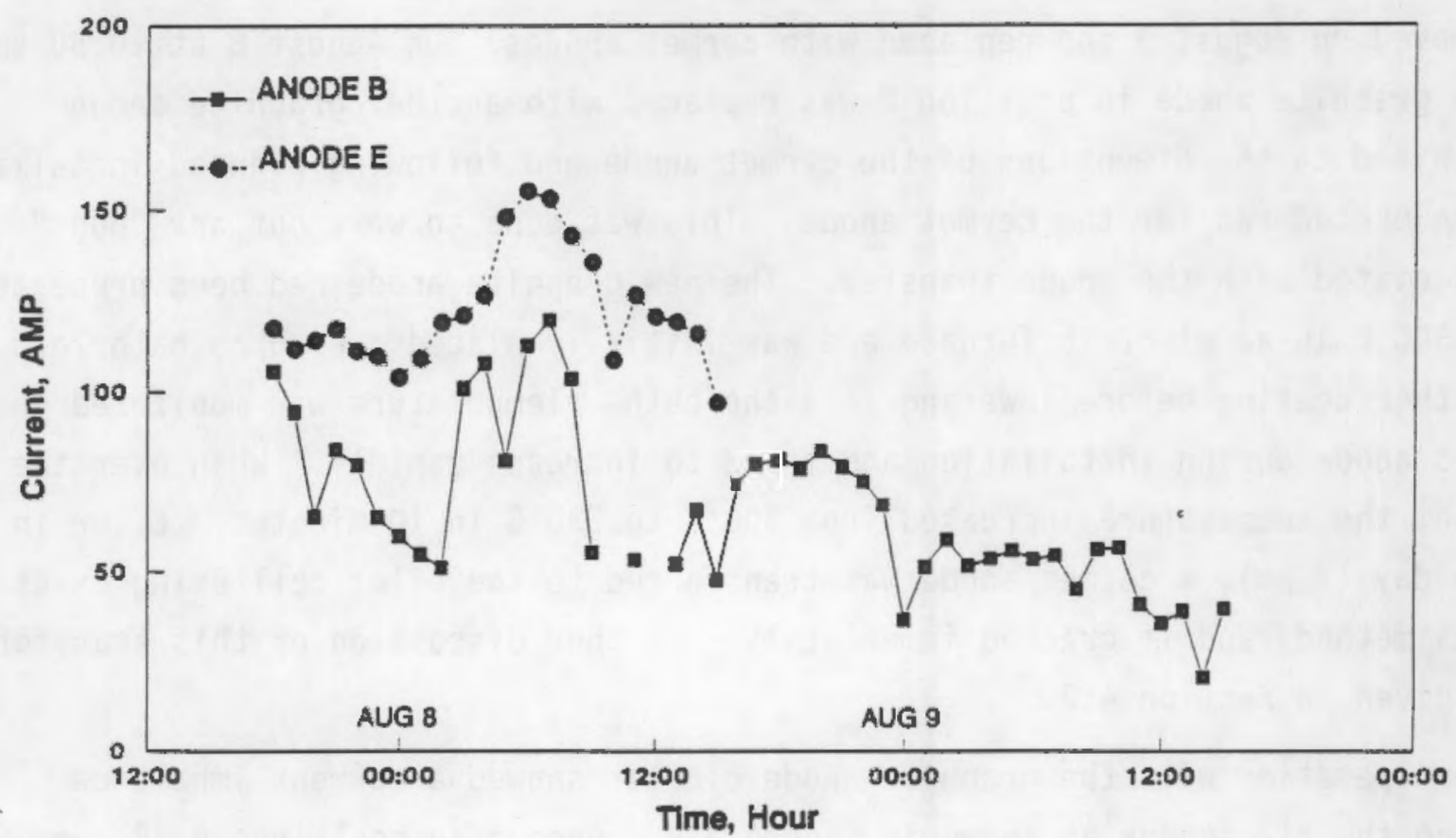

FIGURE 4.3. Current Versus Time for Graphite Anodes in Positions B and E 


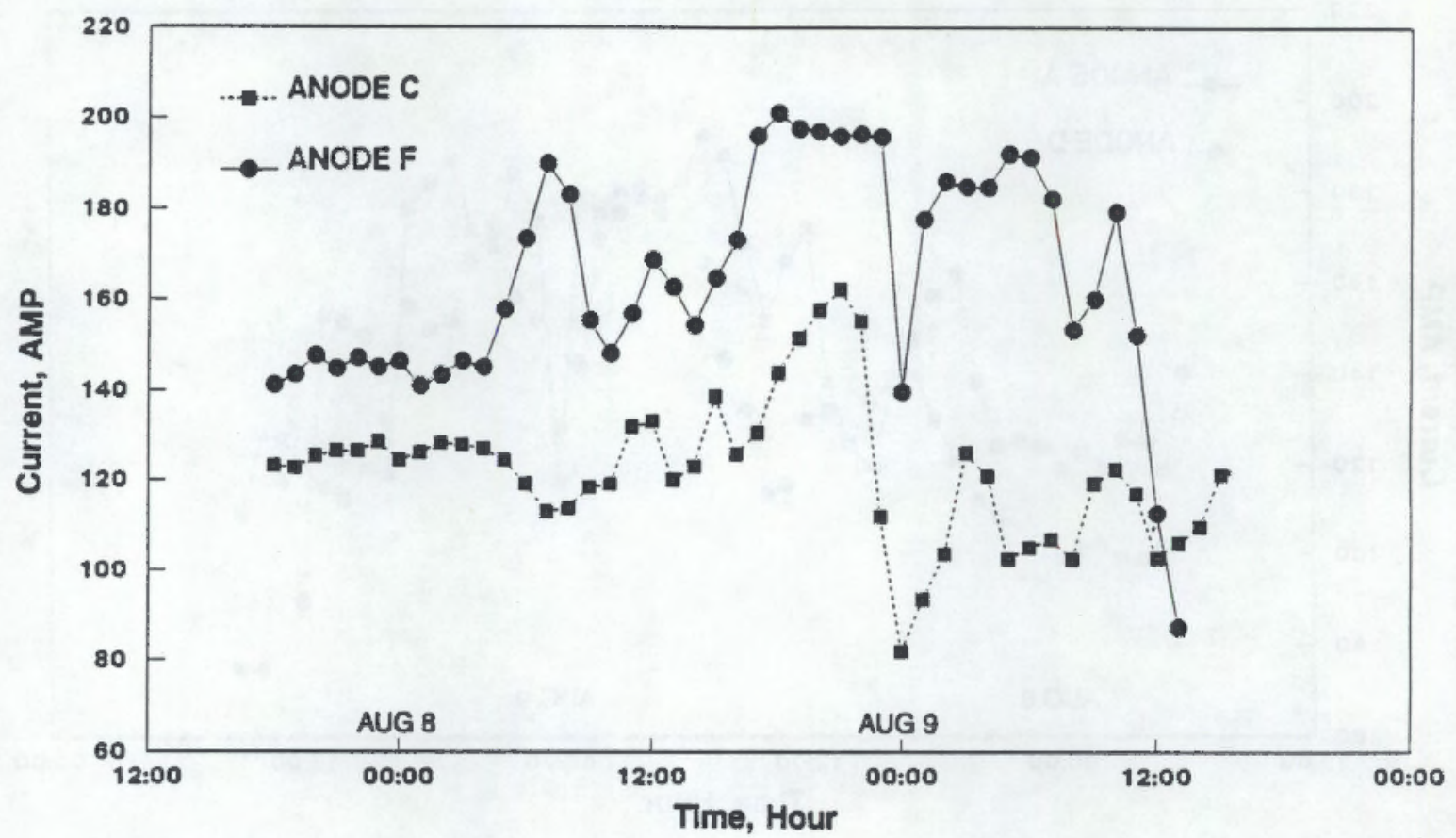

FIGURE 4.4. Current Versus Time for Graphite Anodes in Positions $C$ and $F$

removed on August 9 and replaced with cermet anodes. On August 8 at 10:50 am, the graphite anode in position B was replaced with another graphite anode machined to the dimensions of the cermet anode and following planned installation procedures for the cermet anode. This was done to work out any "bugs" associated with the anode transfer. The new graphite anode had been preheated to $300^{\circ} \mathrm{C}$ in an electric furnace and was initially placed over open bath for further heating before lowering into the bath. Temperature was monitored on this anode during installation and found to increase rapidly. When over the bath, the temperature increased from $300^{\circ} \mathrm{C}$ to $530^{\circ} \mathrm{C}$ in 10 minutes. Later in the day $(2 \mathrm{pm})$, a cermet anode was transferred to the pilot cell using exactly this method, and it cracked immediately. Further discussion of this transfer is given in Section 4.2 .

Operation with the graphite anode cluster showed a current imbalance among the six anodes as shown in Figure 4.5. Anodes in positions $A, B$, and $C$ carried about $17 \%$ less current than those in positions $D, E$, and $F$. Positions $A, B$, and $C$ were closer to the large carbon anode (west anode) which, as discussed below, perturbed the voltage characteristics of the cell. The 


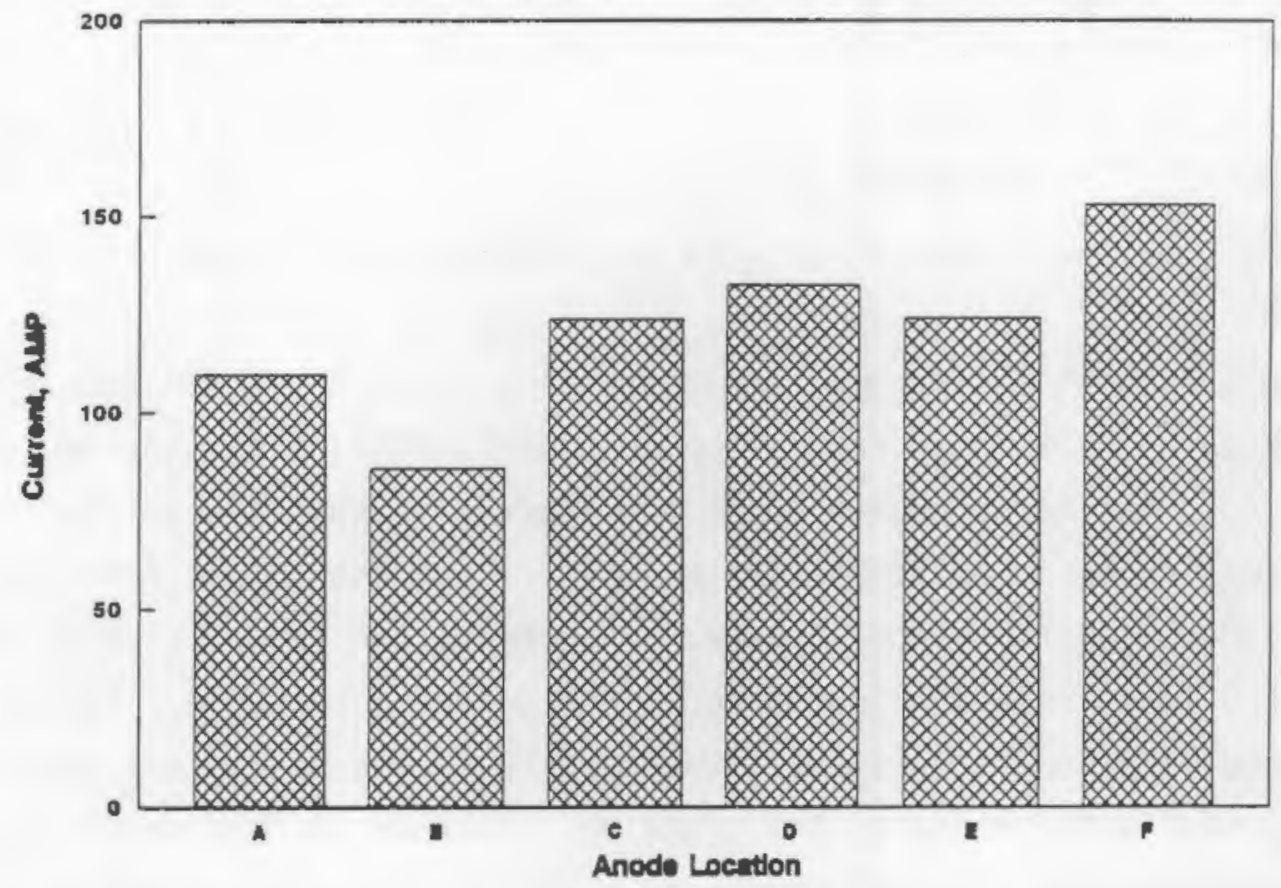

FIGURE 4,5. Current Imbalance on the Carbon Anodes. (Average of readings taken between August 7 at $6: 00$ am and August 8 at 8:00 am)

imbalance was also partly due to the sidewall conduction in the cell. During this period, the cell was operating with 7.7 inches of bath with the anodes immersed 3.1 inches, resulting in an anode-cathode distance of 4.6 inches. The distance to the sidewall was 5.5 inches. With no sidewall freeze, significant sidewall conduction was occurring. This was confirmed by the burnback pattern noted on the anodes when removed, i.e., the sides of the anodes oriented toward the sidewalls showed the most mass loss.

\subsection{PREHEATING OF CERMET ANODES}

The planned method for transferring the cermet anodes to the cell was as follows:

1. Preheat the anodes to $300^{\circ} \mathrm{C}$ at a rate of $50 \% / \mathrm{h}$ in an electric furnace. The anodes would be bundled in a ceramic wool insulation to retard heat loss during transport to the cell some $100 \mathrm{~m}$ away.

2. Remove one graphite anode from the cell, allowing sufficient opening for the cermet anode to be located in its place. 
3. Remove one cermet anode from the preheat furnace, placing it into the cell hanging several inches above the bath.

4. As the temperature increases on the anode, lower it down toward the bath until it is submerged.

5. At this time the current lead will be connected and current passed through the anode.

Figure 4.6 shows the cermet anodes in the preheat furnace. Figure 4.7 shows an anode being transferred to the cell for installation. As indicated in Section 4.1, the first cermet anode transferred in this manner cracked as soon as it was exposed to the open bath. Figure 4.8 shows this first anode, labelled Anode Bl, after it had cracked. As shown, the anode cracked radially down a center line including the $\mathrm{Ni}$ rod/cermet anode connection. Thermal shock coupled with too large a CTE mismatch between the $\mathrm{Ni}$ rod and the cermet anode was probably the cause of the cracking. Further discussion of the thermal shock characteristics of the anode is given in Sections 4.3 and 5.3.

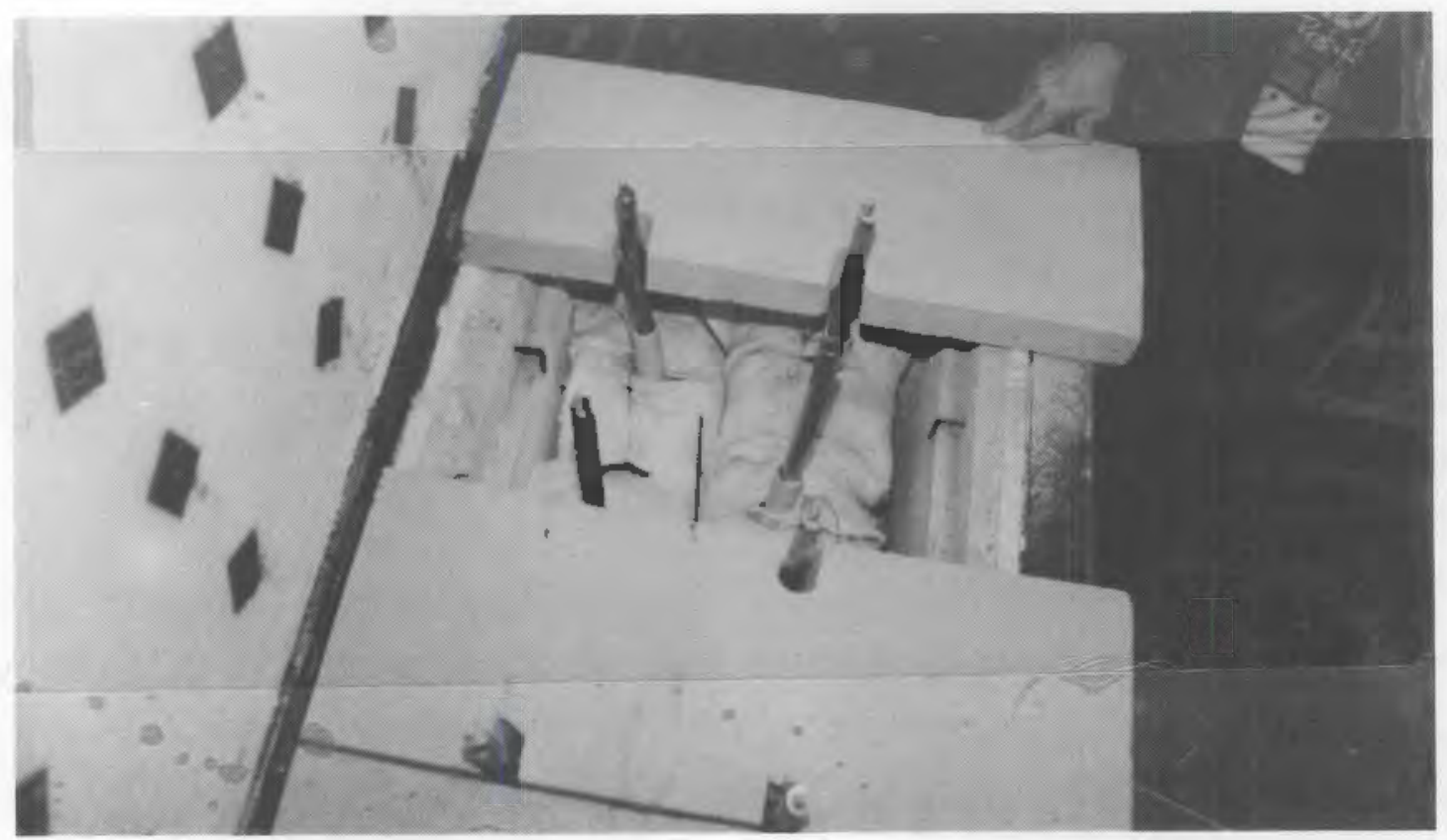

FIGURE 4.6. Photograph of Cermet Anodes in the Preheat Furnace 


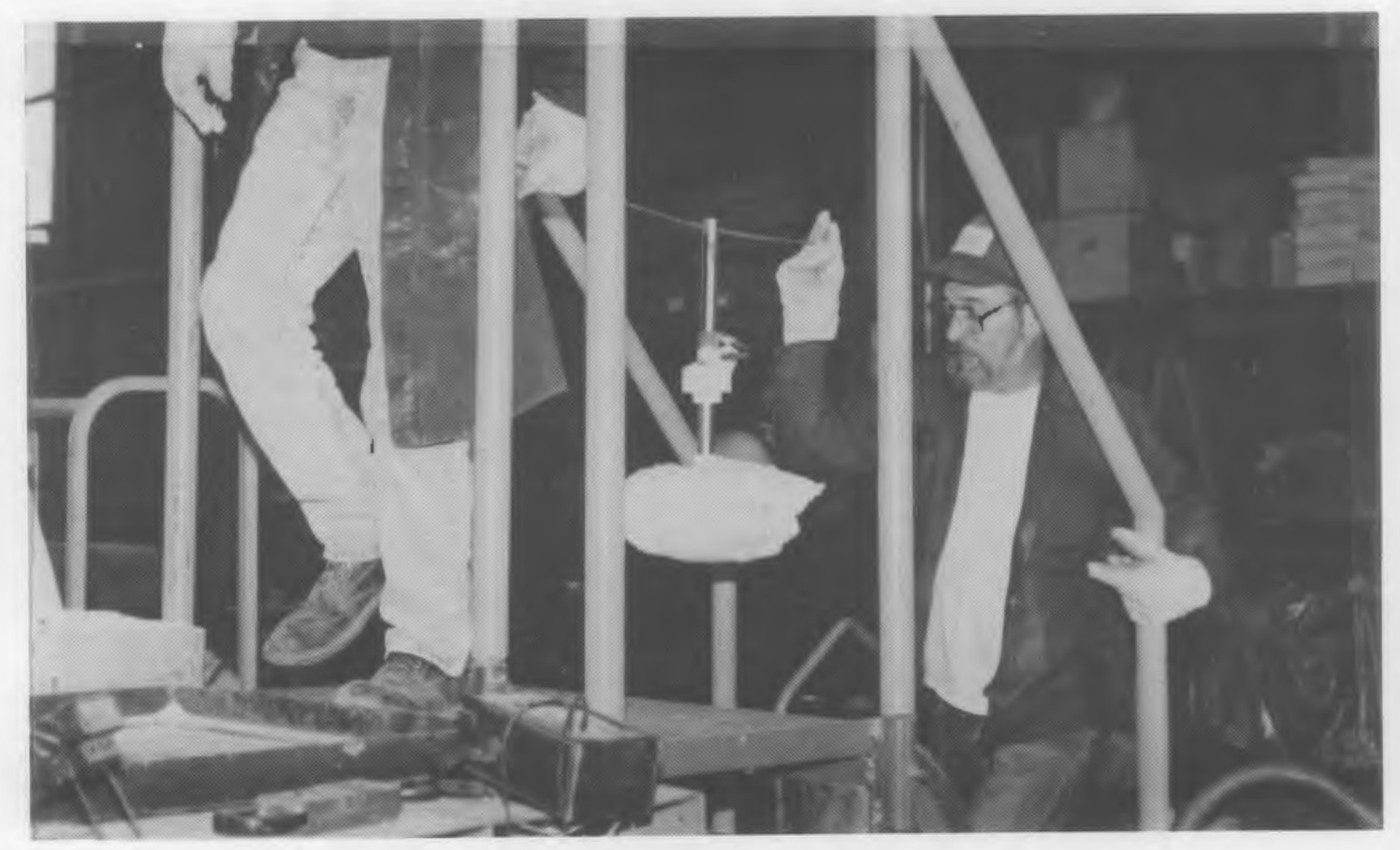

FIGURE 4.7. Transferring a Cermet Anode to the Pilot Cell

Following the initial failure in transferring a cermet anode, the preheating procedures were modified. Two alternative procedures were evaluated:

1. An anode, labelled Anode Aux1, was positioned on the cell and allowed to preheat over the crust near position $E$. Then it was gradually lowered into the cell. Over a 16- to $32-\mathrm{h}$ period, this anode was worked down into the molten bath.

2. An anode, labelled Aux2, was preheated in an electric furnace to $970^{\circ} \mathrm{C}$, then transferred to position $\mathrm{B}$ and inserted directly into the molten bath.

The first of the two alternatives proved to be the simplest and was used for all of the remaining anodes in the test. ${ }^{(a)}$ Normally, an anode could be placed in the cell and would be carrying current in less than $24 \mathrm{~h}$. Initial attempts to measure the anode temperature during heating yielded inconsistent

(a) Some of the anodes were preheated to $300^{\circ} \mathrm{C}$ before they were transformed in this manner. The preheated anodes were those that were originally put in the preheat furnace before the change in procedures was instituted. These were anodes $\mathrm{Al}, \mathrm{Cl}, \mathrm{D1}, \mathrm{El}$, and $\mathrm{Fl}$. 


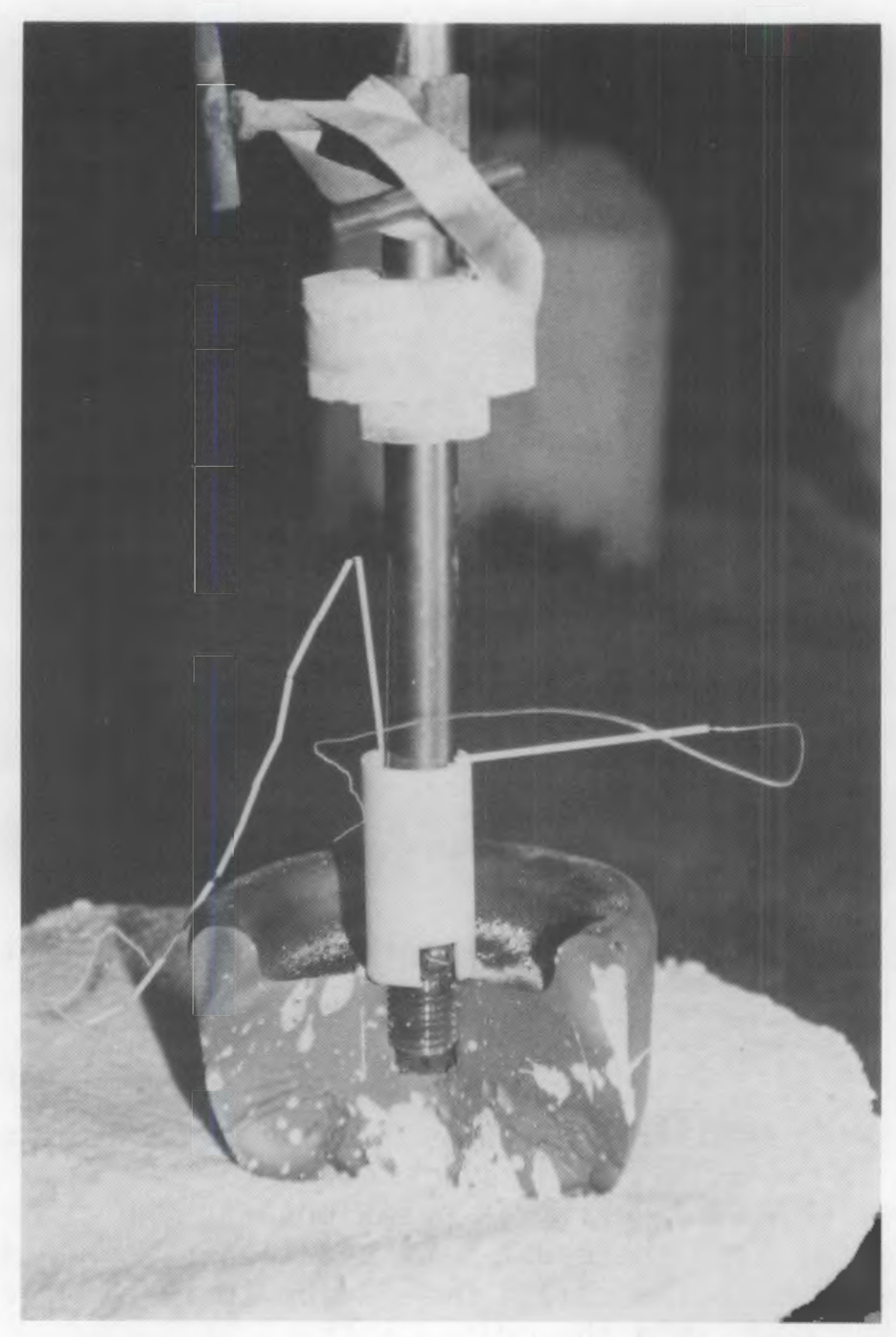

FIGURE 4.8. Anode Bl after It Had Cracked during Transfer to the Pilot Cell

results, as the thermocouples were not fixed in place and would move as the anodes were lowered into the cell. Generally, the anodes were seen to heat up at 40 to $60 \% / \mathrm{h}$ and be at a temperature of 700 to $800^{\circ} \mathrm{C}$ when current was applied. The temperature of the anode was measured by placing a thermocouple on top of the anode near the stem.

\subsection{CERMET ANODE OPERATION}

Operation with the cermet anodes in the pilot cell (PNL phase) began on August 10 and continued until August 30 . During most of the time (until 
August 27), the cermet anodes were tested under "normal" conditions, i.e., at nominal current densities ${ }^{(a)} \leq 0.5 \mathrm{~A} / \mathrm{cm}^{2}$ and as close to alumina saturation as possible. Target test conditions for this phase of cell operation were as follows:

$\begin{array}{ll}\text { Maximum individual anode current } & 90 \mathrm{~A} \\ \text { Anode immersion } & 1.5 \text { inches } \\ \text { Bath ratio } & 1.3-1.4 \\ \mathrm{CaF}_{2} & 4-6 \text { wt\% } \\ \mathrm{Al}_{2} \mathrm{O}_{3} & 100 \% \text { saturation }(7-8 \text { wt\%) }\end{array}$

The test conditions were altered on August 27 ( $4 \mathrm{am}$ ) when the alumina concentration was reduced to values significantly less than saturation. Operation was further modified on August $28(2 \mathrm{pm})$ when the current on each anode was increased to $180 \mathrm{~A}$ (nominal) or about double the value under the "normal" conditions.

\subsubsection{Electrolyte Chemistry}

Figures 4.9 and 4.10 show the variation of bath ratio and $\mathrm{CaF}_{2}$ concentration with time, respectively. Actual numerical data for these conditions are given in Appendix A. Control of the bath ratio was found to be difficult due to the changing bath volumes in the pilot cell as a result of the variability

(a) The target current density was $0.5 \mathrm{~A} / \mathrm{cm}^{2}$. The anticipated exposed surface area of the anodes (assuming 1.5-inch submersion) was about $364 \mathrm{~cm}^{2}$, with the flat bottom surface area about half this value or $182 \mathrm{~cm}^{2}$. As discussed in Windisch et al. (1991a), since very little sidewall conduction was expected, only the bottom surface area was used to calculate the current required to give $0.5 \mathrm{~A} / \mathrm{cm}^{2}$. Consequently, the target current through each anode (or, more properly, the maximum current through any of the six cermet anodes) was about $90 \mathrm{~A}$. As discussed in subsequent sections, significant heterogeneities in current distribution pervaded this test; so, in reality, the current density varied significantly from place to place on each anode. However, the results of voltage drop analysis and profiling indicated that under "normal" conditions, the current density on most of the surface of any cermet anode did not exceed $0.5 \mathrm{~A} / \mathrm{cm}^{2}$. 


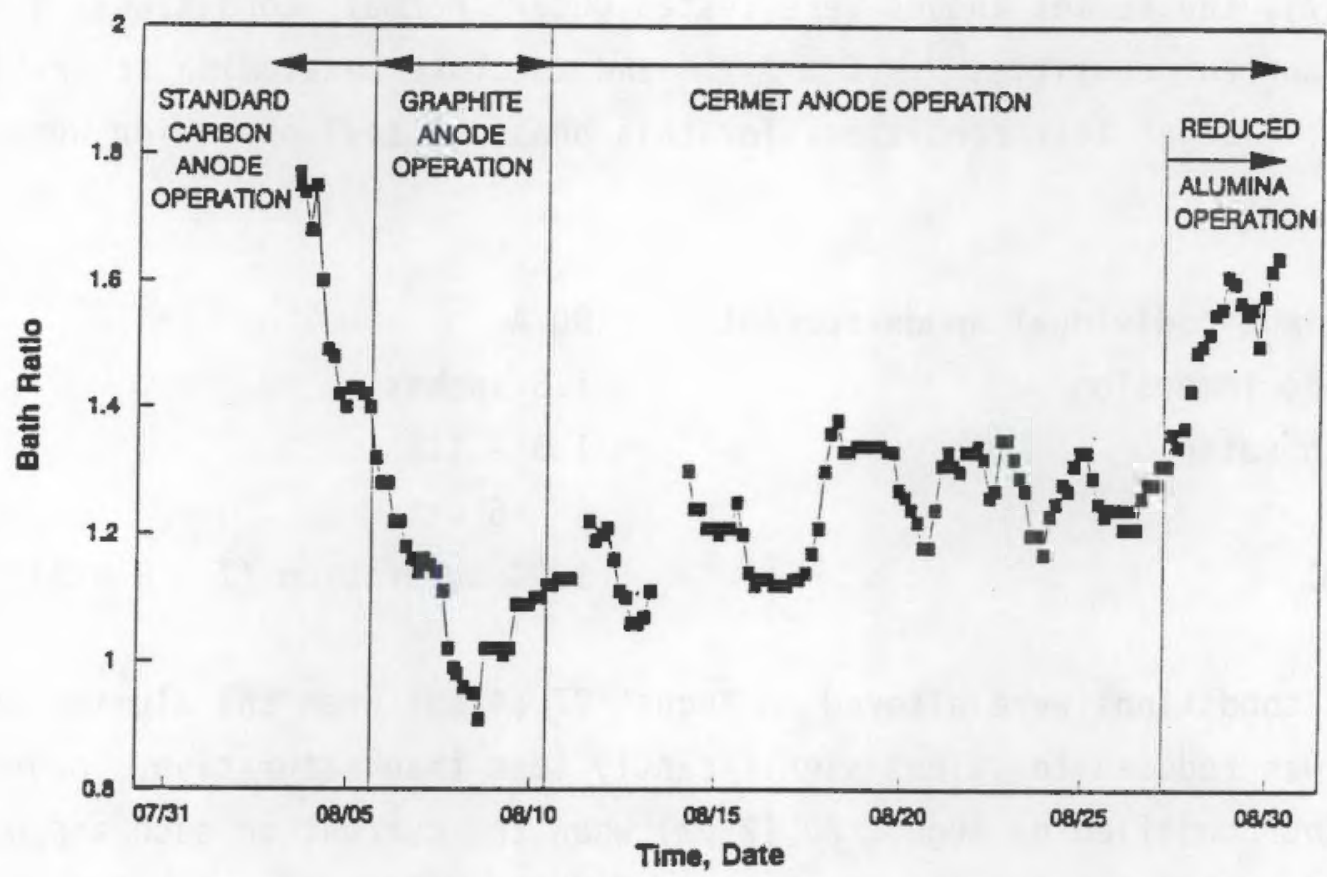

FIGURE 4.9. Bath Ratio Versus Time during the Pilot Cell Test

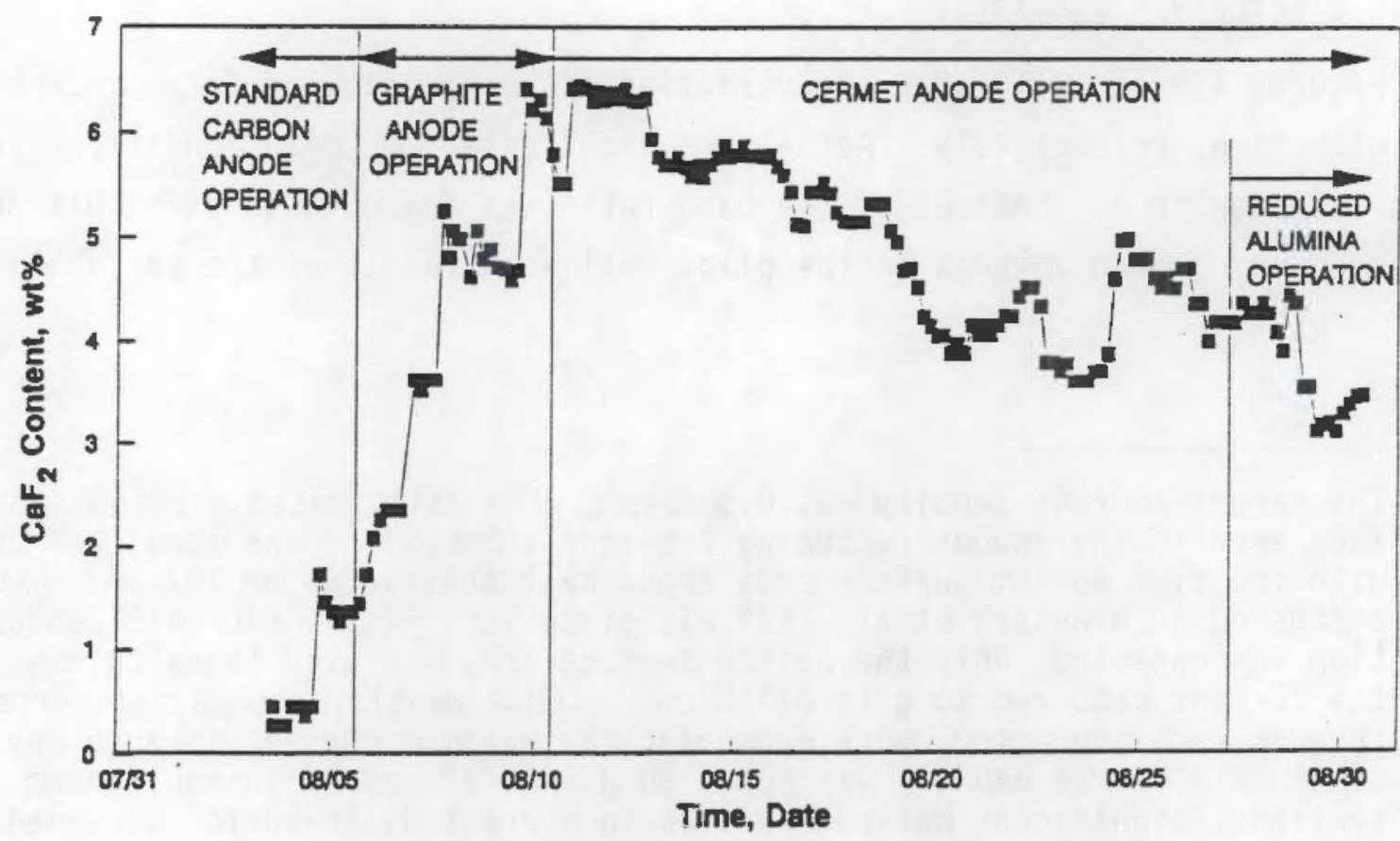

FIGURE 4.10. $\mathrm{CaF}_{2}$ Concentration Versus Time during the Pilot Cel1 Test 
of bath temperature. The $\mathrm{CaF}_{2}$ content was generally controlled within the desired operating limits. Trace amounts of Lif (0.35\%) and $\mathrm{MgF}_{2}(0.15 \%)$ were also present in the electrolyte.

Figure 4.11 shows the electrolyte temperature measured on an hourly basis. A great deal of variability is apparent because the dynamics of the cell are such that a quick response in temperature occurs with disturbances to the cell cover or energy input. Initial measurements of the temperature indicated that it was uniform throughout the cell cavity (less than $5^{\circ} \mathrm{C}$ difference between the center of the cell and the outside edge). As the test progressed, variations were seen as muck began to develop within the cell cavity.

One of the most important operating parameters was alumina concentration. As indicated in Section 2.0 it was necessary in this test to maintain alumina concentration as close to saturation as possible for most of the test. Bath samples were taken every $4 \mathrm{~h}$ for alumina analysis. The RMC alumina meter (Tabereaux and Richards 1983) was also used every $2 \mathrm{~h}$ to provide added insurance against sudden concentration excursions. The RMC alumina meter was used

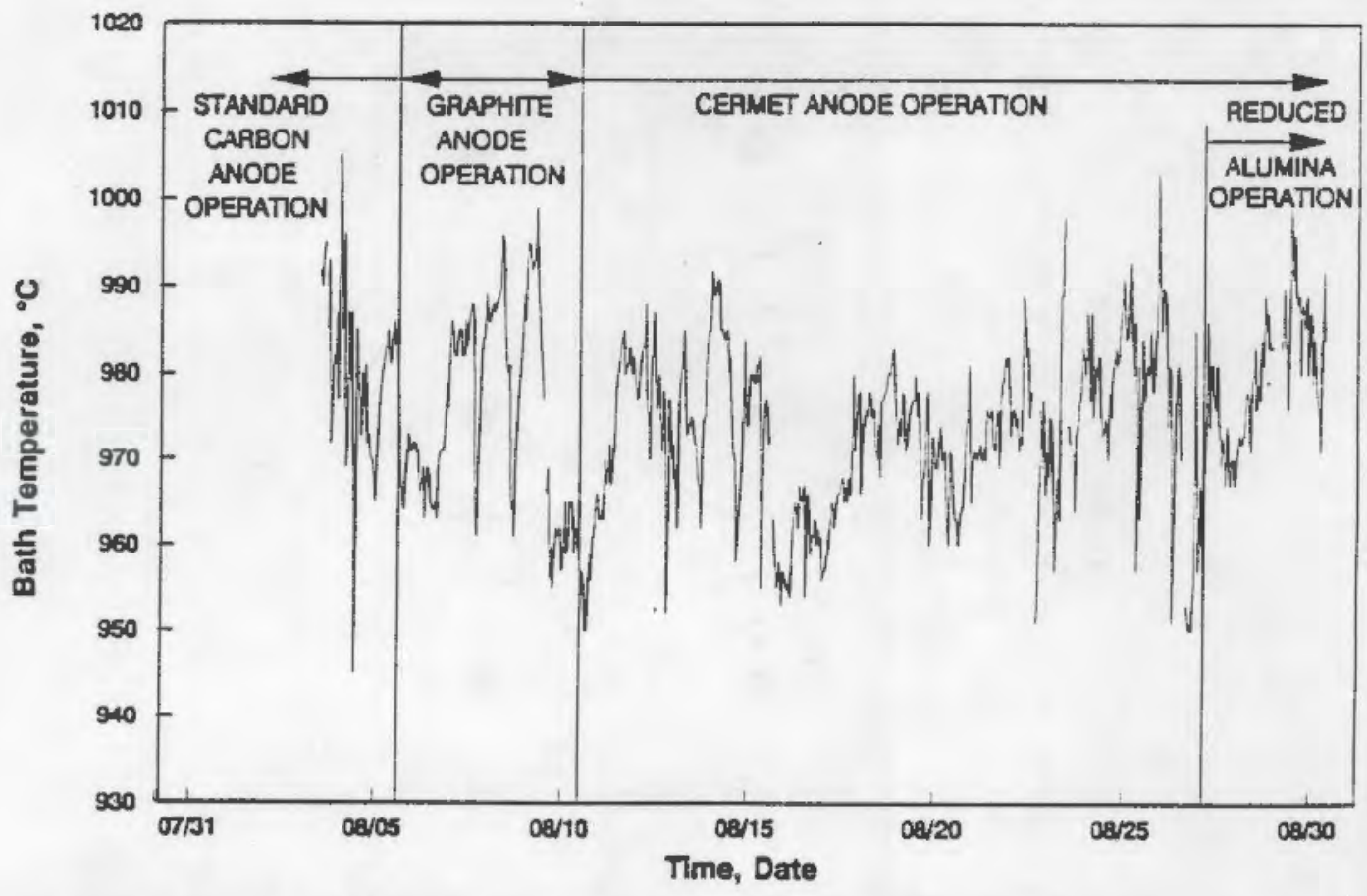

FIGURE 4.11. Temperature Versus Time during the Pilot Cell Test 
to obtain a "rough" measure of alumina concentration during the test and to reduce the possibility of severe excursions. The analyses of bath samples removed from the cell were more accurate and were used in the post-test data reduction. Generally, the cell was sampled between the east anode cluster and the west anode. Samples collected at various locations in the cell at the same time showed this to be a representative sample as shown in Figure 4.12. Figures 4.13 and 4.14 show the results of the measured alumina content in the bath and the calculated percent of alumina saturation throughout the test. As these plots indicate, the alumina content during the cermet anode operation was generally 7 to $8 \mathrm{wt} \%$, resulting in a calculated percent saturation of 80 to $90 \%$. During the test period at reduced alumina content, the concentration was 2 to $3 \mathrm{wt} \%$ or 20 to 30 percent saturation. The values for percent saturation were calculated using the formula by Skybakmoen et al. (1990). It should be noted that the calculated percent saturation is strongly influenced by the operating temperature as shown in Figure 4.15. This plot also indicates the problem operating near saturation within a cell like the pilot cell that can

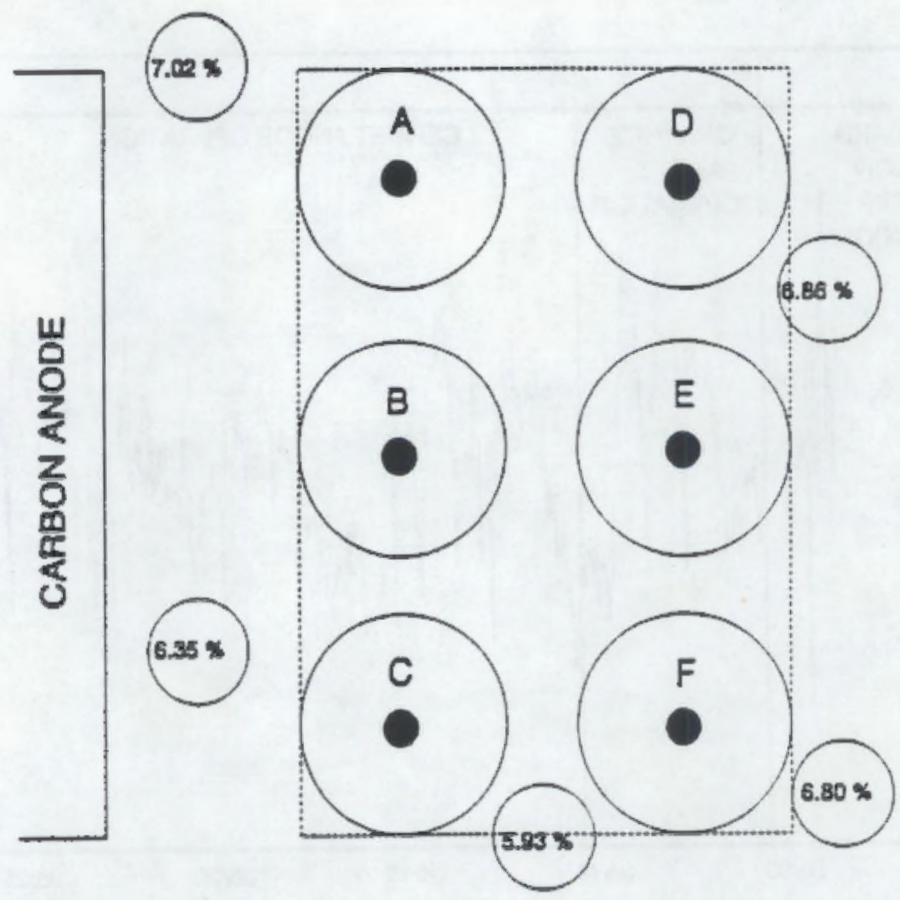

FIGURE 4.12. Diagram Showing Position of Alumina Sampling Points and One Set of Measurements (as Weight Percent) at These Points 


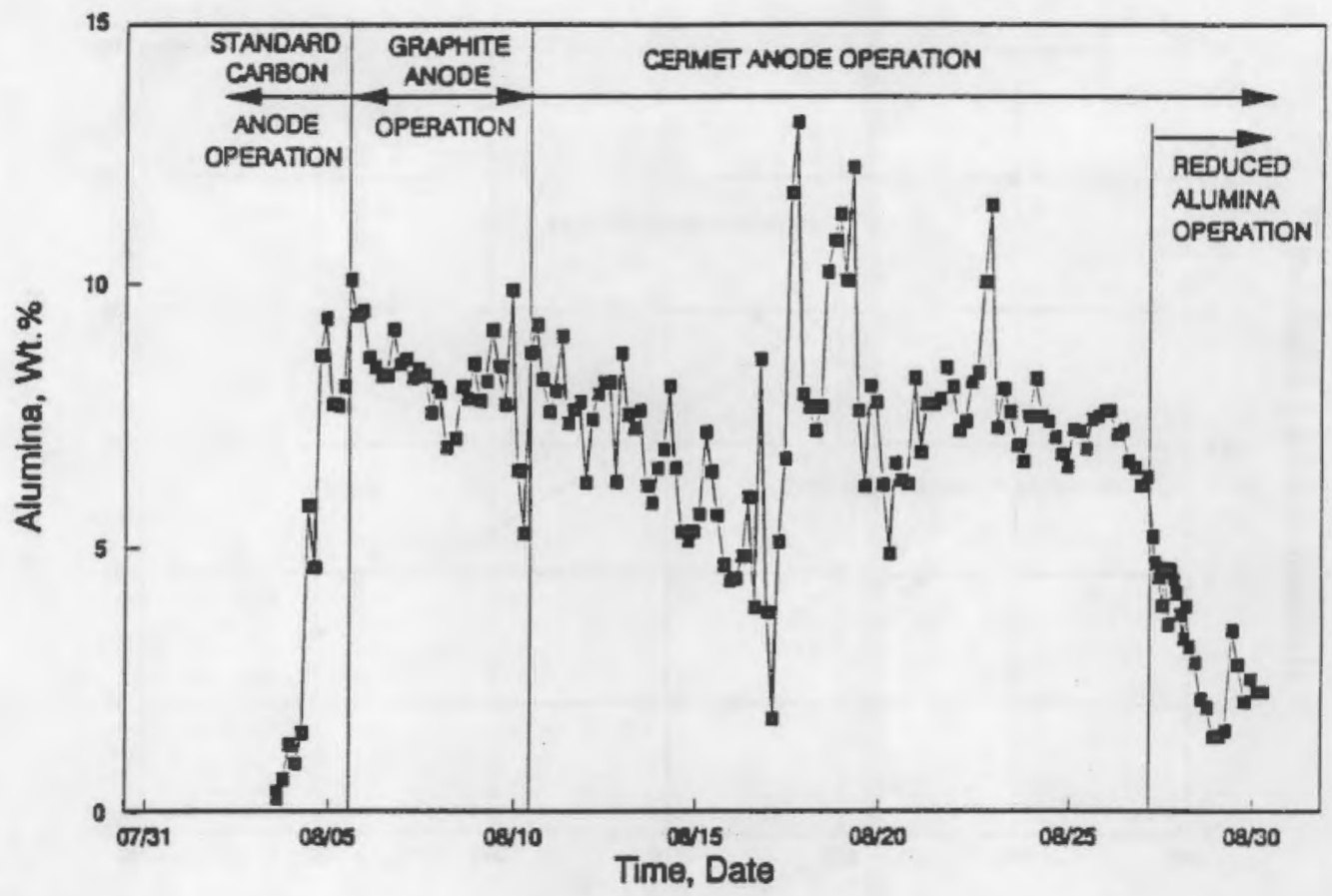

FIGURE 4.13. Weight Percent Alumina Versus Time during the Pilot Cell Test

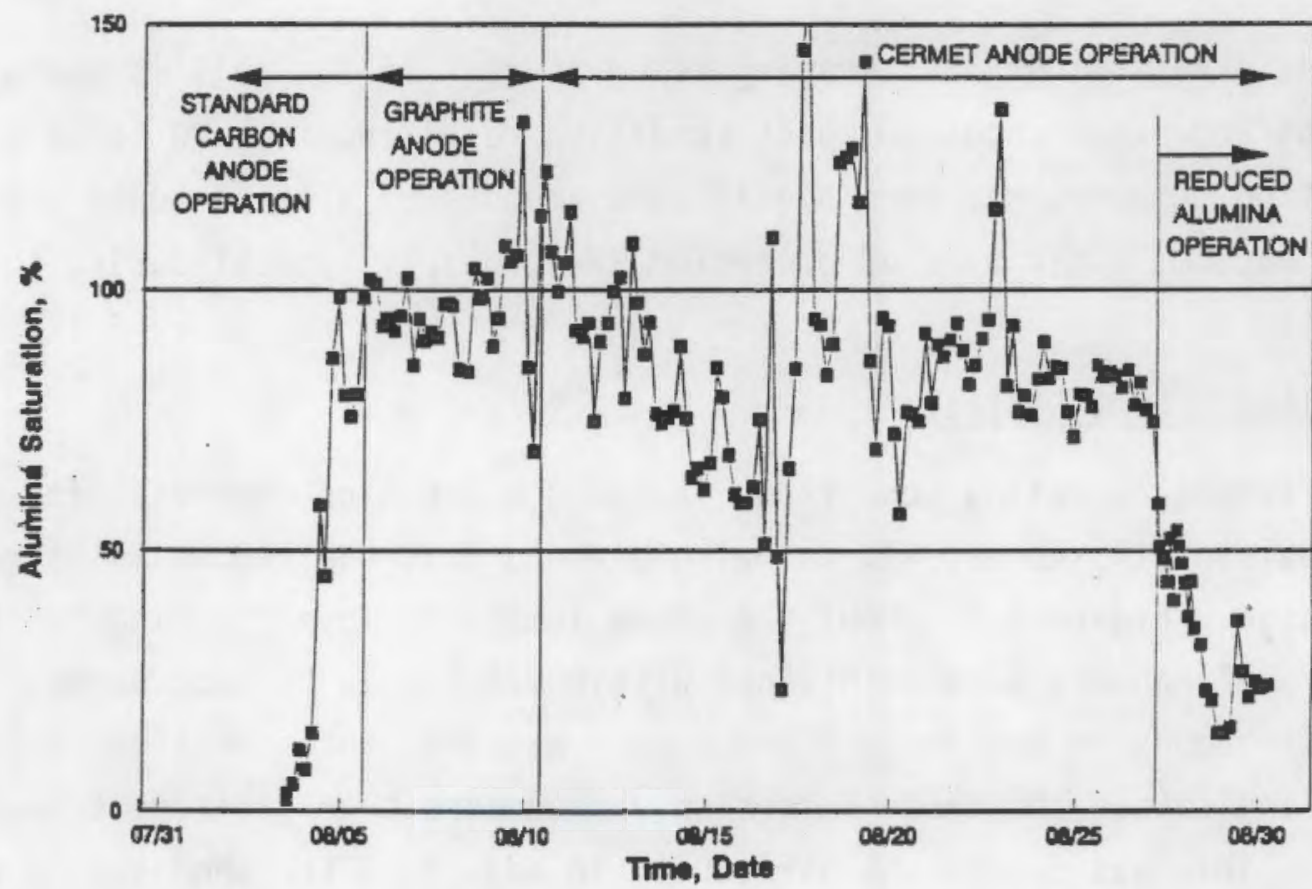

FIGURE 4.14. Percent of Alumina Saturation Versus Time during the Pilot Cell Test 


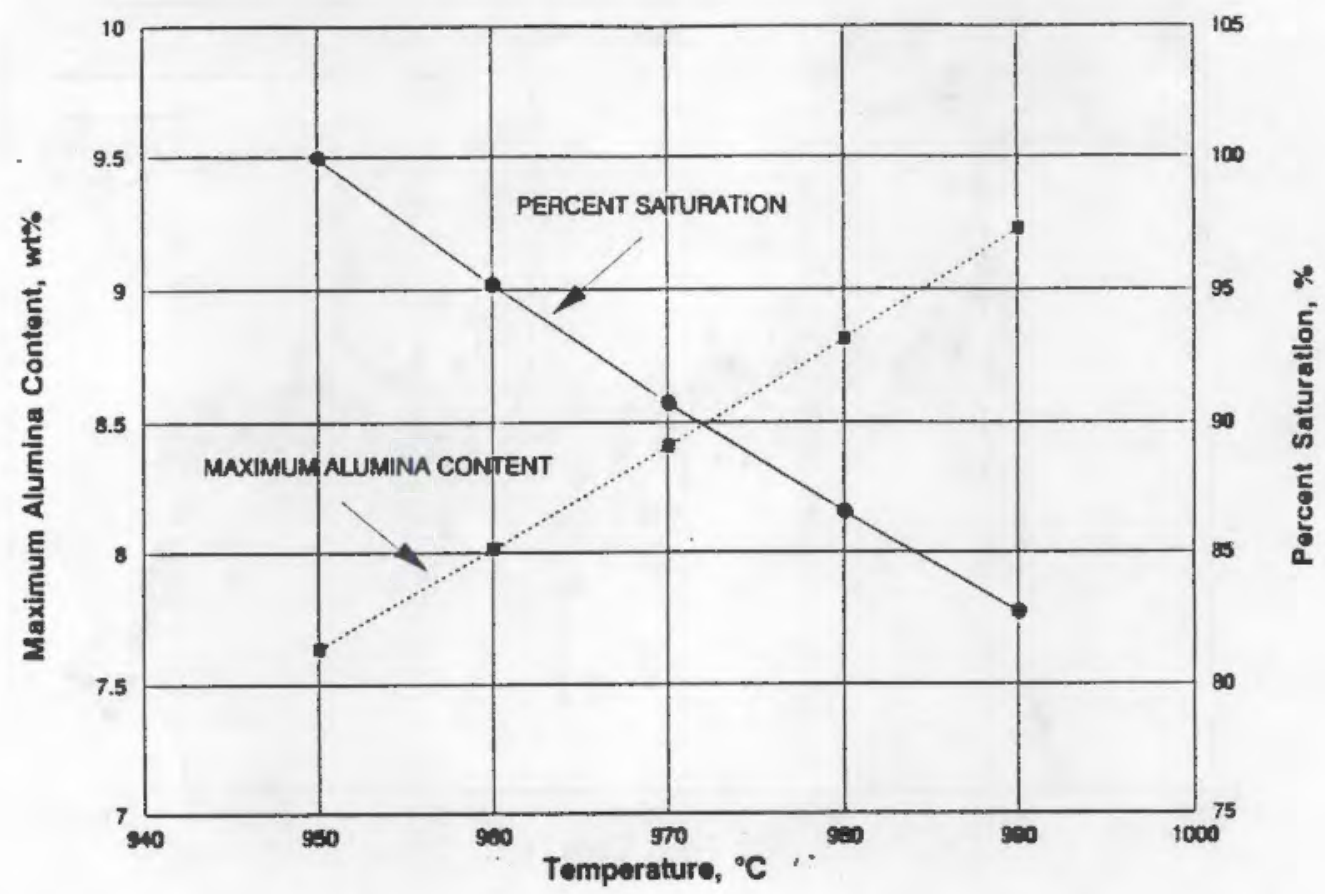

FIGURE 4.15. Effect of Temperature on Alumina Saturation under Pilot Cell Conditions (1.3 Ratio, $5 \% \mathrm{CaF}_{2}, 7.6 \% \mathrm{Al}_{2} \mathrm{O}_{3}$ )

experience great swings in operating temperature. If the cell is operating at saturation and experiences an upset condition resulting in a 20 to $30^{\circ} \mathrm{C}$ drop in operating temperature, then significant amounts of alumina would deposit on the cell bottom. This type of operation was probably typical during the pilot cell test.

\subsubsection{Liquid Level Control}

The target operating conditions included a depth of immersion for the anode equal to 1.5 inches. It was also planned that the ACD would be relatively large. Figure 4.16 shows the anode immersion levels during the test. Generally, all anodes were maintained within 0.5 inches of each other. Typically only anodes in positions $B$ and $C$ were measured for immersion levels. As the plot indicates, the anode immersion varied more than desired, from 1 to 3 inches. This was due to the difficulty in adjusting the anodes as a result of the anode stem problems discussed in Section 4.3.4, as well as the changing bath level. Figure 4.17 shows the bath level throughout the operation. As the run progressed and muck build-up occurred in the cell, the total liquid 


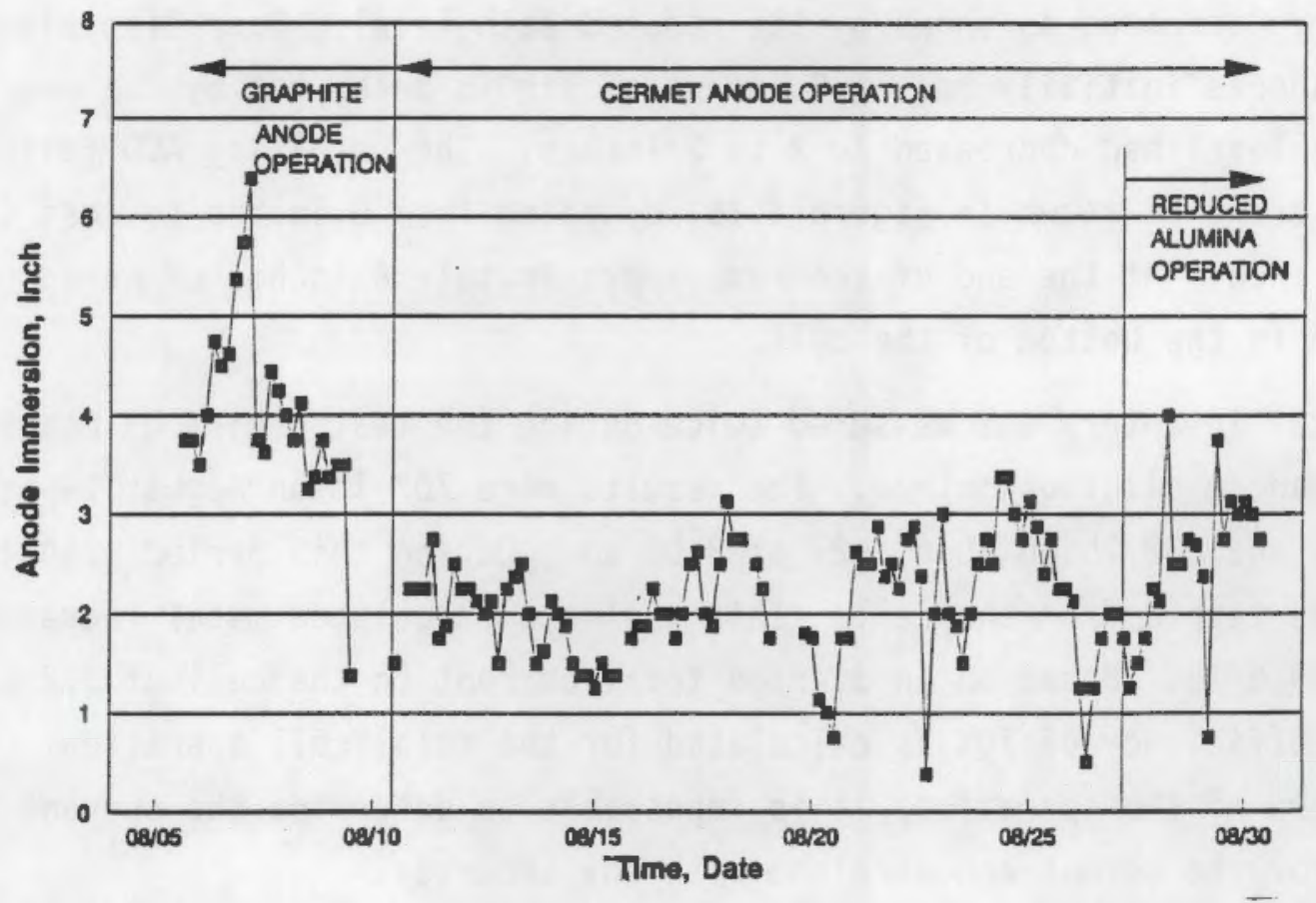

FIGURE 4.16. Anode Immersion Versus Time during the Pilot Cell Test

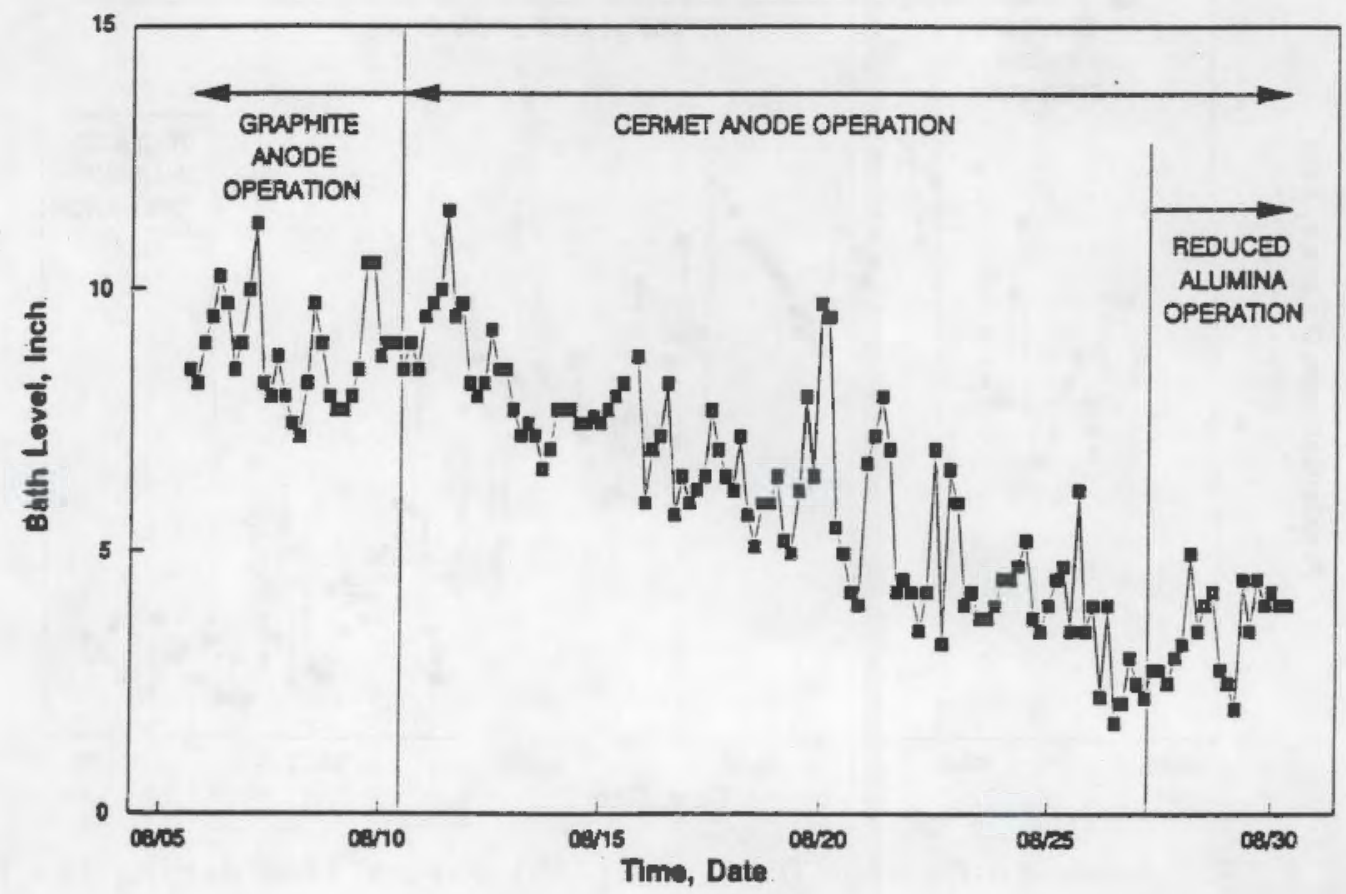

FIGURE 4.17. Bath Level Versus Time during the Pilot Cell Test 
inventory decreased as shown by the reduced bath level. Operation with the cermet anodes initially was at 8 inches of liquid bath, but by the end of the test the level had decreased to 2 to 3 inches. The resulting ACD followed a similar trend as shown in Figure 4.18, dropping from 6 inches to less than about 1 inch. At the end of the run, approximately 6 inches of hard muck had built up in the bottom of the cell.

Metal inventory was measured twice during the test period by means of the manganese dilution method. The results were $707 \mathrm{lb}$ on August 14 at $8: 00 \mathrm{am}$, and $882 \mathrm{lb}$ on August 27 at $8: 00 \mathrm{am}$. During this period, $340 \mathrm{lb}$ of metal was tapped from the cell. This yields a calculated metal increase per day of $39.6 \mathrm{lb}$. Based on an average total current to the cell of $3.2 \mathrm{kA}$, a current efficiency of $70 \%$ is calculated for the total cell operation. Due to the nature of the operation, it is impossible to determine the current efficiency for the cermet anodes alone with any accuracy.

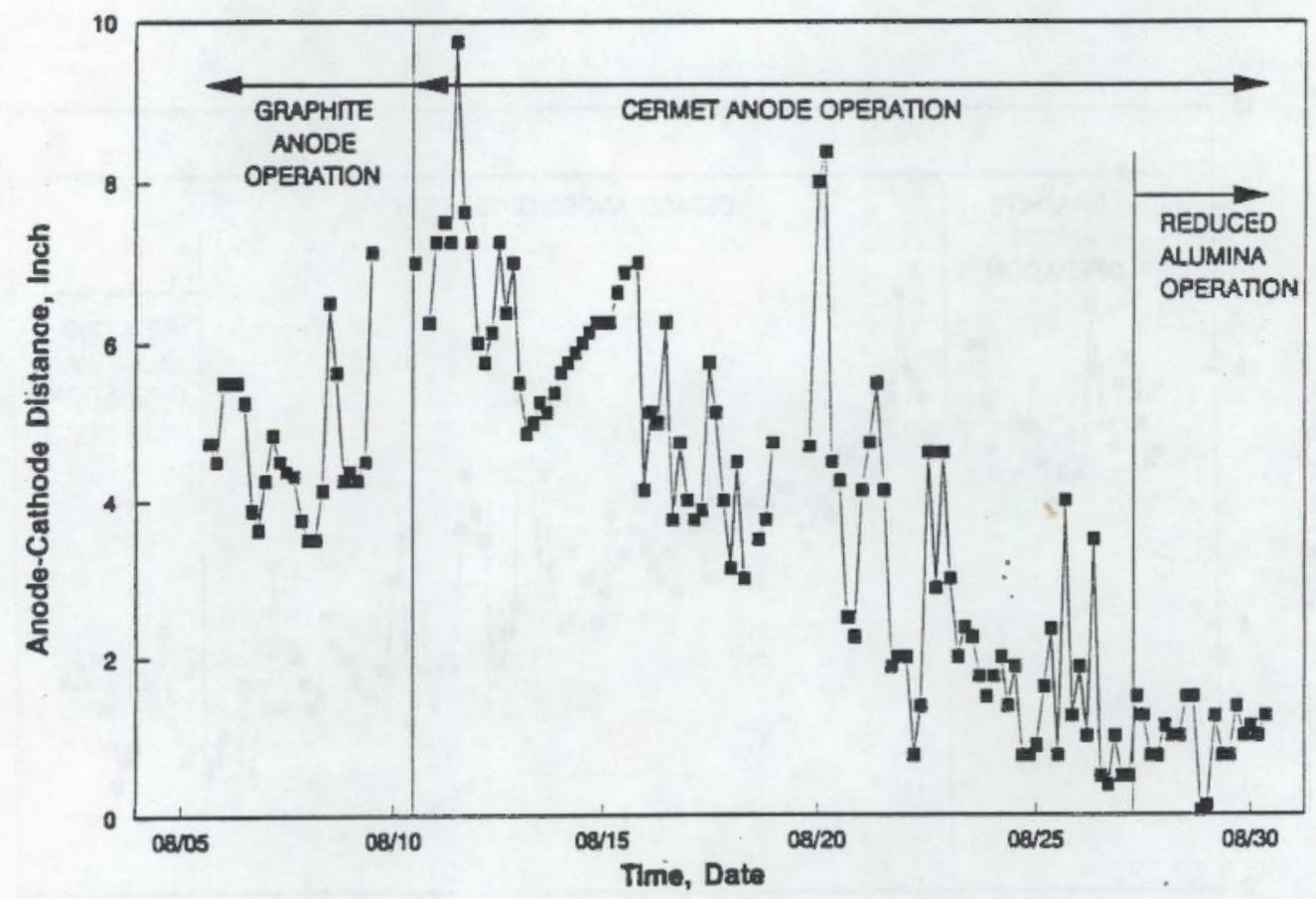

FIGURE 4.18. Anode-to-Cathode Distance (ACD) Versus Time during the Pilot Cell Test 


\subsubsection{Anode Current Distribution}

This section contains a discussion on the distribution of voltages and currents within the pilot cell. The principal issues related to this distribution are how the currents varied from one cermet anode to another, how the current varied as a function of location on the surface of a given cermet anode, and how the currents and voltages varied in a wider context, i.e., at different positions throughout the pilot cell.

\section{Differences in Currents Through the Cermet Anodes}

Thirteen (13) cermet anodes were used during the pilot cell test (PNL phase). The anodes were labelled as A1, A2, B1, C1, C2, D1, D2, E1, E2, F1, F2, Auxl, and Aux2. The intended exchange sequence for these anode in the six positions of the cluster was detailed in Windisch et a1. (1991a). The labelling scheme was created to facilitate the correlation of each anode with the position it occupied during the test: the letter designation indicating the position it occupied and the number denoting whether it was the first or second anode used in that position. For example, Anode E2 would have been the second anode used in position E. Anodes Auxl and Aux2 were "extra" anodes that were to be used in the event of problems or as controls. As it turned out, because of the need to change heatup procedures (Section 4.2) and problems with stem breakage (Section 4.3.4), the exchange sequence was not followed as planned. Consequently, the number and letter designations do not correspond in all cases to the positions or replacement sequence of the anodes. The actual positions for each anode and the replacement sequence are : shown in Figure 4.19.

Figures 4.20 through 4.25 show the current carried by each of the anodes tested, according to cell position. Only 12 of the 13 were tested because B1 cracked immediately upon insertion. Table 4.1 summarizes the lives of the anodes. The earlier anodes tested were generally used for a shorter length of time because of failure of the $\mathrm{Ni}$ connector rods or stems. The exceptions to this were anodes F1 and Auxl which were in operation for over $300 \mathrm{~h}$. Both of these anodes were exposed only to the "normal" operating conditions (close to alumina saturation and $\leq 90 \mathrm{~A}$ ). 

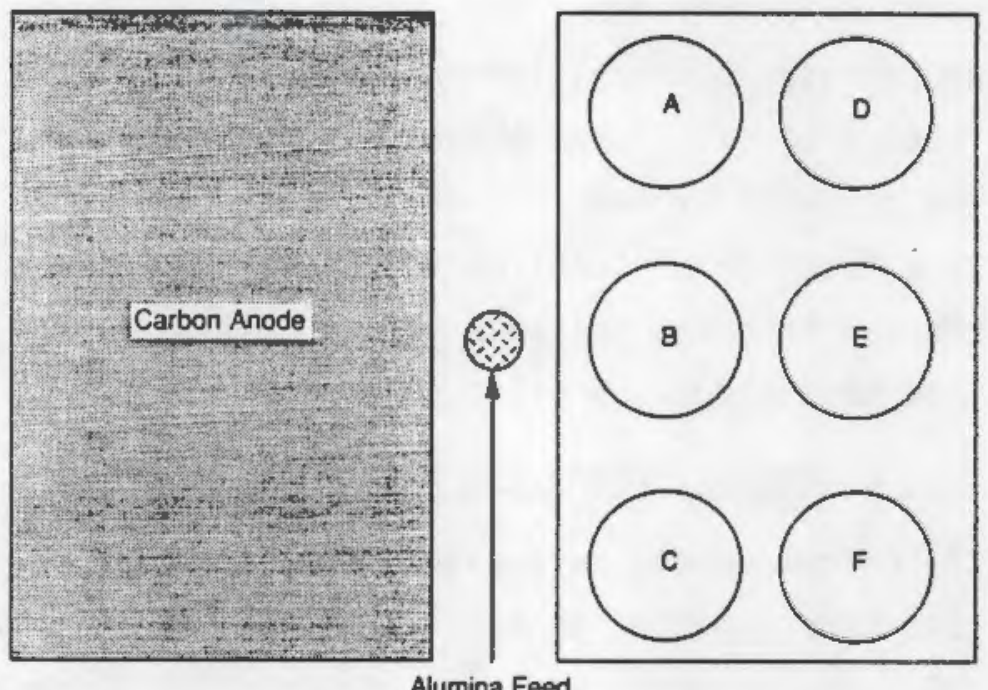

Anode Position

Anodes

Time (h) I (A)

$\begin{array}{lllll}\text { A } & \text { A1, E2* } & 193,260 & 35,74 \\ \text { B } & \text { Aux2, A2 } & 181,182 & 29,51 \\ \text { C } & \text { C1, C2* } & 191,260 & 51,86 \\ \text { D } & \text { D1, D2 } & 123,279 & 82,62 \\ \text { E } & \text { Aux1, E1* } 313,135 & 4572 \\ \text { F } & \text { F1, F2 } & 314,96 & 70,41\end{array}$

"Exposed to high current and low alumina.

FIGURE 4.19. Schematic of Anode Positions Showing Exchange Sequence for Individual Cermet Anodes. (Also shown are time of testing and average currents for each anode.)

Throughout the test, the current was maintained so that the maximum for any one anode was $90 \mathrm{~A}$ (except the last two days of operation when current was raised to a maximum of $180 \mathrm{~A}$ ). As shown in Figure 4.26 , a current imbalance similar to that observed for the graphite anodes existed for the cermet anodes. The current imbalance was caused primarily by two factors: 1) significant sidewall conduction and 2) the perturbing effects of the large carbon anode (west anode). The nature of this current imbalance on the cermet anodes also changed during the test because of changes in operating conditions, particularly the ACD. In general, the impact of the large carbon anode current 


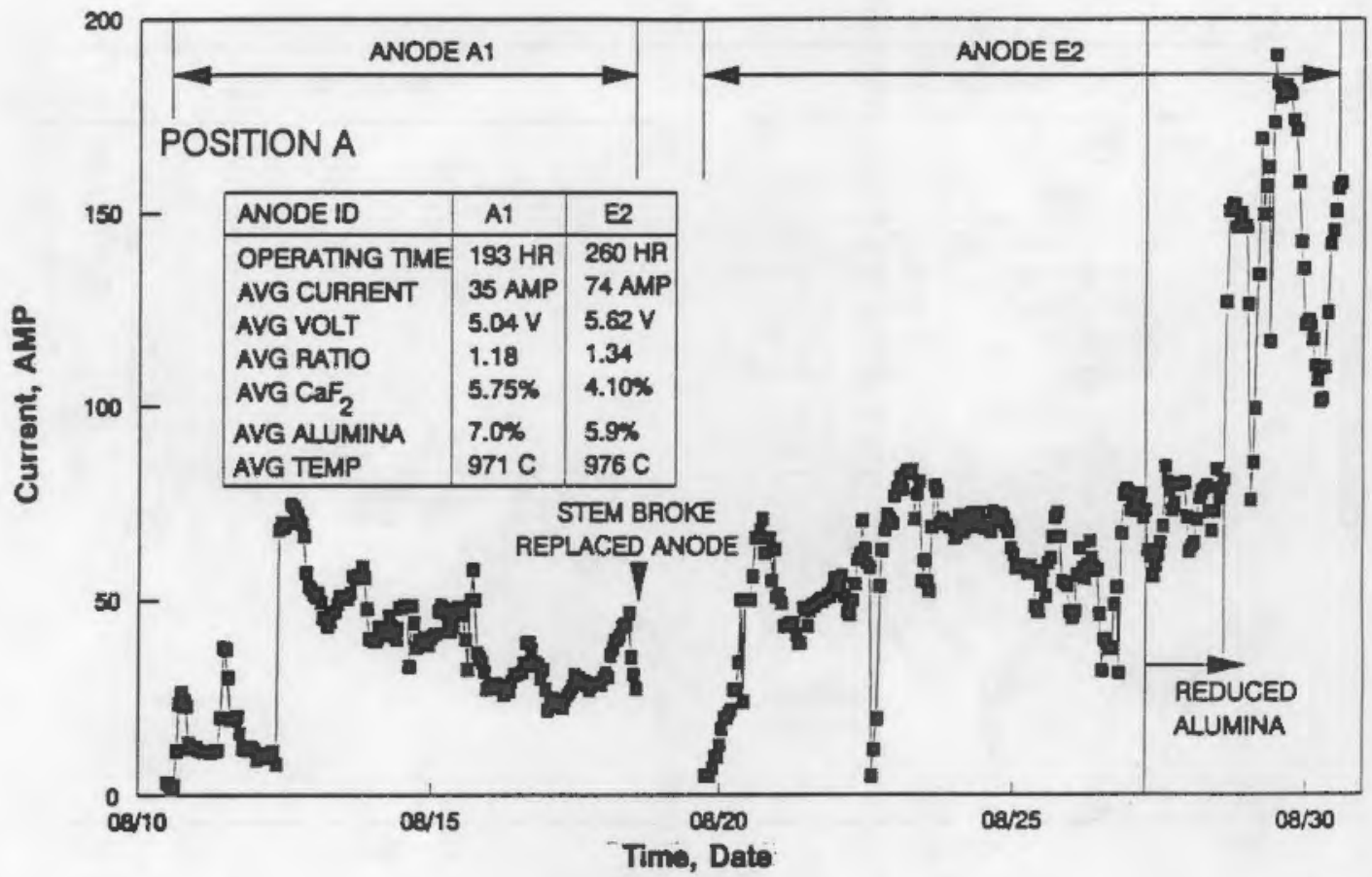

FIGURE 4.20. Current Through Anodes in Position A Versus Time during the Pilot Cell Test

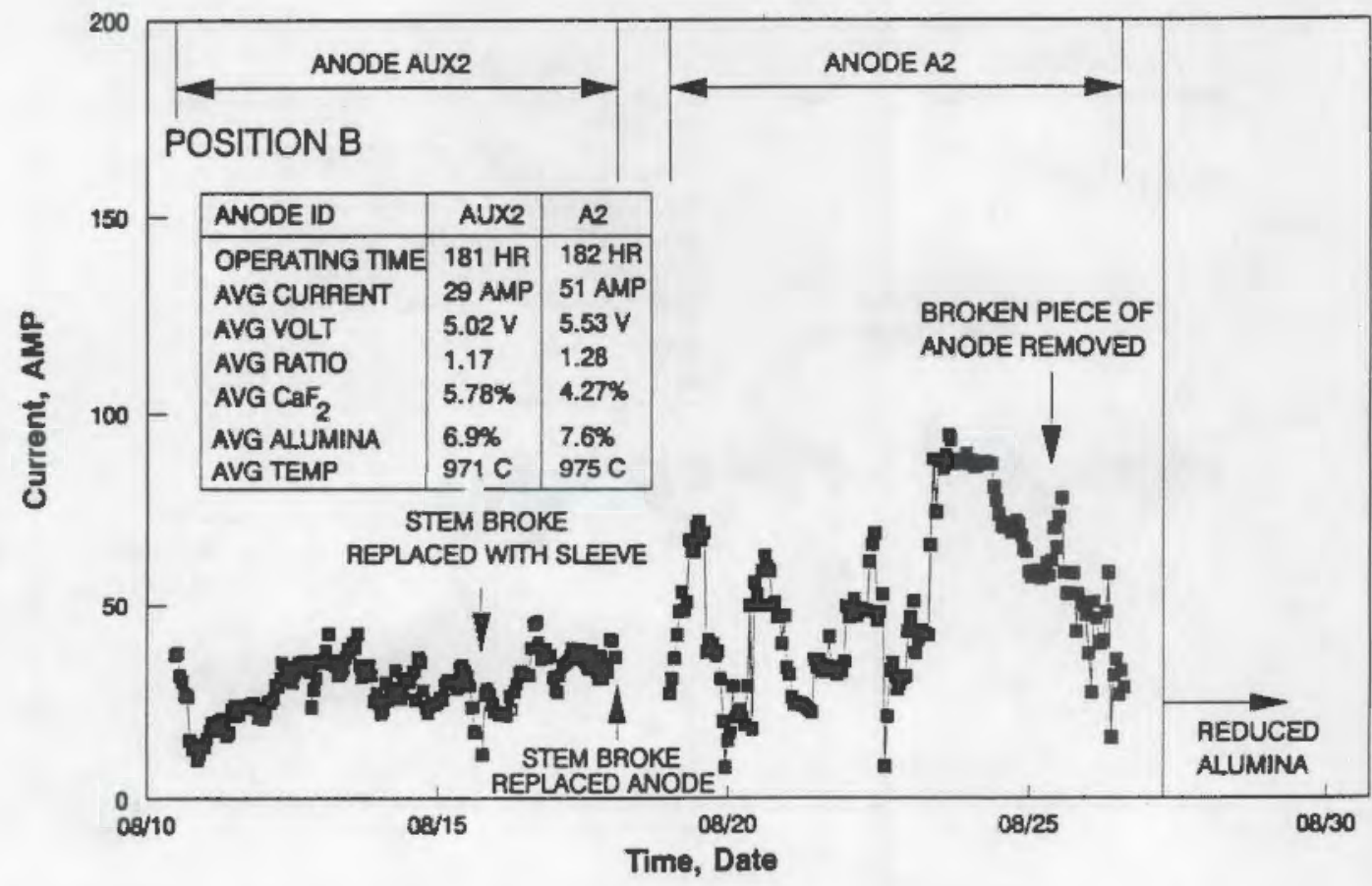

FIGURE 4.21. Current Through Anodes in Position B Versus Time during the Pilot Cell Test 


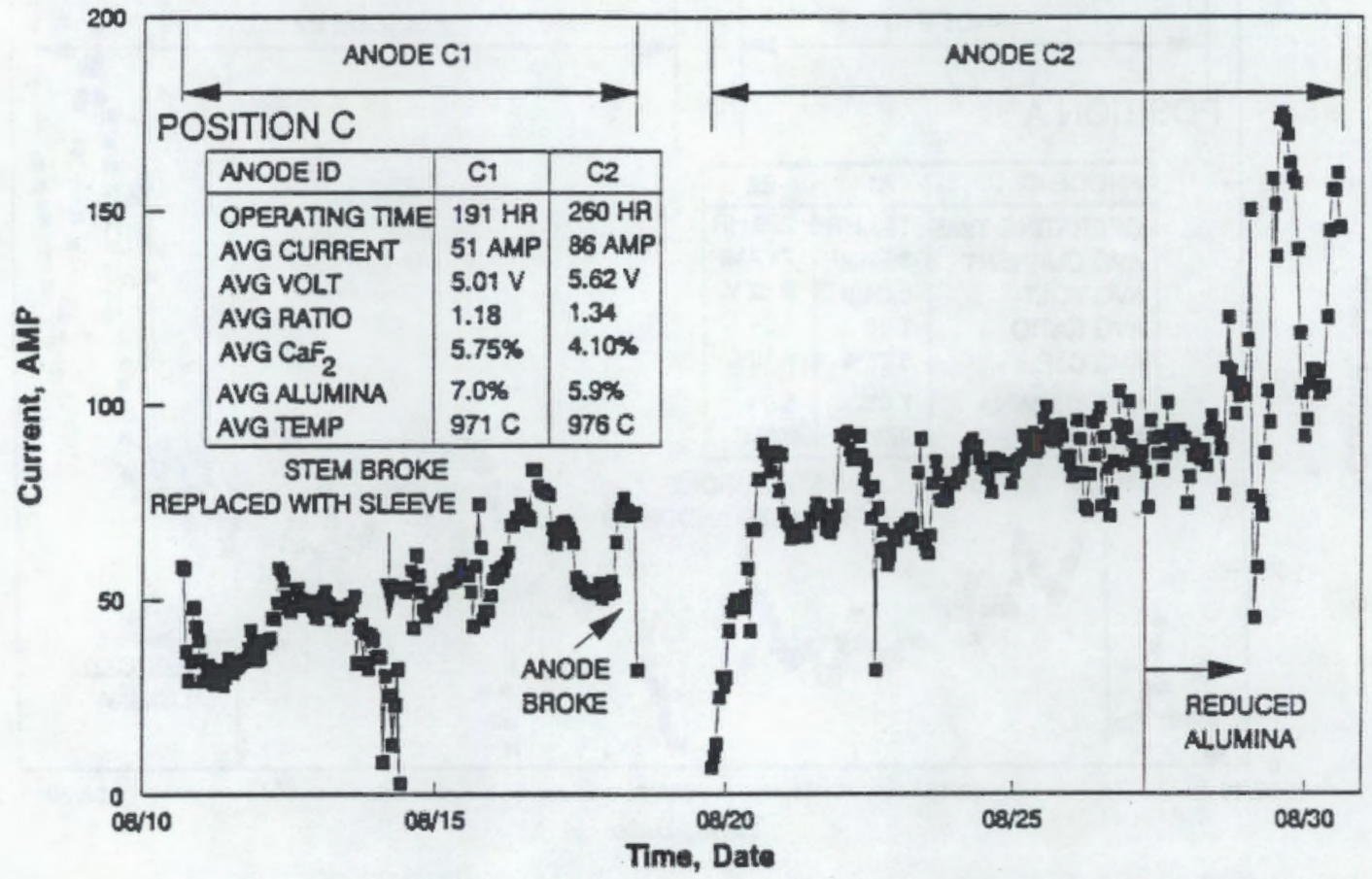

FIGURE 4.22. Current Through Anodes in Position C Versus Time during the Pilot Cell Test

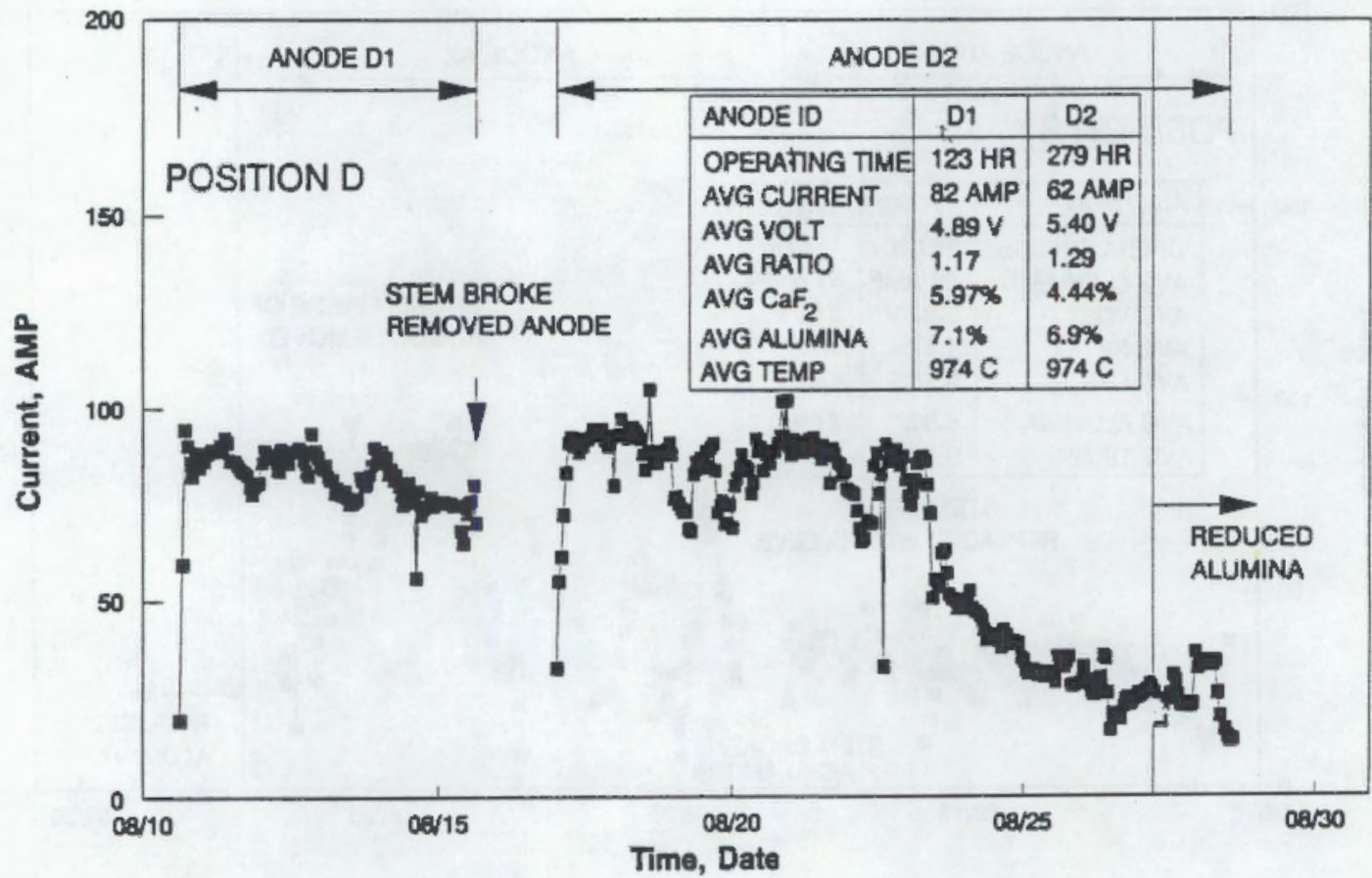

FIGURE 4.23. Current Through Anodes in Position D Versus Time during the Pilot Cel1 Test 


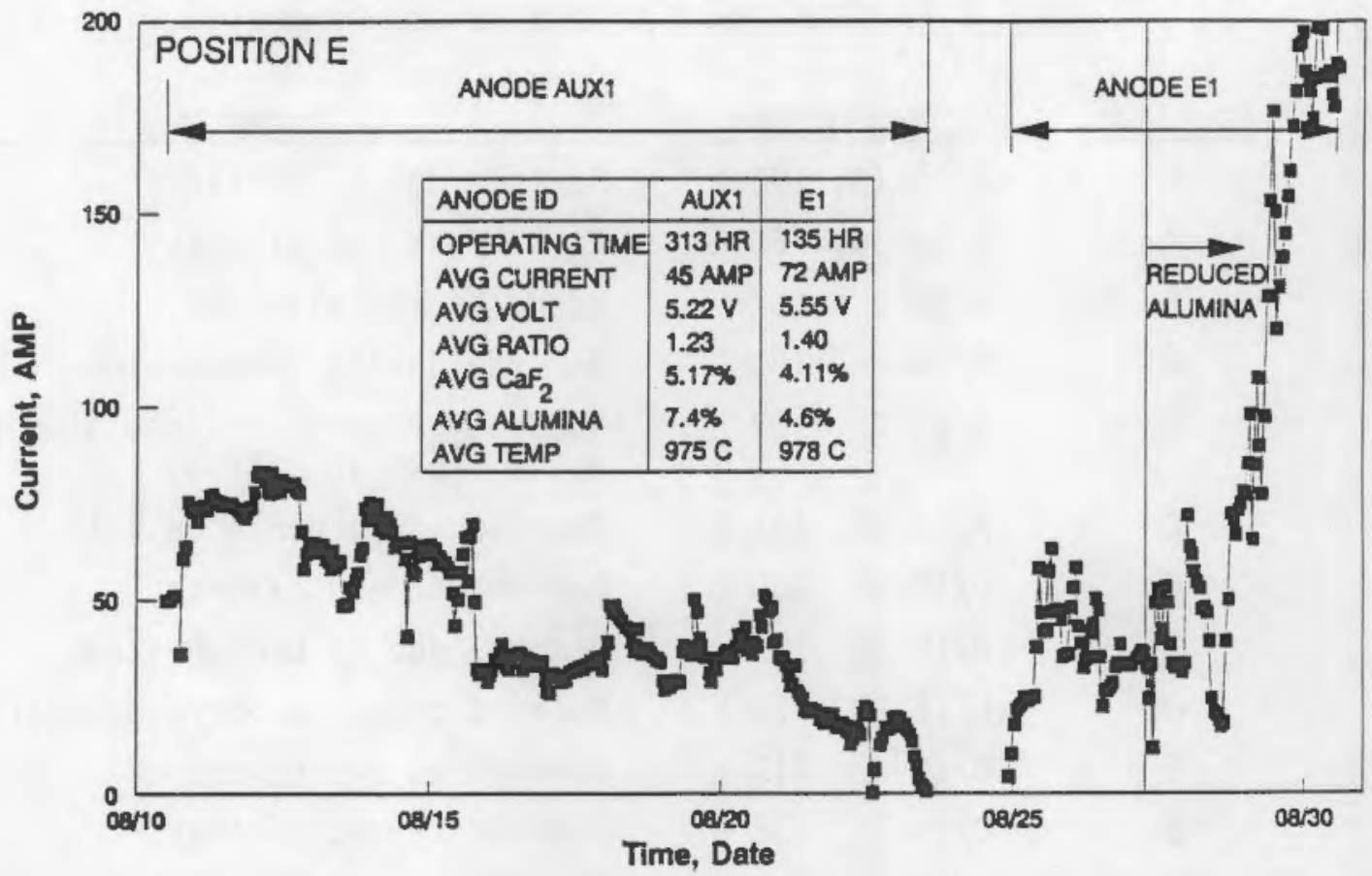

FIGURE 4.24. Current Through Anodes in Position E Versus Time during the Pilot Cell Test

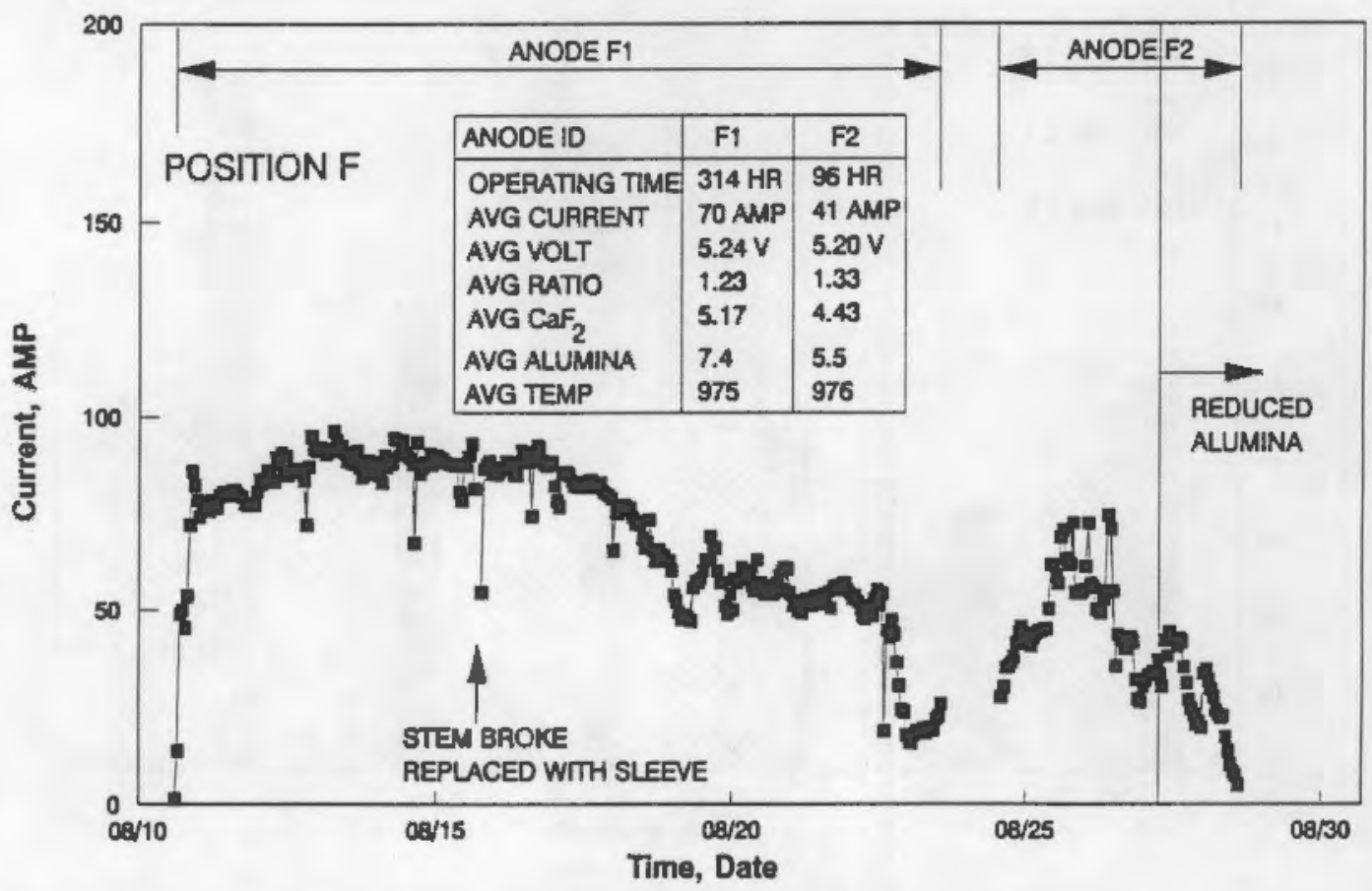

FIGURE 4.25. Current Through Anodes in Position F Versus Time during Pilot Cell Test 
TABLE 4.1. The Lives of the Cermet Anodes

\begin{tabular}{|c|c|c|c|}
\hline Anode & Position & Operation & Comments \\
\hline$\overline{A 1}$ & A & $8 / 10-18,193 \mathrm{~h}$ & Removed due to broken stem. \\
\hline E2 & A & $8 / 19-30,260 \mathrm{~h}$ & Removed at end of test. \\
\hline B1 & B & $8 / 8,0 \mathrm{~h}$ & Broke on installation. \\
\hline Aux2 & B & $8 / 10-18,181 \mathrm{~h}$ & Removed due to broken stem. \\
\hline A2 & B & $8 / 19-26,182 \mathrm{~h}$ & $\begin{array}{l}\text { Removed prior to reduced alumina, } \\
\text { anode broke in half. }\end{array}$ \\
\hline $\mathrm{Cl}$ & C & $8 / 10-18,191 \mathrm{~h}$ & Removed anode broke in half. \\
\hline $\mathrm{C2}$ & C & $8 / 19-30,260 \mathrm{~h}$ & Removed at end of test. \\
\hline D1 & D & $8 / 10-15,123 \mathrm{~h}$ & Removed due to broken stem. \\
\hline $\mathrm{D} 2$ & D & $8 / 16-28,279 h$ & Removed prior to increased current. \\
\hline Auxl & E & $8 / 10-23,313 \mathrm{~h}$ & Removed as scheduled. \\
\hline E1 & E & $8 / 24-30,135 \mathrm{~h}$ & Removed at end of test. \\
\hline F1 & $\mathbf{F}$ & $8 / 10-23,314 \mathrm{~h}$ & Removed as scheduled. \\
\hline F2 & $F$ & $8 / 24-28,96 h$ & Removed prior to increased current. \\
\hline
\end{tabular}

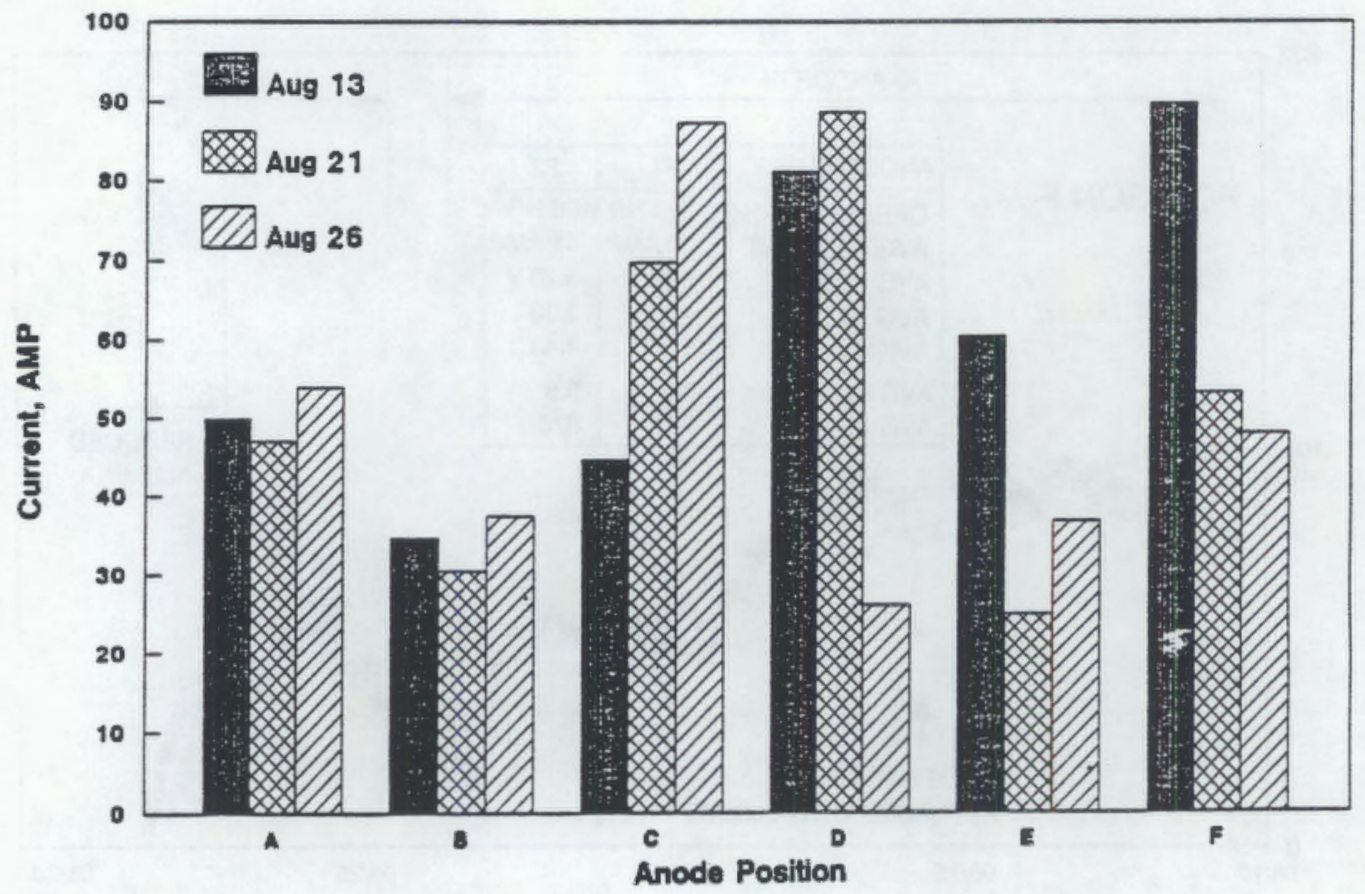

FIGURE 4.26. Current Imbalance on the Cermet Anodes 
and the sidewall conduction was lessened toward the end of the test as the ACD was reduced due to lower bath levels. The effect of the large carbon anode was a unique part of the pilot cell operation due to the separate power supplied to the two sides of the cell and the need to operate the carbon anode at elevated power inputs to maintain sufficient heat balance for the cell.

The voltage of the cermet anodes varied considerably throughout the test as shown in Figure 4.27. This variation was due to a number of variables including cell conditions (muck formation) and carbon anode condition (voltage and current). The average voltage of the cermet anodes was $5.34 \mathrm{~V}$; the total current for the six anodes was $0.32 \mathrm{kA}$. The cathode drop (voltage from the metal pad to negative metering point) of the cell is shown in Figure 4.28 . This measurement reflects the mucky condition of the hearth. As the plot indicates, the cathode drop did increase from $0.65 \mathrm{~V}$ to over $1 \mathrm{~V}$ (at times) throughout the test, indicating a more resistive cell bottom due to muck buildup. Anode drops (positive metering point to the cermet anode) were measured throughout the run and found to be consistent at 0.19 to $0.22 \mathrm{~V}$. This

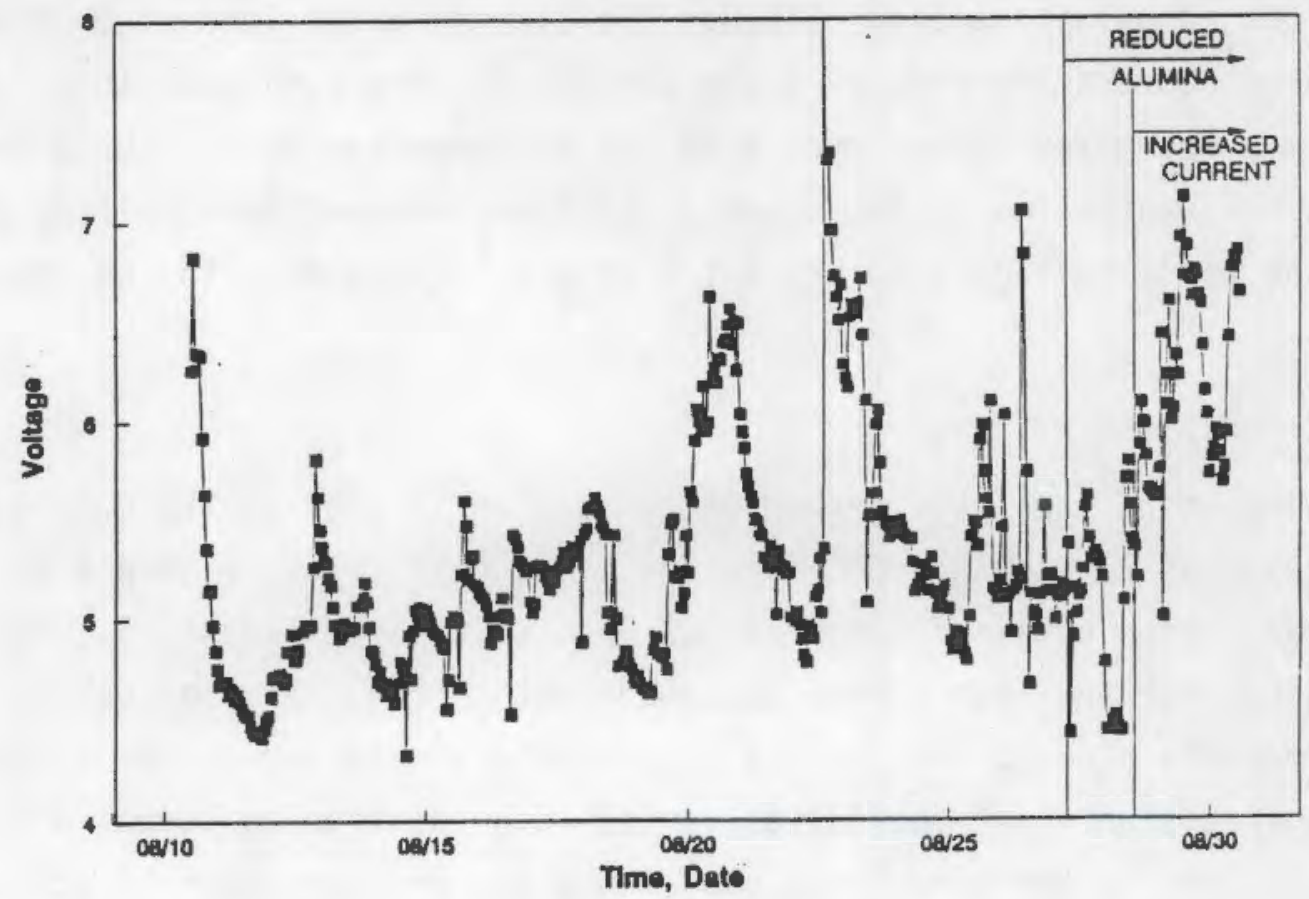

FIGURE 4.27. Variation of Voltage with Time for the Cermet Anodes during the Pilot Cell Test 


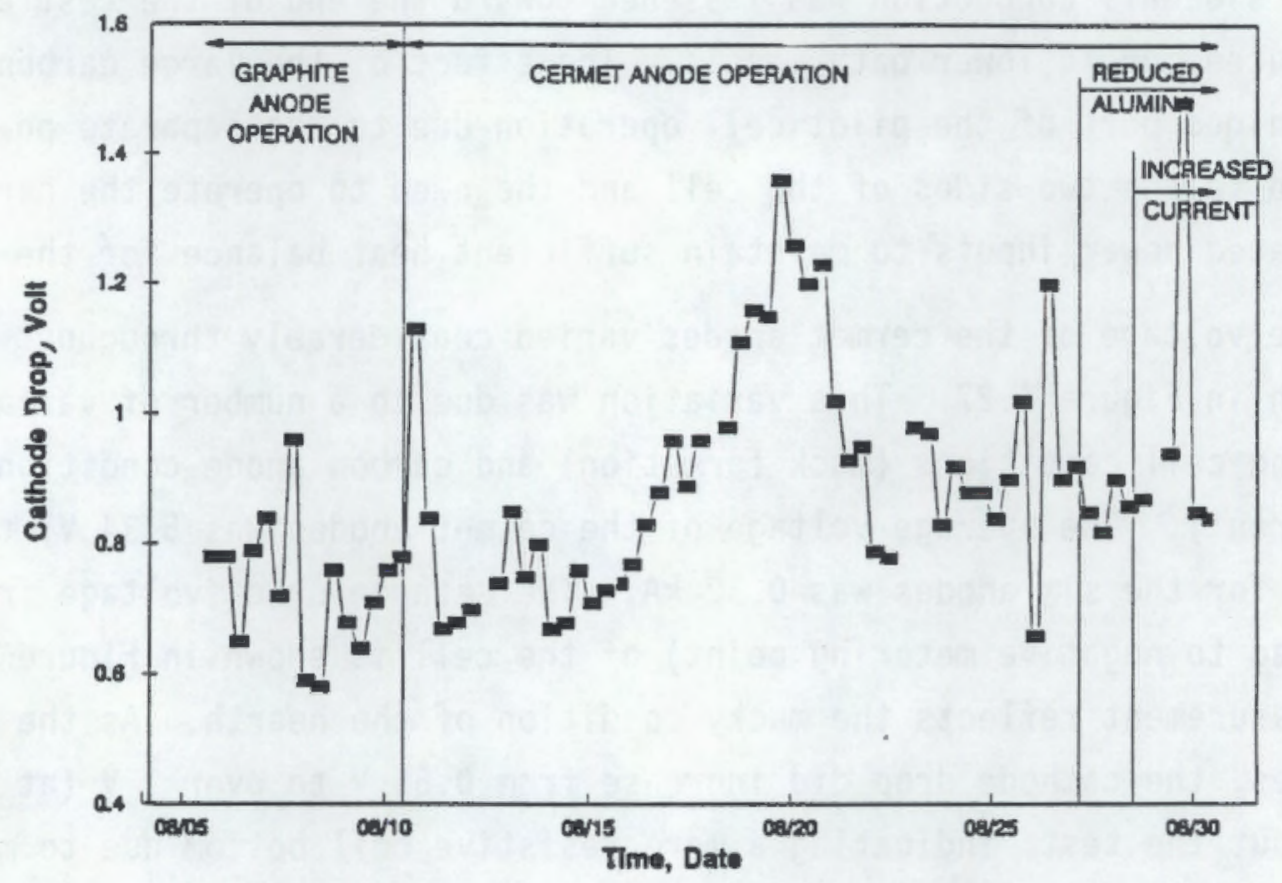

FIGURE 4.28. Cathode Voltage Drop Versus Time during the Pilot Cell Test

drop includes the voltage drops through the shunts, cable, and stem of $0.08 \mathrm{~V}$. Voltage drops across the stem-to-anode connection were estimated to be about $0.1 \mathrm{~V}$ from a few measurements made with the Pt connector wires (those that did not break off) installed on the anodes. At the increased current (180 A per anode), the anode voltage drop was $1.1 \mathrm{~V}$ with a voltage drop to the stem of $0.5 \mathrm{~V}$.

\section{Volt-Amp Scans}

The impact of the large carbon anode is clearly seen in the volt-amp (iv) curves that were obtained during the pilot cell test. Figure 4.29 shows the volt-amp scans obtained for Anode C2 (position C) on August 26. The scans were obtained for the four carbon anode currents shown. Similar behavior was observed for the other cermet anodes in the cell at the same time, although the slope (resistance) of the curves varied with position as shown in Figure 4.30. (This latter effect was expected given the variation of current from anode to anode for the same overall cluster voltage.) Examination of Figure 4.29 indicates that increasing the carbon anode current had the effect 


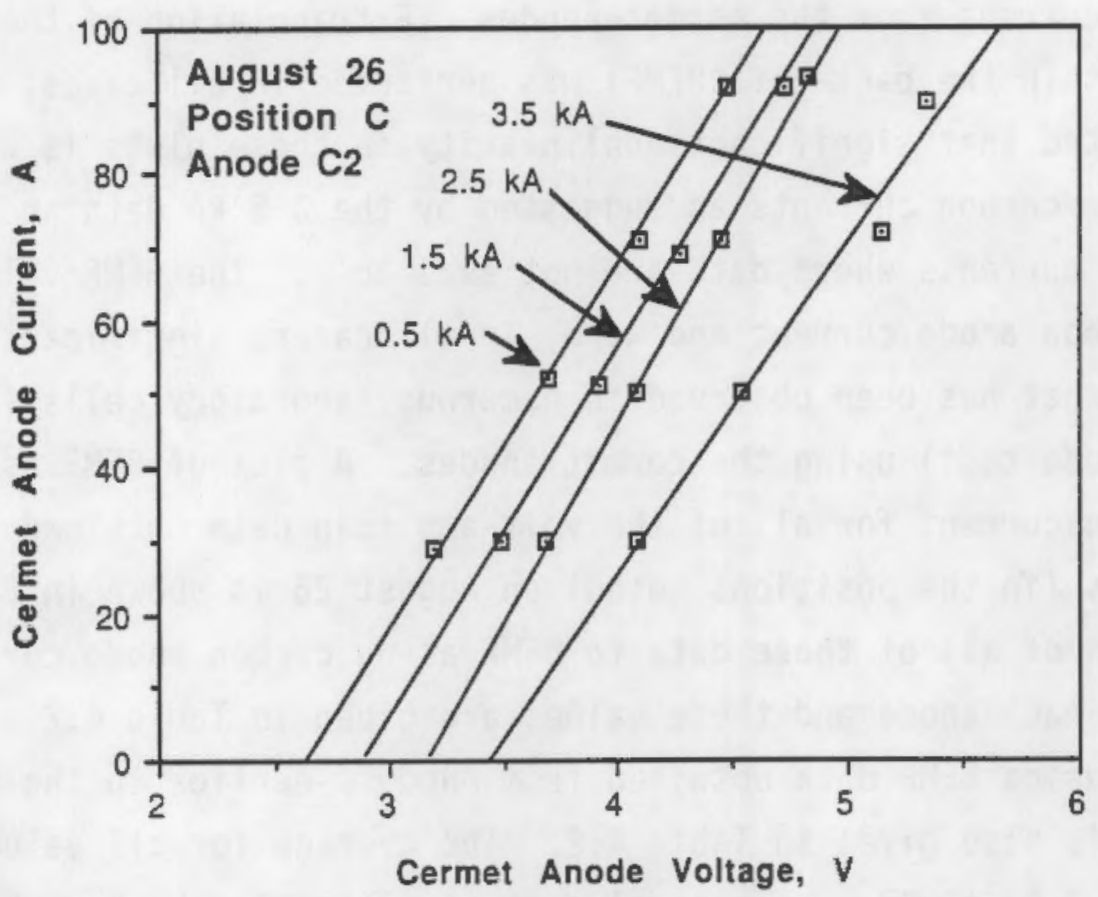

FIGURE 4.29. Current Versus Voltage (iv) Scans for Anode in Position $C$ at Various Carbon Anode Currents

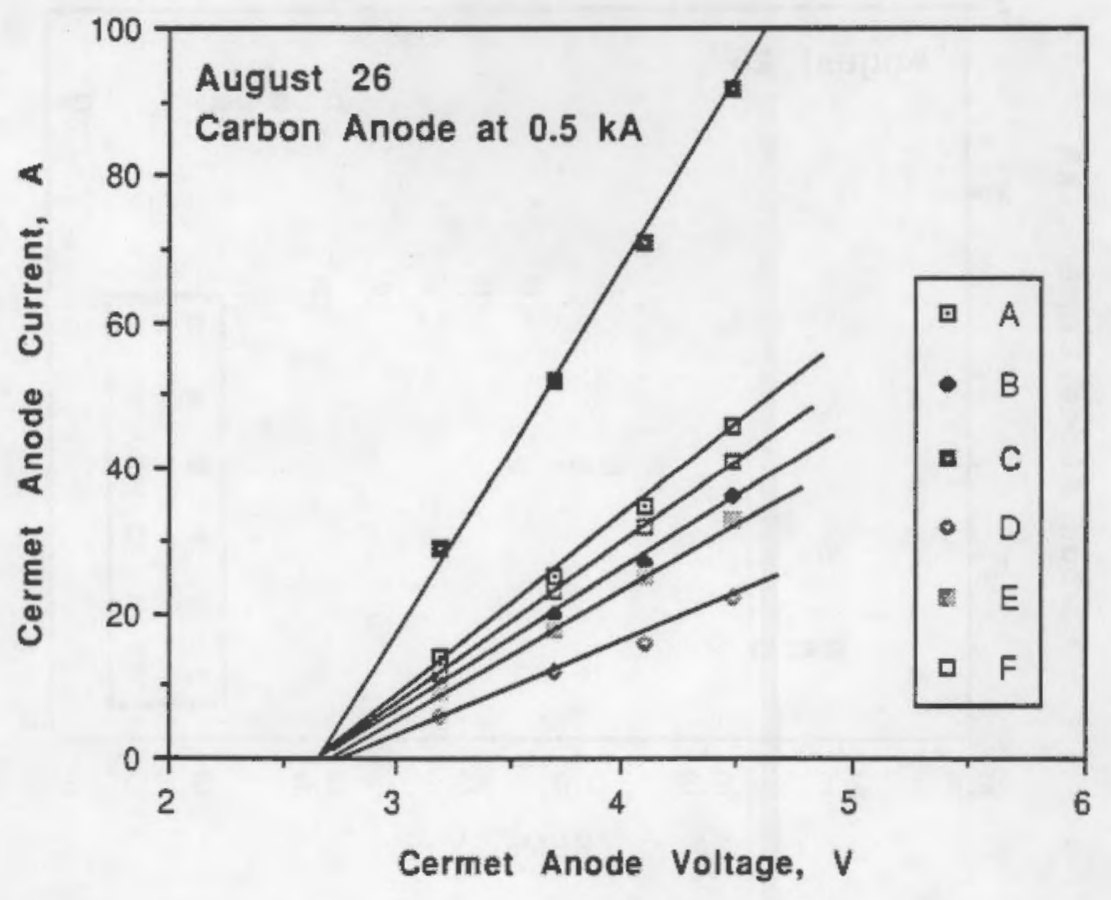

FIGURE 4.30. Current Versus Voltage (iv) Scans for Various Anode Positions with Carbon Anode Current at $0.5 \mathrm{kA}$ 
of reducing current from the cermet anodes. Extrapolation of the volt-amp curves to obtain the back-emf (BEMF) was performed in all cases, although it should be noted that significant nonlinearity in these plots is probably present at higher carbon currents as suggested by the $3.5 \mathrm{kA}$ data and at very low cermet anode currents where data are not available. The BEMF values increase with the carbon anode current and were, in all cases, significantly above the $2.2 \mathrm{~V}$ value that has been observed in numerous laboratory cells (including the prototype anode test) using the cermet anodes. A plot of BEMF as a function of the carbon current for all of the volt-amp scan data obtained from the six cermet anodes (in the positions noted) on August 26 is shown in Figure 4.31. Extrapolation of all of these data to BEMF at no carbon anode current was performed on each anode and these values are given in Table 4.2. The extrapolated value using BEMF data obtained from Anode $C$ earlier in the test (August 14) is also given in Table 4.2. The average for all values on August 26 is $2.52 \pm 0.07 \mathrm{~V}$. This value is significantly higher than the expected $2.2 \mathrm{~V}$ and probably reflects significant nonlinearity in the volt-amp

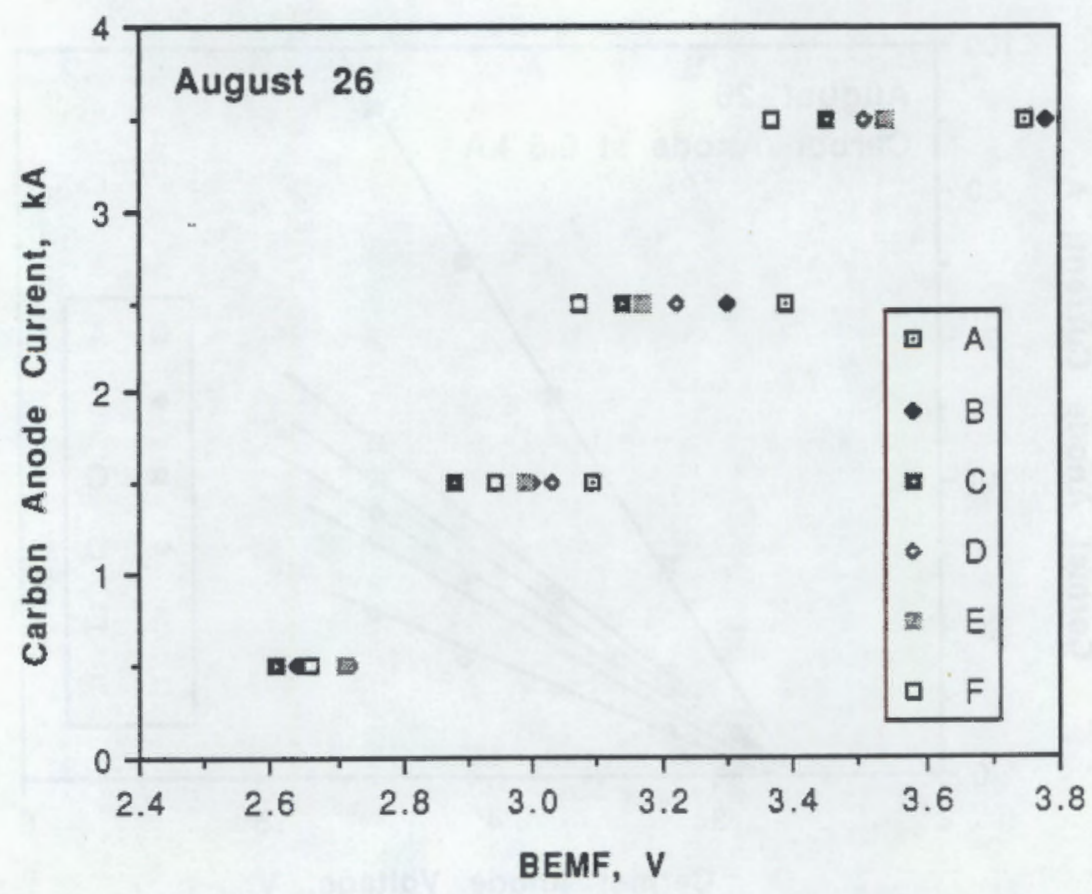

FIGURE 4.31. BEMF as a Function of Current Through the Carbon Anode 
TABLE 4.2. Extrapolated BEMF Values

\begin{tabular}{|c|c|c|}
\hline $\begin{array}{c}\text { Anode } \\
\text { Position }\end{array}$ & Date & $\begin{array}{l}\text { BEMF Extrapolated } \\
\text { (Carbon Current }=0), v\end{array}$ \\
\hline A & $8 / 26$ & 2.50 \\
\hline B & $8 / 26$ & 2.44 \\
\hline C & $8 / 26$ & 2.46 \\
\hline C & $8 / 14$ & 2.35 \\
\hline D & $8 / 26$ & 2.61 \\
\hline$E$ & $B / 26$ & 2.57 \\
\hline $\mathrm{F}$ & $8 / 26$ & 2.56 \\
\hline Average & $8 / 26$ & $2.52 \pm 0.07$ \\
\hline
\end{tabular}

data at small cermet anode currents as well as higher corrosion than experienced in the lab. The generally lower values for positions $A, B$, and $C$ versus $D, E$, and $F$ are also consistent with the carbon anode effects being stronger for those cermet anodes located closer to the carbon anode. Comparison of BEMF at no carbon anode current for the anode in position $C$ at early and later times in the test shows a small difference $(2.35 \mathrm{~V}$ versus $2.46 \mathrm{~V}$ in Table 4.2). However, as shown in Figure 4.32, a more extensive data base for the anodes in position $C$ at carbon anode currents between $0.2 \mathrm{kA}$ and $0.5 \mathrm{kA}$ shows no significantly large or consistent variation in the volt-amp curves with time. This conclusion is made with some caution since volt-amp data collected under exactly the same conditions as a function of time were limited. The largest volt-amp data base was obtained on August 26, late in the test, and reflects conditions of small ACD; earlier data were limited to volt-amp curves for only certain anode positions at fewer carbon anode currents. Consideration of the effect of the carbon anode voltage on the total cermet anode voltage (Figure 4.33) led to similar conclusions.

\section{Distribution of Current at an Anode}

The large carbon anode and the proximity of the sidewall also had a significant effect on the current distribution on each anode. More properly, the irregular current distributions result from the unique voltage profiles in the pilot cell which, in turn, are ultimately caused by the large carbon anode and 


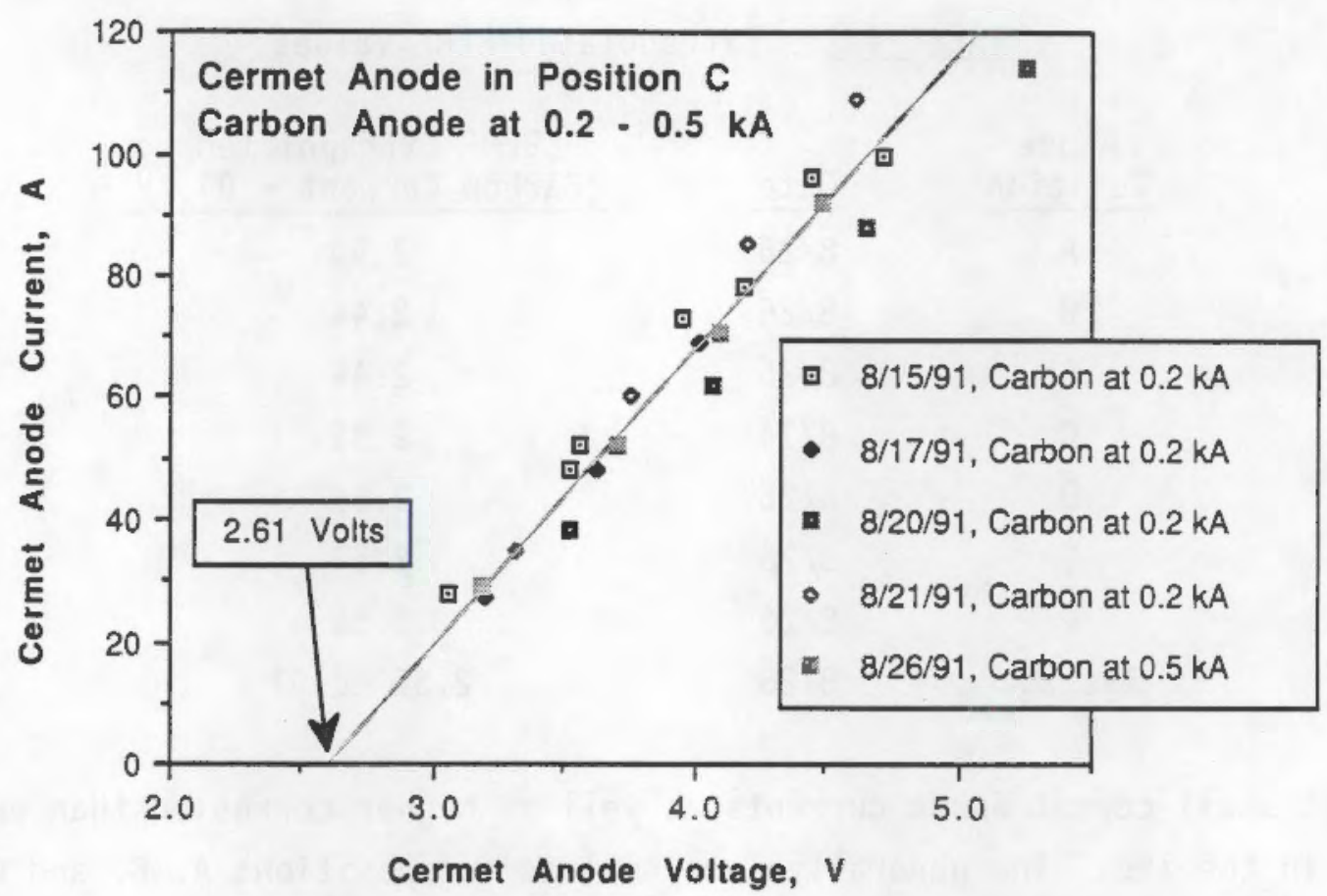

FIGURE 4.32. Plot Showing Negligible Variation of BEMF with Time during the Pilot Cell Test. (Data are for anodes in position C with carbon anode current between 0.2 and $0.5 \mathrm{kA}$.)

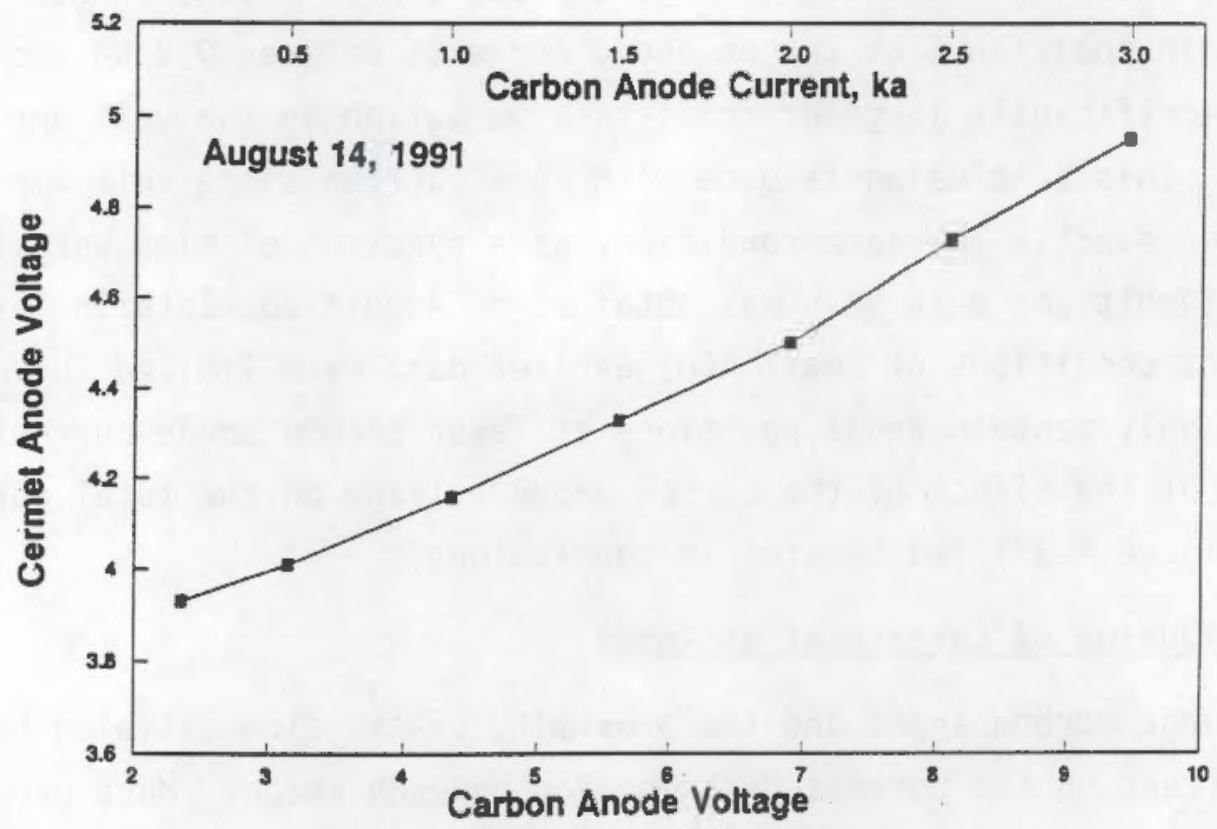

FIGURE 4.33. Effect of Carbon Anode Voltage on the Cermet Anode Voltage. (Data were obtained on August 14.) 
the sidewall effects. To characterize the distribution of current densities on a given anode, voltage measurements were made on the cermet anodes during the test using voltage probes. A schematic of the two types of probes used is shown in Figure 4.34. The probes were based on a design by Haupin (1971) and consisted of a tungsten wire threaded through a heavy-walled quartz tube. The quartz was "balled-up" at the end of the tube and about 0.25 inches of wire were allowed to protrude from the end. The curved version of the probe was used to measure voltages under the anodes; the straight probes were used to

$$
\text { Curved V-Probe Straight V-Probe }
$$

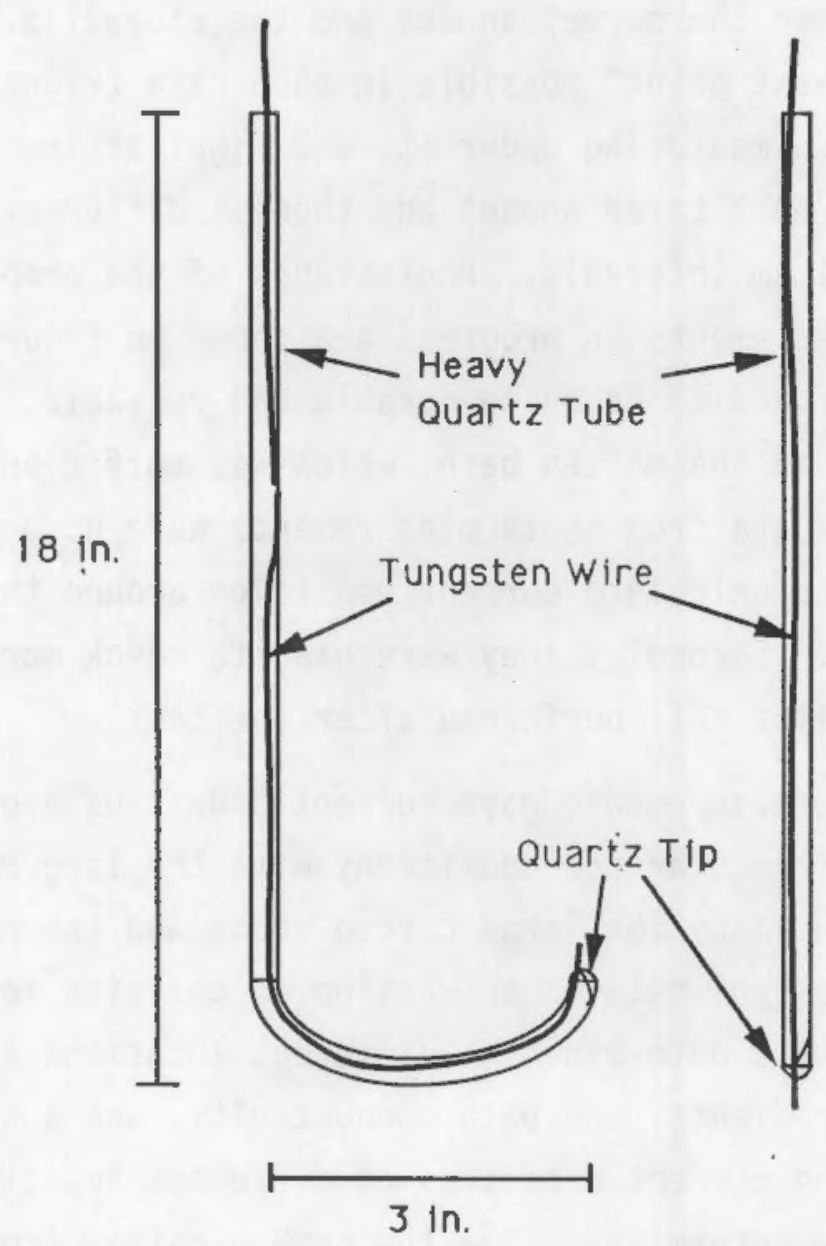

FIGURE 4.34. Schematic of Voltage Probes Used in the Pilot Cell Test 
measure potentials at the sides of the anodes, between the cermet anodes and the sidewalls, other cermet anodes, and the carbon anode. Voltage measurements were made by inserting the probe to the desired location using a specially constructed positioning device, cathodically polarizing the probe briefly (via a switching mechanism connected to the cathode) to plate aluminum metal on the probe tip, and then making a voltage measurement. All voltages were measured between an electrical tap at the top of the connector rod and the tip of the voltage probe. A series of these types of measurements were made at various locations around the cermet anodes on August 13 and 14 and also later in the test on August 26 . Measurements were made directly below the cermet anodes, between cermet anodes, between the cermet anodes and the carbon anode, and between the cermet anodes and the sidewalls. Measurements were taken at the "highest point" possible in each case (right at the bottom surface of an anode when measuring under $i t$, and right at the top of the electrolyte when measuring next to an anode) and then at different levels of immersion, usually at $1 \mathrm{~cm}$ intervals. Photographs of the probes before and after use and with measurements in progress are shown in Figure 4.35. Generally, the probes were found to be quite durable and reliable. The probes lasted for about $0.5 \mathrm{~h}$ in the molten bath, which was sufficient time to perform a complete scan. Data from these measurements were used in two ways. First, they were used to calculate current densities around the anodes for short-term information. Secondly, they were used to check more detailed voltage profiling of the pilot cell performed after the test.

The voltage probe measurements gave current densities around the cermet anodes that were very irregular and consistent with the larger-scale trends over the whole cell caused by the large carbon anode and the proximity of the sidewalls. From the voltage data as a function of position in the cell, average voltage gradients were determined at different locations around the cermet anodes. Using these gradients, the bath conductivity, and a correction factor for current fanning, the current densities at different locations on the cermet anode surfaces were determined. See the communication from Dr. W. E. Haupin in Appendix B for a discussion of the calculation method. Figure 4.36 shows the results of the calculations on an arbitrary cermet anode at the 

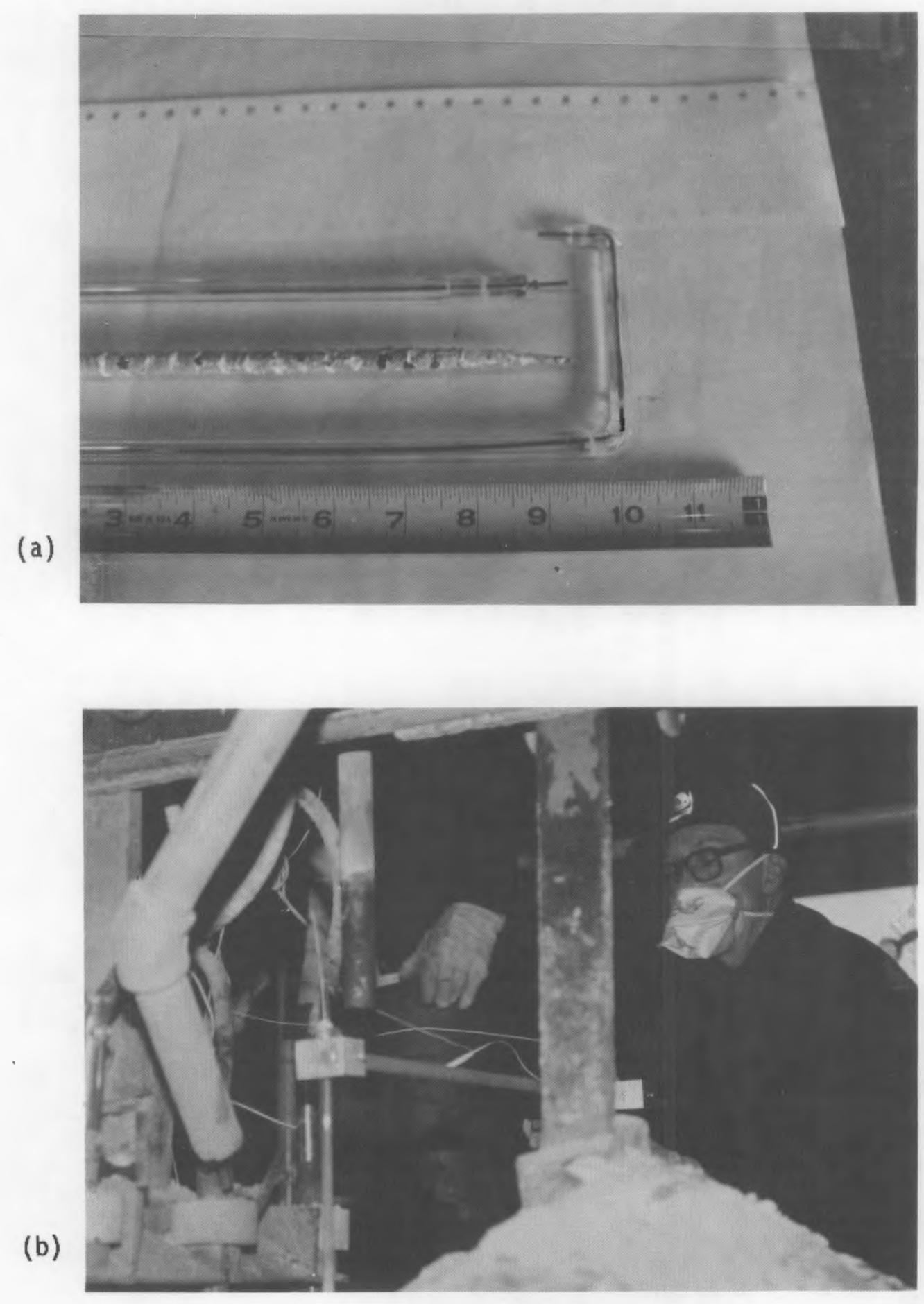

FIGURE 4.35. Voltage Probe Measurements a) Photograph of voltage probes and b) Photograph of voltage probe measurement in progress 

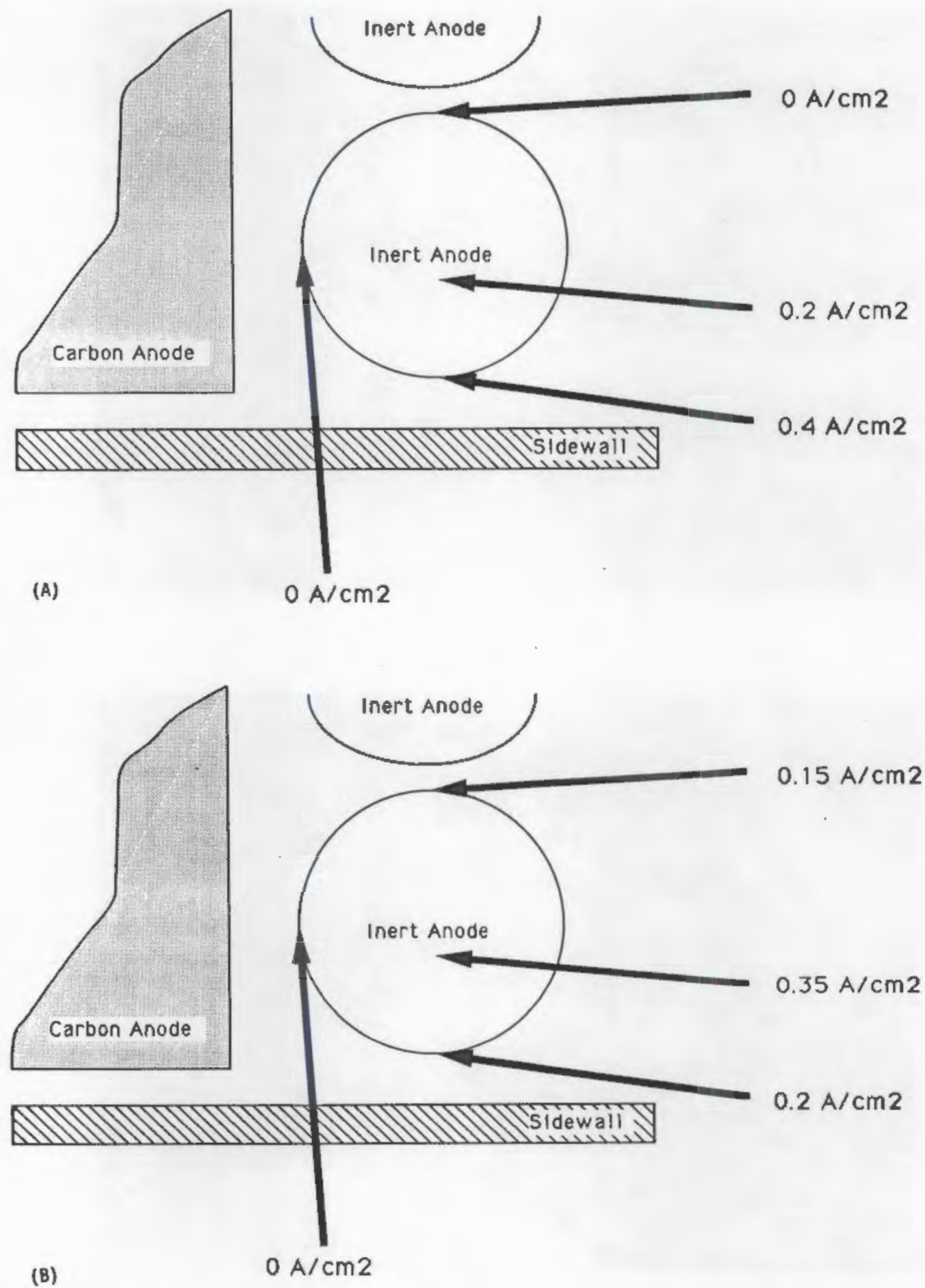

FIGURE 4.36. Schematic Showing Current Densities on Different Parts of a Cermet Anode: a) Based on measurements made on August 13,1991 when total current $=68 \mathrm{~A}$ and $\mathrm{ACD}=7 \mathrm{in}$, and b) Based on measurements made on August 26,1991 when total current $=79 \mathrm{~A}$ and $A C D=1$ in. 
currents shown ${ }^{(a)}$ at two different times during the test (i.e., when the voltage probe data were obtained). In general, current densities at the bottom surface of the anodes appear to have been $\leq 0.35 \mathrm{~A} / \mathrm{cm}^{2}$ (August 26 value) over most of the test. It appears that the current densities were lower at the start of the test when the cell had a larger ACD. Current densities on the sides of the anodes facing the cell sidewalls were the largest at the start of the test because of the larger ACD and somewhat smaller at the end of the test because of the smaller ACD and crust formation; current densities on the sides facing the carbon anode were essentially zero for anodes in positions $A, B$, and $C$ only; current densities on sides facing other cermet anodes were also lower than on the bottom surface and may have been slightly larger at the end of the test than at the beginning. Despite the lower-than-expected current densities on some parts of the cermet anodes, the calculations indicate that the main procedural objective was still apparently achieved, i.e., that the cermet anodes would not exceed an operating current density greater than $0.5 \mathrm{~A} / \mathrm{cm}^{2}$.

\section{Voltage and Current Profile Modelling}

The voltage profile for the pilot cell (voltage values at different locations in the cell) was also modelled to characterize better the heterogeneous environment of the cermet anodes. Two modelling approaches were used. In one case, the results of the model were compared with the data from the voltage probe measurements.

The first modelling approach was performed at RMC using the Landau L-CHEM model (U. Landau, Case Western Reserve University, Cleveland, Ohio). The principal result of the modelling was the evidence that the carbon anode imposes a residual base voltage on the cermet anode voltage. The effect was predicted by determining BEMF as shown in Figure 4.37. These calculated results are consistent with the experimental values described earlier. The

(a) These currents are either near the average or on the high side for currents actually realized on the cermet anodes during the test. Consequently, the current density values given here reflect values below which most of the anodes experienced most of the time. 


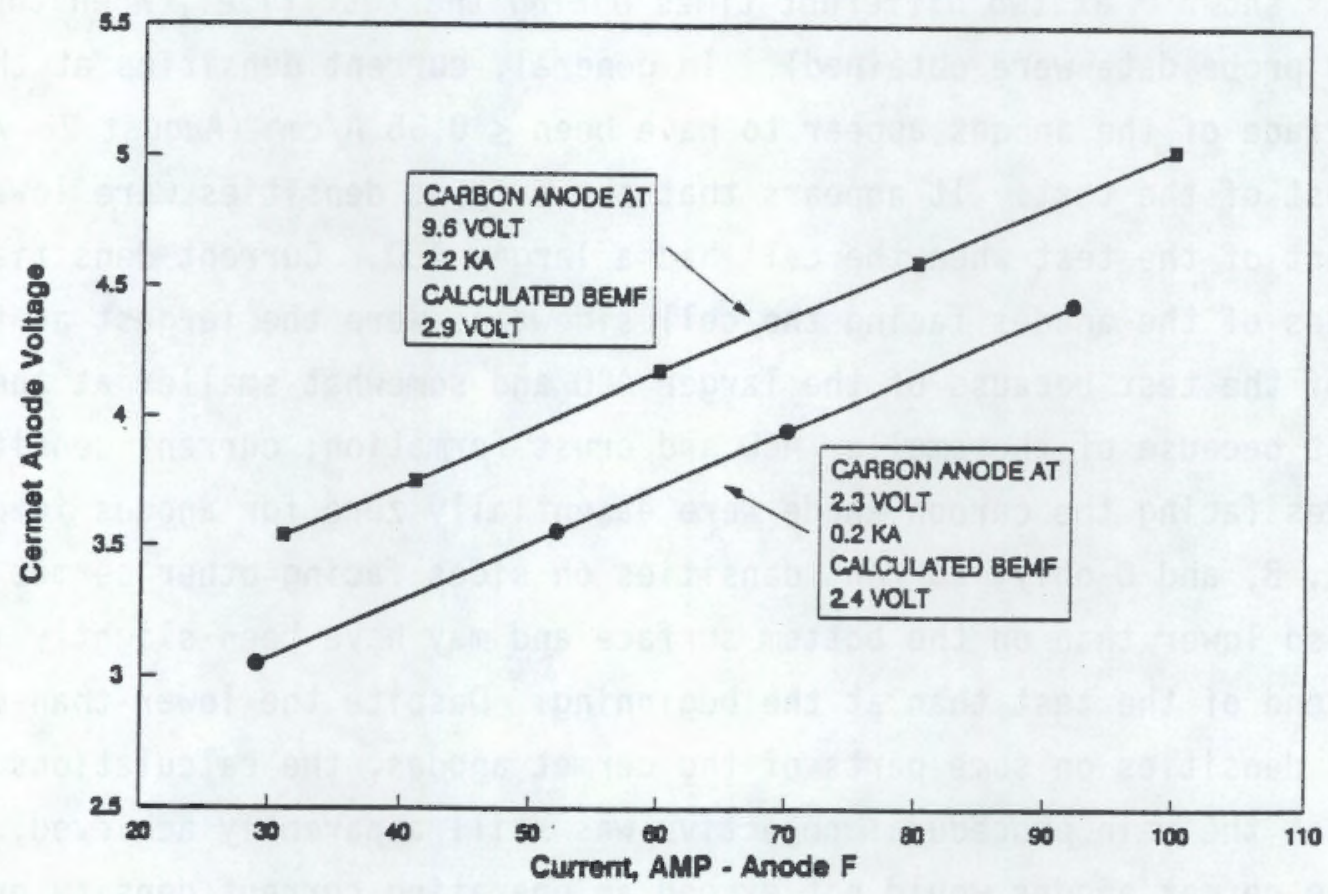

FIGURE 4.37. Calculated BEMF from the Landau Model

calculated value for the cermet anode when the adjacent carbon anode current is low $(<0.2 \mathrm{kA})$ was 2.4 to $2.6 \mathrm{~V}$, which compared well with the extrapolated value in Figure 4.30.

The second model was used at PNL and developed from the software titled "M-Grid 3D," a program originally developed at PNL to model groundwater flows. The visualization software is the "Application Visualization System" (AVS), by AVS, Inc, Cambridge, Massachusetts. The following assumptions were used in the model: 1) the bath, cell walls, molten aluminum, and anode (carbon and inert) conductivities were uniform, constant, and known; 2) the sidewalls had no frozen bath on them; and 3 ) the bottom of the cell was uniformly covered with aluminum. There was no attempt to model the BEMF, cathode drop, or voltage losses in the connections and stem of the inert anodes. The dimensions used for the pilot cell, the carbon anode, and the cermet anodes are shown in Figures 2.2, 2.3, 2.4, and 2.7. 
A mathematical model of the pilot cell was constructed as a threedimensional grid of points spaced 0.5 inch apart vertically and 1 inch horizontally. The conductivities in Table 4.3 were used for the bath and carbon components (sidewalls and carbon anode), the bath, and the cermet anode. For each run of the model, values measured during the pilot cell test for the anode voltages, vertical spacing, bath, and aluminum pad heights were inputs to the model. Electric field vectors at each point in the grid throughout the cell were obtained as output from the model. The local current densities were derived directly from the output using the bath conductivity.

The program permitted flexible "visualization" of the results. The field and model data were used to produce isometric renderings of the cell that could be viewed from any angle. These renderings could show electric field vectors, equipotentials, two-dimensional "slices" through any plane, and mapping of data magnitude to color and height. The program could be used to determine the total current through any surface (e.g., a single cermet anode) by integrating the current density over a plane passing through an anode stem.

The quality of the model was checked by comparing the results to measurements taken with the voltage probes during the pilot cell test. This was done in three ways:

1. A data set that appeared to have good measurements for ACD was selected to provide the anode distances. The voltages on the model were adjusted until the ratio of the anode currents (carbon anode to cermet cluster total) was the same as the test values. These voltages could then be compared with the actual cell voltages after allowing for voltage losses due to BEMF, cathode drop, and stem and other connections.

\section{TABLE 4.3. Conductivities of Cell Components}

$\begin{array}{lrll}\text { Component } & \begin{array}{c}\text { Conductivity, } \\ \Omega^{-1} \mathrm{~cm}^{-1}\end{array} & & \frac{\text { Reference }}{\text { Carbon }} \\ & 250 & & \text { Typical value. } \\ \text { Bath } & 2 & & \text { Grjotheim, et al. } 1982 \\ \text { Cermet } & 90 & \text { Weyand, et al. } 1986\end{array}$


2. For the case above, a comparison of current ratios between cermet anodes for the model and the pilot cell measurements provides a more sensitive test of the model fields near the cermet anodes.

3. Once the "large scale" features (voltage, current, and ACD) were in nominal agreement, the electric field of the model was directly compared with the electric field scans made during the pilot cell operation with the voltage probes.

When attempts were made to compare the calculated fields with the measurements on the pilot cell, several problems with the data were discovered: 1) Some of the scans exhibited "hysteresis", i.e., there was a significant difference in the readings taken with increasing depth and those taken with decreasing depth; 2) apparent anomalies in the scan data made it difficult to discern where the bottom of the anode (top of scan) and the top of the aluminum pool (bottom of scan) really were; and 3) the scans were taken in areas with steep horizontal voltage gradients, ${ }^{(a)}$ such that small errors (less than 1 inch) in the horizontal position of the probe tip would have large effects on the voltages measured during a vertical scan. The anode and probe positions are not known accurately enough to determine a corresponding location in the model with any confidence.

In general, the model appeared to be a good representation of the pilot cell, and was definitely an aid in understanding the test situation. In particular, it indicated that the $0.5 \mathrm{~A} / \mathrm{cm}^{2}$ maximum desired current density was not exceeded, which is consistent the with calculations by Haupin reported previously and discussed in Appendix B. An unexpected result from the model was the finding that current flowed from the carbon anode to the three nearest cermet anodes, as shown in Figure 4.38 (b) $^{\text {(b) }}$ and particularly to the center anode of those three (position $B$ ). This reverse flow was caused by higher voltage at which the carbon anode was operated and its proximity to the cermet

(a) This was caused by the conduction in the sidewalls and large size and higher voltage of the carbon anode relative to the inert anode cluster.

(b) In the figure, the current flow appears to go from the inert anode to the carbon anode because the flow is shown as going from $(-)$ to $(+)$, opposite conventional current flow. 


\section{CURRENT VECTOR FIELD}

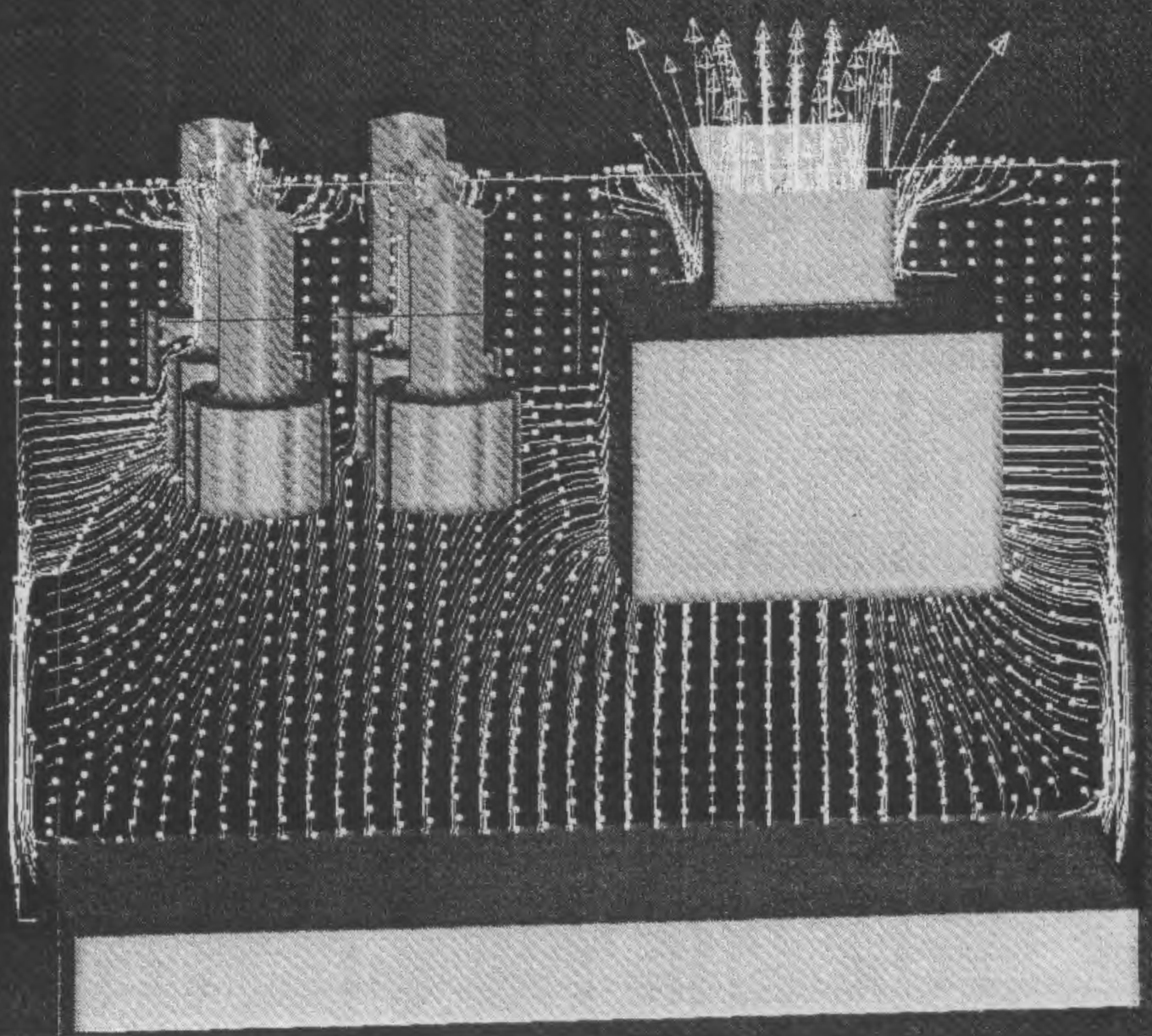

FIGURE 4.38. Three-Dimensional Current Vector Field Calculated with PNL Model

anodes in positions $A, B$, and $C$. No physical evidence (other than the voltage measurements) for this reversed current flow was obtained in the test. In particular, no unusual wear characteristics were obvious on sides of the cermet anodes adjacent to the carbon anode. However, since very few of the anodes in the positions next to the carbon anode were removed with their 
orientation preserved $^{(a)}$ because the stems failed and anodes fell off their connections, it is uncertain whether any special sort of corrosion reactions might be observed on these surfaces upon closer scrutiny under more controlled conditions.

The model exhibited the same sensitivity to the relative anode voltages as did the pilot cell. As shown in Figure 4.39, a cross-section of the pilot cell with isopotential lines makes the reason clear: the larger size and smaller ACD of the carbon anode relative to the cermet anodes gives it an

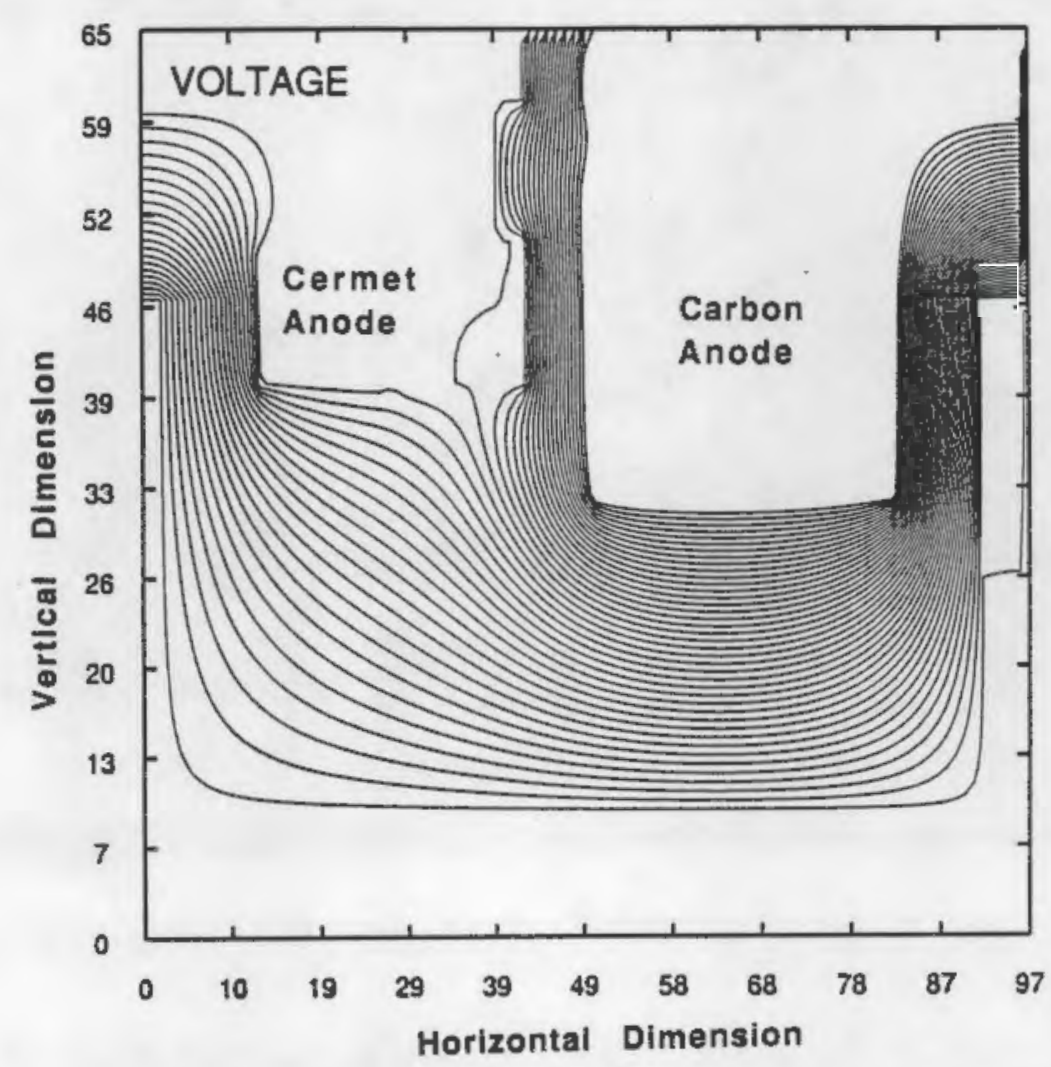

FIGURE 4.39. Cross-Section of the Pilot Cell with Isopotential Lines

(a) Of all the anodes tested in positions next to the carbon anode (positions A, B and C), on ly anodes E2 and C2 had their orientations preserved. Unfortunately, these were also two of the three anodes that were subjected to the very aggressive conditions of high current density and low alumina. As shown later in the report, these conditions resulted in extreme amounts of corrosion and obscured any other effects such as those caused by the carbon anode. 
overwhelming influence on the fields in the cell. This an important factor in the current differences between the two rows of cermet anodes (positions A, B, and $C$ versus $D, E$, and $F$ ). In addition, as shown in the picture of the current fields in Figure 4.38 , there is heavy conduction from the sidewalls to the three cermet anodes next to it. This sidewall current occurs despite the small amount of anode area oriented toward the sidewall relative to the bottom of the cell.

The informative results of modelling the pilot cell suggest that in the future modelling should be done while the test is in the design stage. This would provide several advantages:

1. The selected geometry could be examined for current distribution. If the distribution is unsatisfactory, the geometry and anode voltages could be adjusted before any fabrication is started. Other factors, such as temperature gradients due to current variations, might be considered at the same time.

2. Sensitivity of the voltage characteristics to variations in operating conditions could be checked, e.g., the amount of sidewall conduction due to frozen bath. Contingency plans could be developed for factors with undue influence.

3. Locations for voltage scans in the bath could be chosen for better tolerance to position errors. This should allow more useful data to be acquired.

4. Calculated currents, voltages, and fields could be used to improve the selection of data acquisition equipment. During the test, the calculated values could be compared with the measured values as checks on the quality of the measurement. Excessive deviations would alert the experimenters to possible problems in the test or measurement.

\section{Voltage Orops Through the Cermet Anodes}

As the above data indicate, a more exact breakdown of the voltage components for the cermet anodes is not possible because the large carbon anodes, sidewall conduction, and bottom muck formation have a multiplicity of current paths. The multiple paths prevent reliable calculations of a "representative" bath voltage drop and the "effective" anode area required for determining the respective voltage components. As illustrated by the modelling work, at the very least, an extremely complex and multivalued three-dimensional profile 
would have to be obtained. At this point, the value of this level of detailed analysis is questionable given the less-than-optimal performance of the cermet anodes. It is strongly recommended, however, that any future pilot cell test be designed with more simplicity of voltage characteristics in mind. Coupled with the suggested modelling studies performed prior to testing, the current and voltage characteristics of the cell should be much more manageable. Under these circumstances, the important voltage drops through the anode and the cell could be more easily documented and correlated with anode performance.

\subsubsection{Operational Problems}

Two important operational problems that developed during the pilot cell test were 1) breakage of the $\mathrm{Ni}$ connector rods or stems, and 2) cracking and breaking of the cermet anodes.

Breakage of the $\mathrm{Ni}$ rods used for current conductors to the cermet anodes began to occur very early in the pilot cell test. The anode stems had a loose alumina sleeve around the stem as depicted earlier for chemical protection. The anodes, during operation, typically had a cryolite cover over the top of this sleeve as shown in Figure 4.40. Temperatures were measured in the 700 to $850^{\circ} \mathrm{C}$ range in the stem area submerged in the crust cover. It was in this area, approximately 3 inches (or less) above the top of the anode, that the stem failures occurred. The chronological listing of stem failures is summarized in Table 4.4.

As shown in Table 4.4, the stem failures first occurred four days after beginning operation, and only one anode (in position E) did not fail. If sufficient stem remained on the anode, a steel pipe was fitted over the stub and operation of the anode continued. Replacement anodes used 304 SS for the stems, which proved to be satisfactory in combination with packing the alumina sleeve with a "pumpable" castable as shown in Figure 4.41. Examination of the fractured $\mathrm{Ni}$ rod surface using SEM/EDS (Appendix $\mathrm{C}$ ) indicated abnormally large grains/crystals and high $\mathrm{S}$ content, suggesting embrittlement of the $\mathrm{Ni}$ rod had occurred. The prolonged operation at the elevated temperatures in the presence of the cryolite crust, which contains some 5 , probably led to rapid 


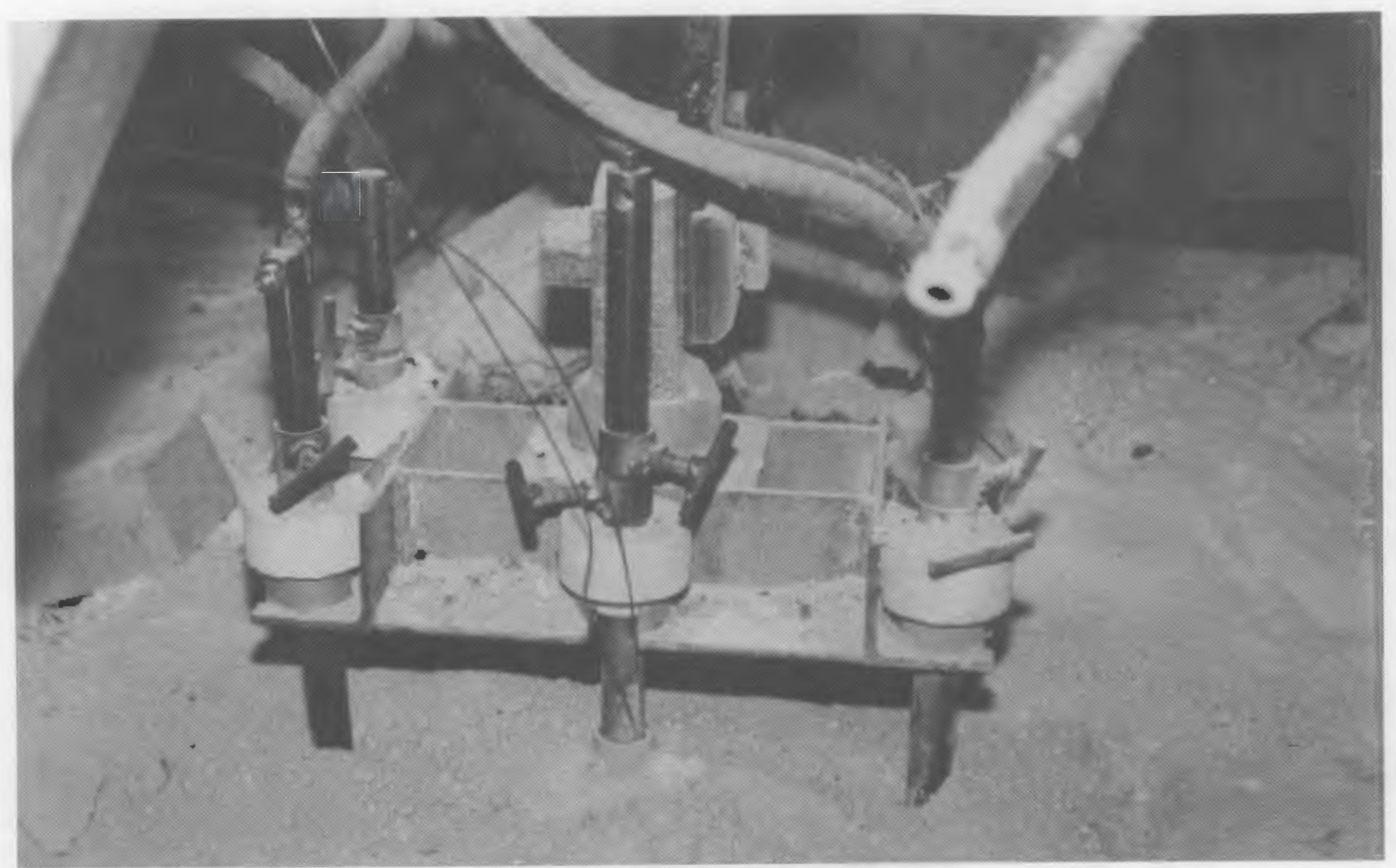

FIGURE 4.40. Photograph Showing the Cryolite Cover on Top of the Cermet Anodes

TABLE 4.4. Chronological Listing of Stem Failures

\begin{tabular}{|c|c|c|}
\hline Date & $\begin{array}{c}\text { Anode } \\
\text { Position }\end{array}$ & Comment \\
\hline Aug 14,9 am & c & Replaced with sleeve. \\
\hline Aug $15,3 \mathrm{pm}$ & $B, F, D$ & $\begin{array}{l}B \text { and } F \text { replaced with } \\
\text { sleeve, anode } D \text { replaced. }\end{array}$ \\
\hline Aug 18,1 am & B & $\begin{array}{l}\text { Stem broke beneath } \\
\text { sleeve, replaced anode. }\end{array}$ \\
\hline Aug $18,1 \mathrm{pm}$ & A & Replaced with new anode. \\
\hline
\end{tabular}

oxidation and early failure of the stems. These failures of the anode stems dominated the early part of the cell operation, resulting in significant modification of the test schedule.

The other significant operational problem was the breakage of the cermet anodes during operation. As indicated in Section 4.2, the first cermet anode that was transferred to the pilot cell broke immediately upon exposure to the 


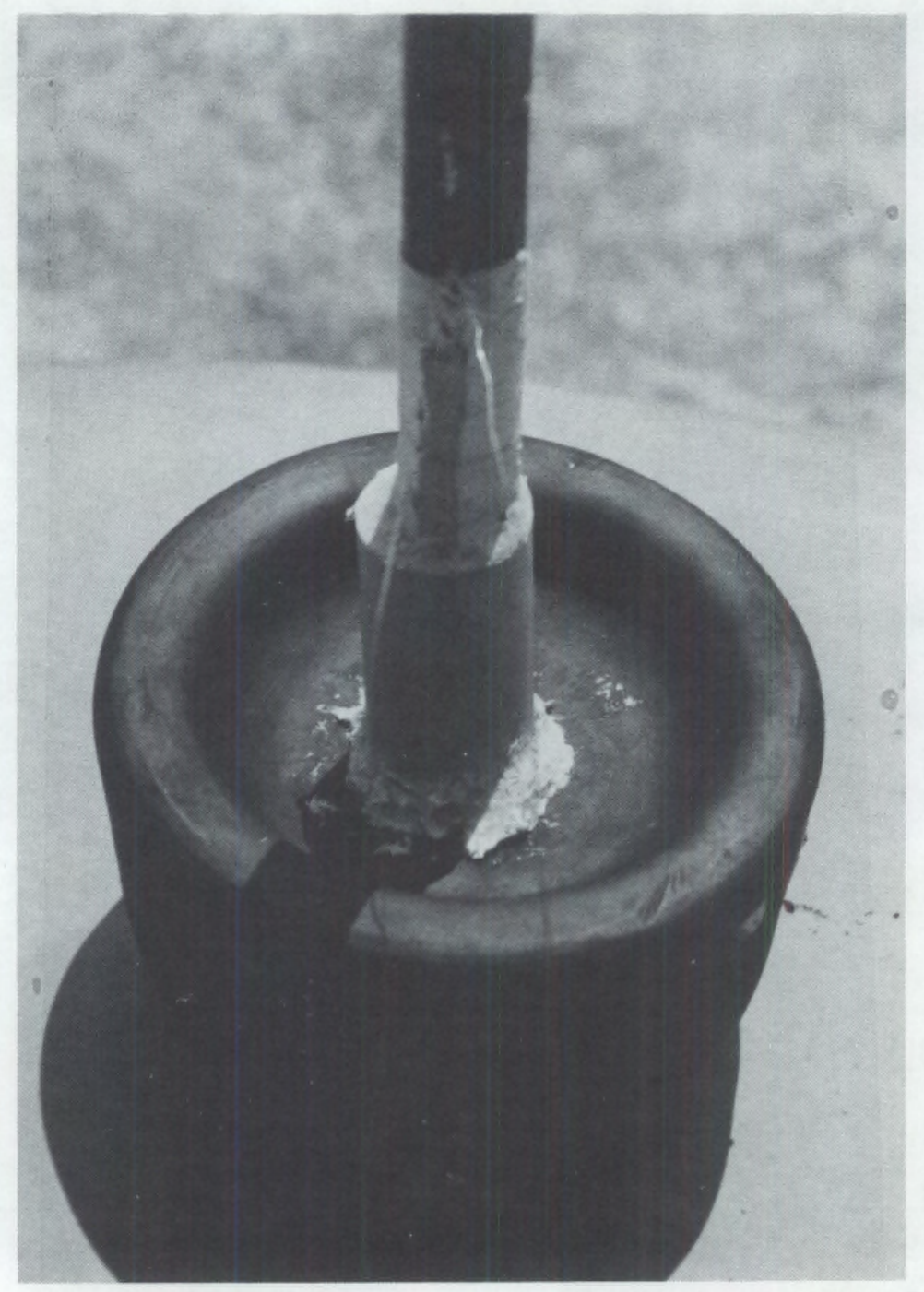

FIGURE 4.41. Photograph Showing the "Packed" Alumina Sleeve

heat from the open bath. Even though the transfer procedures were modified to reduce thermal shock, as discussed in Section 4.2, all of the anodes still cracked, although not as suddenly and catastrophically as the first anode. All of the anodes cracked down the center of the anode. Two anodes broke completely during cell operation: Anode A2 (position B, August 26) and Anode C1 (position C, August 18). Part of Anode Cl broke off, fell in the cell and, unlike other large pieces that had broken off, was never recovered. It is suspected that all of the anodes cracked during heatup or operation. Posttest analysis (Section 5.2) revealed significant penetration of electrolyte 
into most of the cracks, indicating they were present during operation. It is also suspected that the strong alumina-cryolite crust prevented the anodes from falling apart in most instances.

The problems with anodes cracking were not unexpected given the mismatch in thermal expansivities of the $\mathrm{Ni}$ rod and the cermet material. High thermal shock sensitivity of the cermet has also been determined (Section 5.3). As discussed in Section 3.2, attempts to alleviate some of these shortcomings by fabricating the anodes with a graded core of metal blended with the cermet powder were unsuccessful. Anodes with these cores cracked during sintering. Since this fabrication-induced cracking could not be remedied, it was decided to eliminate the core entirely. The cermet anodes were made without any core and were drilled and tapped directly. This approach, of course, created an undesirable situation when the anode was actually tested, i.e., with the metal rod now in direct contact with the cermet. Nevertheless, it was decided that it was far more preferable to have anodes without any cracks at the start than to use anodes that were already flawed and likely to get worse upon testing in the pilot cell. (a) Unfortunately, using the anodes without the graded cores made it more likely that the anodes would develop cracks at some time during the test.

\subsubsection{Bath and Metal Impurities}

During cell operation, the primary indicator of the corrosion rate of the cermet anodes was the rate of increase of $\mathrm{Ni}, \mathrm{Cu}$, and $\mathrm{Fe}$ impurity content in the Al metal. Metal samples were collected every $4 \mathrm{~h}$ to track the concentration of these elements. The results from these analyses are summarized in Appendix $D$ and Figures 4.42 through 4.44. Impurities from other sources were minimized during operation of the cell. Trace amounts of $\mathrm{Fe}, \mathrm{Ni}$, and $\mathrm{Cu}$ that came from the additives to the cell are summarized in Table 4.5 along with the estimated usage rate (based on amounts used from August 10 through August 25).

(a) An experiment was actually performed at PNL in which one of the test anodes that had cracked during sintering was heated slowly to operating temperature $\left(970^{\circ} \mathrm{C}\right)$ in a furnace. The cracks in this anode were found to have grown significantly. Consequently, using an anode that had cracked during sintering did not seem to be advisable. 


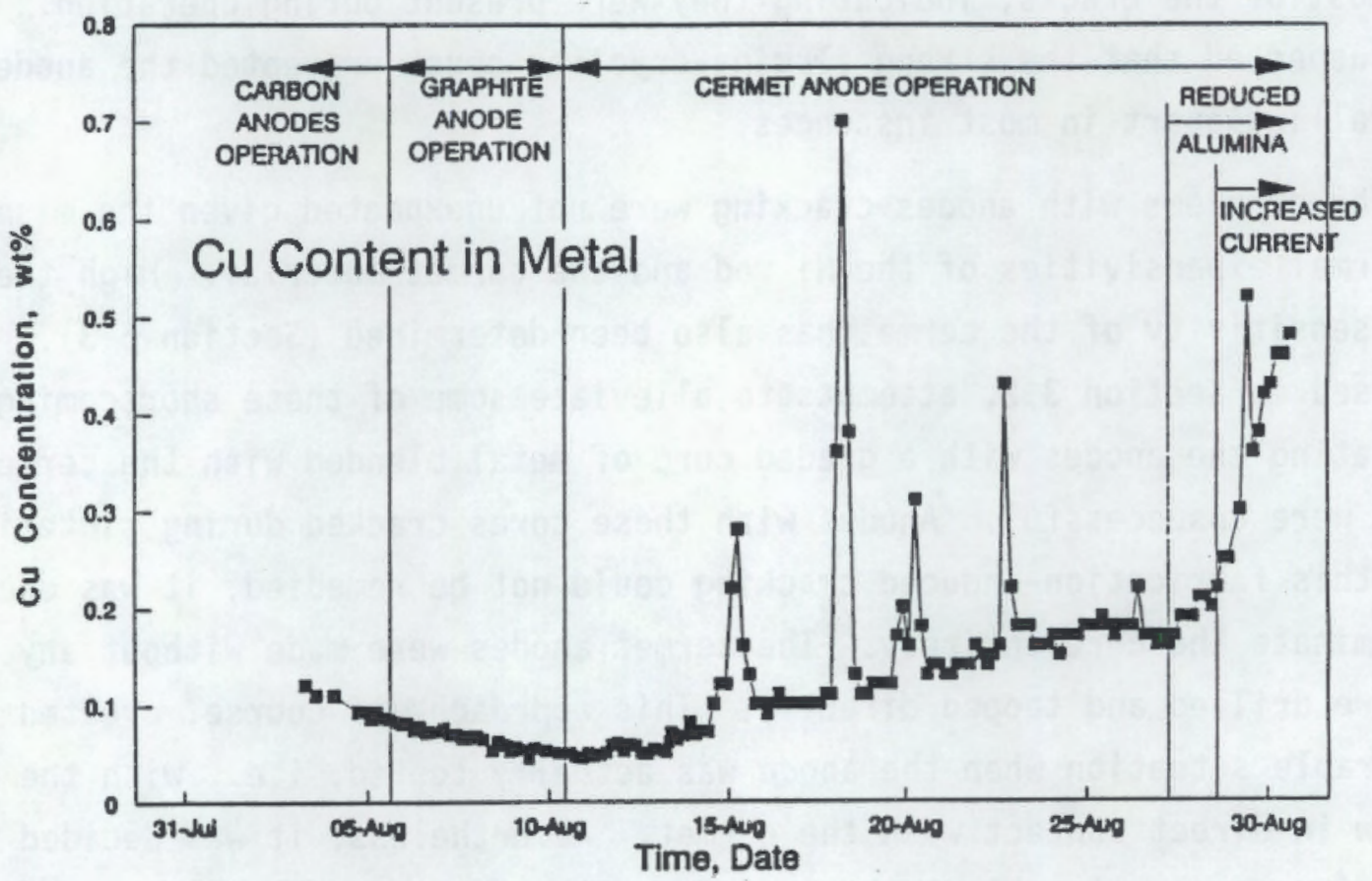

FIGURE 4.42. Concentration of $\mathrm{Cu}$ in the Metal as a Function of Time during the Pilot Cell Test

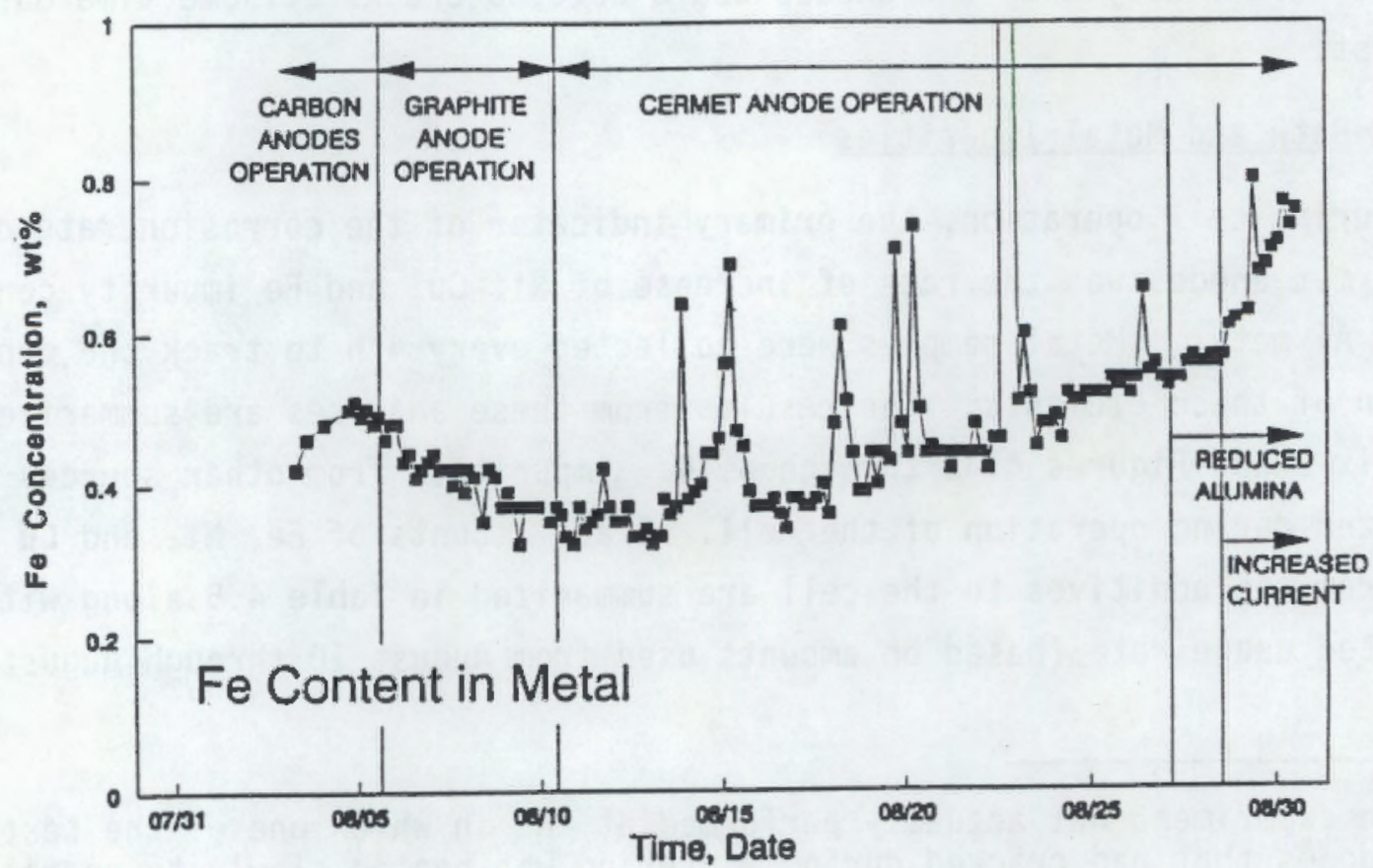

FIGURE 4.43. Concentration of $\mathrm{Fe}$ in the Metal as a Function of Time during the Pilot Cell 


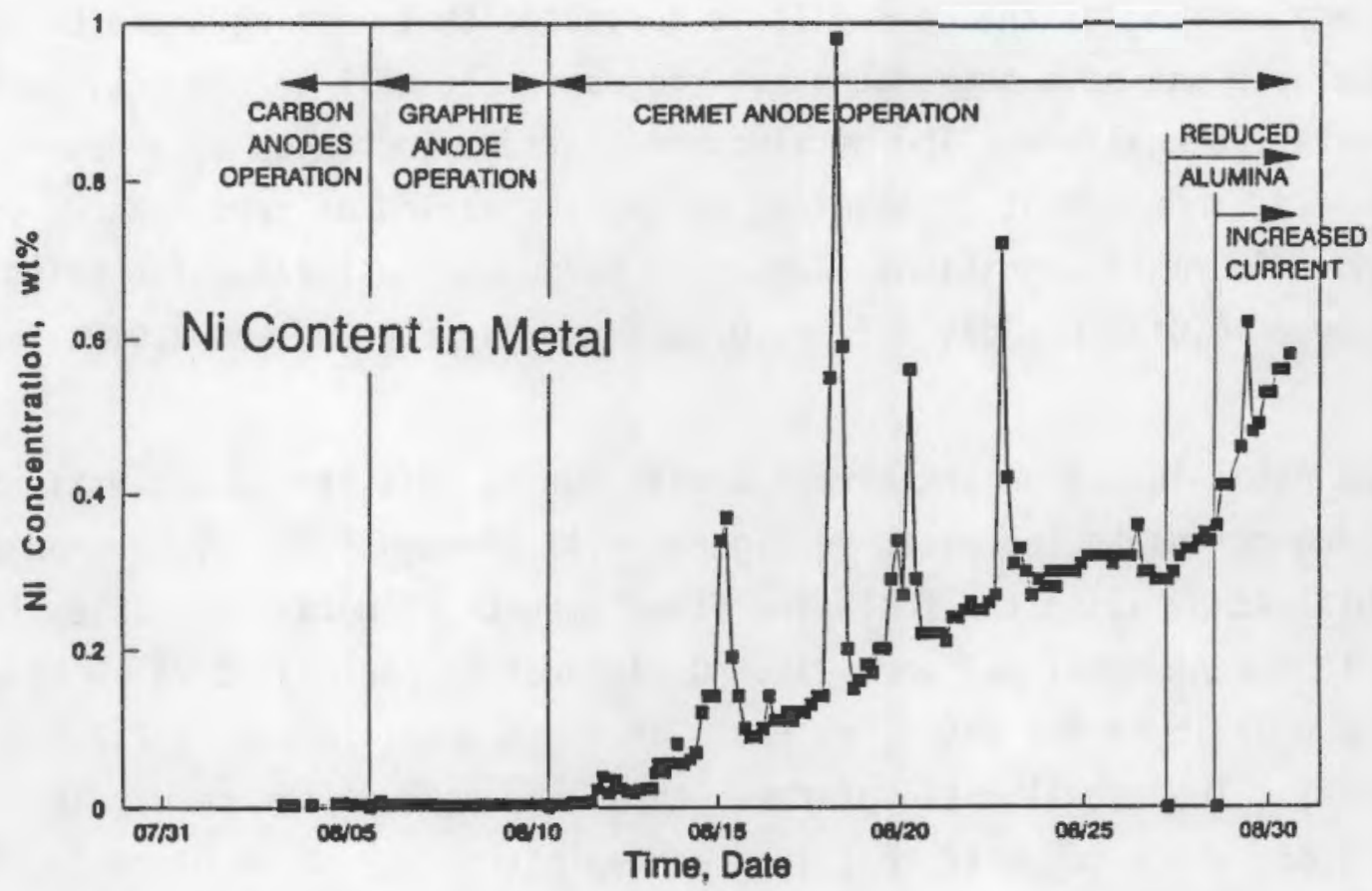

FIGURE 4.44. Concentration of $\mathrm{Ni}$ in the Metal as a Function of Time during the Pilot Cell Test

TABLE 4.5. Impurities in the Bath Additives

\begin{tabular}{|c|c|c|c|c|}
\hline Additive & $1 \mathrm{~b} /$ day & $\% \mathrm{Fe}$ & $\% \mathrm{Cu}$ & $\% \mathrm{Ni}$ \\
\hline Cryolite & 50 & 0.20 & 0.008 & 0.004 \\
\hline Alumina & 91 & 0.017 & 0.001 & $<0.001$ \\
\hline $\begin{array}{l}\text { Carbon } \\
\text { Anode }\end{array}$ & 17 & 0.086 & 0.004 & 0.018 \\
\hline Soda Ash & 18.7 & 0.001 & $<0.001$ & 0.002 \\
\hline $\mathrm{CaO}$ & 0.5 & 0.14 & 0.002 & 0.003 \\
\hline $\mathrm{AlF}_{3}$ & 0 & 0.015 & $<0.001$ & $<0.001$ \\
\hline
\end{tabular}

Based on the concentrations in Table 4.5, and an aluminum production rate of $39.6 \mathrm{lb}$ per day, the following equilibrium concentrations were predicted in the meta $1: 0.33 \% \mathrm{Fe}, 0.014 \% \mathrm{Cu}$, and $0.013 \% \mathrm{Ni}$. The higher observed values for these impurities were attributed mostly to the cermet anodes. Spikes in the impurity concentrations are related to upsets in the cell operation, such as anode changes, broken cermet anodes, or tapping, that resulted 
in extreme cooling of the cell. It is suspected that, during these periods, the metal pad may have segregated but ridges in the cell bottom prevented representative analysis. The metal concentrations increased at a nearly 1 inear rate, independent of tapping, during the period of cermet anode operation under "normal" conditions (August 10 through August 27). The rates were as follows: $0.017 \%$ per day for $\mathrm{Fe}, 0.008 \%$ per day for $\mathrm{Cu}$, and $0.019 \%$ per day for $\mathrm{Ni}$.

The metal loss from the cermet anodes during this period was estimated by fitting curves to the plots in Figures 4.42 through 4.44 . Very good fits were obtained by using the following fixed amounts of metal impurities transferred to the Al metal pad each day: $0.13 \mathrm{lb}$ of $\mathrm{Cu}$ per day, $0.26 \mathrm{lb} \mathrm{Ni}$ per day, and $0.31 \mathrm{lb} \mathrm{Fe}$ per day. The ratio of these metal losses is $1: 2: 2.4$ (Cu: $\mathrm{Ni}: \mathrm{Fe})$. The actual ratio of these three elements in the cermet is $1: 1.98: 1.65$, which suggests that iron contamination may be supplemented by other sources. Iron tools were used at tapping, removal of cermet anodes and metal sampling. If a11 components came from the anodes uniformly, Fe would have been released at a rate of $0.21 \mathrm{lb}$ per day. This would suggest that the other sources, such as tools, contributed about $0.1 \mathrm{lb}$ or $1.6 \mathrm{oz}$ of Fe per day. This quantity of $\mathrm{Fe}$ from other sources is not unreasonable, particularly in light of all of the manipulation, measurement, and sampling that took place during most of the pilot cell test. Other explanations for the disparity in the $\mathrm{Fe}$ versus $\mathrm{Cu}$ and $\mathrm{Ni}$ rates are also possible, including differences in volatility and the tendency to form minerals in the bath. Refer to the "confirmation tests" discussed in Windisch et a1. (1991b).

Assuming the calculated rates of $\mathrm{Cu}$ and $\mathrm{Ni}$ buildup in the metal are indicative of the dissolution rates of the anodes, it can be calculated that the rate of total material loss from the anodes was $0.76 \mathrm{lb}$ per day. This corresponds to a volumetric loss of $57.5 \mathrm{~cm}^{3}$, based on an anode density of $6 \mathrm{~g} / \mathrm{cm}^{3}$. Applying this uniformly to all surfaces of all of the anodes gives a "wear rate" of $0.2 \mathrm{~mm} /$ day.

The rate of impurity metal buildup increased dramatically during the time period of reduced $\mathrm{Al}$ content in the bath and increased current density 
(August 27 through August 30 ), as shown in Figures 4.42 through 4.44 . Insufficient time at each of these conditions prevented determining accurately an impurity metal increase rate or the ability to distinguish the effects from these two changes in cell conditions.

All of the impurity measurements may have been affected by the broken pieces of cermet anodes that fell into the bath. One of these pieces, which came from Anode $\mathrm{Cl}$, was never recovered. However, based on careful scrutiny of the impurity plots in Figures 4.42 through 4.44 , which show no evidence for a systematic increase beginning on the day the piece fell in (August 18), it is suspected that the piece from $\mathrm{C} 1$ was submerged in the muck in the bottom of the cell and did not significantly affect the metal purity increases noted. Unfortunately, this conclusion cannot be fully confirmed.

The $\mathrm{Fe}, \mathrm{Ni}$, and $\mathrm{Cu}$ levels were also monitored in the bath throughout the operation. These values are given in Appendix $E$ and plotted in Figures 4.45 through 4.47. As shown in these plots, little change occurred in the levels of the impurities in the bath throughout the test despite increased levels in

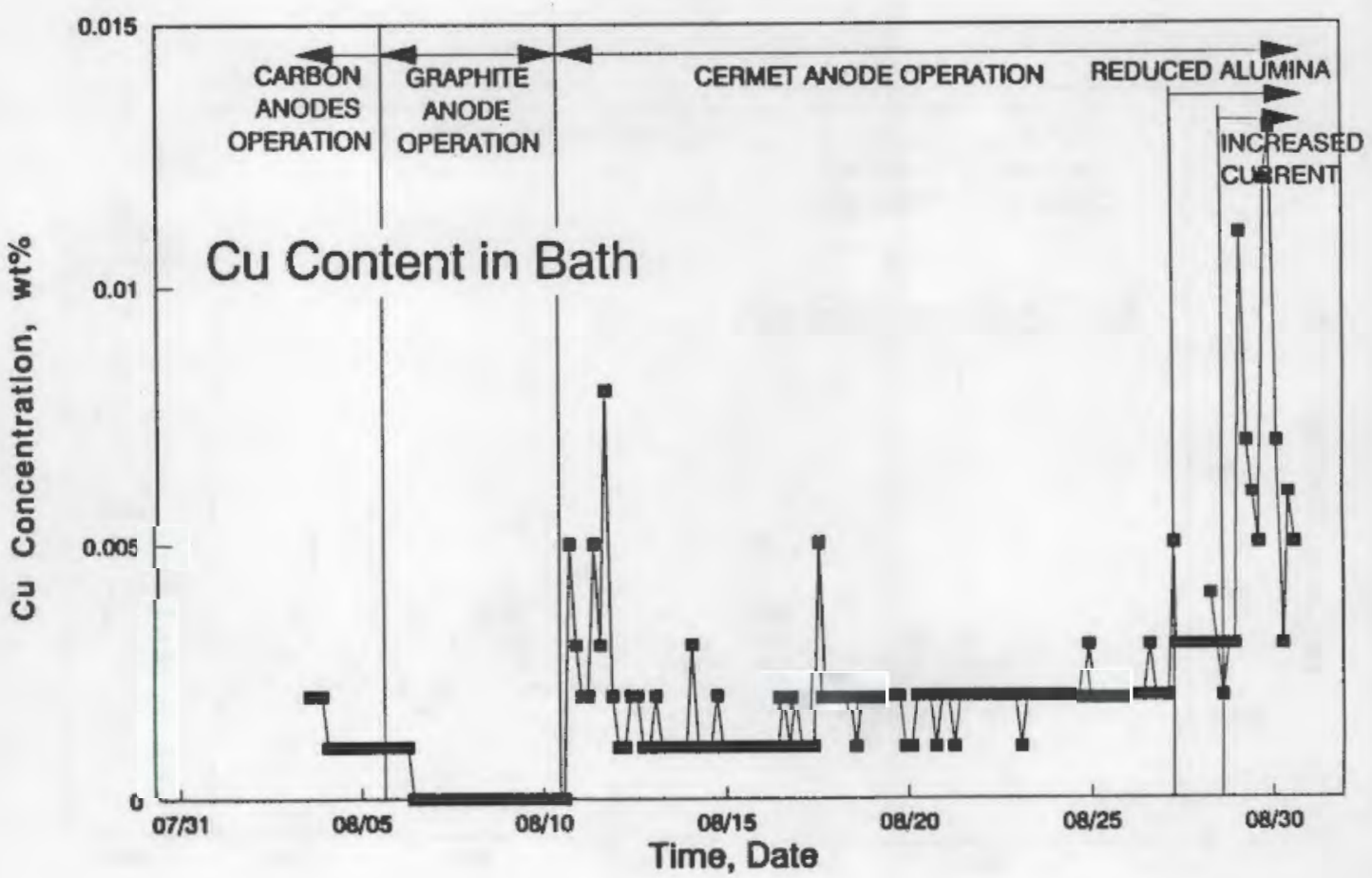

FIGURE 4.45. Concentration of $\mathrm{Cu}$ in the Bath as a Function of Time during the Pilot Cell Test 


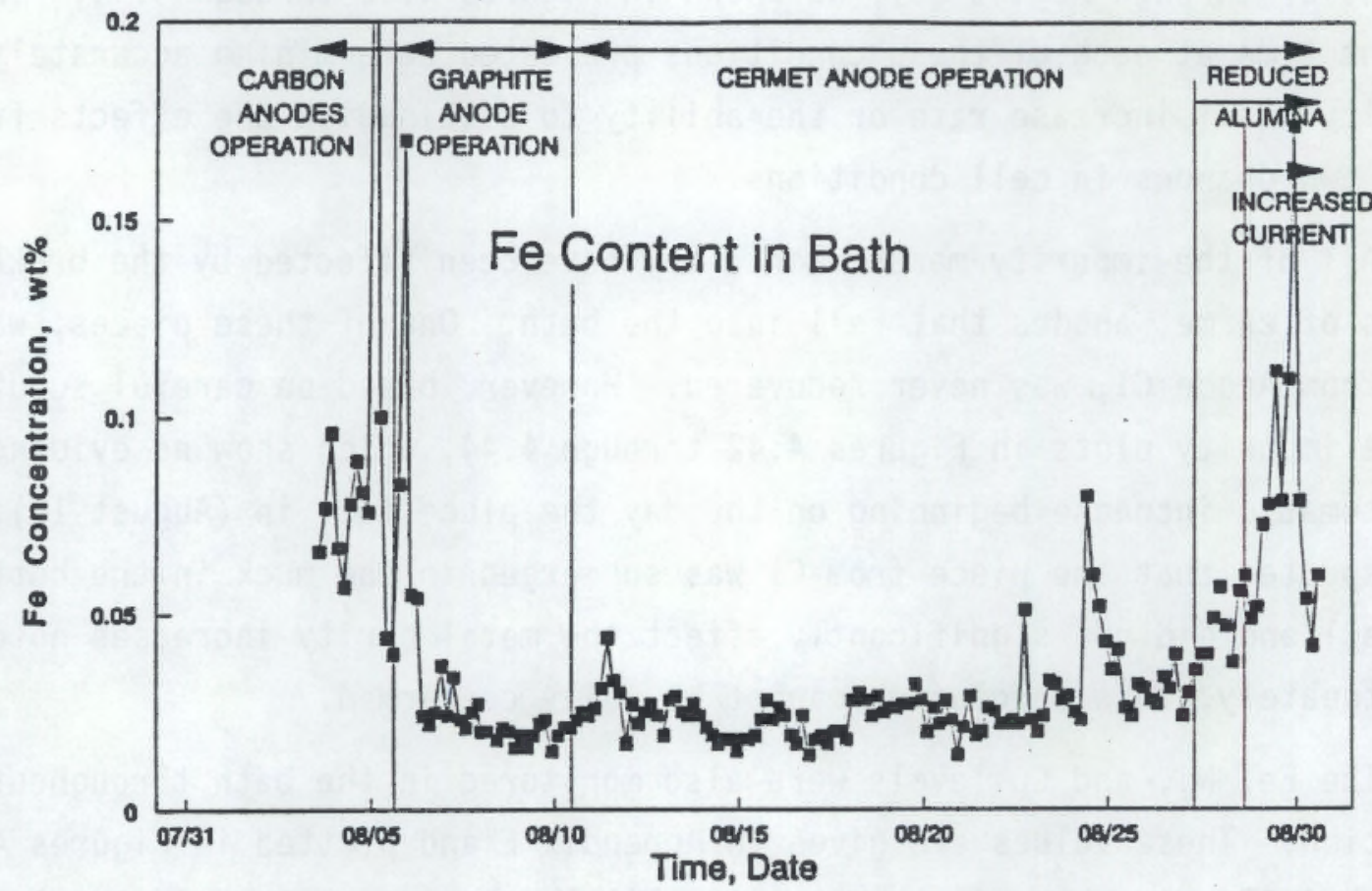

FIGURE 4.46. Concentration of $\mathrm{Fe}$ in the Bath as a Function of Time during the Pilot Cell Test

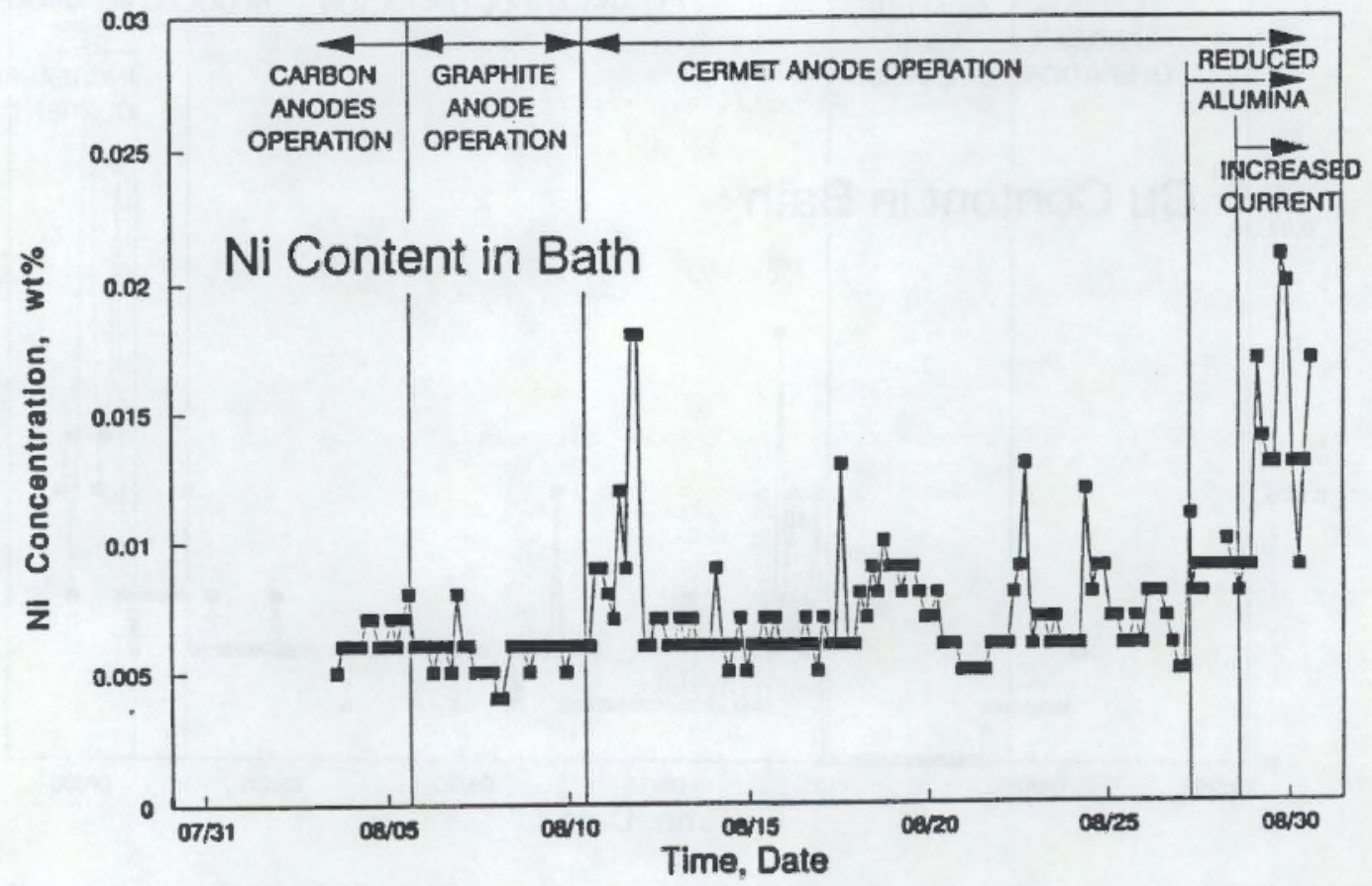

FIGURE 4.47. Concentration of $\mathrm{Ni}$ in the Bath as a Function of Time during the Pilot Cell Test 
the metal. (a) Wide variations in values were seen during the period of increased current. These variations probably resulted from the unstable nature of the operation during this period and from the extremely low bath volume.

(a) The concentrations of these metals are also, in general, significantly lower than those reported by Weyand et al. (1986) for the solubilities of the respective oxides. This result is consistent with the argument that the metal concentrations never attain saturation in the electrolyte during normal cell operation. 


\subsection{POST-TEST ANALYSIS}

This section covers the results of the post-test analyses of the cermet anodes. Thirteen of these anodes were delivered to RMC for testing in the pilot cell. "Of these 13, 12 were actually tested. As indicated in Section 4.2, Anode BI broke before it was inserted in the cell. The analyses of these 12 anodes are discussed in this section. The analyses of the anodes are

grouped into three sections. Section 5.1 addresses the overall appearance of the anodes and how this appearance changed upon testing. In addition, the results of measurements of anode dimensions before and after testing are given. In Section 5.2, the compositional and microstructural changes that occurred as a result of testing are discussed. Section 5.3 presents the results of physical and mechanical properties testing of the anodes.

\subsection{APPEARANCE AND DIMENSIONAL CHANGES \\ 5.1.1 Appearance Changes}

Figures 5.1 through 5.12 show the 12 cermet anodes that were tested in the pilot'cell after they were removed from the cell. Each figure contains a photograph of the exterior of one of the anodes, and two photographs (at different magnifications) of the cross section of the same anode. Each figure is denoted by the name of the anode displayed, its position, and the time it was in the pilot cell. Test conditions were "normal" unless noted. Only three anodes were exposed to conditions of low alumina concentration and higher current density (Section 4.3): Anodes C2, E1, and E2.

As shown in Figures 5.1 through 5.12, the anodes were severely cracked. All of the anodes showed cracking to varying extents. Most of the cracks transected or appeared to originate from the connector rod region, suggesting that a design to reduce thermal expansion mismatch between the connector rod and the cermet may have made the anodes somewhat more durable. Although, as indicated in Section 5.3, it is doubtful that this strategy would have completely eliminated the cracking problem because of the high thermal shock sensitivity of the material. In some instances, large pieces of the anodes 


\section{Anode A1 Position A $193 \mathrm{~h}$ ( 8.0 days)}
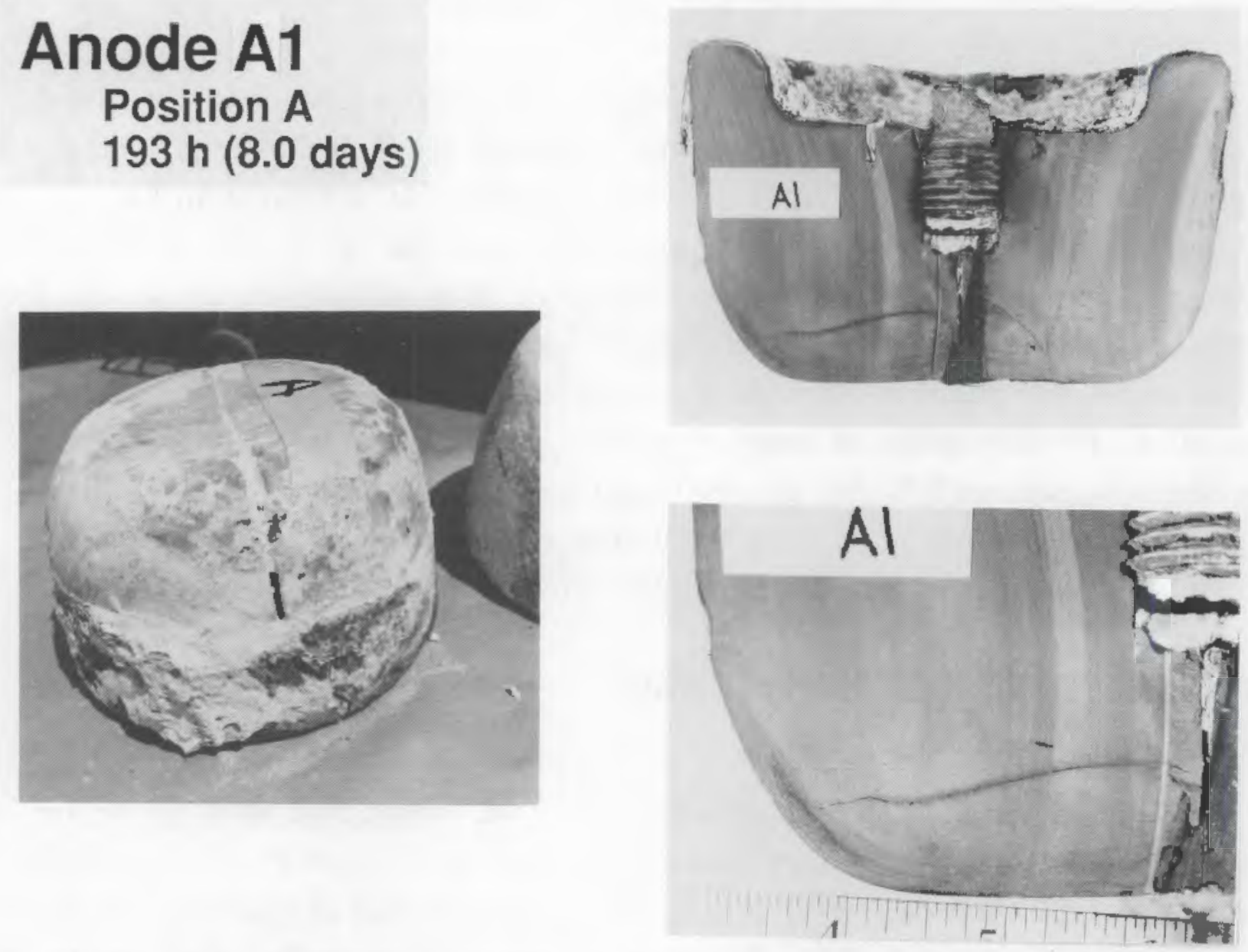

FIGURE 5.1. Photographs of Exterior and Interior of Anode Al after Testing in the Pilot Cell

actually broke off and only parts of the cross sections could be shown in the figures. In only one case (Anode C1) was a piece lost in the bath and never recovered.

In general, those anodes tested for longer times showed more wear than those tested for shorter times. One of the most obvious and consistent changes occurring in the anodes was the growth of reaction layer where there was contact with the electrolyte. The layer appears to be thicker for anodes tested at longer times. Anodes C2, E1, and E2, which were tested under conditions of low alumina concentration and higher current density, showed the most corrosion. These three anodes exhibited very thick reaction product layers 


\section{Anode E2 \\ Position A $260 \mathrm{~h}$ (10.8 days) High Current / Low Alumina (EOT)}
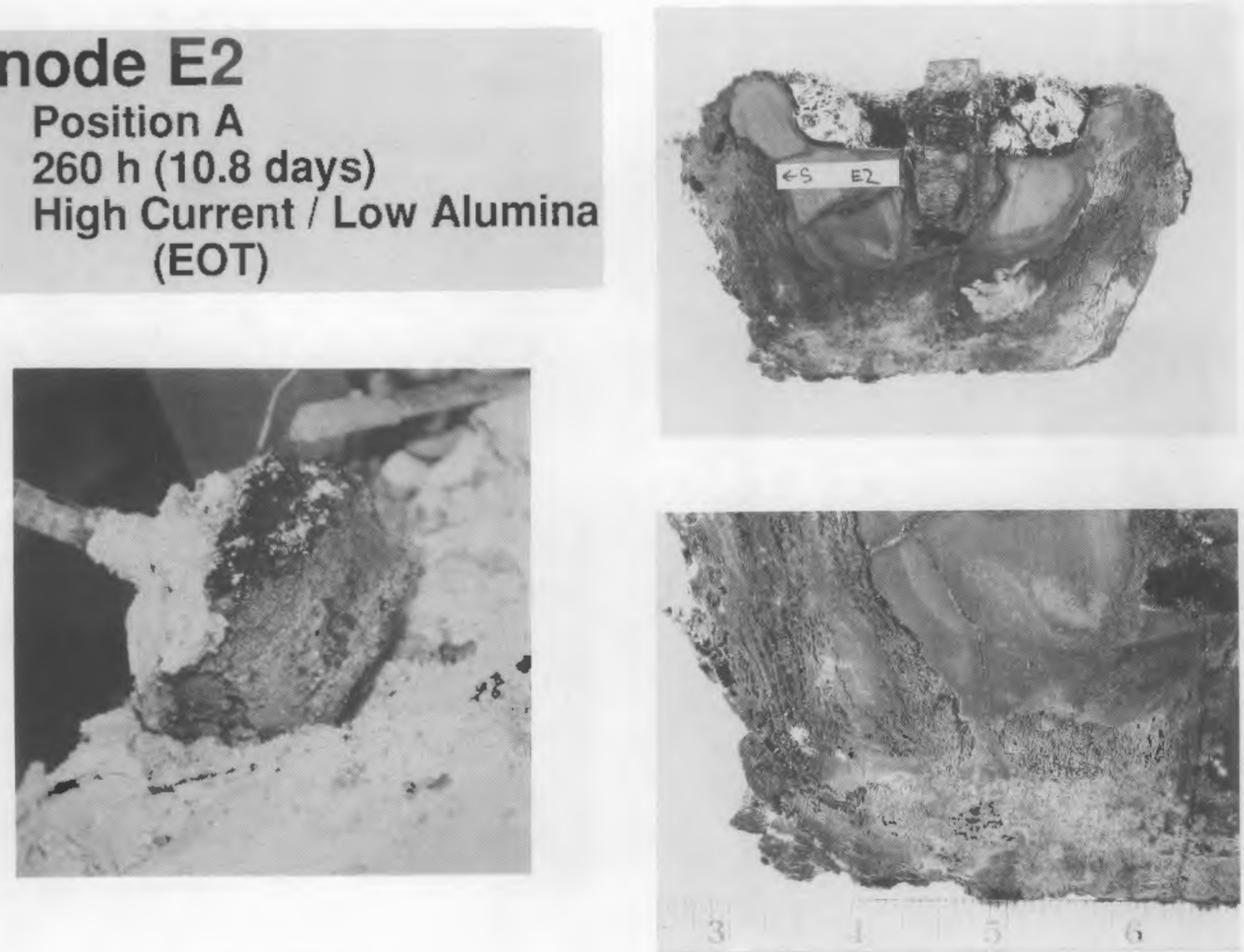

FIGURE 5.2. Photographs of Exterior and Interior of Anode E2 after Testing in the Pilot Cell

along with generally gross and very irregular wear. In contrast, anodes tested under normal conditions did not appear to change much dimensionally (their original shape was essentially preserved), except for the growth of the reaction layer. In some cases, the wear on the anodes appears to be slightly irregular. Anode Auxl, for example, shows a "kink" in the surface exposed to the bath in the region near a crack (lower right side of cross section). Other than around cracks, the anodes may also have corroded more at surfaces oriented in a particular way during testing. For example, Anode E2 appears to have corroded more on the "north" side, which was oriented toward a cell sidewall. This would suggest the higher current associated with that orientation 


\section{Anode Aux 2 \\ Position B \\ $181 \mathrm{~h}$ (7.5 days)}
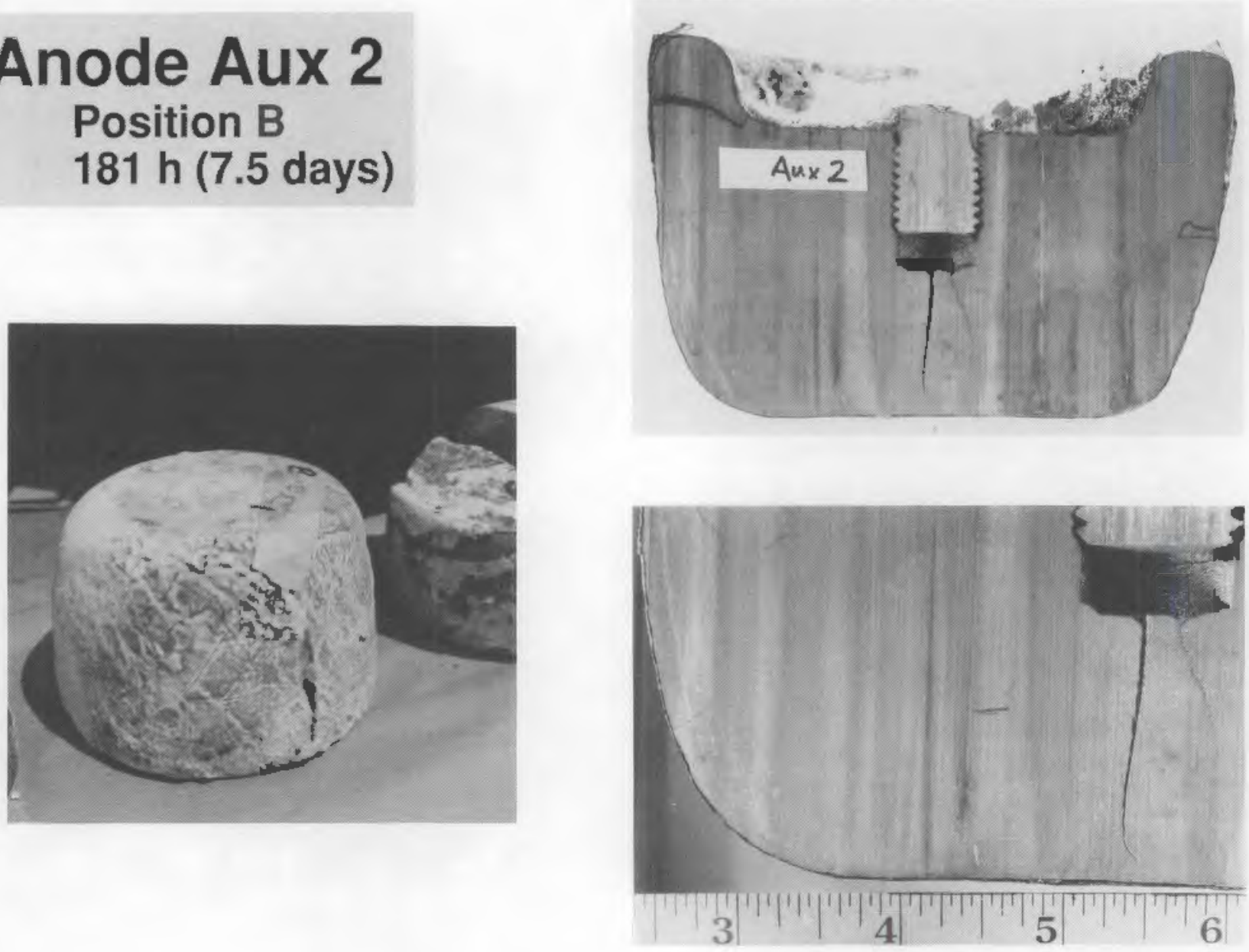

FIGURE 5.3. Photographs of Exterior and Interior of Anode Aux2 after Testing in the Pilot Cell

(Section 4.3) induced higher corrosion rates. The result would also be consistent with higher current density being part of the cause for the increased corrosion of Anodes C2, E1, and E2. Unfortunately, orientation effects such as these could not be sufficiently substantiated by comparison with other anodes. In most instances, the anodes broke from their stems at some time during the test so that the original orientation (marked on the connector rod in each case) was lost. In general, those anodes whose orientation was preserved (marked as compass directions in Figures 5.1 through 5.12) were tested under less than optimal conditions (short time, or not under "normal" conditions) or the effects were too small to make strongly defensible conclusions regarding orientation effects on anode corrosion. 


\section{Anode A2 \\ Position B $182 \mathrm{~h}$ (7.6 days)}
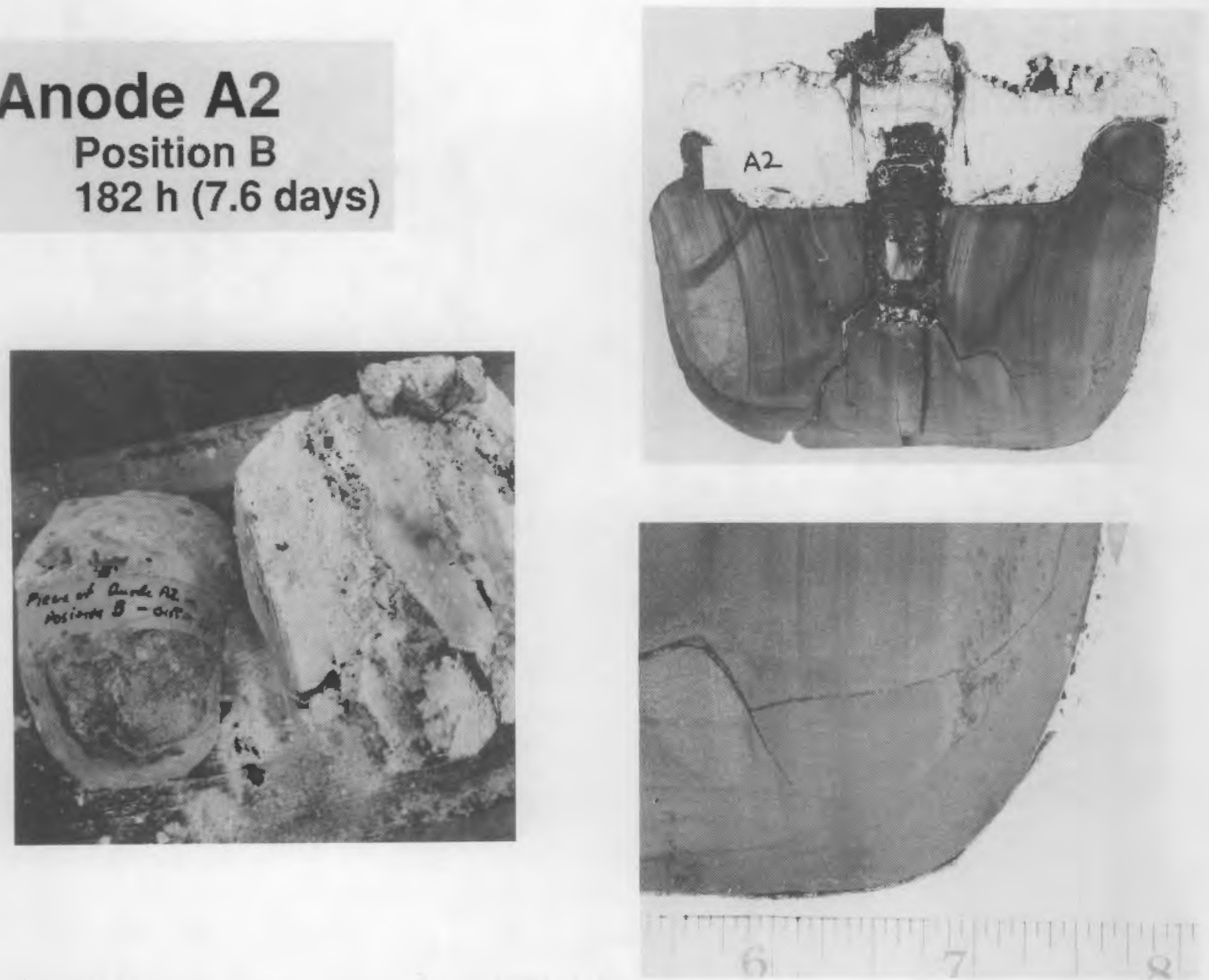

FIGURE 5.4. Photographs of Exterior and Interior of Anode A2 after Testing in the Pilot Cell

The anodes tested for the longest time under "normal" conditions were Anodes Aux1 (13.0 days) and F1 (13.1 days). Anode F1 is the focus of the bulk of the microstructure and compositional studies in Section 5.2. As shown in Figures 5.9 and 5.11 , these anodes exhibited cracks similar to those in the other anodes, no drastic changes in overall shape, and the presence of a reaction layer of significant thickness.

The regions of the cermet anodes above the electrolyte level (about 1.5 inches from the bottom surfaces) showed significantly less corrosion than 


\section{Anode C1 \\ Position C \\ $191 \mathrm{~h}$ (8.0 days)}
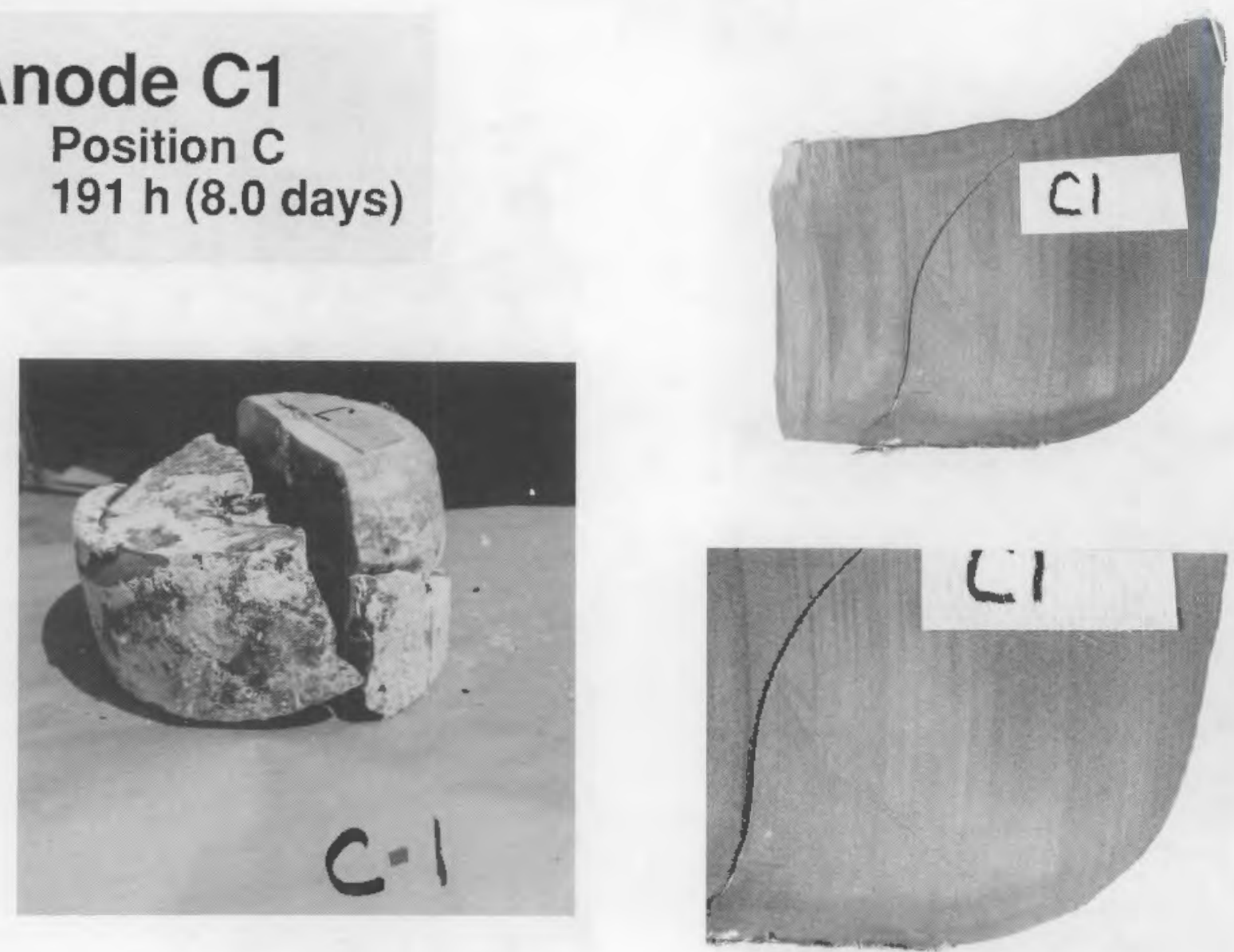

FIGURE 5.5. Photographs of Exterior and Interior of Anode $\mathrm{Cl}$ after Testing in the Pilot Cell

similar regions on cermet anodes tested previously, in particular the prototype anode (Strachan et a1. 1990). The lips or "wings" (the l-inch extensions up from the upper edge of the anodes) of the pilot cell anodes showed very little deterioration. This can be attributed to making these lips significantly smaller than in the prototype anode design. In the prototype anode, the lips were about 5 inches high. Keeping the lips closer to the bath level, i.e. at higher temperature, lower oxygen fugacity, and also covered with powdered alumina/cryolite, significantly reduced the susceptibility of the cermet to corrosion by the vapor phase. See Section 5.2 for further discussion of this corrosion process. 


\section{Anode C2 \\ Position C \\ $260 \mathrm{~h}$ ( 10.8 days) \\ High Current / Low Alumina (EOT)}
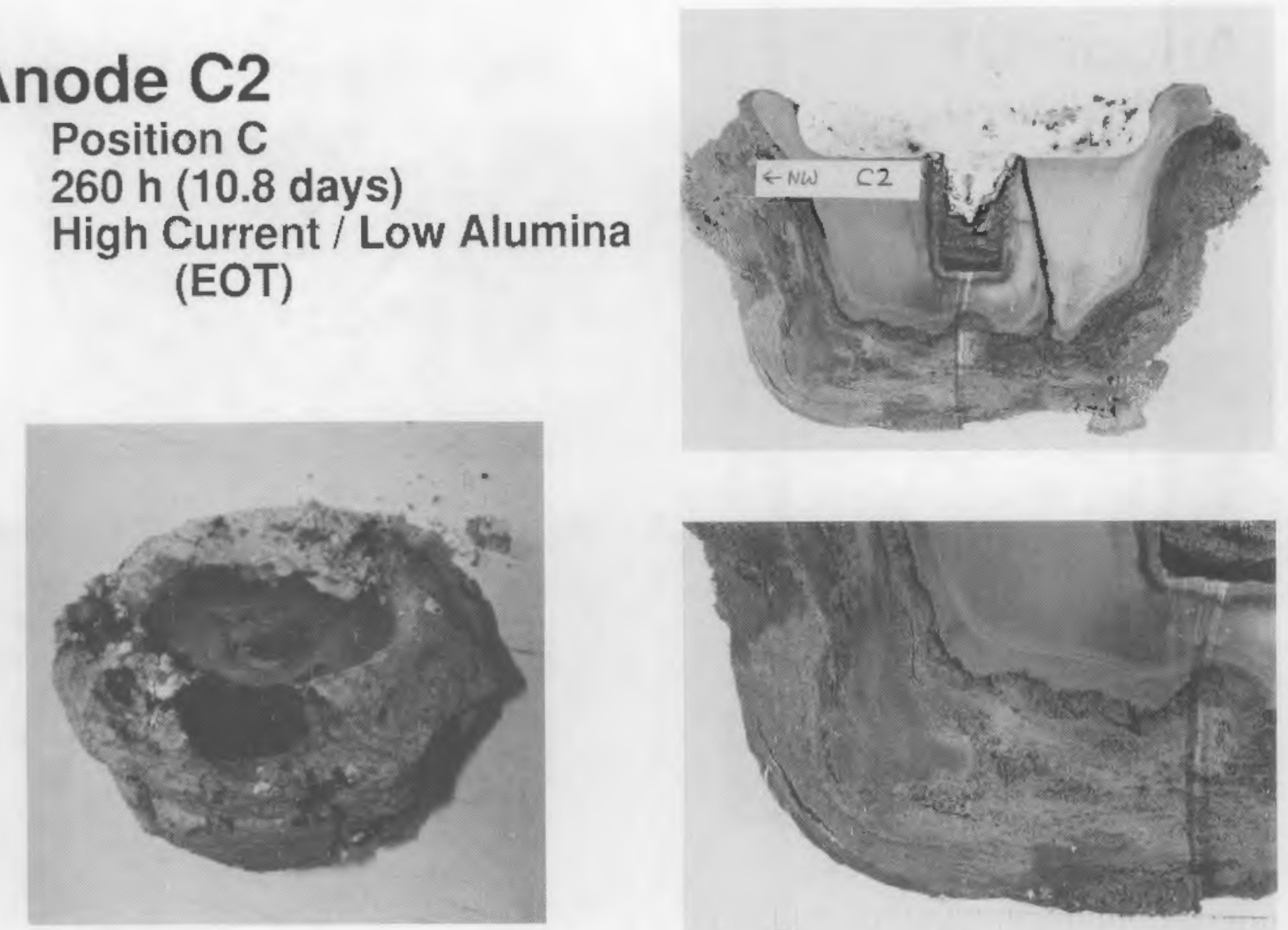

FIGURE 5.6. Photographs of Exterior and Interior of Anode C2 after Testing in the Pilot Cell

An interesting characteristic, but of perhaps less importance, in Figures 5.1 through 5.12 is the nature of the connection between the connector rod and the cermet anode. As indicated in Section 3.2, considerable effort went into developing a connection strategy that minimized thermal expansion mismatch and, at the same time, maintained good electrical continuity. Unfortunately, the approach that was used for the pilot cell anodes compromised some of these criteria in order to obtain crack-free anodes for delivery on schedule. As discussed in Section 3.2, the connector rods were threaded into the cermet anode, which had been drilled and tapped directly. To help provide a better electrical connection, in some of the anodes a mixture of metallic $\mathrm{Cu}$ 


\section{Anode D1 \\ Position D \\ $123 \mathrm{~h}$ (5.1 days)}

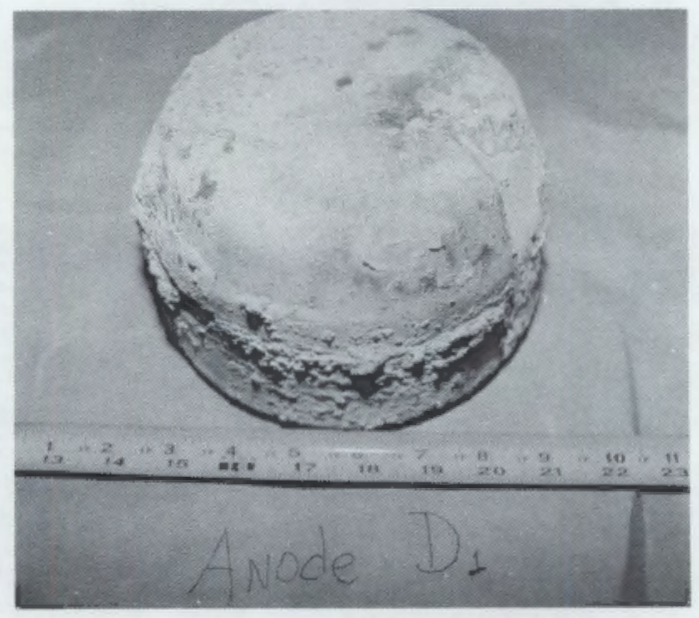

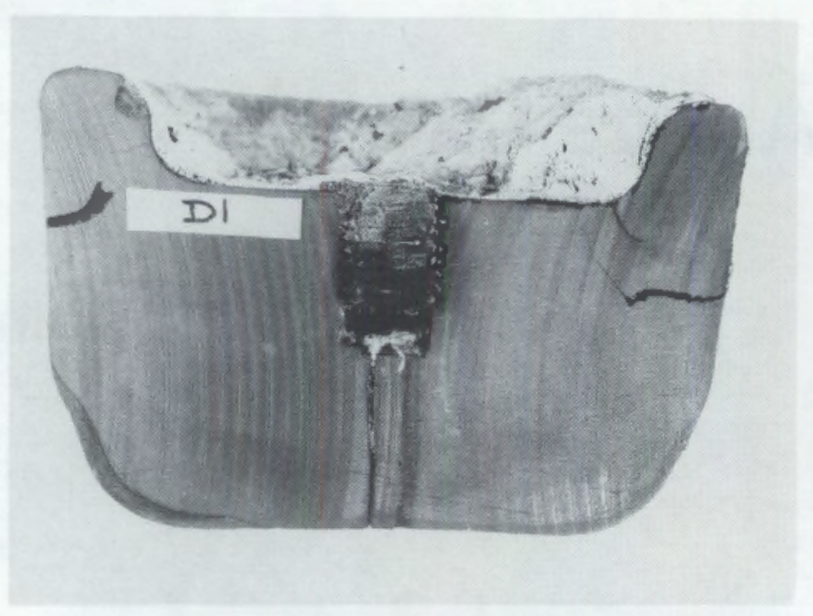

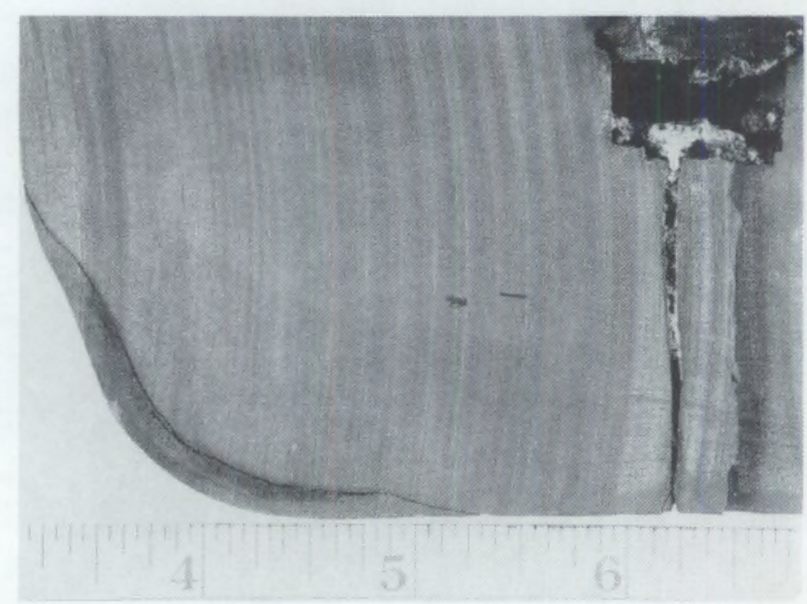

FIGURE 5.7. Photographs of Exterior and Interior of Anode Dl after Testing in the Pilot Cell

and $\mathrm{Ni}(80: 20$ as $\mathrm{Cu}: \mathrm{Ni})$ powder was poured into the threaded area as the connector rod was screwed in. It was hoped that the powder would braze during the operation of the anodes at elevated temperatures. As shown in the case of Aux1, for example, a very good connection formed as a result of the brazing. The voltage drop from the top of the anode connector rod to a point on the anode surface (one of the Pt wire connections), which includes the rod-anode connection, was measured to be about $0.1 \mathrm{~V}$ at $80 \mathrm{~A}$. This corresponds to a resistance of only about $0.001 \Omega$, suggesting that the connection was adequate and that the brazing approach was an acceptable option for jointing cermet anodes to their connector rods. The impact of the "tighter" connection on 


\section{Anode D2 \\ Position D \\ $279 \mathrm{~h}$ (11.6 days)}
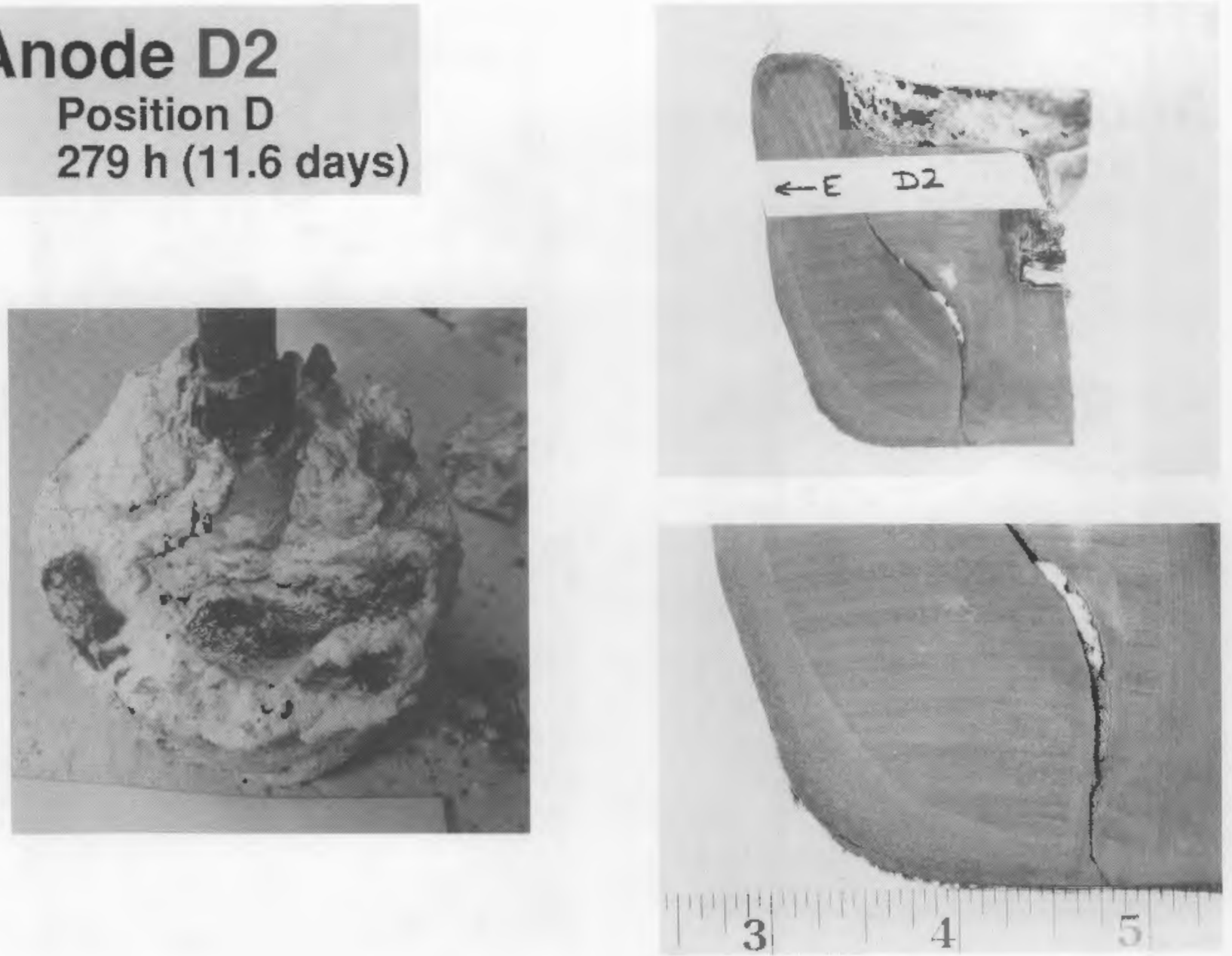

FIGURE 5.8. Photographs of Exterior and Interior of Anode D2 after Testing in the Pilot Cell

thermal expansion considerations was probably not advantageous, however, so future use of the brazing approach should be coupled with thermal shock sensitivity studies.

\subsubsection{Dimensional Changes}

Selected dimensions of the cermet anodes were measured before and after testing in the pilot cell in an attempt to quantify wear rates. The dimensions measured are shown in the schematic of an anode in Figure 5.13. Dimensions a, b, c, and $d$ were measured before and after testing. Dimension e, the thickness of the reaction layer, was measured in the center of the anode and, 


\section{Anode Aux 1 Position E $313 \mathrm{~h}$ ( 13.0 days)}
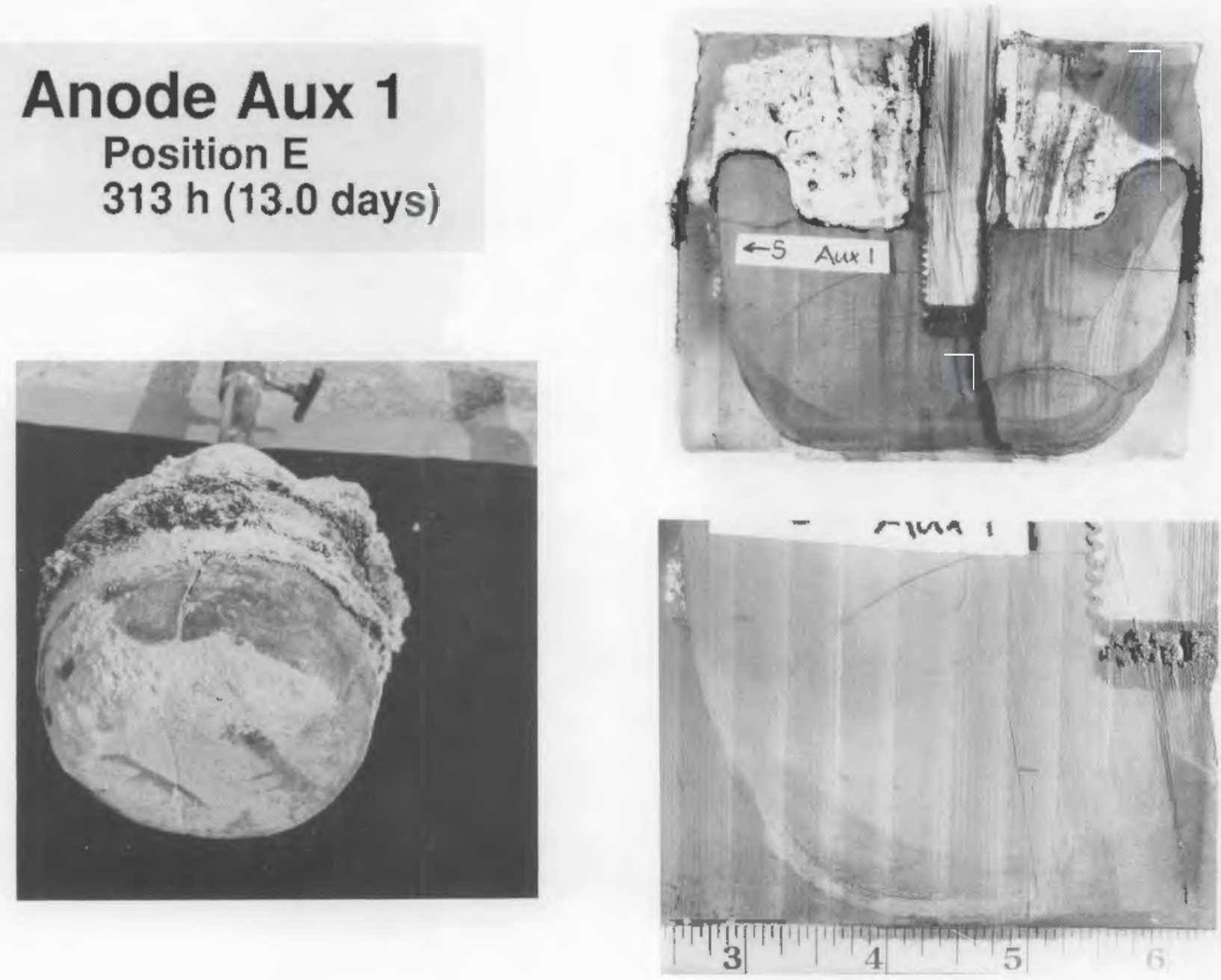

FIGURE 5.9. Photographs of Exterior and Interior of Anode Auxl after Testing in the Pilot Cell

of course, only on the anodes after testing. In all cases, three measurements were taken at different, but equivalent, locations; and these values were averaged. As would be expected from the irregular wear of the anodes (different sides corroded slightly differently), the dimensions $c$ and $d$ showed too much variation with position to be useful. Dimensions a and b contained the same information, so only the results for a are reported here. Consequently, the following discussion concerns primarily how the dimensions a and e varied as a function of test conditions. 


\section{Anode E1 \\ Position E \\ $135 \mathrm{~h}$ (5.6 days) \\ High Current / Low Alumina (EOT)}
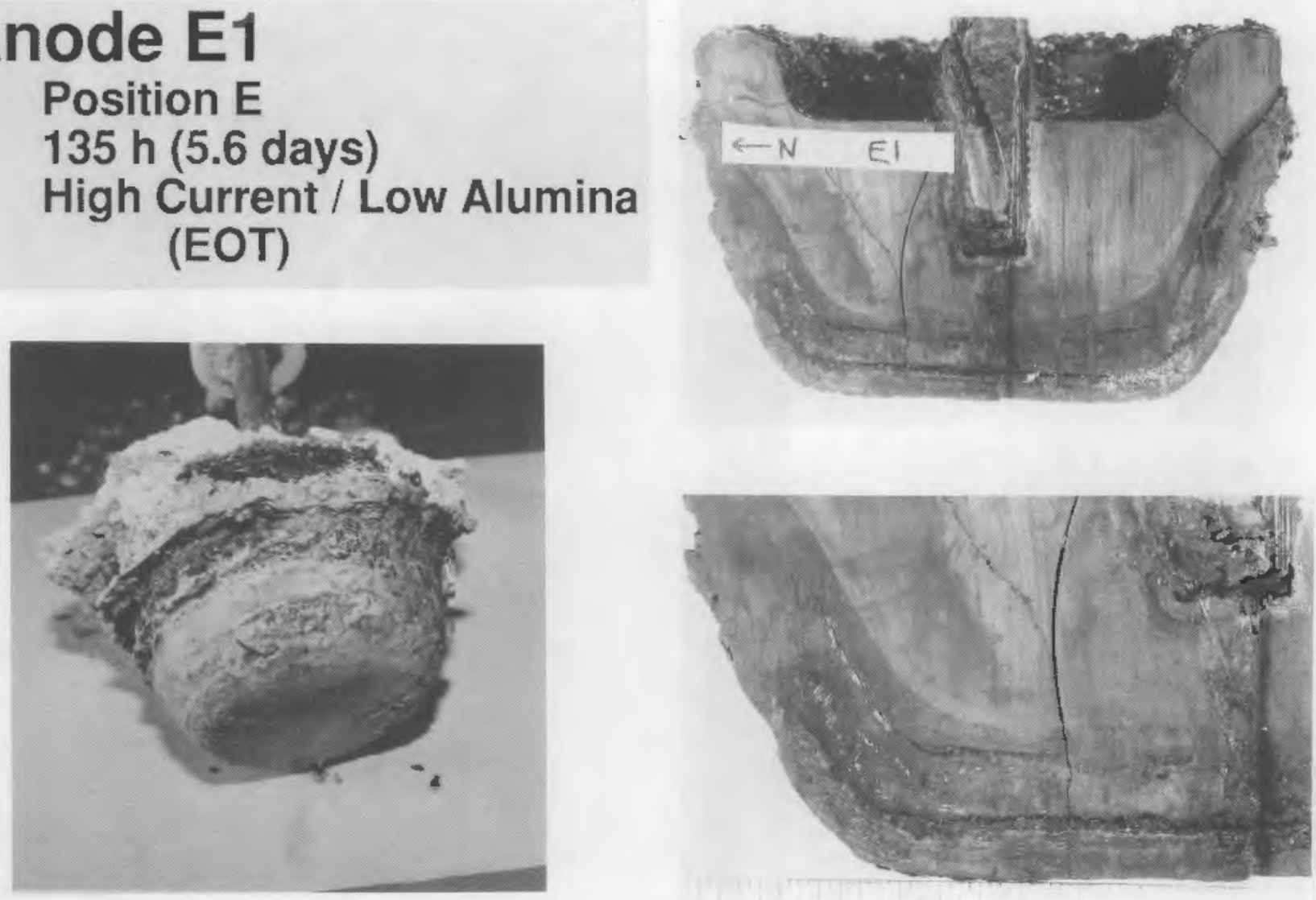

FIGURE 5.10. Photographs of Exterior and Interior of Anode El after Testing in the Pilot Cell

As shown in Figure 5.14, the "inside-height" (vertical dimension a) did not vary significantly as a function of $A \cdot h$ ("amp hours") for anodes tested under "normal" conditions. (A similar result is obtained as a function of time only.) Each point in Figure 5.14 corresponds to one of the anodes. Points for Anodes E1, E2, and C2, which were subjected to low alumina and high current density conditions, were not included. The result shown in Figure 5.14 suggests that if the current density is maintained at $\leq 0.5 \mathrm{~A} / \mathrm{cm}^{2}$ (actually, between 0.2 and 0.35 as estimated on the bottom surface, in Section 4.3), the anodes will not exhibit much dimensional loss. If "wear" is equated to dimensional changes, this result is encouraging. On the other hand, subsequent data will show that this lack of change in dimensions is 


\section{Anode F1 \\ Position F \\ $314 \mathrm{~h}$ (13.1 days)}
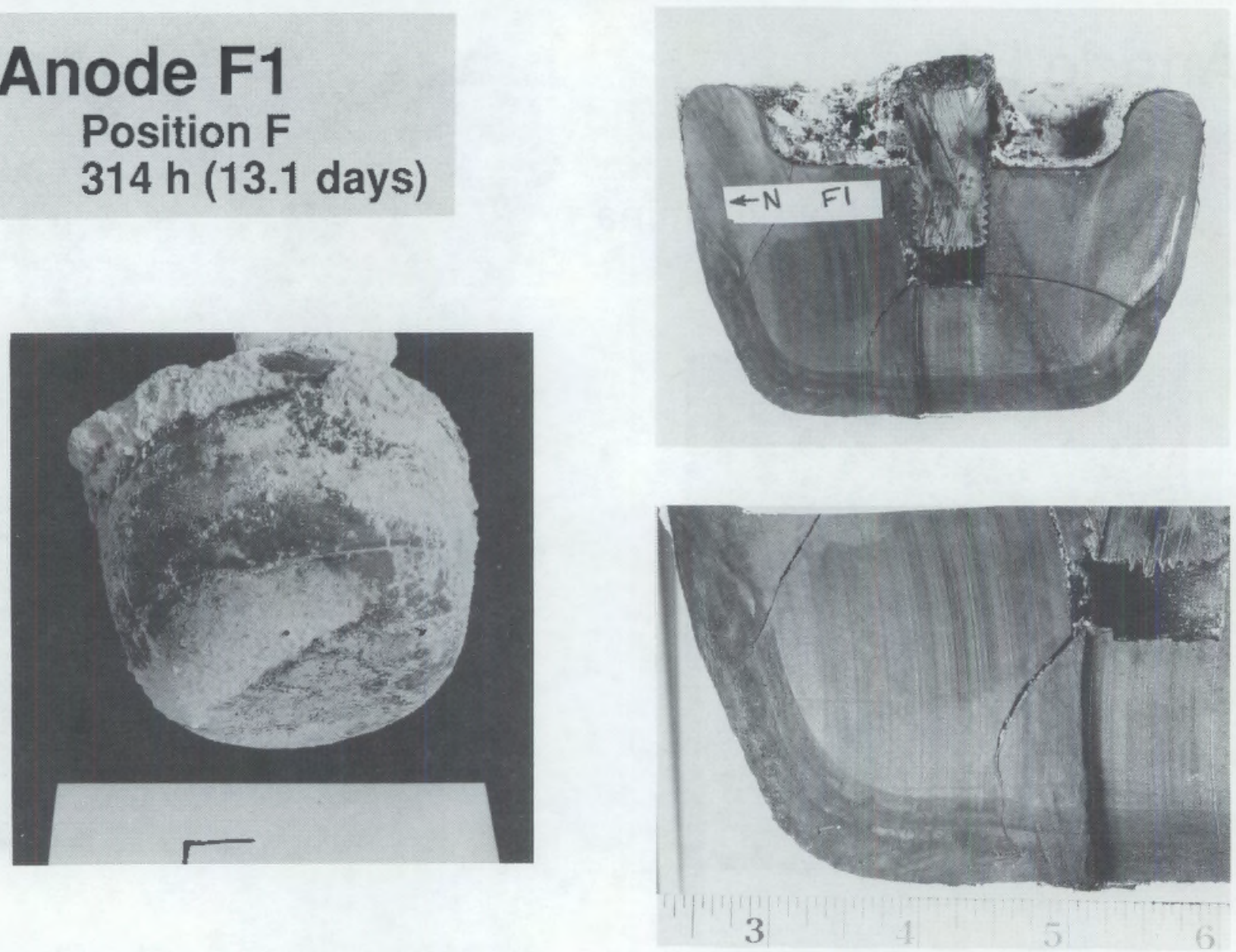

FIGURE 5.11. Photographs of Exterior and Interior of Anode F1 after Testing in the Pilot Cell

accompanied by the growth of a reaction layer of significant thickness. The reaction layer apparently occupies the same volume as the unreacted material, so no significant dimensional change occurs. The significance of the reaction layer and its impact on anode performance are discussed below.

The thickness of the reaction layer (measurement e, Figure 5.13) is plotted in Figure 5.15 versus $A \cdot h$ for all of the pilot cell anodes. Similar plots of e versus current or time alone showed less meaningful trends. The data appear to group themselves into two regions. The anodes tested under conditions of low alumina and higher current densities gave significantly higher reaction layer thickness (boxed area) than anodes tested under "normal" conditions. For anodes treated under "normal" conditions, the reaction layer 


\section{Anode F2 \\ Position F \\ $96 \mathrm{~h}$ (4.0 days)}
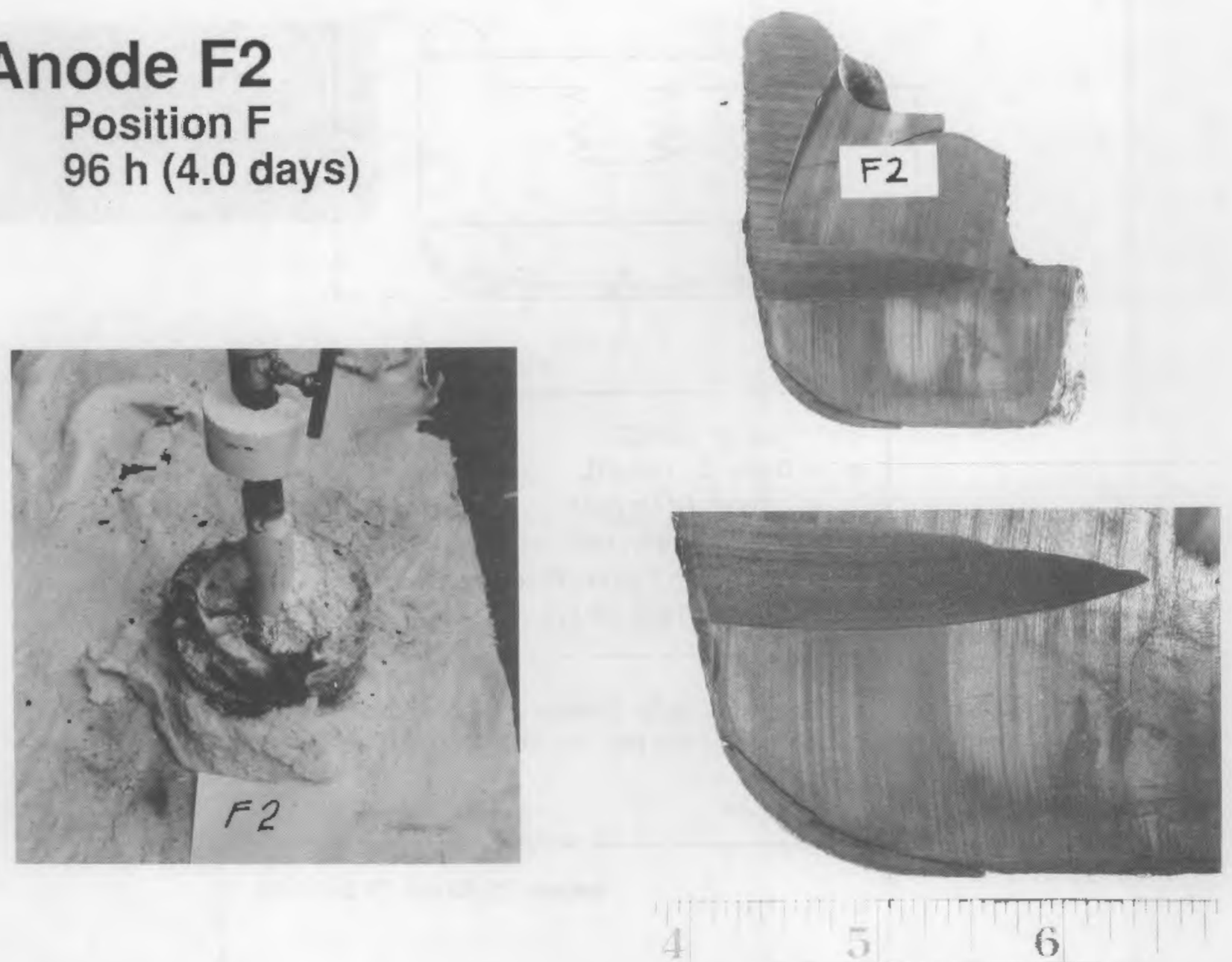

FIGURE 5.12. Photographs of Exterior and Interior of Anode F2 after Testing in the Pilot Cell

thickness was about $13 \mathrm{~mm}$ after 13.1 days of testing (Anode $\mathrm{F} 1$ ); thicknesses for anodes treated under the more severe conditions were over 1 inch at much shorter times. The thicknesses of the reaction layers on the anodes treated under "normal" conditions appear to follow a roughly linear trend with A.h as shown in Figure 5.15 and in the detail in Figure 5.16. The trend is not exact, and estimated uncertainties fall short of explaining all the variances; however, given the varying conditions in the pilot cell test it is likely that even these uncertainties were underestimated. Thus, the linear approximation is not completely unfounded. Moreover, the single result from the prototype 


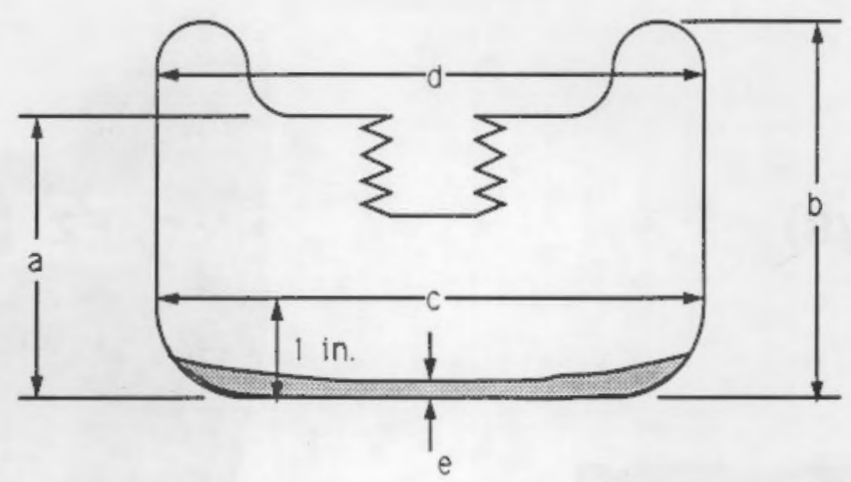

$$
\begin{aligned}
a= & \text { Inside Height } \\
b= & \text { Outside Height } \\
c= & \text { Lower Diameter } \\
d= & \text { Upper Diameter } \\
e= & \text { Reaction Layer Thickness } \\
& \text { (After Test Only) }
\end{aligned}
$$

FIGURE 5.13. Schematic of Cermet Anode Showing Dimension That Were Measured Before and/or After Testing in the Pilot Cell

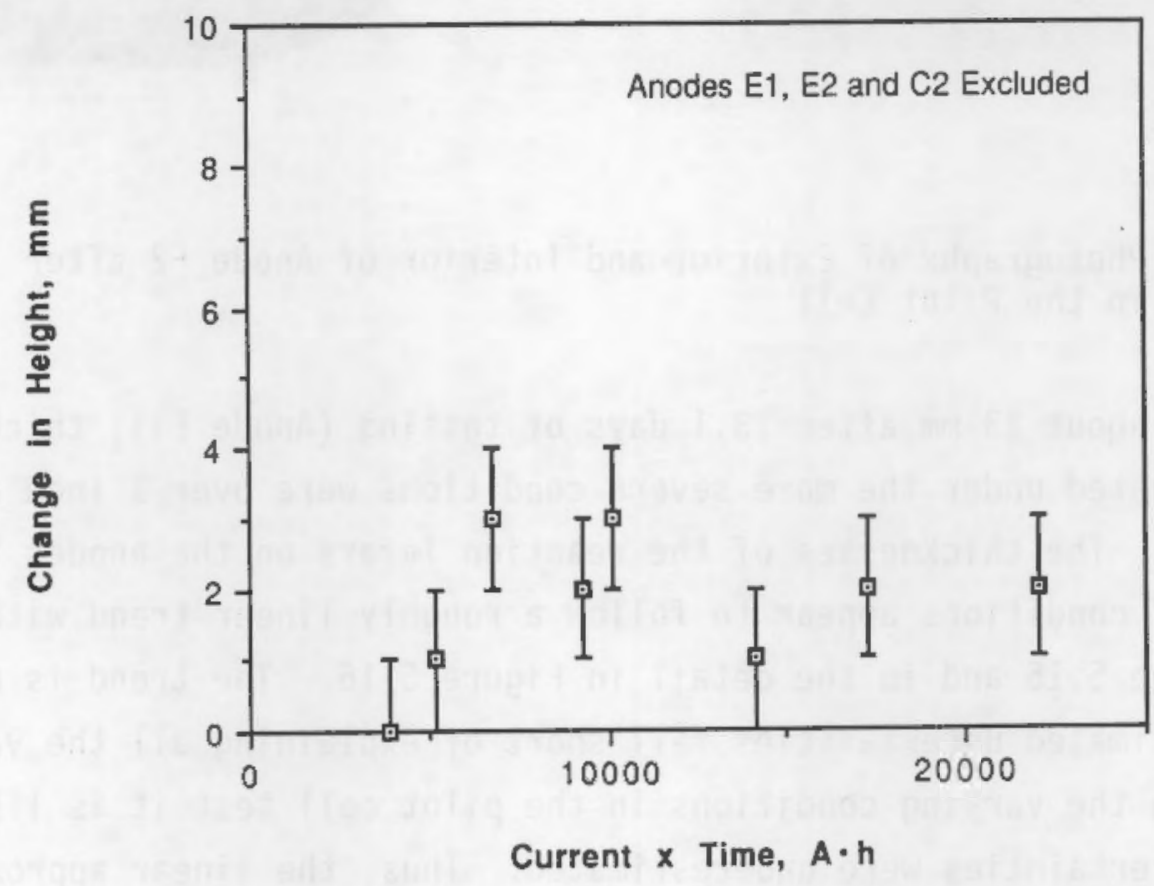

FIGURE 5.14. Variation of Change in Inside Height Dimension with $A \cdot h$ for Cermet Anode during the Pilot Cell Test 


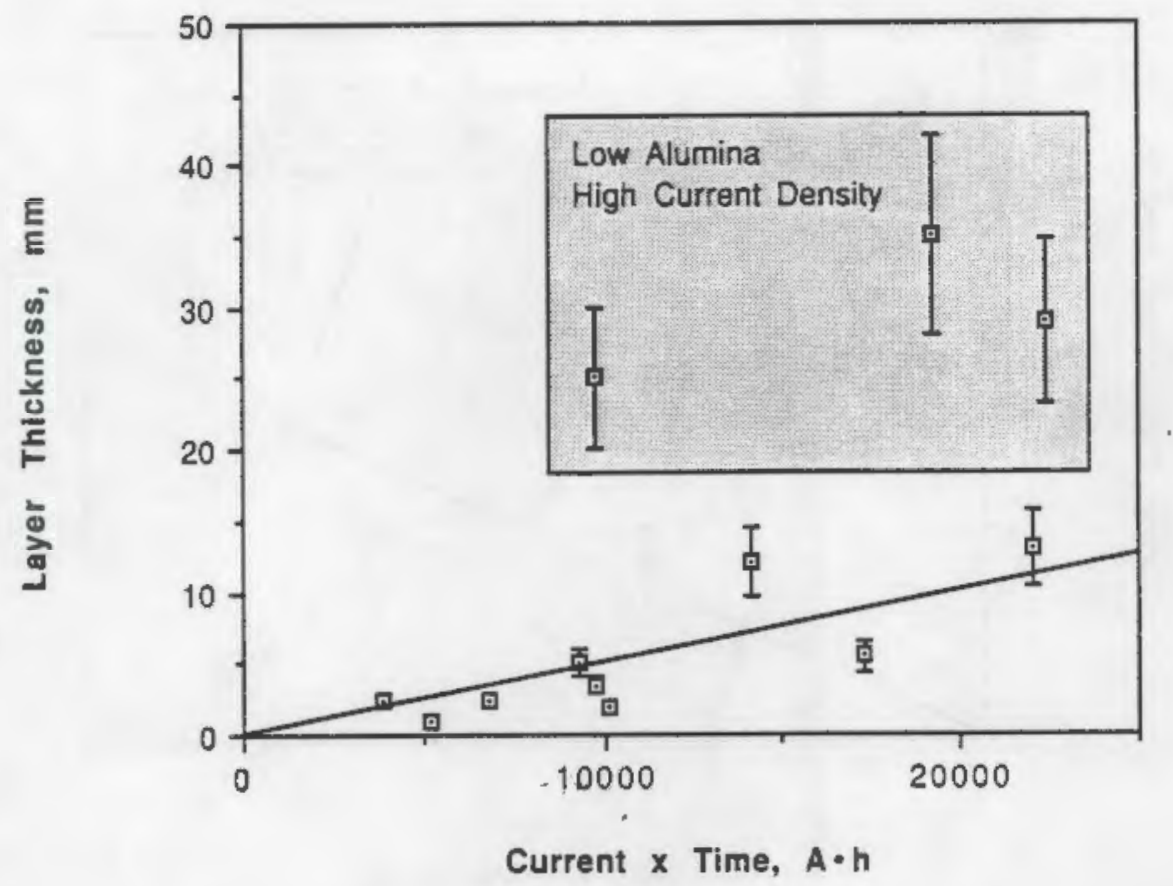

FIGURE 5.15. Variation of Reaction Layer Thickness with A.h for Cermet Anodes during the Pilot Cell Test

anode test falls surprisingly close to the linear plot. The prototype anode had dimensions similar to the pilot cell anodes but was tested at $120 \mathrm{~A}$ instead of $90 \mathrm{~A}$ (Strachan et al. 1990).

A linear fit to these data (pinned to the origin to give no layer at the start of the test) gives a slope or layer growth rate equal to $5 \times 10^{-4} \mathrm{~mm} / \mathrm{A} \cdot \mathrm{h}$, or $0.8 \mathrm{~mm} /$ day for $70 \mathrm{~A}$ of current. Recognizing that this rate is appropriate for only those current densities close to the actual value at the bottom surface of these anodes $\left(0.2\right.$ to $0.35 \mathrm{~A} / \mathrm{cm}^{2}$ from the calculations in Section 4.3) and assuming linearity, this growth rate gives an extrapolated annual rate of $31 \mathrm{~cm} / \mathrm{yr}$ for a pilot cell-style anode operating at $70 \mathrm{~A}$.

Clearly, this rate is unacceptable since it corresponds to over four times the height of the anode. Even if the properties of the reaction layer were not that detrimental, it would appear that this large an extent of a materials transformation would be undesirable especially for metal purity. of course, the extrapolation relies on the assumption of linearity for up to a year's time. 


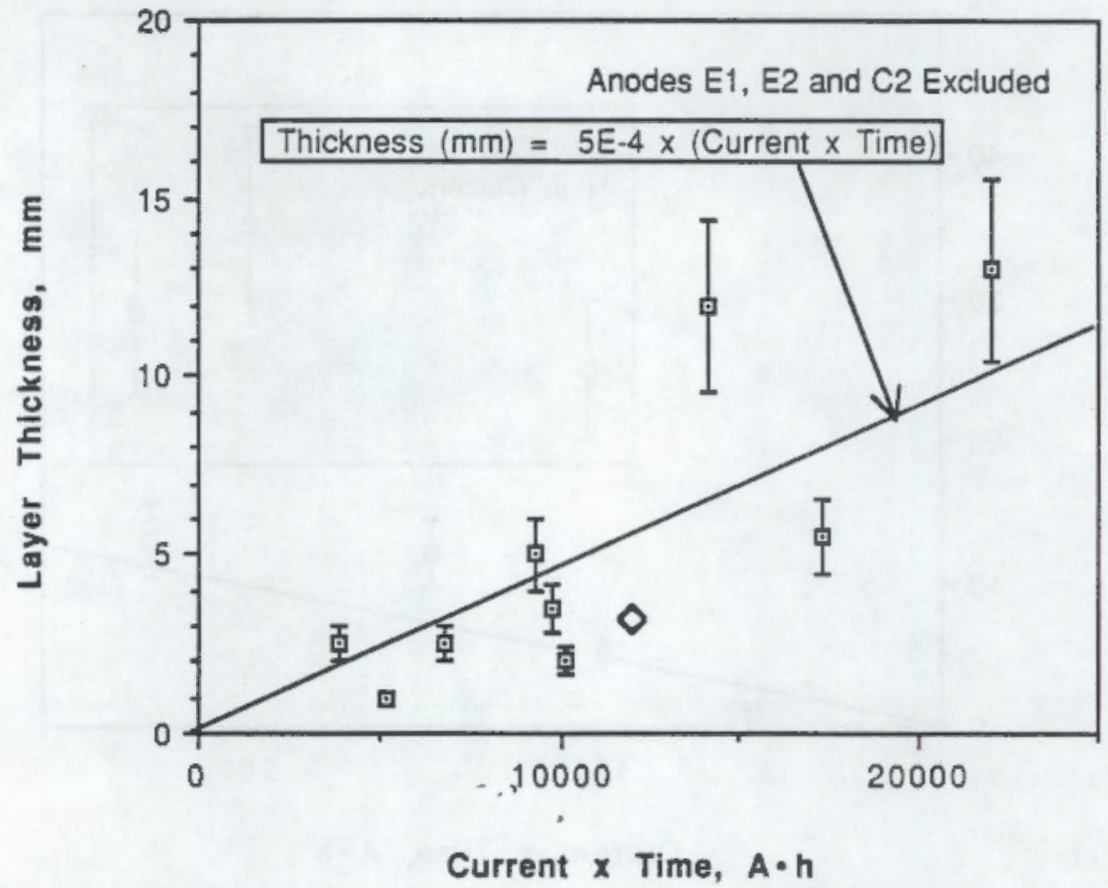

FIGURE 5.16. Variation of Reaction Layer Thickness with A.h for Cermet Anodes during the Pilot Cell Test (Detailed Plot). Data Point ( $(0)$ from the Prototype Anode Test is Also Shown.

If the rate of layer growth does, instead, decrease over some time greater than the tested 13.1 days, the thickness of the layer may reach some sort of steady-state value. Consequently, it is of interest to determine the properties of this layer, especially its electrical conductivity. If the conductivity is acceptable, a layer of some small finite thickness might be tolerated. Other properties of the layer, including its morphology and composition are discussed in Section 5.2. Assuming the reaction layer growth rate of $5 \times 10^{-4} \mathrm{~mm} /(A \cdot h)$, the thickness of the reaction layer on Anode $F 1$ on August 13 is estimated to be $2.9 \mathrm{~mm}$. This value was calculated by using the average current $(80 \mathrm{~A})$ on the anode up to this date, the third day the anode was in service. On August 13, voltage probe measurements were made that provide some indication of the conductivity of the reaction layer. The voltage drop between the top of the connector rod for Anode Fl to a point in the electrolyte right below the bottom surface of the anode was $2.4 \mathrm{~V}$. Correcting this value for the BEMF $(2.2 \mathrm{~V})$ and the voltage drop through the anode, rod, and connection $(0.1 \mathrm{~V}$ total) gives a voltage drop through the reaction layer 
of about $0.1 \mathrm{~V}$. Since the layer was $0.29 \mathrm{~cm}$ thick at the time the measurement was taken and the current density on the bottom surface was calculated to be $0.2 \mathrm{~A} / \mathrm{cm}^{2}$ (Section 4.3 ), this gives a conductivity for the reaction layer equal to $0.58 \mathrm{~s} / \mathrm{cm}$. It is interesting that the conductivity of the cermet oxide material (without metal phase) is close to this value or about $0.5 \mathrm{~S} / \mathrm{cm}$ (Weyand et a1. 1986). This is consistent with the reaction layer having "lost" its metal phase, a result that will be discussed in Section 5.2 . Recognizing that significant approximations were made in determining this conductivity, both experimentally and in the equations used, it nevertheless sug-

gests that the voltage drop across a relatively thin reaction layer may not be significant. Consequently, if it can be shown that this layer does not get extraordinarily large (which, unfortunately, was not demonstrated in this work), its effect on performance may be negligible. On the other hand, a layer that grows linearly without arrest, as suggested by the data up to 13.1 days, would impart a serious contribution to the voltage drop of the cell.

\subsection{MICROSTRUCTURAL AND COMPOSITIONAL CHANGES}

The following sections on the microstructural and compositional analysis of the pilot cell anodes are focused on Anode Fl, which was the anode tested for the longest time under "normal" operating conditions. Anode Fl was tested for $314 \mathrm{~h}$ ( 13.1 days) at an average current of $70 \mathrm{~A}$. The anode was located in position F. A complete history of the current through this anode and alumina concentration during its operation are given in Figures 4.25 and 4.14 , respectively. A description of the core sections removed from Anode Fl for microscopic analysis is given in the first of the following sections. This description is followed by the results of optical microscopy, scanning electron microscopy (SEM), and energy dispersive $x$-ray spectroscopy (EDS) analyses on pieces of these core sections. Results of $x$-ray diffraction (XRD) and wet laboratory analyses are also reported.

\subsubsection{Description of Core Sections}

Three cylindrical ( $1-\mathrm{cm}$ diameter) core sections were removed from Anode $\mathrm{Fl}$ as shown in Figure 5.17. Two of the core sections were taken vertically from equivalent parts of the center region of the anode. These sections 
CORE SECTIONS

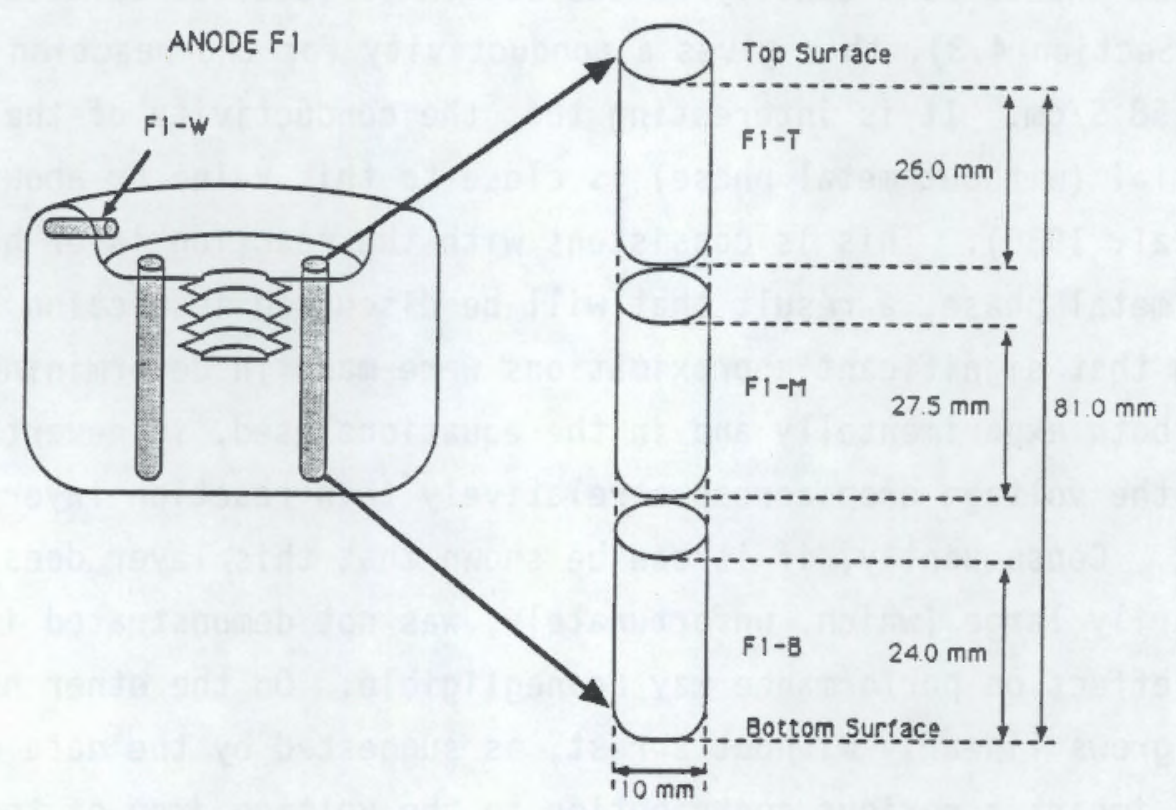

FIGURE 5.17. Schematic Showing Core Sections Removed from Cermet Anodes for Analysis

were each divided into three approximately 1 -inch tall pieces to facilitate the microscopic analysis. Both of the core sections encompassed regions 1) at . the bottom surface of the anode which was exposed to the electrolyte and carried current at approximately $0.2 \mathrm{~A} / \mathrm{cm}^{2}$ based on the analyses reported in Section $4.3,2$ ) in the interior of the anode, and 3) at the top surface of the anode where it was contacted by vapors and the solid overlayer. One of the two vertical core sections was subjected to extensive microscopic and EDS analysis; the other was used for XRD and wet lab analysis. The three pieces of the vertical cores were labelled Fl-B (bottom piece), Fl-M (middle piece), and F1-T (top piece). The remaining core section, labelled F1-W, was removed from the "wing" or "lip" portion of the anode. One side of this core section was oriented toward the "outside" region of the anode; the other side was oriented toward the "inside" or facing the connector rod.

\subsubsection{Optical Microscopy of Core Sections: Overall Perspective}

Figures 5.18 through 5.21 are "macros" (10w magnification optical images) of each of the pieces of one of the vertical core sections and the 


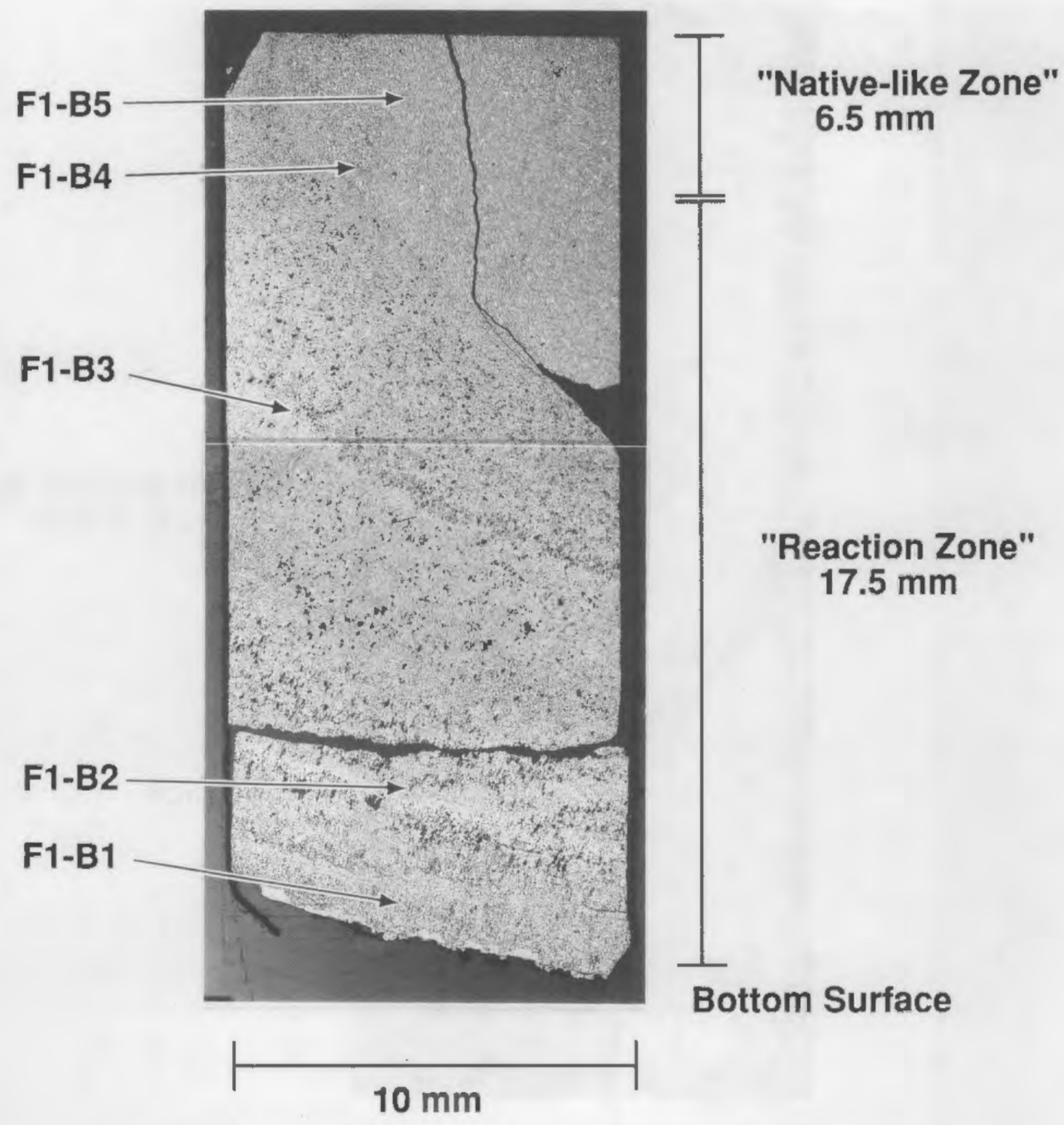

FIGURE 5.18. Low Magnification Photograph of F1-B 


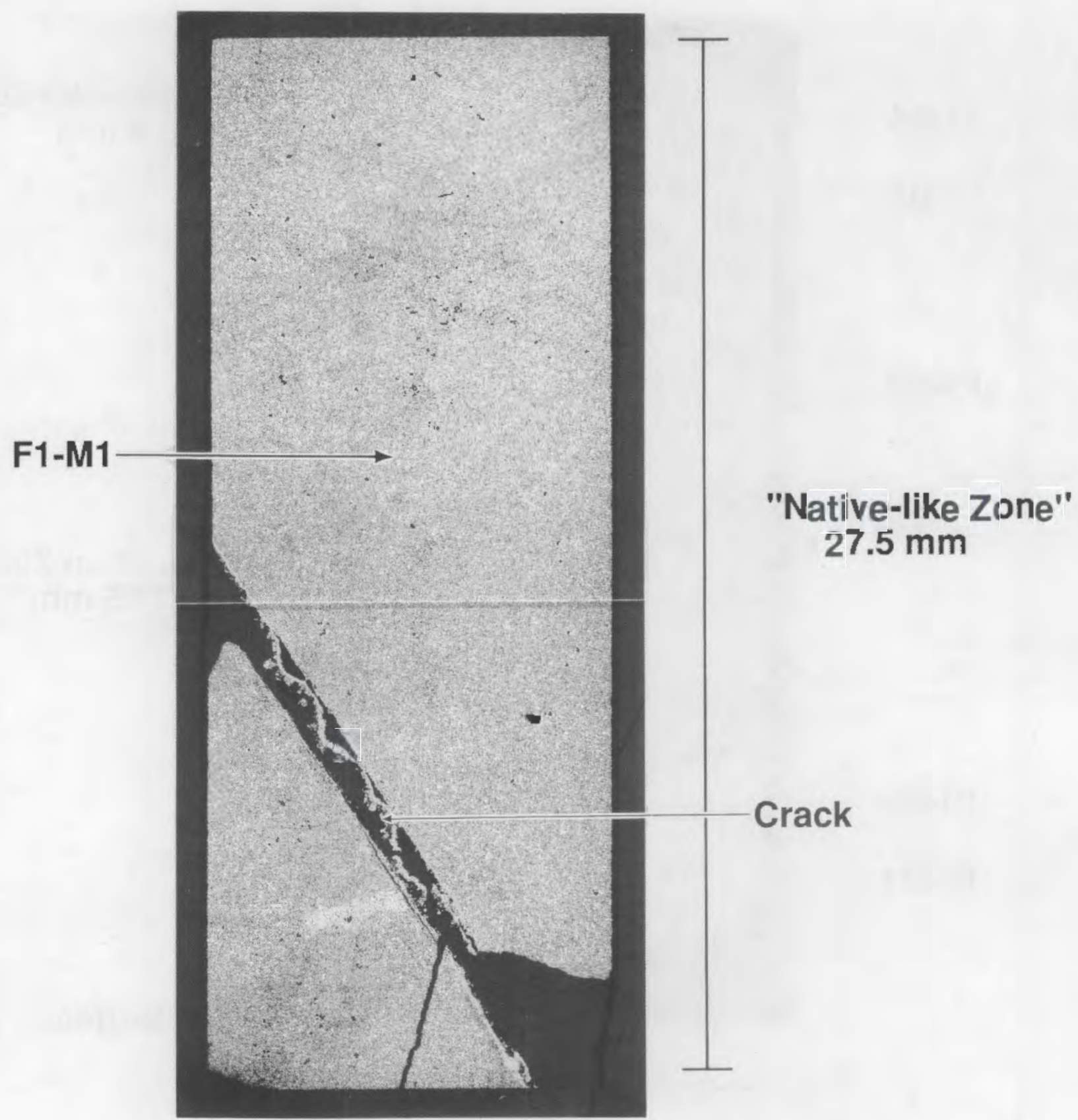

FIGURE 5.19. Low Magnification Photograph of F-1M 


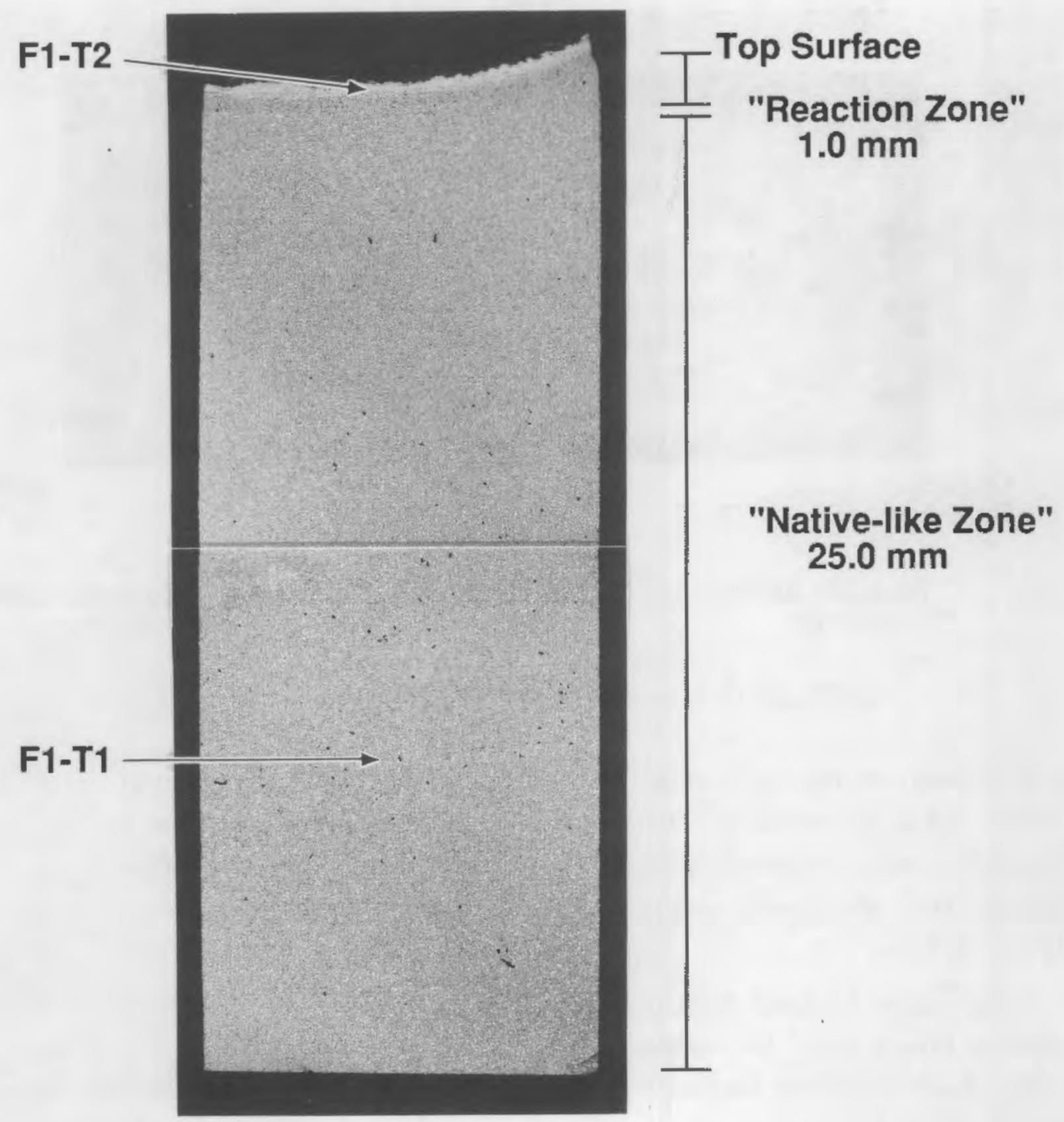

FIGURE 5.20. Low Magnification Photograph of Fl-T 


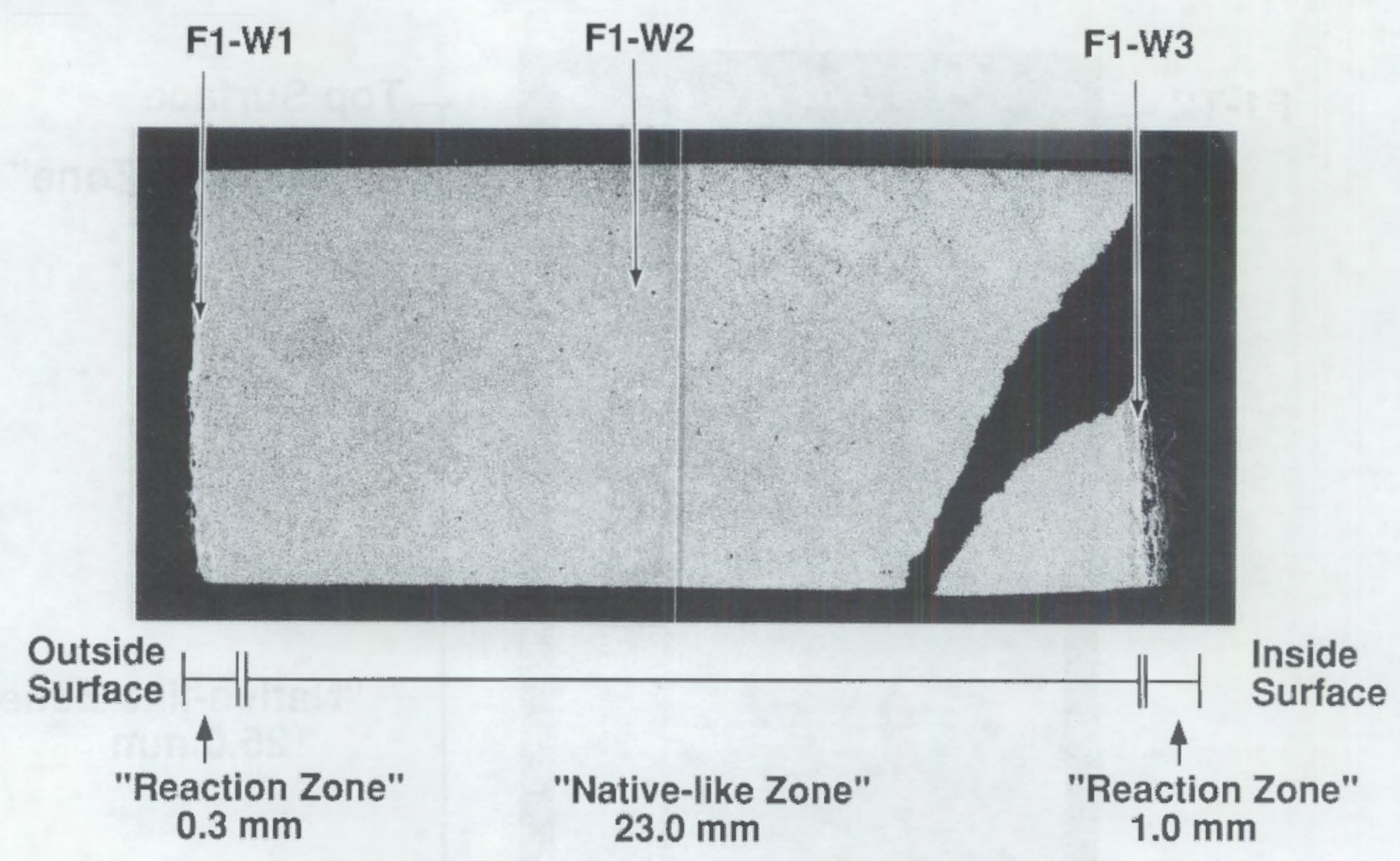

FIGURE 5.21. Low Magnification Photograph of F1-W

wing section. Each figure shows the optical image, some indication of orientation, and a set of designations (e.g. F1-B1) that indicate regions of the pieces that were interrogated with higher magnification optical microscopy, SEM, and EDS. These more detailed analyses are discussed in Sections 5.2.3 through 5.2.5.

The sample F1-B was from the bottom of the vertical core section. As shown in Figure 5.18, the sample contained essentially all of the "reaction layer" whose thickness variations were quantified in Section 5.1.2. The reaction layer in this region of the anode had an average thickness of about $17.5 \mathrm{~mm}$. The thickness varied somewhat in this region because it was near the beginning of the curvature of the bottom of the anode. As shown in the figure, the reaction layer is very complicated in structure. It is composed of many sublayers. Analyses using XRD and EDS indicated that the reaction layer was essentially devoid of metallic phase and the many sublayers were varied in 
composition (Sections 5.2.3 through 5.2.5). Above the reaction layer in Fl-B, the microstructure appears similar to the original or "native" microstruc-

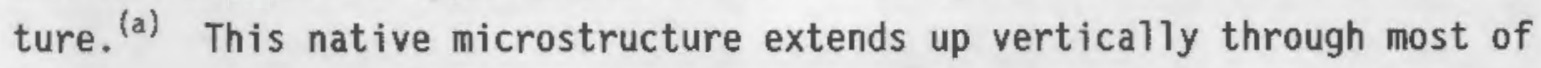
the core section, as shown in the micrographs for F1-M and Fl-T in Figures 5.19 and 5.20 , respectively. As shown in Figure 5.20, at the very top of the vertical cross section (surface exposed to the vapor phase and solid overlayer), another, albeit much thinner, reaction layer is apparent. This layer was about $1.0 \mathrm{~mm}$ thick and is also devoid of metallic phase.

The core section from the wing region of the anode, labelled Fl-W, is shown in Figure 5.21. This section exhibited largely native microstructure with very thin reaction layers on the outside $(0.3 \mathrm{~mm})$ and inside $(1.0 \mathrm{~mm})$ surfaces. Analysis showed that these reaction layers, similar to those at the other surfaces, contained very little metallic phase.

\subsubsection{Reactions at the Bottom of the Anode}

In this section the detailed results from the analyses of sample F1-B are given. As shown in Figures 5.22 through 5.25, the elemental dot maps for $\mathrm{Cu}, \mathrm{Fe}, \mathrm{Ni}$, and $\mathrm{Al}$, respectively, reveal significant compositional changes in this part of the anode and help identify some of the phases in the reaction layer that are apparent in the SEM backscattering image adjacent to each dot map. Figure 5.22 shows how $\mathrm{Cu}$, in particular, segregated into sublayers in the reaction zone. The $\mathrm{Cu}$ in this region was identified as $\mathrm{Cu}_{2} \mathrm{O}$ and also $\mathrm{Cu}_{x} \mathrm{Ni}_{y} \mathrm{O}$ by XRD. Also, as shown in Figure 5.22, other regions, in particular right at the surface, are severely depleted in Cu. Figure 5.23 shows that, in general, $\mathrm{Fe}$ is predominant in regions were $\mathrm{Cu}$ is absent and depleted in regions where $\mathrm{Cu}$ is strong. As shown in Figure 5.24, $\mathrm{Ni}$ is distributed more uniformly, but appears to be more concentrated in regions high in $\mathrm{Cu}$, particularly near the electrode surface. This is consistent with the formation of the $\mathrm{Cu}_{x} \mathrm{Ni}_{y} \mathrm{O}$ compounds that were identified with XRD.

(a) As discussed in Section 5.2.3, the composition of the regions of "native" microstructure are, in fact, different in important ways from the original material. 
SEM

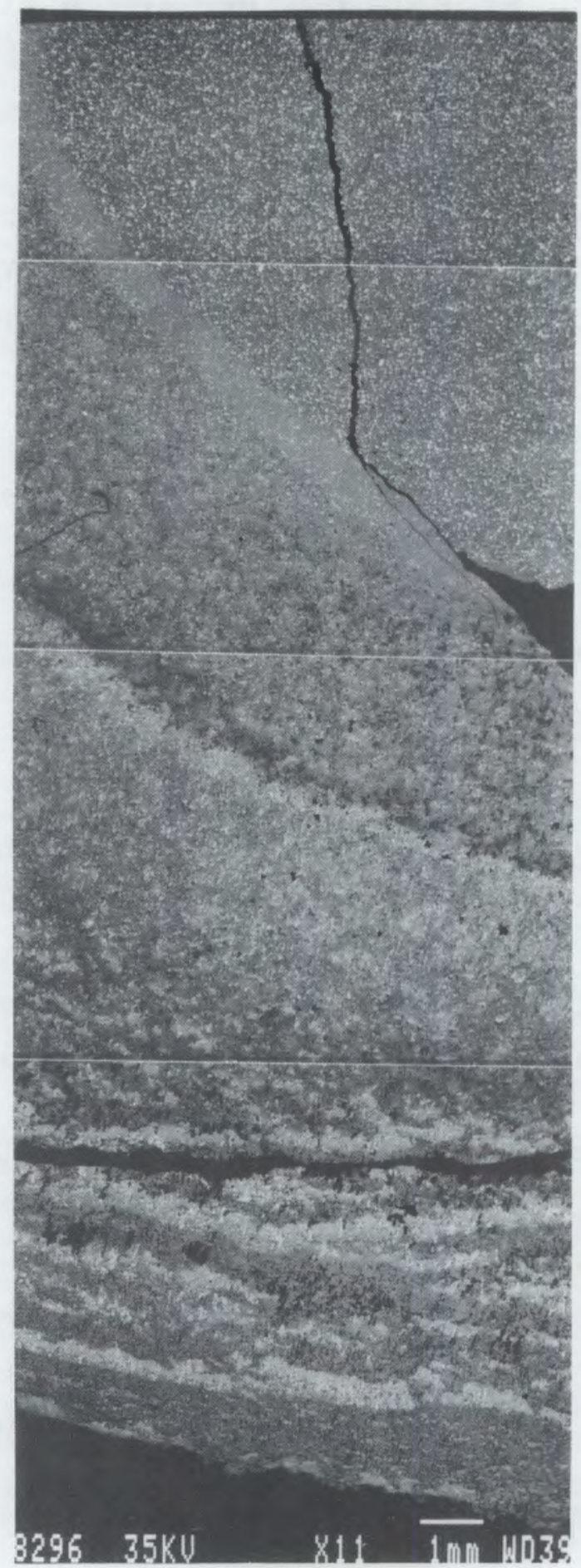

$\mathrm{Cu}$

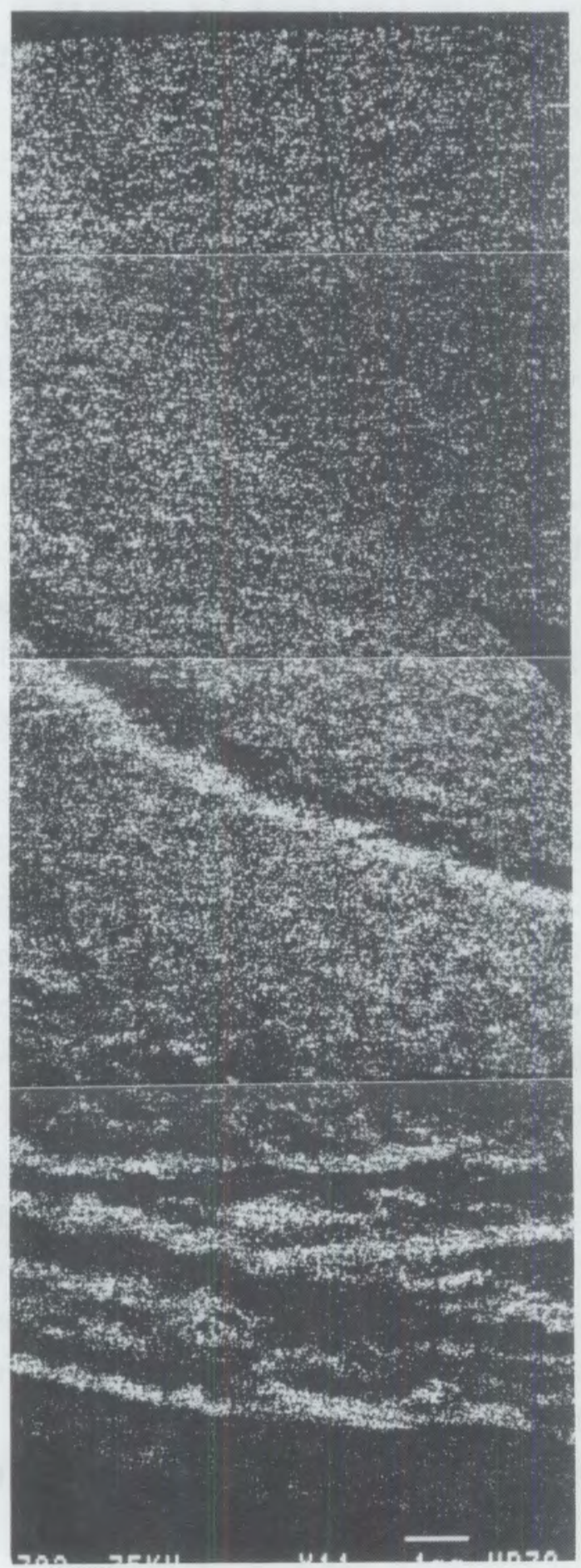

FIGURE 5.22. "Dot" Map for the Element Cu in Fl-B 


\section{SEM}

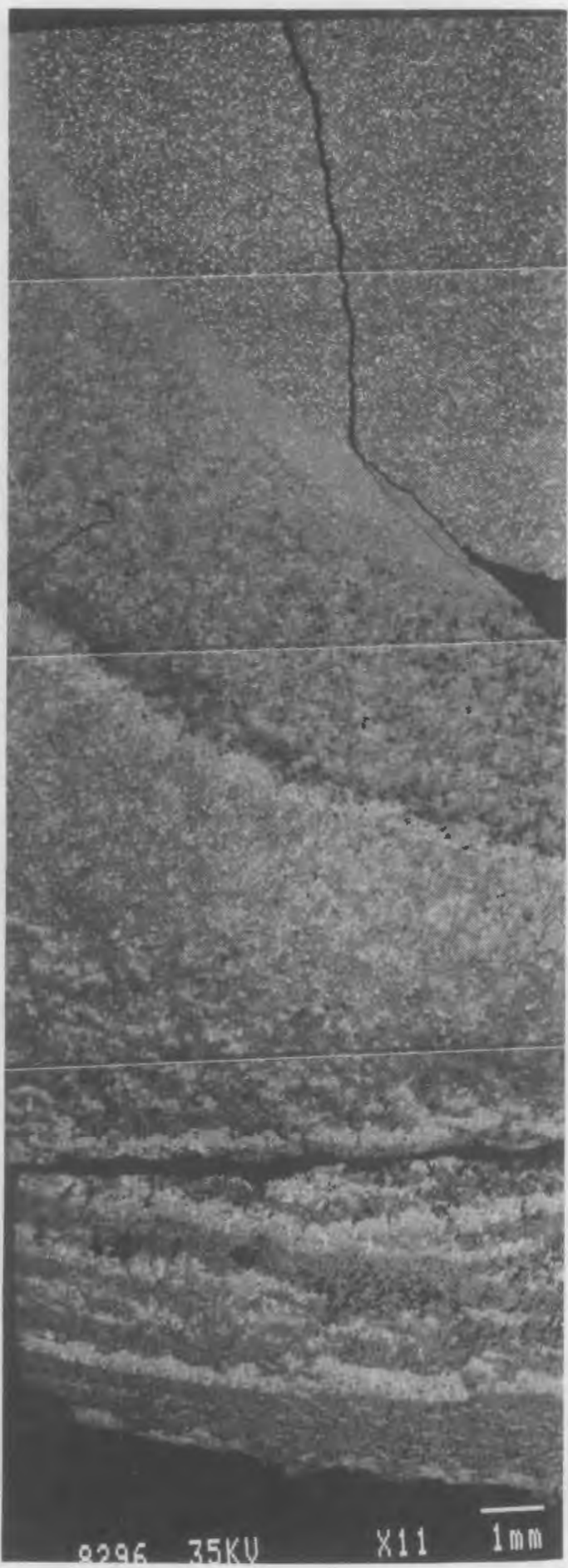

$\mathrm{Fe}$

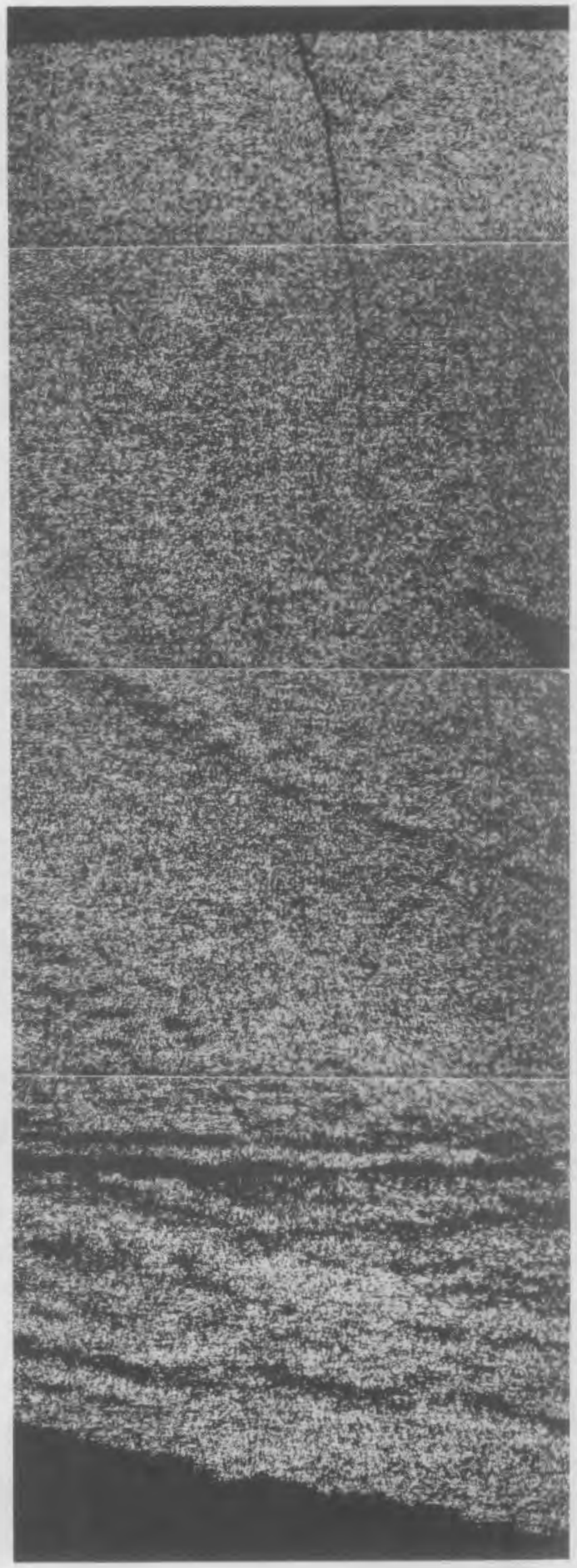

FIGURE 5.23. "Dot" Map for the Element Fe in Fl-B 
SEM

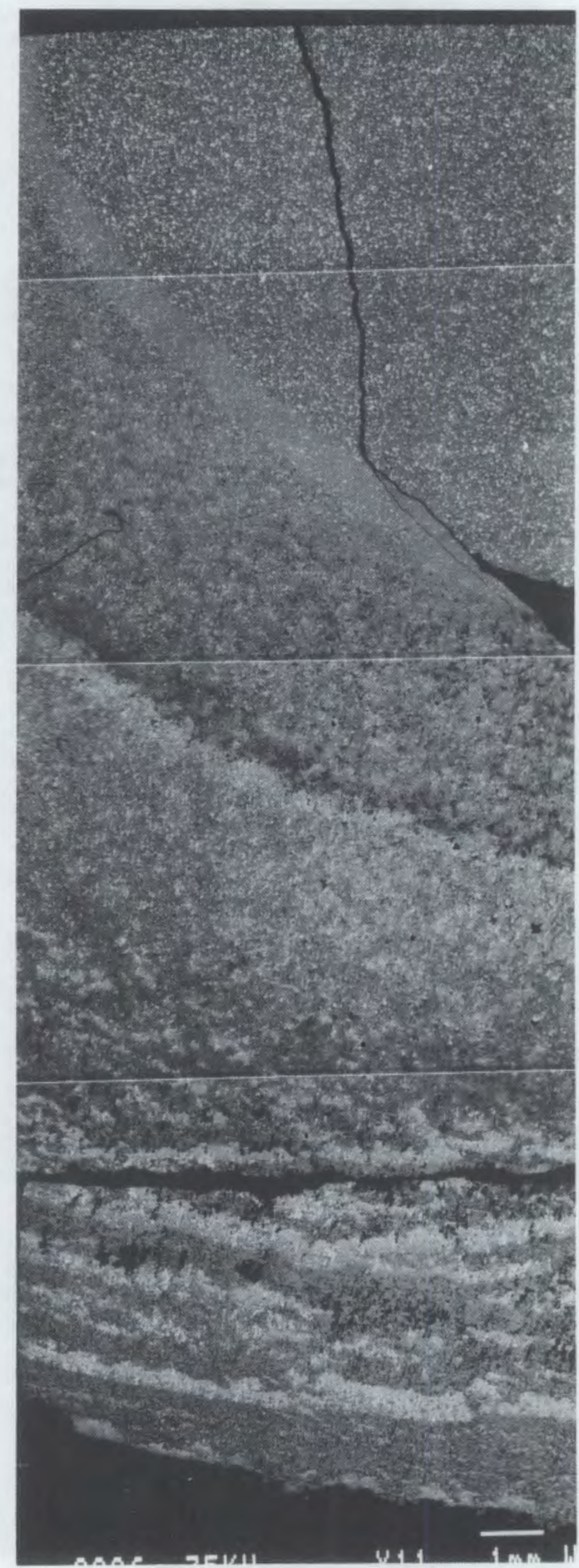

\section{$\mathrm{Ni}$}
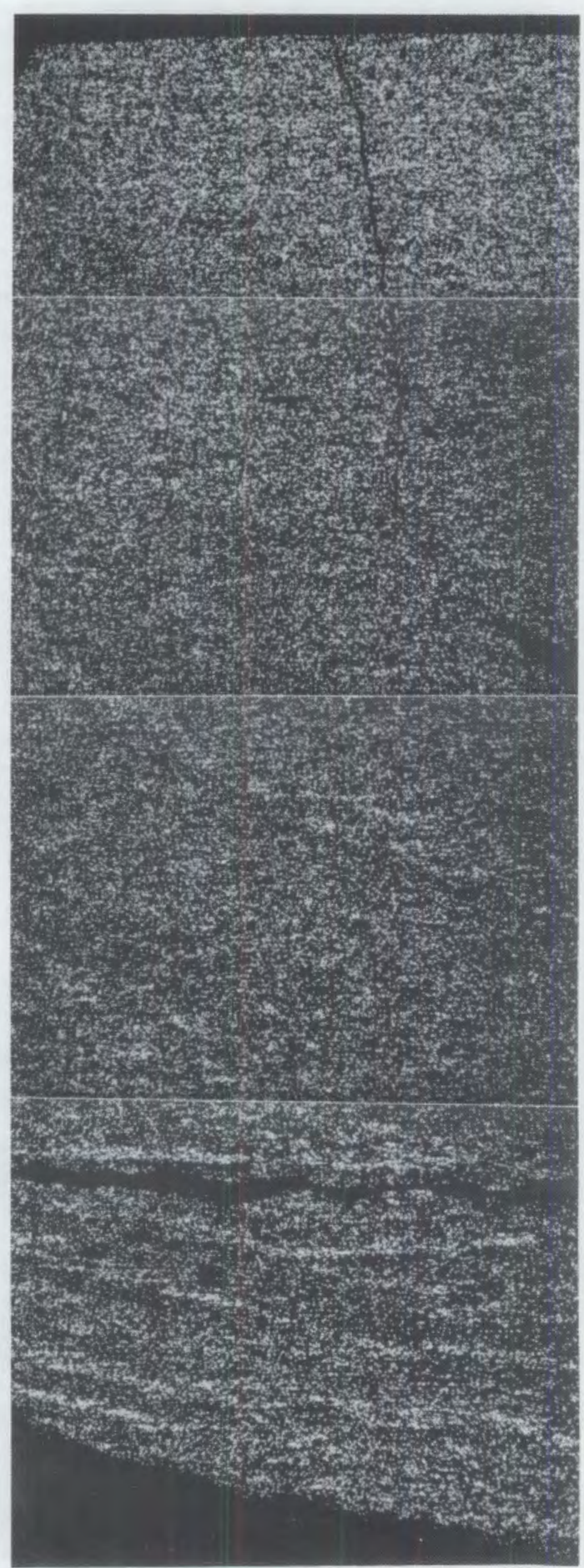

FIGURE 5.24. "Dot" Map for the Element $\mathrm{Ni}$ in Fl-B 

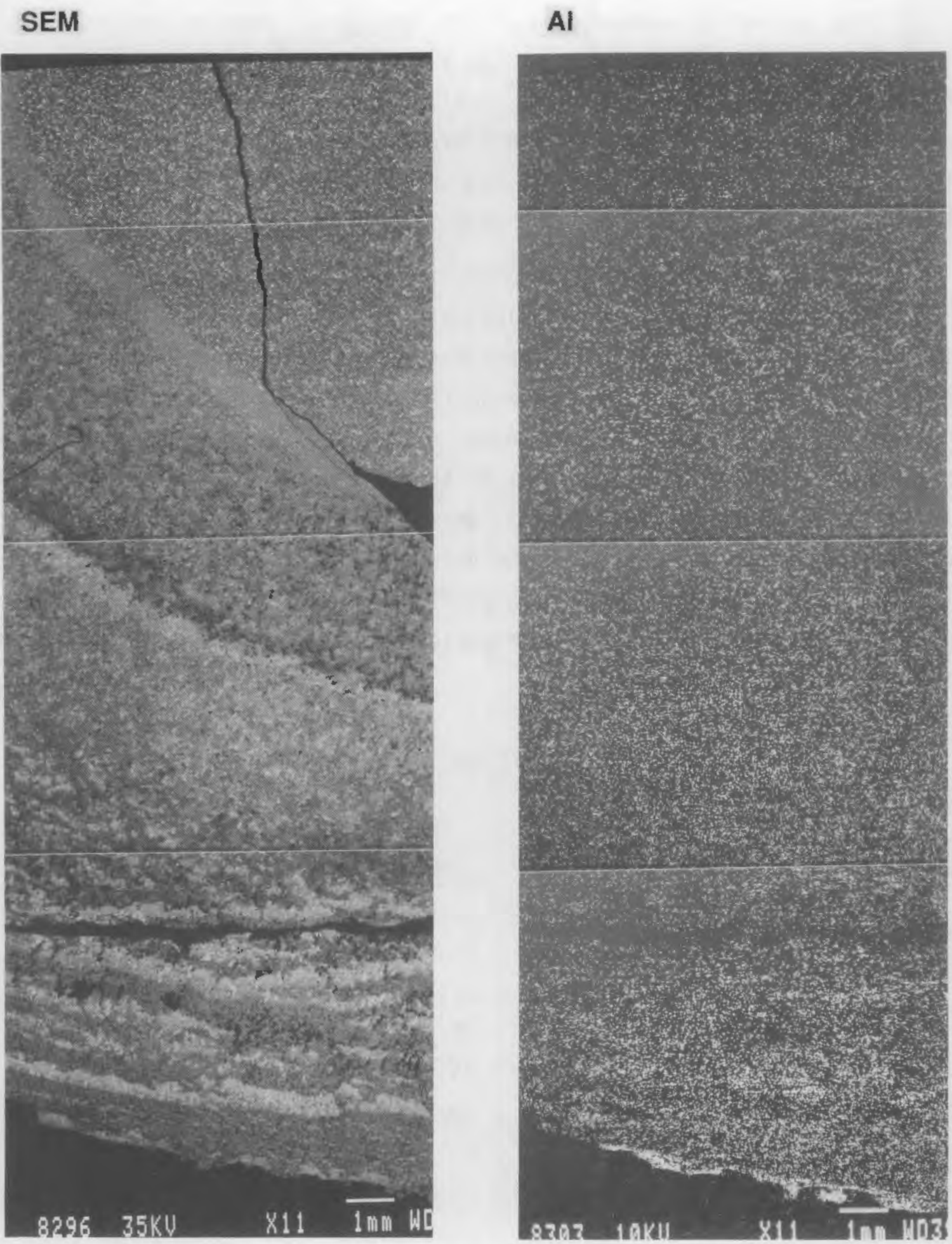

FIGURE 5.25. "Dot" Map for the Element Al in Fl-B 
Despite the varied composition of the sublayers shown in Figures $\mathbf{5 . 2 2}$ through 5.25, it is interesting that the ratio of $\mathrm{Cu}: \mathrm{Ni}: \mathrm{Fe}$ for pieces taken from the reaction layer were not drastically different from the original cermet material. Although, some small differences were observed and these are discussed below. The results of wet lab analysis using ICP according to the methods described in Section 3.2 are given in Table 5.1.

The observed differences between the actual compositions and the composition calculated from the raw materials used to make the anode can be at least partly explained by preferential loss of some of the $\mathrm{Cu}$ from the anode. Lowering $\mathrm{Cu}$ in the cermet would increase the calculated ratios for the other two elements. The ratio of $\mathrm{Ni}: \mathrm{Fe}$, on the other hand, stays roughly the same for all locations (1.1 to 1.2 ) except at the very surface (Sample $C$ ) where the ratio is $1.3 .^{\text {(a) }}$ The reason the weight percentages for the pieces from Anode F1-B are generaliy less than the values for the control (anode not tested) can be attributed partly to significant amounts of $\mathrm{Al}$ and $\mathrm{Na}$ in these samples. The aluminum content, for example, ranged from 1.46 weight percent in Sample $C$ to 0.76 in Sample A2.

TABLE 5.1. Results of Wet Lab Analys is of F1-B

\begin{tabular}{|c|c|c|c|c|c|}
\hline \multirow[b]{2}{*}{ Sample } & \multirow[b]{2}{*}{ Distance from Bottom } & \multicolumn{3}{|c|}{ Weight Percent } & \multirow[b]{2}{*}{ Ratio } \\
\hline & & $\mathrm{Cu}$ & $\mathrm{Ni}$ & $\mathrm{Fe}$ & \\
\hline c & Right at bottom surface & $\overline{12.2}$ & 30.4 & 23.0 & $1: 2.5: 1.9$ \\
\hline B1 & $3 \mathrm{~mm}$ & 11.4 & 28.0 & 23.9 & $1: 2.5: 2.1$ \\
\hline B & $9 \mathrm{~mm}$ & 12.2 & 30.6 & 26.3 & $1: 2.5: 2.2$ \\
\hline Al & $14 \mathrm{~mm}$ & 14.1 & 31.0 & 27.4 & $1: 2.2: 1.9$ \\
\hline A2 & $18 \mathrm{~mm}$ & 14.4 & 31.4 & 27.5 & $1: 2.2: 1.9$ \\
\hline Control & & 16.2 & 32.0 & 27.4 & $1: 1.98: 1.69$ \\
\hline
\end{tabular}

(a) The higher value for $\mathrm{Ni}: \mathrm{Fe}$ right at the surface can be explained by the substitution of $\mathrm{Al}$ for $\mathrm{Fe}$ in this region as discussed later in this section. 
The elemental dot map for Al in Figure 5.25 shows that significant amounts of this electrolyte component penetrated the anode. The penetration extends through the reaction layer and significantly into the native material. Some regions right at the sample surface were very rich in Al. As shown in Figure 5.26, significant amounts of $F$ were also detected. However, because the $\mathrm{K} \alpha$ line for $\mathrm{F}$ is near the $\mathrm{L} \alpha$ line for $\mathrm{Fe}$, the pervasive composition of $\mathrm{Fe}$ (Figure 5.26) made the dot map analysis of $F$ not as useful, especially for regions deep within the anode. For the near-surface region in Figure 5.26, the presence of $\mathrm{F}$ can be associated with the Al-rich phases at the surface in Figure 5.25. These phases are probably largely deposited cryolite $\left[\mathrm{Na}_{3} \mathrm{AlF}_{6}\right]$. The penetration of the electrolyte is also clearly evident in samples F1-M and F1-T. Figures 5.27 and 5.28 show the variation of AT and F (aS EDS intensities relative to $\mathrm{Fe}$ ), respectively, from the bottom to the top of the vertical core section. Note that, in both cases, at all positions the concentrations exceed those for a control sample that was not tested in the pilot cell. (The "bump" in the plots at about $35 \mathrm{~mm}$ is probably due to the crack in the anode, evident in Figure 5.19. Some electrolyte may have leaked in through this crack and provided another avenue for ingress into the anode.)

$\mathbf{F}$

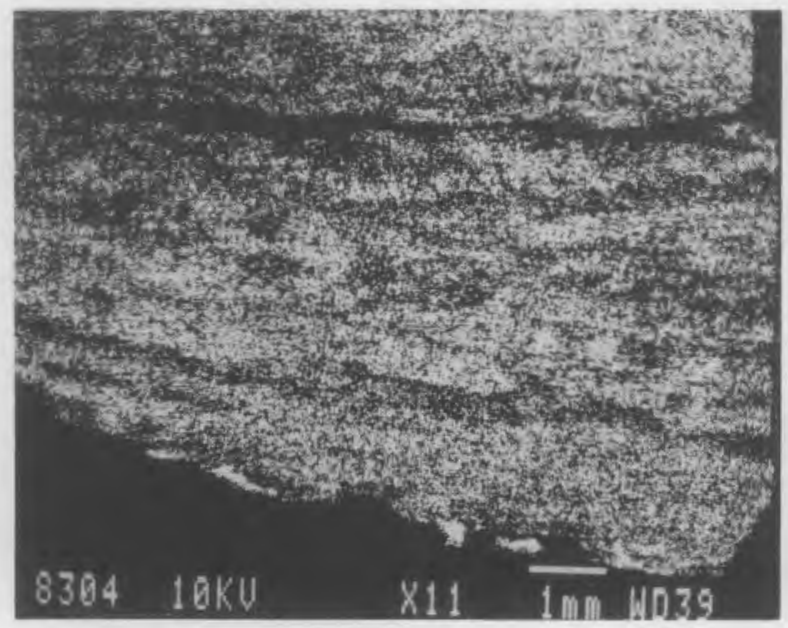

Fe (Interference)

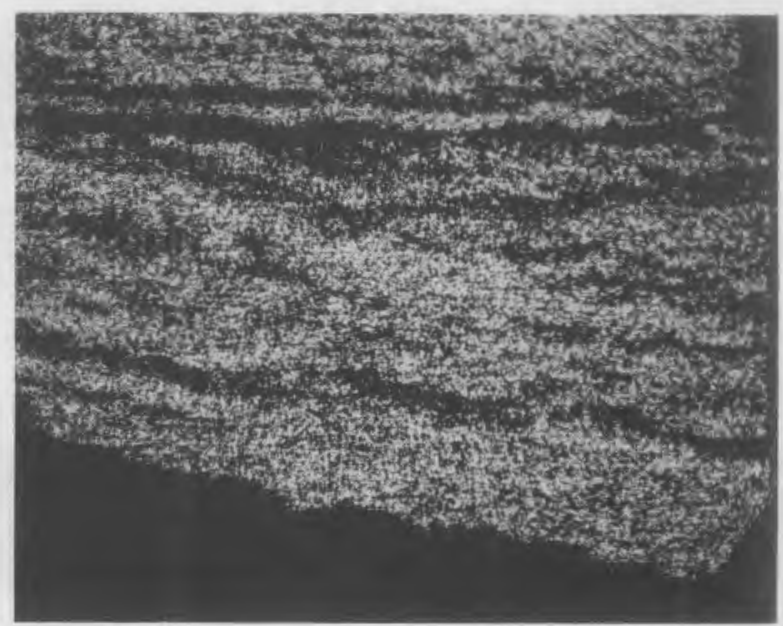

FIGURE 5.26. "Dot" Map for the Element $F$ in F1-B Near the Surface Region. Also Shown is Dot Map for Fe Illustrating Interference from this Element. 


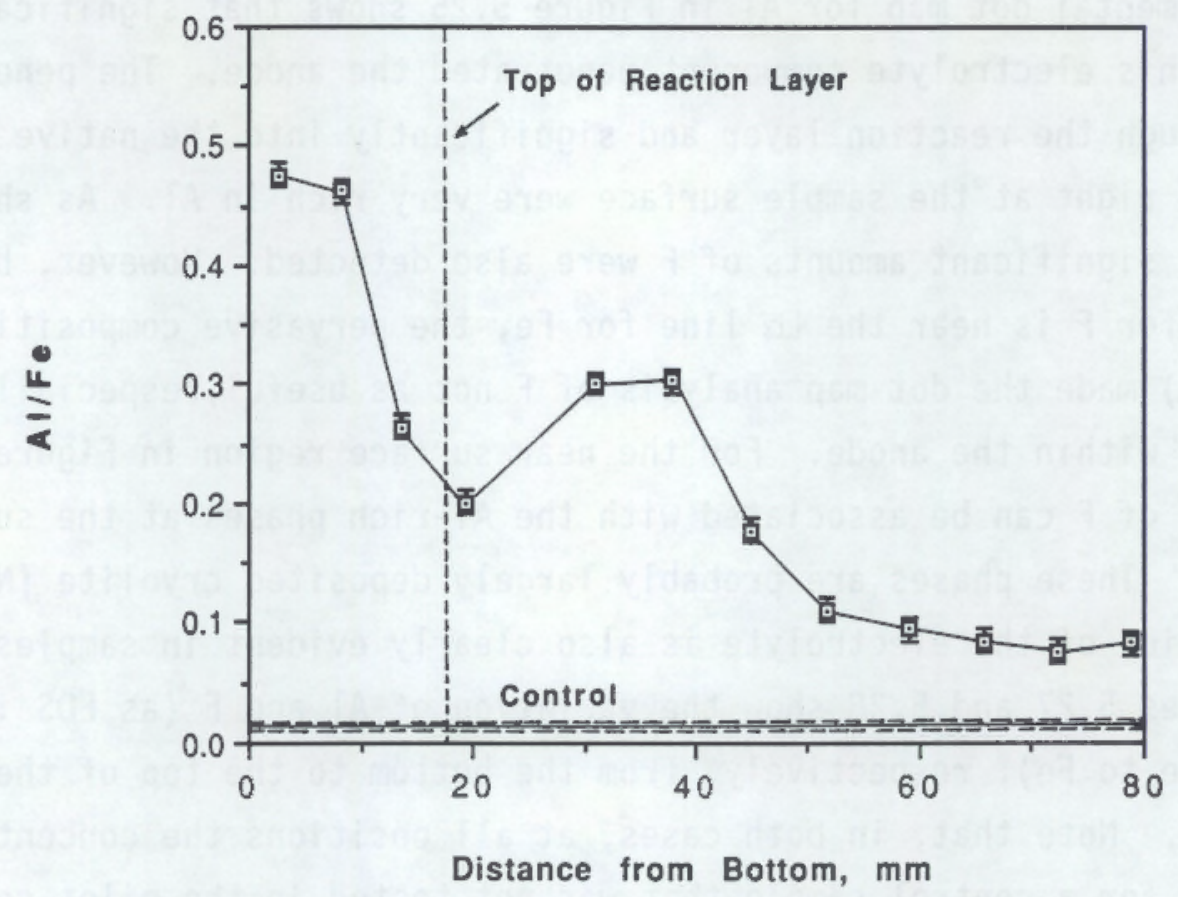

FIGURE 5.27. Variation of Al/Fe Intensity Ratio as a Function of Distance from the Bottom of Anode F1

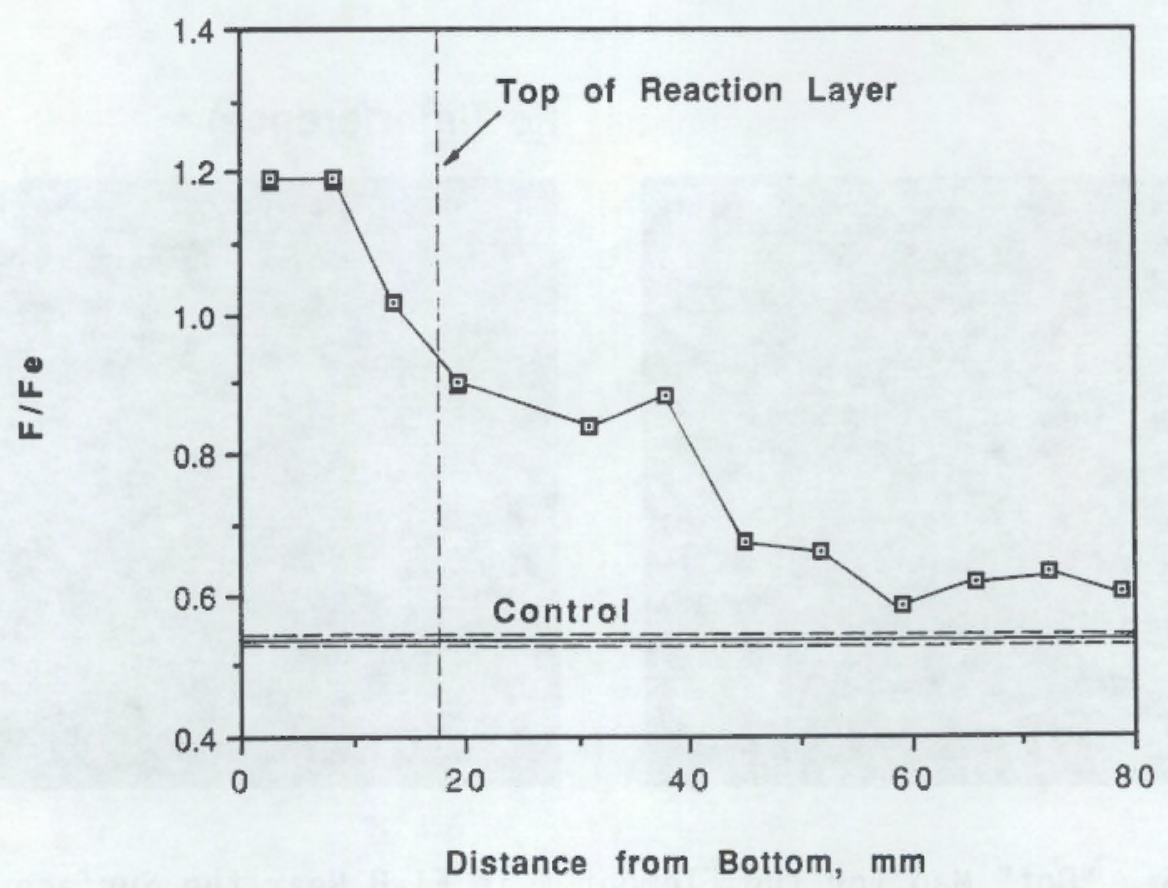

FIGURE 5.28. Variation of $F / F e$ Intensity Ratio as a Function of Distance from the Bottom of Anode F1 
Additional information on the nature of the cermet/electrolyte interactions is provided by the higher-magnification optical and SEM micrographs. Figure 5.29 shows region $\mathrm{Fl}-\mathrm{Bl}$ which is right at the anode bottom surface. As indicated in the figure, the significant phases in this region are primarily $\mathrm{Al}-\mathrm{Ni}$-Fe compounds. The stoichiometry of some of these phases determined by EDS suggests that $A l$ from the electrolyte replaces Fe to varying amounts in the $\mathrm{NiFe}_{2} \mathrm{O}_{4}$ (ferrite) phase. (a) In genera1, the amount of substitution is the greatest right at the surface and decreases as a function of depth into the anode. Also, significant amounts of $F$ were detected in these phases. For this reason, the relative stoichiometries of 0 and $F$ were left ambiguous by denoting their subscripts as $x$ and $y$. In some cases, the phases may correspond to stoichiometric aluminates since $\mathrm{Ni}$ and $\mathrm{Fe}$ aluminates were detected in

OPTICAL

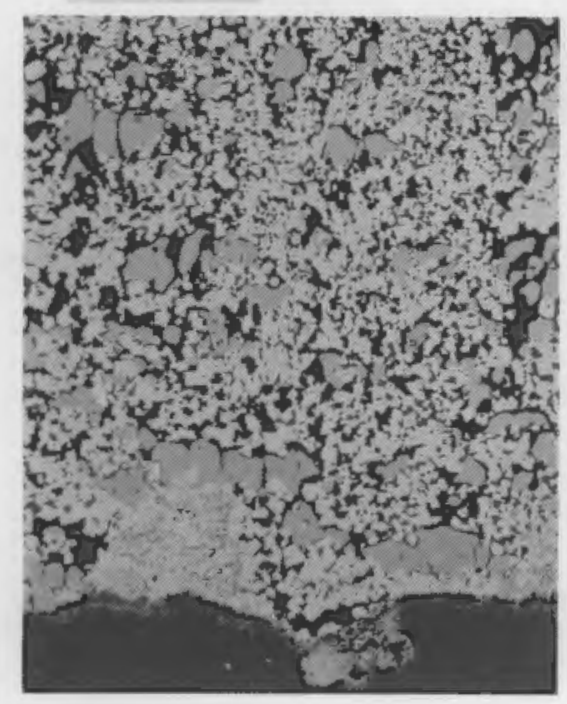

$\overline{100 \mu m}$

\section{SEM}

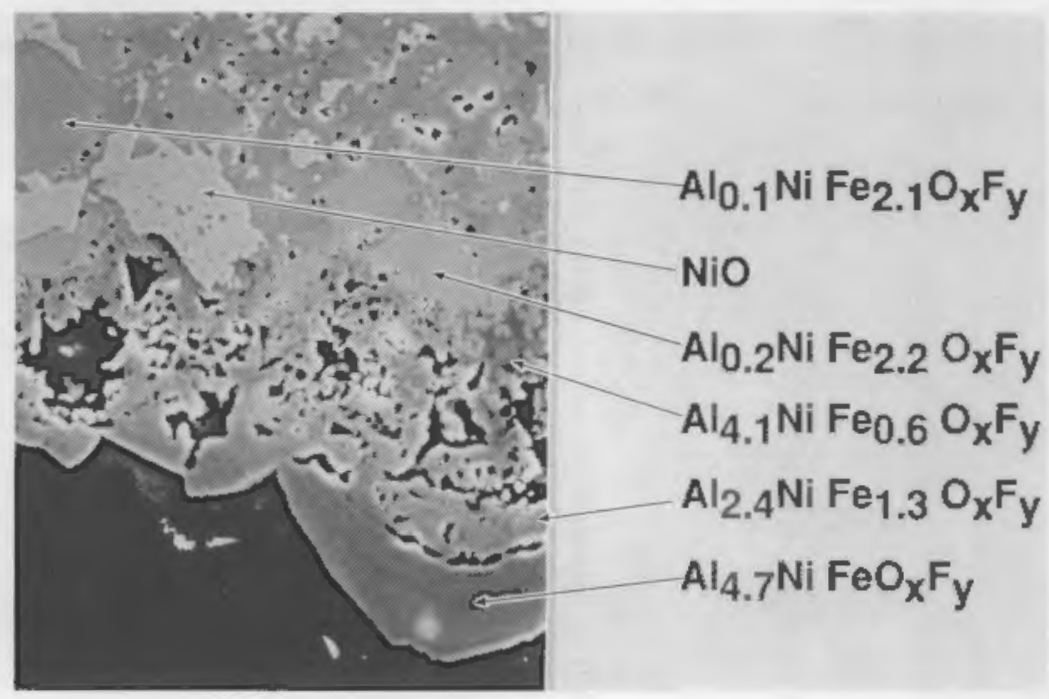

$10 \mu \mathrm{m}$

FIGURE 5.29. Micrographs of Region Fl-Bl

(a) It should be noted that the ferrite phase is actually not the stoichiometric $\mathrm{NiFe}_{2} \mathrm{O}_{4}$. This phase actually contains more $\mathrm{Fe}$ (probably as $\mathrm{Fe}^{2+}$ replacing some $\mathrm{Ni}^{2+}$ ) in the spinel structure. Analyses of numerous samples at PNL suggest the composition of the phase in unreacted material is closer to $\mathrm{NiFe}_{2.2} \mathrm{O}_{4.2}$. 
this region with $\mathrm{XRD}$. Figure 5.30 shows the variation of the $\mathrm{Al} / \mathrm{Fe}$ ratio in the ferrite-1ike phases as a function of distance from the bottom of the vertical core section (log scale). Clearly, most of the substitution occurs within the first $100 \mu \mathrm{m}$, but significant amounts still occur deep within the anode.

In addition to the Al-containing ferrite-like phases, Figure 5.29 shows some $\mathrm{NiO}$ in $\mathrm{Fl}-\mathrm{Bl}$, but no significant amounts of $\mathrm{Cu}$ metal. This is consistent with the elemental dot map for $\mathrm{Cu}$ in Figure 5.22.

Figures 5.31 through 5.34 show micrographs for regions F1-B2, F1-B3, F1$\mathrm{B} 4$, and $\mathrm{F} 1-\mathrm{B} 5$, respectively, which correspond to locations in piece $\mathrm{Fl}-\mathrm{B}$ at increasing distances from the bottom surface of the anode. Regions F1-B2, F1-B3, and F1-B4 are within the reaction layer while F1-B5 is in the region with native microstructure just above the reaction layer boundary. Figure 5.31 shows some of the varied microstructure within the reaction layer. In F1-B2, the primary phase is an A1-containing ferrite phase but with a grain structure very different from the original. The grains in this region appear

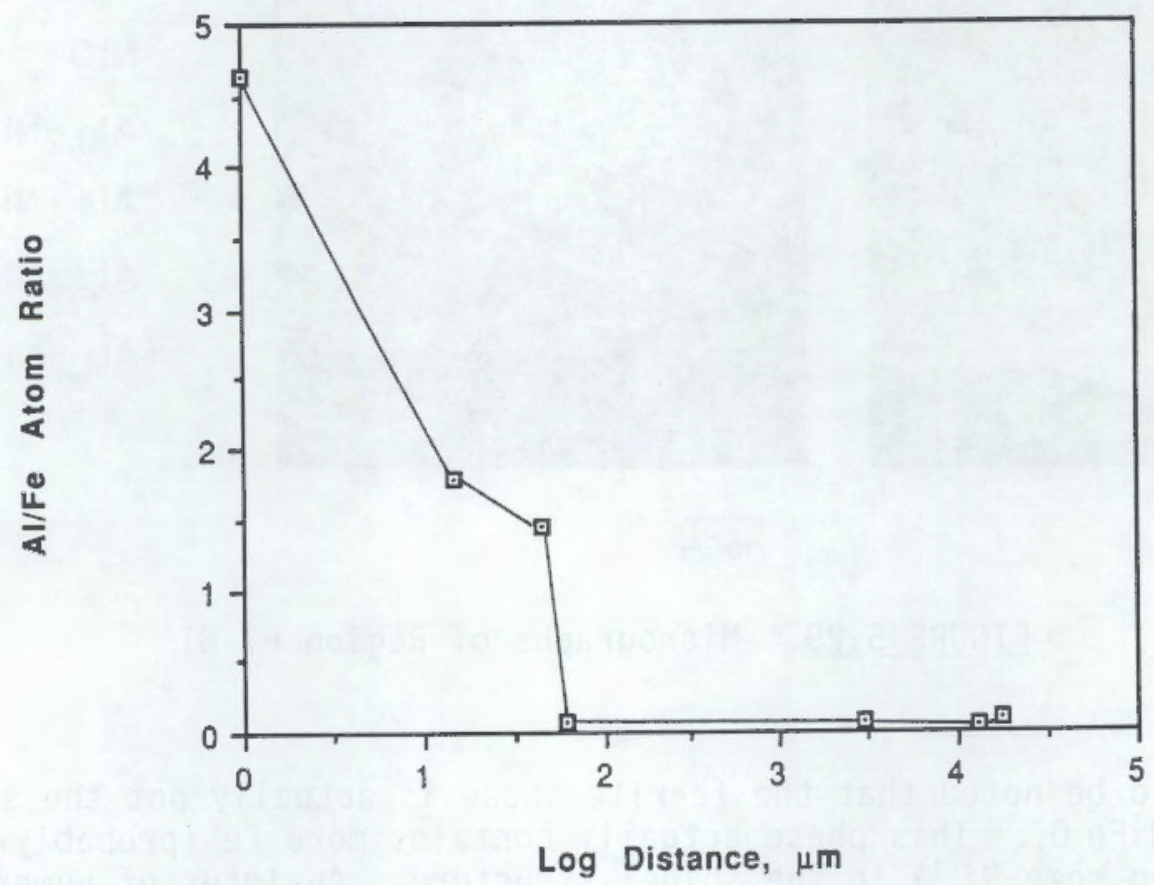

FIGURE 5.30. Variation of Al/Fe Ratio for the Ferrite Phase as a Function of Distance (Log Scale) from the Bottom of Anode F1 


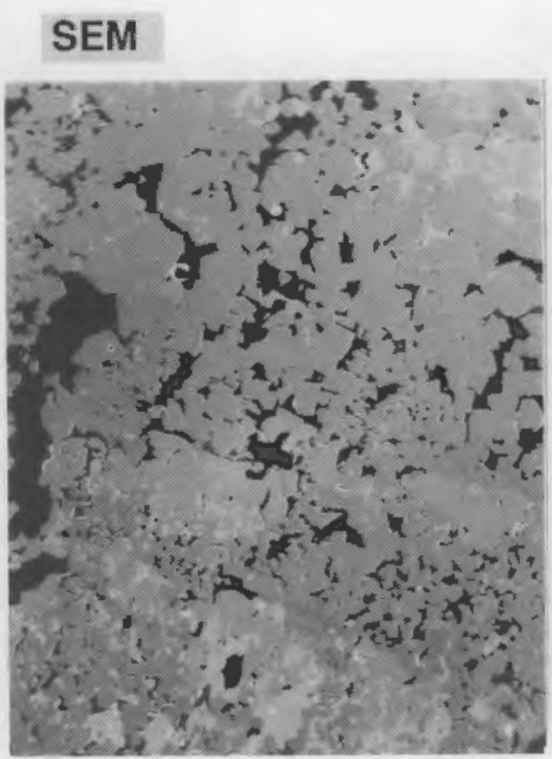

SEM (Above "band")

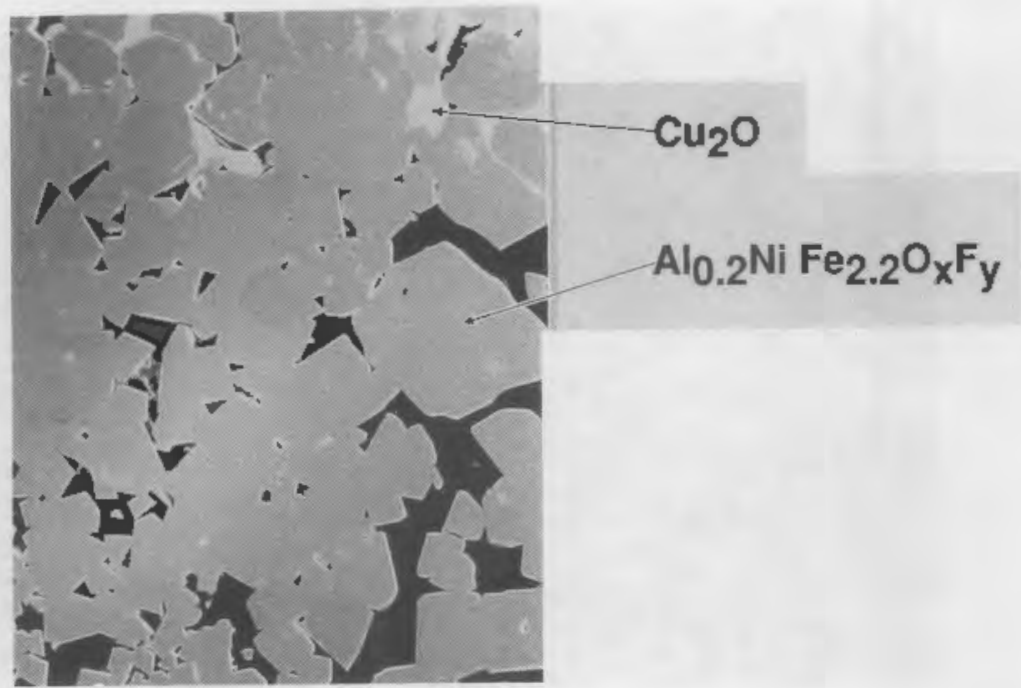

$\overline{100 \mu \mathrm{m}}$

\section{$\overline{33 \mu \mathrm{m}}$}

FIGURE 5.31. Micrographs of Region F1-B2

\section{SEM}

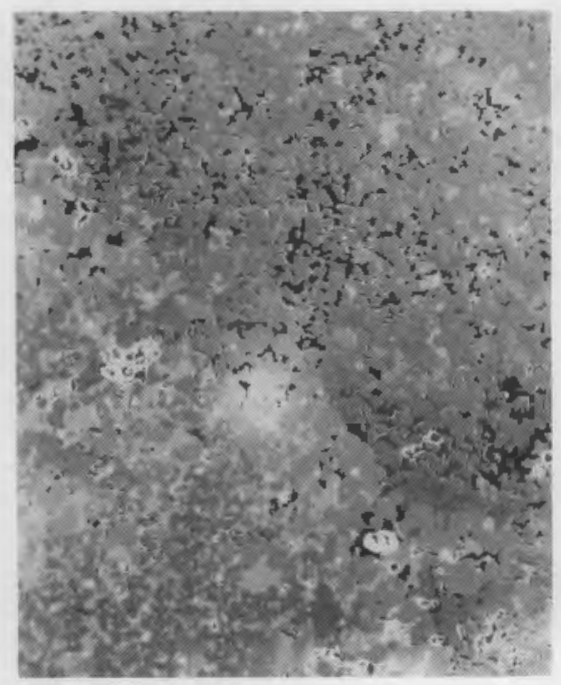

$\overline{100 \mu \mathrm{m}}$
SEM (Top of "band")

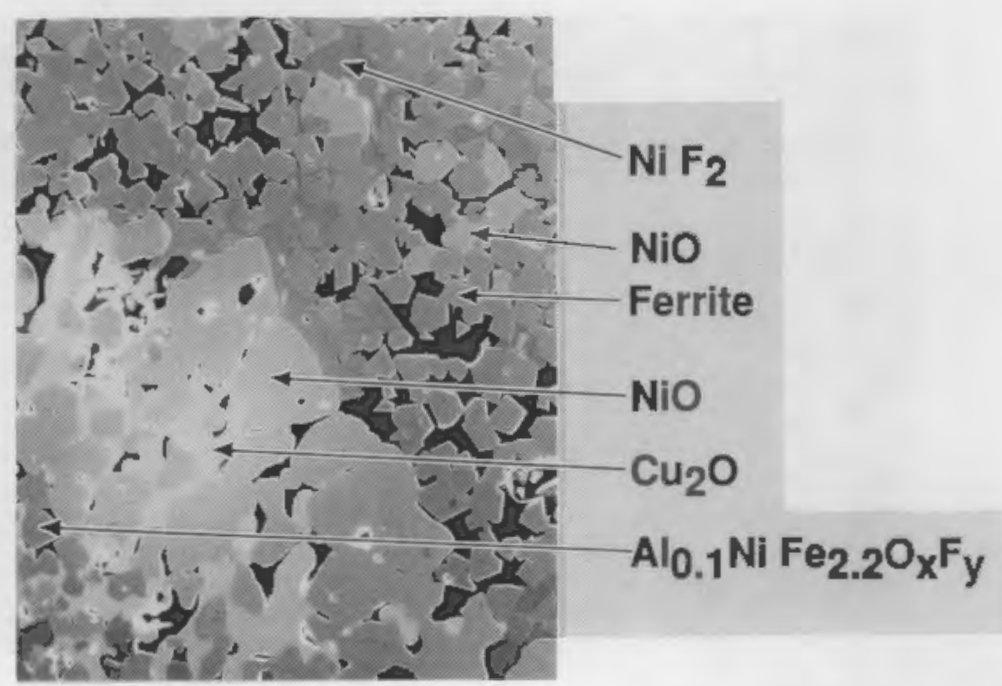

$\overline{33 \mu \mathrm{m}}$

FIGURE 5.32. Micrographs of Region F1-B3 


\section{SEM}

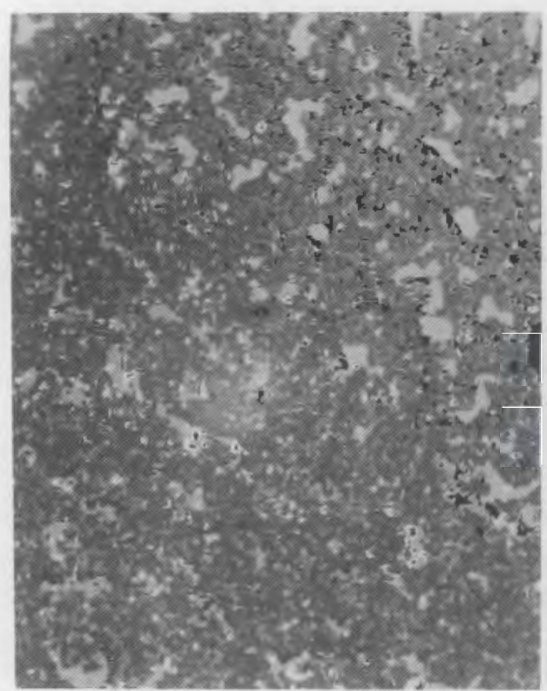

$\overline{100 \mu \mathrm{m}}$
SEM (Inside "band")

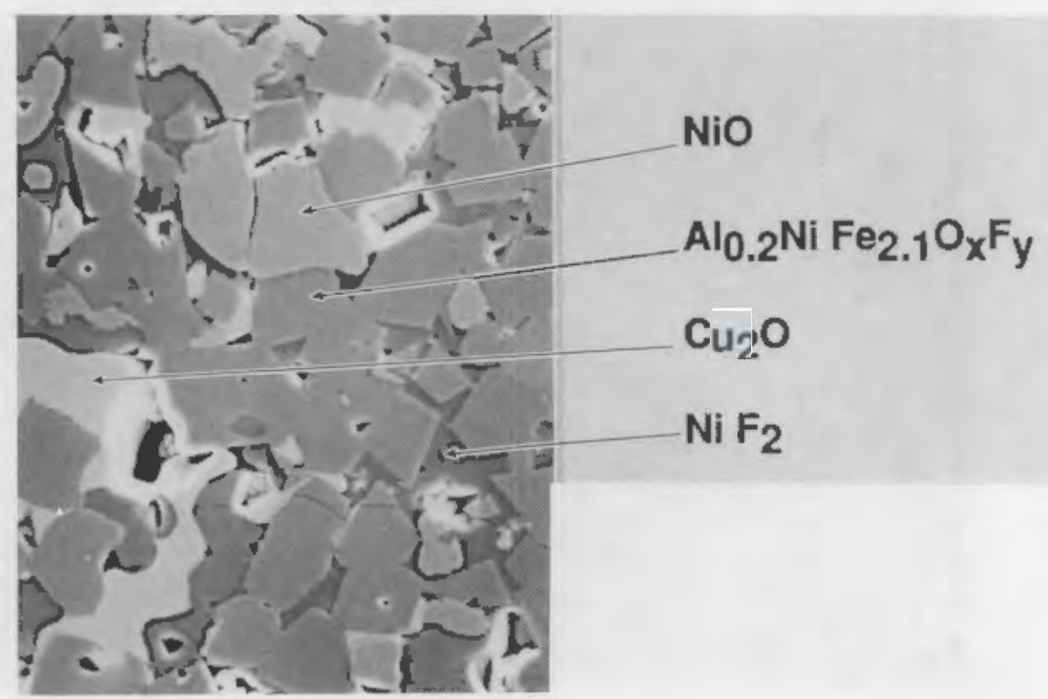

$$
\overline{10 \mu \mathrm{m}}
$$

FIGURE 5.33. Micrographs of Region F1-B4

Optical

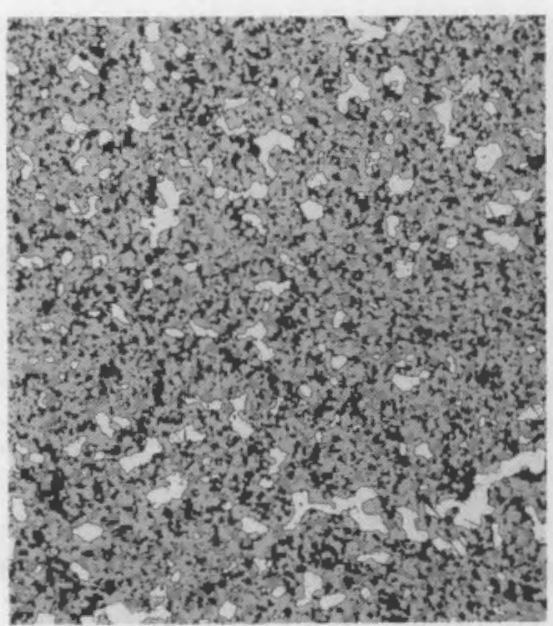

$\overline{100 \mu \mathrm{m}}$
SEM

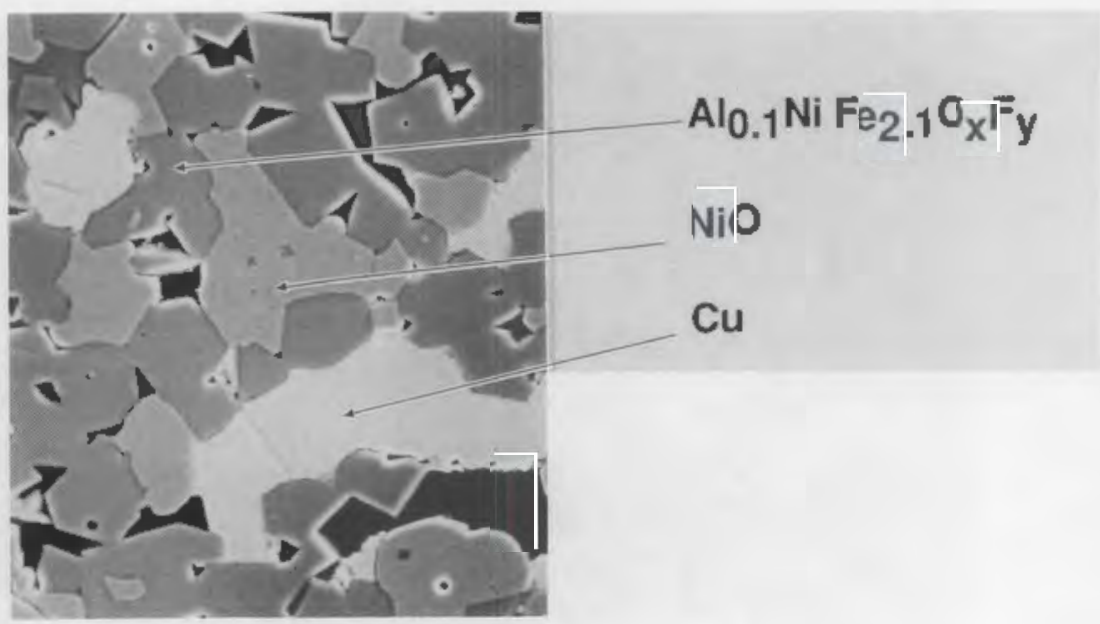

$\overline{10 \mu \mathrm{m}}$

FIGURE 5.34. Micrographs of Region Fl-B5 
to have grown significantly and fused together (forming a "band" or sublayer when examined at lower magnification). The only other significant phase in this region was a copper oxide, which was identified as $\mathrm{Cu}_{2} \mathrm{O}$ based on XRD results. It appears that the $\mathrm{Cu}$ in this region, which was originally part of the metallic phase, oxidized to $\mathrm{Cu}_{2} \mathrm{O}$. Figure 5.32 shows the phases in region $\mathrm{F} 1-\mathrm{B} 3$, which is near another band in the reaction layer. This region contains more Al-containing ferrite (with $\mathrm{Al}$ at lower concentrations), some largely unreacted ferrite, $\mathrm{NiO}, \mathrm{Cu}_{2} \mathrm{O}$, and a phase composed mostly of $\mathrm{Ni}$ and $\mathrm{F}$. This phase was identified as $\mathrm{NiF}_{2}$ from XRD data of this region. $\mathrm{NiF}_{2}$ was also found in region F1-B4 as shown in Figure 5.33.

Figure 5.34 shows micrographs for region $\mathrm{F} 1-\mathrm{B} 5$, which is in the native microstructure region just above the reaction layer. This region contains some $\mathrm{Al}$-containing ferrite and $\mathrm{NiO}$ but, unlike the reaction layer, it also contains the metallic phase. Interestingly, this metallic phase was almost pure $\mathrm{Cu}$. The metallic phase in an unreacted anode is actually an alloy with the nominal composition of $86 \% \mathrm{Cu}, 13 \% \mathrm{Ni}$, and $1 \% \mathrm{Fe}$ (by weight). (a) The "refinement" of $\mathrm{Cu}$ in the metallic phase just above the reaction layer has also been observed in other studies on cermet anodes (Strachan et al. 1990). As shown in Figure 5.35, the amount of $\mathrm{Ni}$ relative to $\mathrm{Cu}$ in the metallic phase rises from the very low value (almost pure $\mathrm{Cu}$ ) right above the reaction layer to values close to an unreacted control anode at further distances into the anode. At the top of the anode, where another reaction layer is present (Section 5.2.4), the ratio again becomes low. The thickness of the Cu-enriched metallic zone seems to be related to the overall corrosion performance of the anode. For example, Anode $\mathrm{Fl}$, which had a reaction layer about $13 \mathrm{~mm}$ thick (on the average), shows a Cu-enriched metallic zone about $35 \mathrm{~mm}$ thick (Figure 5.36). In contrast, the prototype anode (Strachan et al. 1990), which had a reaction layer about $3 \mathrm{~mm}$ thick, exhibits a Cu-enriched zone of only about

(a) The composition of the alloy varies somewhat from anode to anode. The values reported here are representative of measurements made on control anodes for the pilot cell test. In some previous studies, the nominal composition was reported as $85 \% \mathrm{Cu}$ and $15 \% \mathrm{Ni}$, i.e. without $\mathrm{Fe}$ because of its minor contribution. 


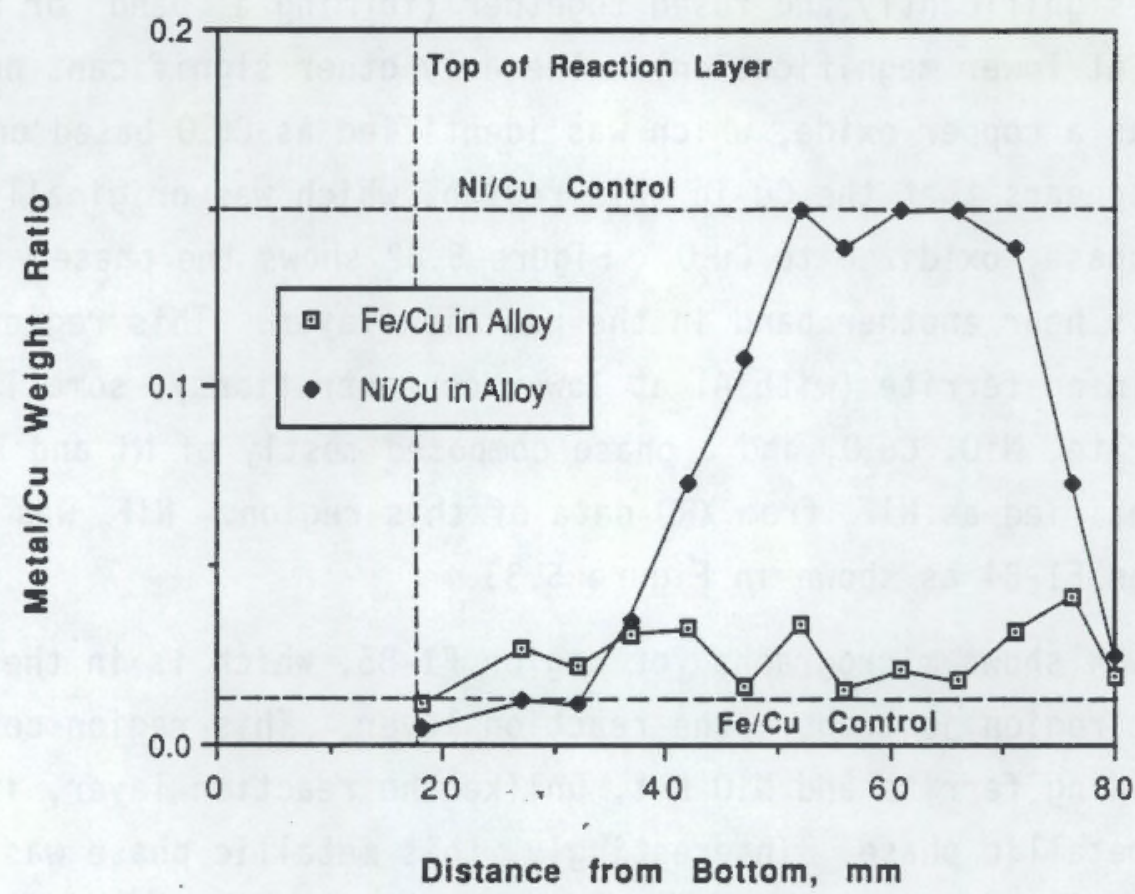

FIGURE 5.35. Composition of Alloy Phase as a Function of Distance from the Bottom of Anode F1

$10 \mathrm{~mm}$, as shown in Figure 5.36. The ratio of Cu-enriched zone thickness to reaction layer thickness is roughly 3 to 1 in both cases.

Considering the identification of $\mathrm{NiF}_{2}$ within the anode, it seems likely that the $\mathrm{Ni}$ in the metallic phase is oxidized to $\mathrm{NiF}_{2}$ in the presence of F-containing bath components. The extent of this conversion appears to be related to how far the electrolyte can penetrate into the cermet anode material.

Another interesting variation that occurred primarily in the reaction layer was the relative amount of $\mathrm{Cu}$ in the NiO phase. As shown in Figure 5.37, the ratio $\mathrm{Cu} / \mathrm{Ni}$ is much higher near the bottom surface and in the reaction layer than deeper in the anode and in the control sample. This is also consistent with the occurrence of both $\mathrm{Cu}$ and $\mathrm{Ni}$ in the same sublayers in the elemental dot maps in Figures 5.22 and 5.24. This result suggests that $\mathrm{Cu}$ oxidizes in the reaction layer to give not only $\mathrm{Cu}_{2} \mathrm{O}$, but also $\mathrm{Ni}_{x} \mathrm{Cu}_{y} \mathrm{O}$, with 


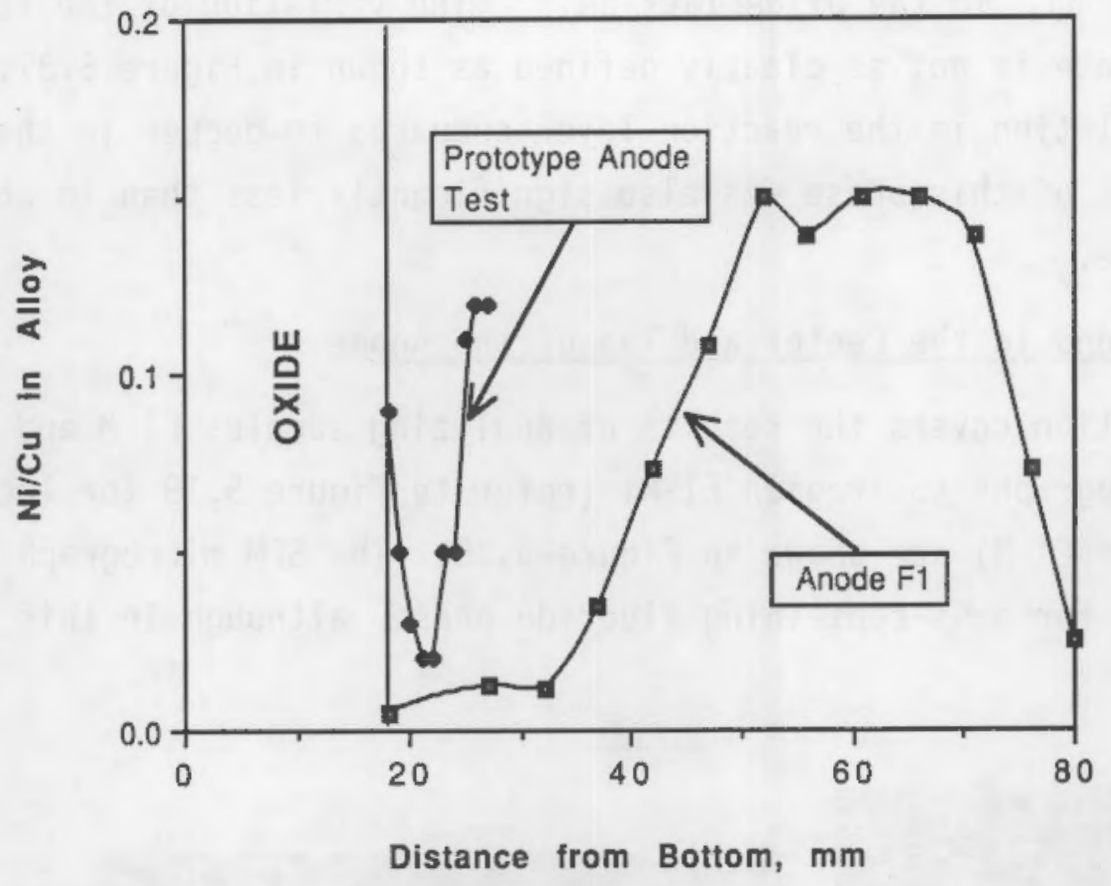

FIGURE 5.36. Ni/Cu Ratio in the Alloy Phase as a Function of Distance from the Bottom of Tested Anodes. Data are shown for Anode Fl and for the prototype anode.

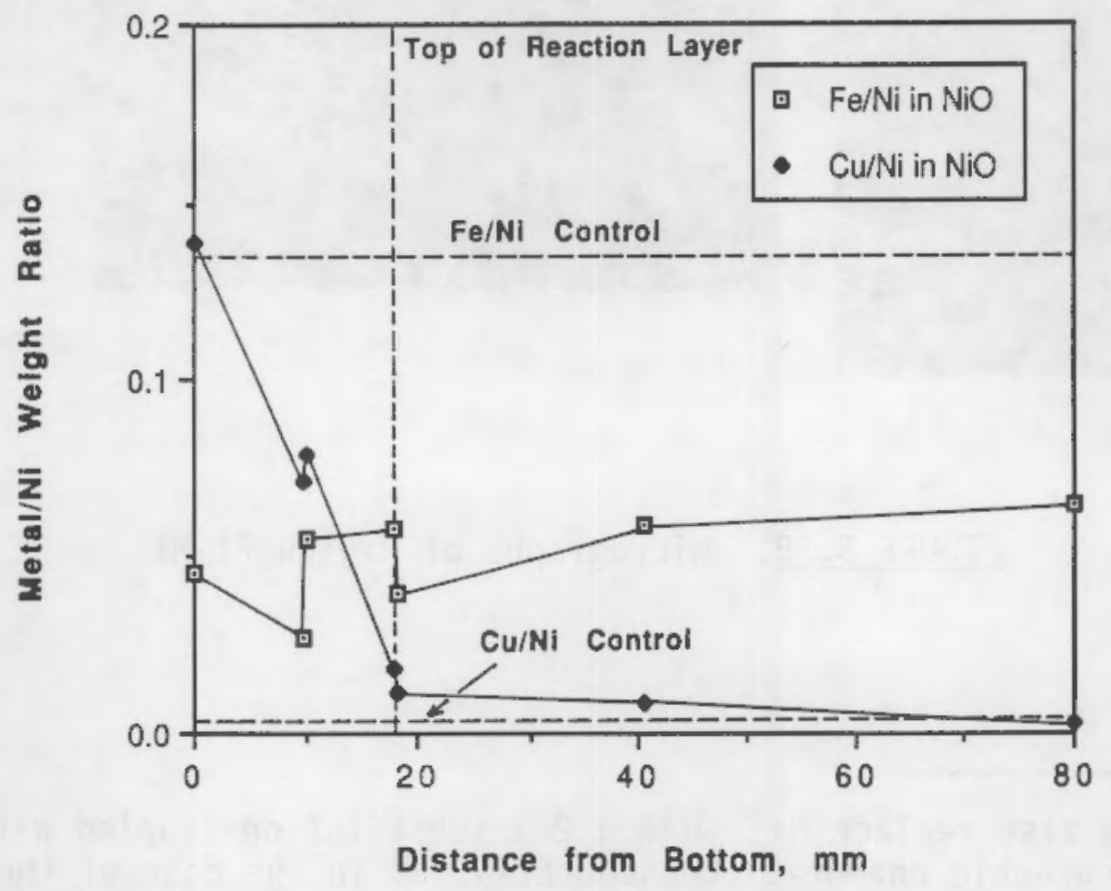

FIGURE 5.37. Composition of the NiO Phase as a Function of Distance from the Bottom of Anode Fl 
$\mathrm{Cu}^{2+}$ replacing $\mathrm{Ni}^{2+}$ in the oxide lattice. ${ }^{(a)}$ The variation of the Fe content of the NiO phase is not as clearly defined as shown in Figure 5.37, but may show some depletion in the reaction layer compared to deeper in the anode. The Fe content of this phase was also significantly less than in an unreacted control sample.

\subsubsection{Reactions in the Center and Top of the Anode}

This section covers the results of analyzing samples F1-M and F1-T in detail. Micrographs for region F1-M1 (refer to Figure 5.19 for location of this region in $F 1-M$ ) are shown in Figure 5.38. The SEM micrograph revealed more evidence for a $\mathrm{Ni}$-containing fluoride phase, although in this region the

\section{Optical}

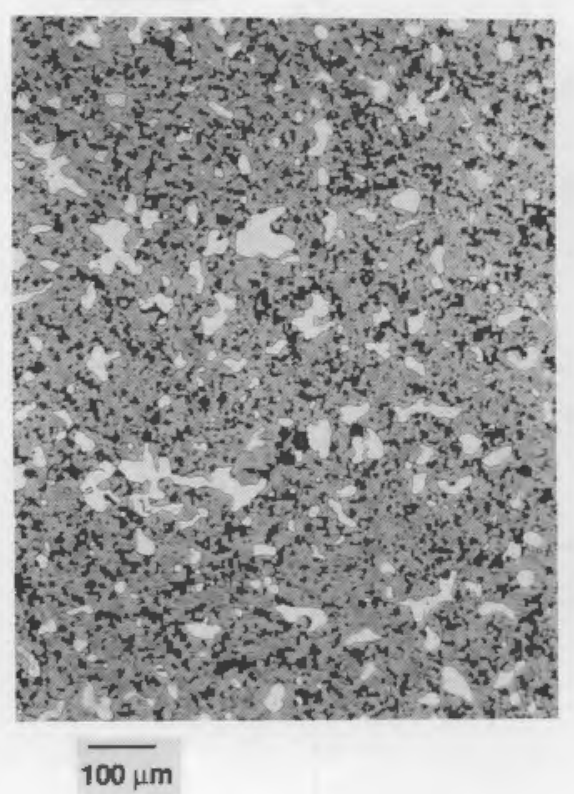

SEM

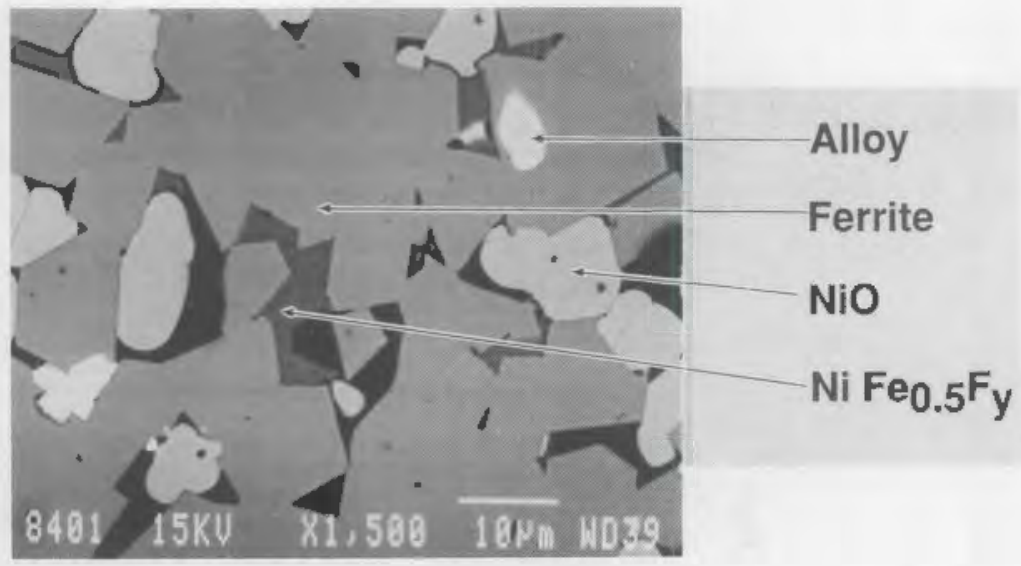

FIGURE 5.38. Micrographs of Region F1-M1

(a) $\mathrm{Cu}^{+}$could also replace $\mathrm{Ni}^{2+}$ with a $2: 1$ substitution coupled with radical crystallographic changes. Consequently, as in the case of the reacted ferrite phase, the stoichiometric subscripts are indicated as $x$ and $y$ (instead of $x$ and $1-x$ ) to allow for this possibility. 
phase also contained a significant amount of Fe. The fluoride phase in F1-M1 was interrogated using EDS; it exhibited an atom ratio of $\mathrm{Fe} / \mathrm{Ni}$ of about 0.5. In region $\mathrm{Fl}-\mathrm{Tl}$ in sample $\mathrm{Fl}-\mathrm{T}$, significant amounts of a $\mathrm{Ni}-\mathrm{Fe}$ fluoride phase were also found, but with an even larger $\mathrm{Fe} / \mathrm{Ni}$ ratio of about 0.6 , as shown in Figure 5.39. It appears that the Fe content of the fluoride phase increased as a function of distance from the bottom surface of the anode. The plot in Figure 5.40 shows that this is indeed the case. The $\mathrm{Fe} / \mathrm{Ni}$ intensity ratio of the EDS lines obtained from the fluoride phases increased significantly from the bottom to the top surfaces of the anode. Since the $\mathrm{Ni}$ in the fluoride phase is proposed to come from the $\mathrm{Ni}$ in the original alloy phase, it is also likely that the $\mathrm{Fe}$ in the fluoride phase has the same source. As one proceeds deep into the anode material, however, the relative tendency for the transformations of the $\mathrm{Ni}$ and $\mathrm{Fe}$ may change so that the $\mathrm{Fe}$ makes up an increasingly larger component of the reaction product phase, i.e., the fluoride, at these more remote locations. All of these reactions, of course, depend on $F$ from the electrolyte significantly penetrating the anode. While no direct evidence for the identity of this reactant species was obtained from analysis of the
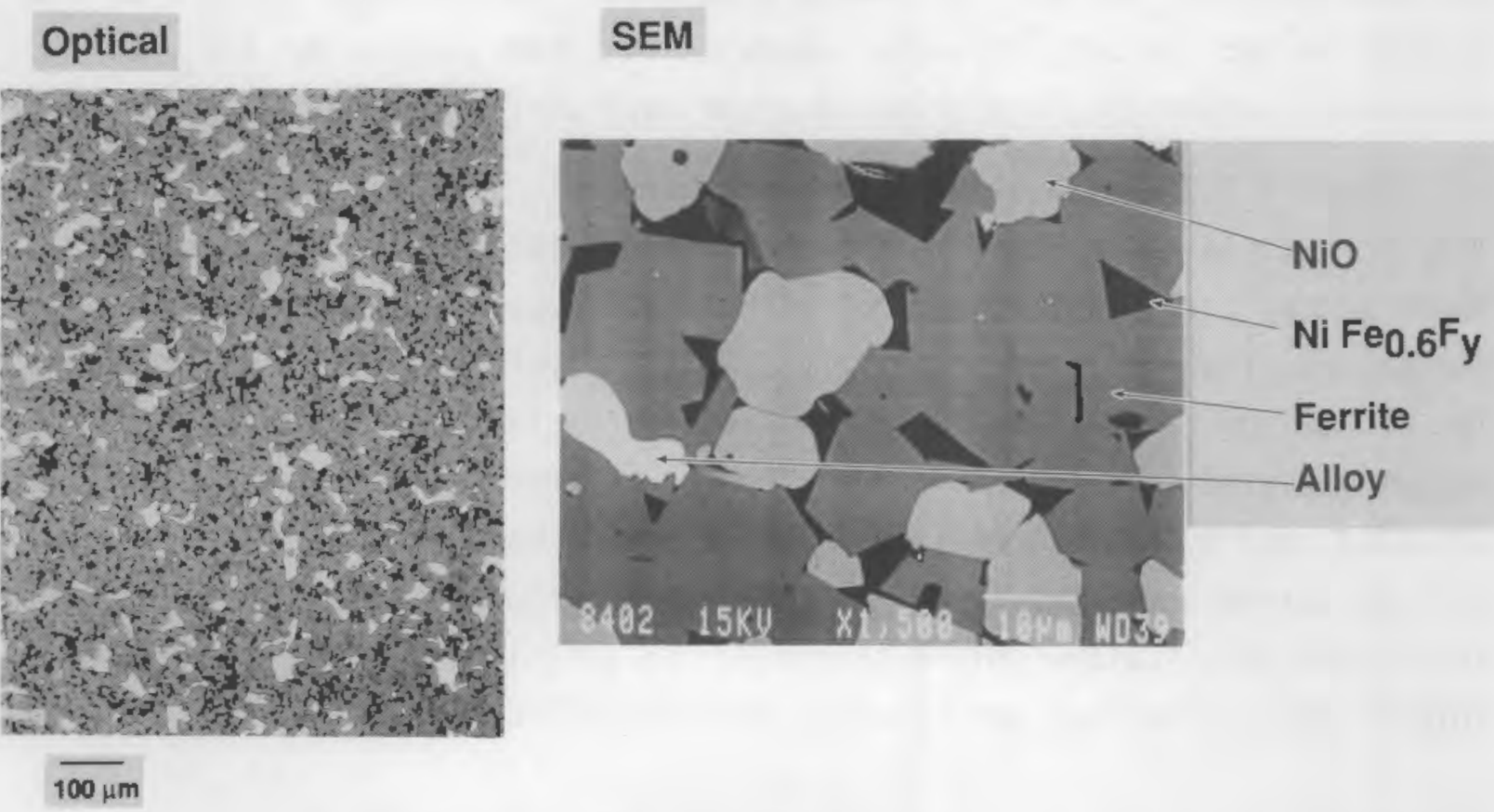

FIGURE 5.39. Micrographs of Region F1-T1 


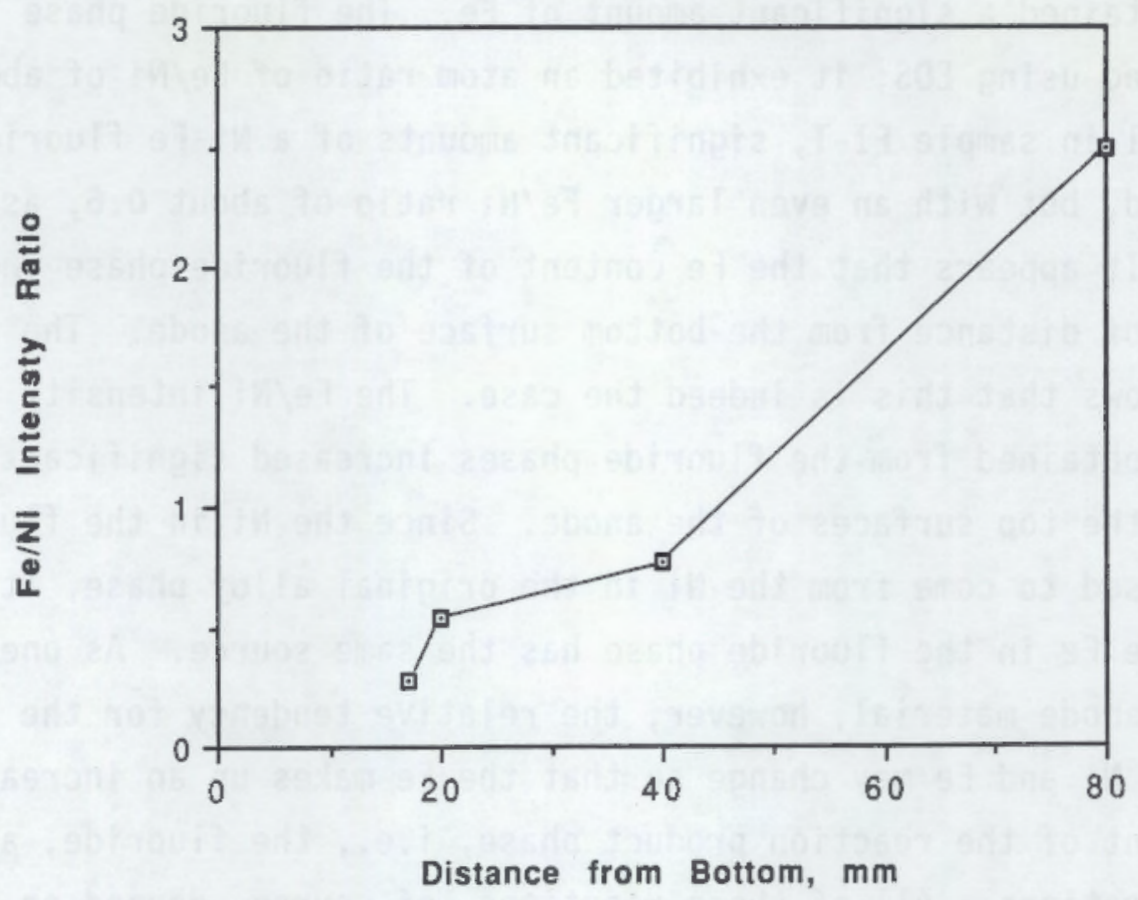

FIGURE 5.40. Composition of the $\mathrm{NiF}_{2}$ as a Function of Distance from the Bottom of Anode F1

polished samples, analysis of fracture surfaces, interrogated as part of the studies in Section 5.3, strongly suggested that the species was $\mathrm{AlF}_{3}$, an aluminum fluoride ion, and/or an aluminum oxyfluoride ion. ${ }^{\text {(a) }}$

Figures 5.18 and 5.19 show that the vertical core section studied in this work contained cracks. Although it is possible that the presence of these cracks assisted transport of electrolyte species into the anode (making the extent of penetration appear greater than "typical"), it is unlikely that they contributed significantly to the results on this core section. Their effect appeared to take the form of "bumps" on the concentration curves (Figures 5.27 and 5.28). In addition, the extent of degradation of the cermet material along these cracks was not great, with the adjacent material exhibiting essentially "native" microstructure. In all likelihood, these cracks formed later in testing and possibly even during cool-down. Other cracks in

(a) The presence of an aluminum oxyfluoride species along grain boundaries was also proposed by Strachan et al. (1989). 
the cermet anodes that were known to be present for significant times in the electrolyte during testing exhibited reaction layers (much like those on the bottom surface) of significant thickness along their lengths. Consequently, it appears that the principle mode of transport of the electrolyte species into the body of Anode $\mathrm{Fl}$ was through pores and/or along grain boundaries. The latter mode of transport was proved likely from the results of Windisch et a1. (1991c) and from the mechanical properties tests reported in Section 5.3.

$X$-ray diffraction analyses were performed on a number of pieces removed from the vertical core section; some of these were discussed already. A summary of the various species identified using XRD are given in Figure 5.41, which also shows a schematic of the core section as an aid to identifying sample location. Some of the obvious trends that support the EDS results include the variation in composition of the alloy phase and the presence of $\mathrm{NiF}_{2}$. The presence of some other phases, such as the iron oxides, were not corroborated by other methods. ${ }^{(a)}$

Micrographs of the reaction layer at the top of the vertical core section are shown in Figure 5.42. This reaction layer formed under a crust of a solid alumina/cryolite composition. It was not exposed to liquid bath but was in contact with any vapors that could penetrate the crust from above. The temperature of the top surface was significantly lower than the bottom of the anode. The reaction layer that formed was characterized by essentially a single phase of Al-containing ferrite-solution-like composition. As shown in Figure 5.42 , the Al composition appears to vary somewhat in this region. The individual grains also have disappeared at the magnifications shown, appearing essentially fused together. No significant amounts of $\mathrm{Cu}$ were present in this reaction layer.

(a) The compound lithium ferrite ( $\mathrm{LiFeO}_{2}$ and other stoichiometries) was not identified in any of the samples using XRD. Personal communications with Dr. Haupin indicated this compound might be present as a result of a thermodynamically favored reaction involving LiF, but no evidence for its presence was found in this work. 


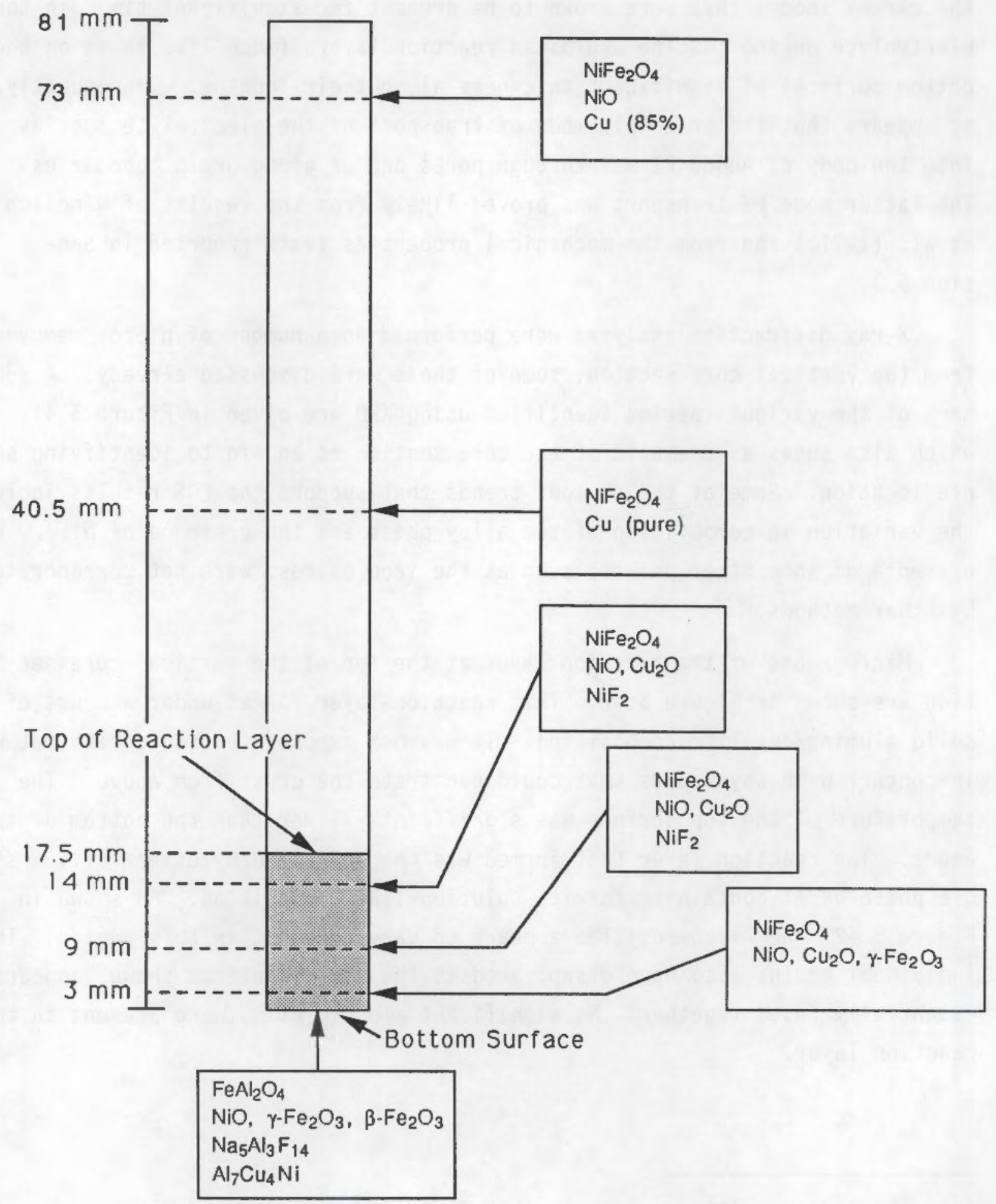

FIGURE 5.41. Schematic Showing Summary of XRD Results on Vertical Core Section from Anode F1 


\section{Optical}

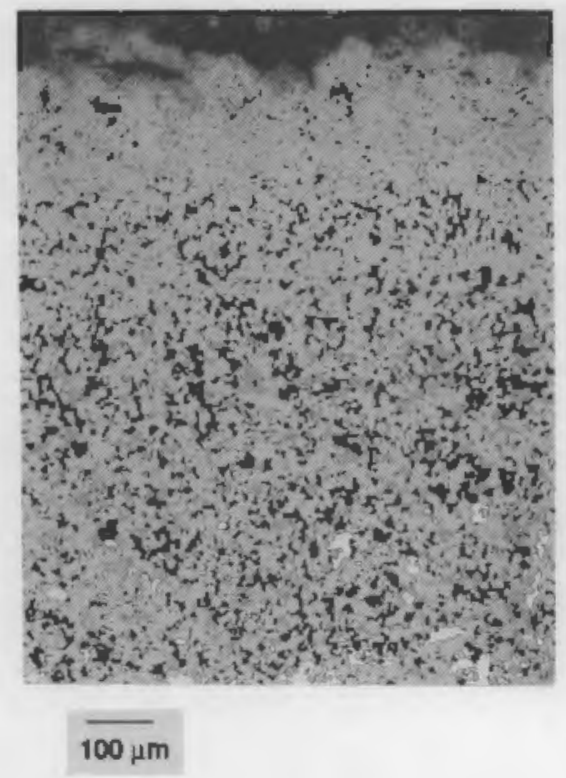

SEM

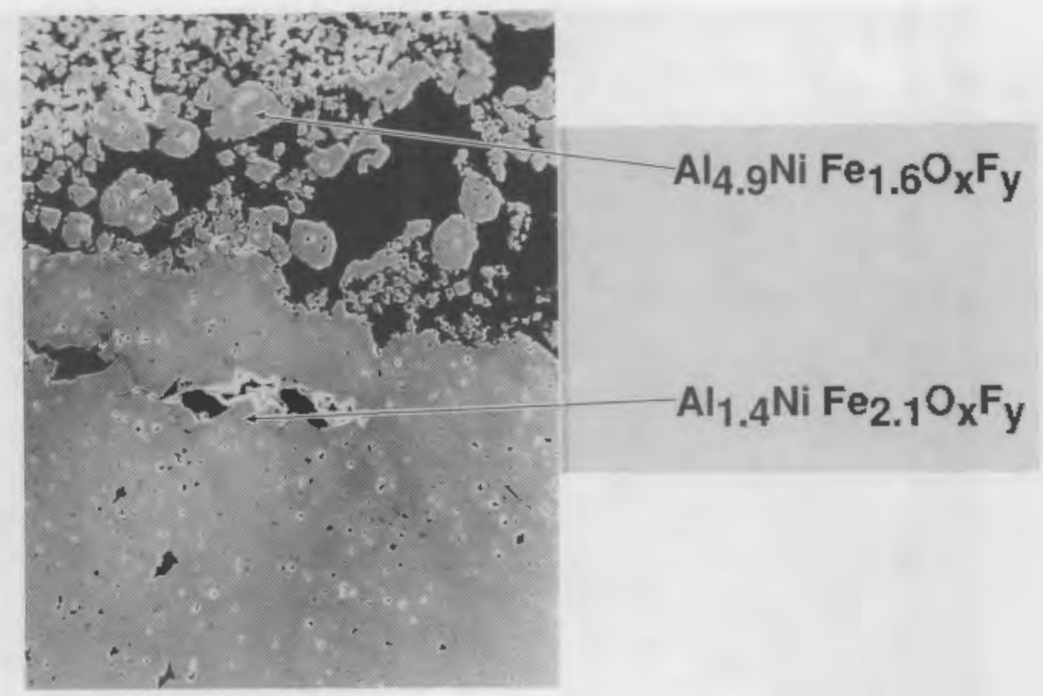

$\overline{33 \mu \mathrm{m}}$

FIGURE 5.42. Micrographs of Region F1-T2

\subsubsection{Reactions in the Wing Region}

This section covers the results of analyzing sample F1-W in detail. Three regions were studied in this core section: both sides of the core and its center. Both the inside and outside surfaces had a reaction layer that was similar in composition although somewhat thicker on the inside than on the outside (Figure 5.21). This layer, shown for the outside surface in Figure 5.43, appeared very similar to the layer on top of the vertical core section (Figure 5.42). The layer was composed of a consolidated Al-containing ferrite-like phase. It also contained no significant amounts of $\mathrm{Cu}$. The interior of the wing was very similar in microstructure and composition to the original anode material. The variation of the $\mathrm{Ni} / \mathrm{Cu}$ ratio in the metallic phase follows the expected pattern as shown in Figure 5.44. The ratio is low under both of the reaction layers and is higher, closer to the control composition, toward the center of the core.

The results for the wing region were one of the promising outcomes of the pilot cell test. Significant thought went into designing an anode shape that reduced the amount of corrosion of any "upper" regions (exposed to the 

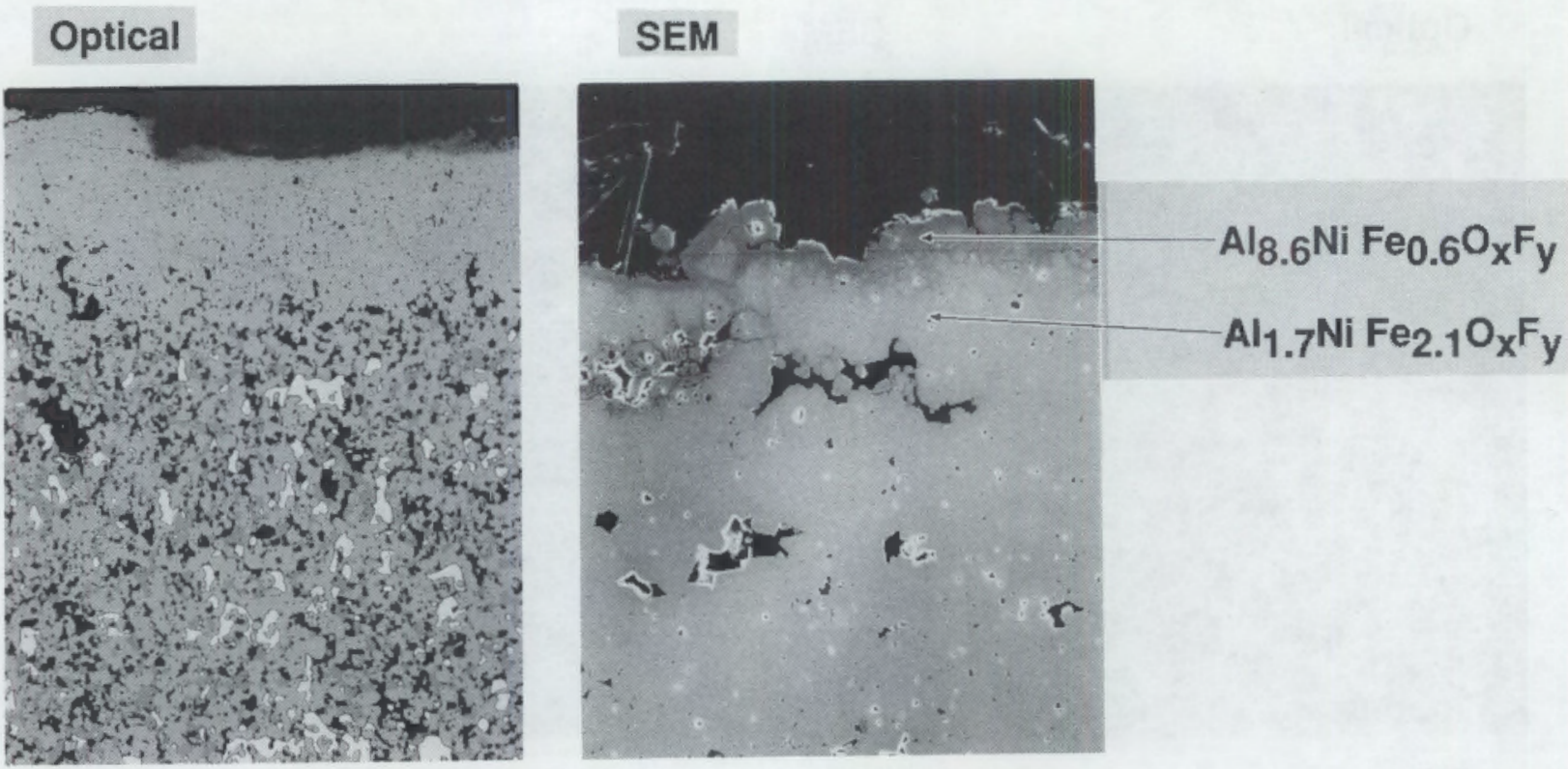

$$
\overline{100 \mu \mathrm{m}}
$$

FIGURE 5.43. Micrographs of Region F1-W1 ("Outside")

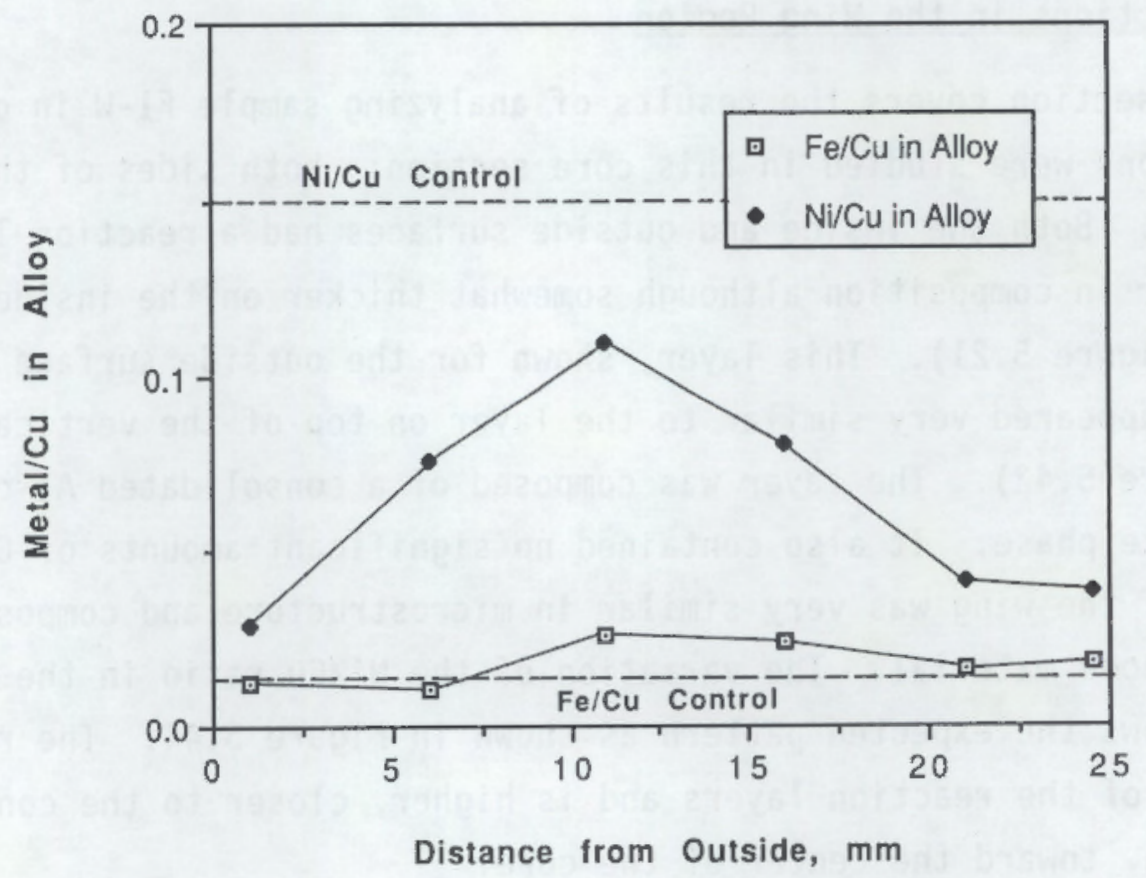

FIGURE 5.44. Composition of Alloy Phase as a Function of Position in the Wing Region 
vapor phases). In the prototype anode test (Strachan et al. 1990), the muchlarger upper surfaces of that anode corroded severely, forming mostly Cu0 in the process. This type of degradation appears to have been minimized in the pilot cell test by making the wings smaller and keeping them largely covered with crust. Also, part of the reason for the less severe attack in the pilot cell test may have been that the wings were kept in a region of lower oxygen fugacity. The presence of $\mathrm{CuO}$ on the prototype anode also suggests that the redox potential (amount of oxygen) at the upper anode surfaces in this test was higher than in the pilot cell.

\subsubsection{Reactions in Other Anode Core Sections}

Core sections were also removed from other cermet anodes from the pilot cell test. One of these anodes was Anode C2, which was exposed to the severe conditions of higher current and low alumina concentrations. (See Figures 4.14 and 4.22 for the operating conditions of Anode C2.) Figures 5.45, 5.46 and 5.47 show micrographs of the three pieces of the vertical core section taken from Anode $\mathrm{C2}$. This core was $2.2 \mathrm{~cm}$ in diameter (instead of $1 \mathrm{~cm}$ ) but was similar in all other dimensional respects to the vertical core sections from Anode F1. As shown in these figures (as well as the cross section of the entire anode in Figure 5.6), the reaction layer in Anode C2 was over 1 inch thick. This is much thicker than the layer in Anode F1. It is also extremely complicated in structure as shown in the figures. However, some of the trends in composition are similar to those observed in Anode F1. In particular, the $\mathrm{Cu}$ in the reaction layer was oxidized primarily to $\mathrm{Cu}_{2} \mathrm{O}$, which was segregated into sublayers or regions, and the metallic phase behind the reaction layer was obviously enriched in $\mathrm{Cu}$ relative to $\mathrm{Ni}$. Because of the complexity of the structure of this anode, however, no additional chemical analyses were performed on it.

\subsubsection{Summary of Chemical Changes in the Cermet Anode}

Since evidence for a number of important chemical changes was found in this work, it seems appropriate at this time to summarize these results. Further discussion, in particular regarding any proposed chemical reactions, is given in Section 6.1. The most significant chemical changes in the cermet 


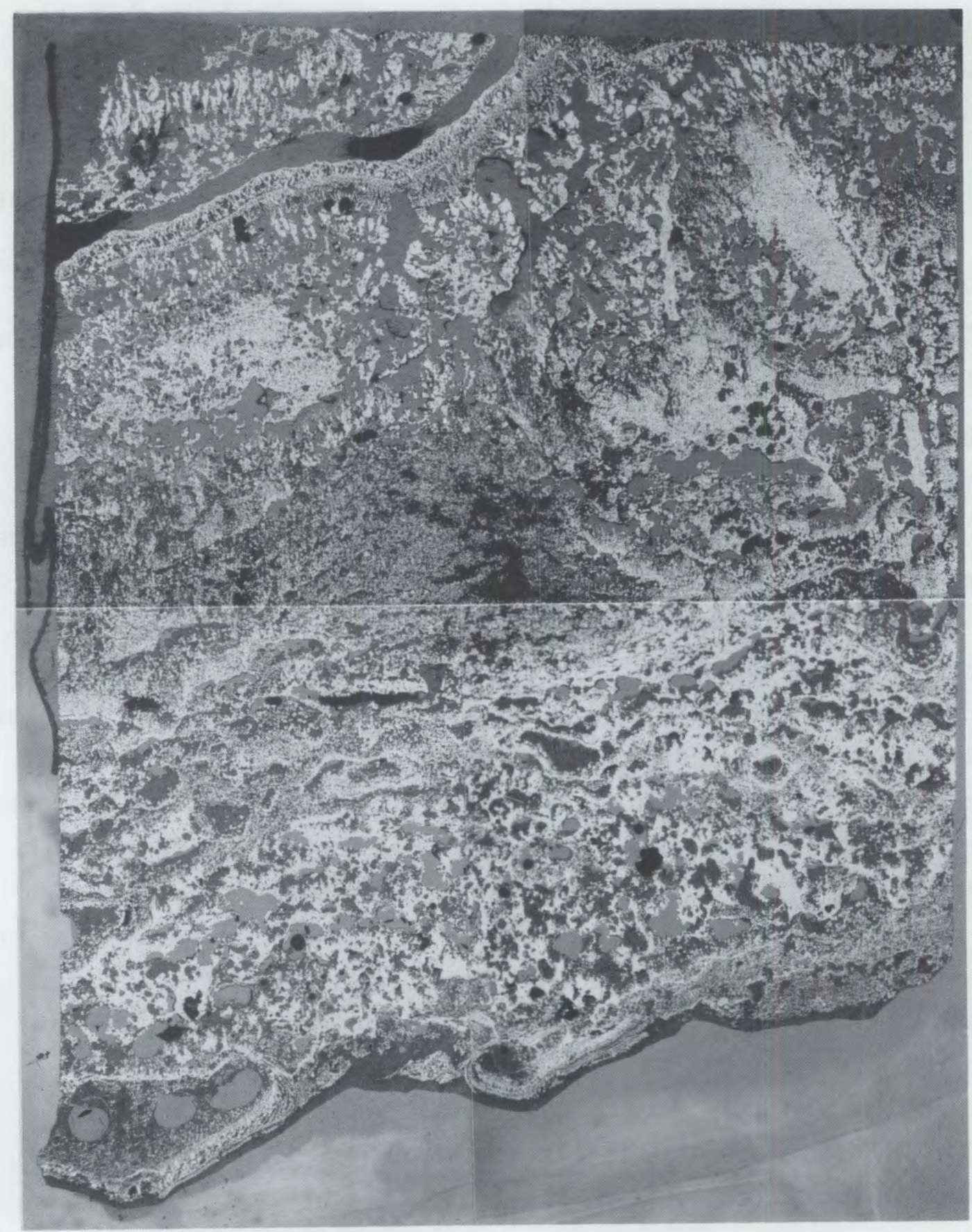

Bottom

Surface

\section{$\sqrt{3 \mathrm{~mm}}$}

FIGURE 5.45. Low Magnification Photograph of Core Section from Anode C2 (Bottom Region) 

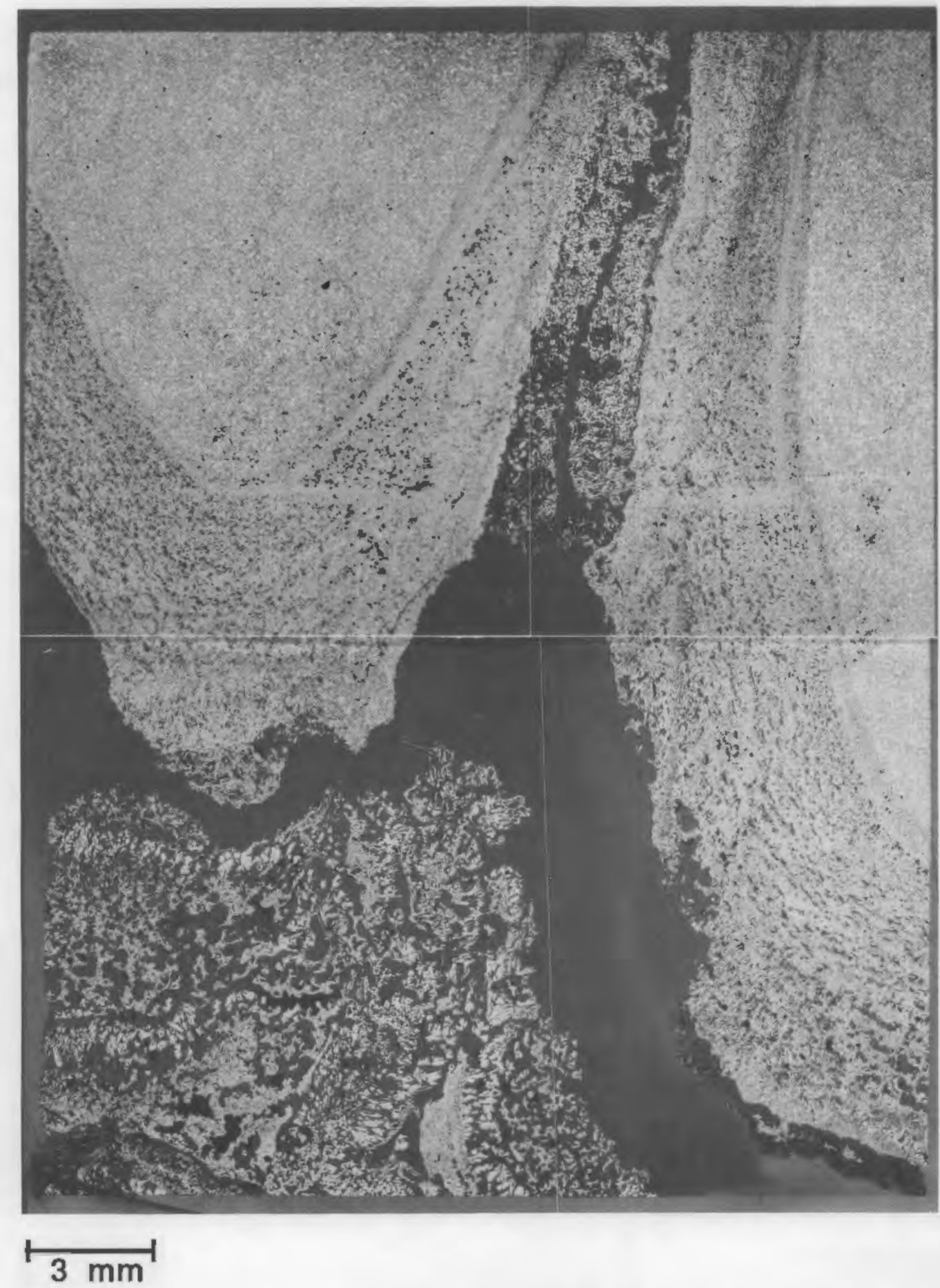

FIGURE 5.46. Low Magnification Photograph of Core Section from Anode C2 (Middle Region) 


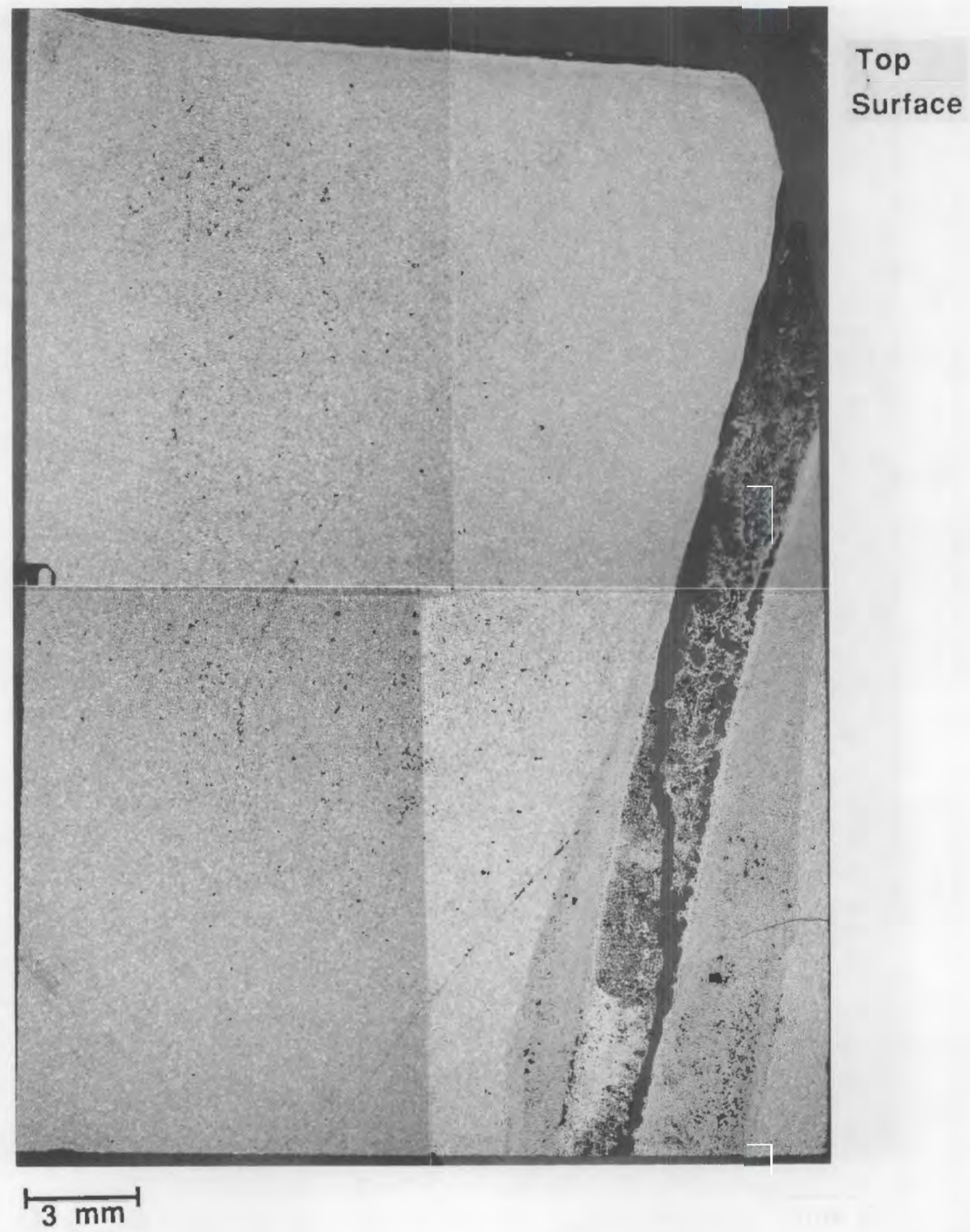

FIGURE 5.47. Low Magnification Photograph of Core Section from Anode C2 (Top Region) 
anode that appeared to result from the pilot-scale testing, as determined from the post-test analyses, included the following:

- Reaction layers formed on all surfaces of the anodes.

- For the reaction layer on the surfaces exposed to electrolyte:

- There was significant redistribution and segregation of phases.

- The metallic phase oxidized completely.

- In general, $\mathrm{Cu}$ oxidized to give $\mathrm{Cu}_{2} \mathrm{O}$ and $\mathrm{Cu}_{2} \mathrm{Ni}_{\mathrm{O}} \mathrm{O}$. The amount of $\mathrm{Cu}$ in the $\mathrm{Cu}-\mathrm{Ni}$ oxide decrease as a function of distance from the surface.

- Copper was completely absent from regions right at the electrode surface.

- Nickel oxidized to give $\mathrm{NiF}_{2}$.

- Aluminum was incorporated into the nickel ferrite phase to give solid solutions of varying compositions, but all containing $\mathrm{Ni}, \mathrm{Fe}$, and $\mathrm{Al}$.

- For reaction layers on surfaces exposed to the vapor phase:

- Copper was essentially absent.

- The primary phase was a ferrite-1ike $\mathrm{Ni}-\mathrm{Fe}-\mathrm{Al}$ phase with varying $\mathrm{Al}$ composition.

- The $\mathrm{Ni}-\mathrm{Fe}-\mathrm{Al}$ phase showed a large-grain structure that was significantly different from the original microstructure. The phase was essentially consolidated.

- Deeper within the anode:

- The metallic phase was enriched in $\mathrm{Cu}$ (relative to $\mathrm{Ni}$ )

close to the reaction layer boundaries.

- Evidence for electrolyte ingress was found. An Al-F containing species was identified along grain boundaries in fracture specimens.

- A fluoride species containing both $\mathrm{Ni}$ and $\mathrm{Fe}$ was found. The amount of $\mathrm{Fe}$ relative to $\mathrm{Ni}$ in the fluoride increased as a function of distance from the bottom surface of the anode. 


\subsection{PHYSICAL AND MECHANICAL PROPERTIES CHANGES}

The following section covers the results of density measurements on the anodes used in the pilot cell test and of studies on their mechanical properties. In all of this work, measurements were made on samples removed from the center of Anode F1 after testing in the pilot cell. The samples were from the region of "native microstructure," i.e., they did not include any of the reaction layers. Measurements on F1 were then compared to results on another anode (control) fabricated by CMI but not tested in the pilot cell.

\subsubsection{Density}

Density measurements were made on rectangular samples taken from the anodes for the purpose of mechanical properties testing. These samples are described in Section 5.3.2. The results of the density measurements are given in Table 5.2. As shown in Table 5.2, the anodes appear to have become significantly less dense as a result of testing in the pilot cell. The control anode was also significantly less dense than anodes made previously at PNL, probably due to the lower consolidation pressure used by CMI (Section 3.2). It is possible that the lower densities contributed to a more open pore structure that assisted electrolyte ingress and attack. The subsequent internal degradation of the anode material appears to have contributed to an additional lowering of density. Alternatively, the ingress could also have involved grain boundary migration of electrolyte components. In all likelihood, both avenues of penetration were utilized.

\section{TABLE 5.2. Densities of Cermet Anodes}

\begin{tabular}{lc}
\multicolumn{1}{c}{ Anode Material } & Density, $\mathrm{g} / \mathrm{cm}^{3}$ \\
Control CMI Anode & $5.82 \pm 0.01$ \\
Anode Fl (After Test) & $5.67 \pm 0.05$ \\
Typical PNL-Fabricated Anodes & $6.05-6.10$
\end{tabular}




\subsubsection{Mechanical Properties}

Fracture strength, fracture toughness, and ductile-brittle transition temperature (DBTT) were measured for the cermet anodes as a function of temperature. Measurements were made on samples taken from Anode F1 and a control anode (which was not tested in the pilot cell). The samples from Anode Fl were removed after testing in the pilot cell and were taken from the interior region of the anode, i.e., they did not contain the reaction layer. Strength and toughness were determined to be rather low for the cermet material and both were significantly degraded during the pilot cell test. In addition, the DBTT was reduced from $1000^{\circ} \mathrm{C}$ for the control anode material to $500^{\circ} \mathrm{C}$ for Anode Fl. Scanning electron microscopy (SEM) revealed that the fracture mode changed from transgranular to intergranular accompanying the decrease in toughness and shift in DBTT due to pilot cell testing. A thermal shock resistance parameter was calculated and found to be very low for a typical cermet material.

\section{Procedures for Mechanical Properties Testing}

Four-point bend testing was performed on rectangular bend bars $(4 \mathrm{~mm} x$ $4 \mathrm{~mm} \times 50 \mathrm{~mm}$ ) using SiC fully-articulated bend fixtures having a lower span of $40 \mathrm{~mm}$ and an upper span of $20 \mathrm{~mm}$. Tests were performed in air from ambient up to $1100^{\circ} \mathrm{C}$ at a strain rate of $1.27 \times 10^{-5} \mathrm{~s}^{-1}$. The mid-point bending deflection was measured and used to calculate stress-strain curves for each specimen. In addition, chevron-notched bend (CVN) bars (Figure 5.48) were used to measure the chevron-notch fracture toughness over the same temperature range. These tests were performed at the same strain rate in four-point bending and the overall specimen dimensions were the same as the unnotched bend bars. Details of the CVN geometry are given in Figure 5.48. The test temperature was measured by a Type $K$ thermocouple inserted into the bend fixture. All data were recorded onto a computer-based data acquisition system. SEM stereo photomicrographs were taken of representative fracture surfaces above and below the DBTT of each material. Other test details are given in Table 5.3. 


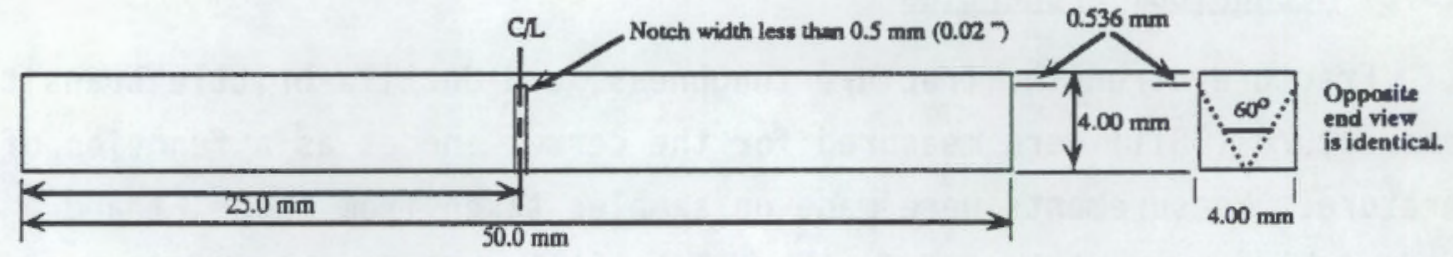

Detail of Chevrom Noteb Geometry
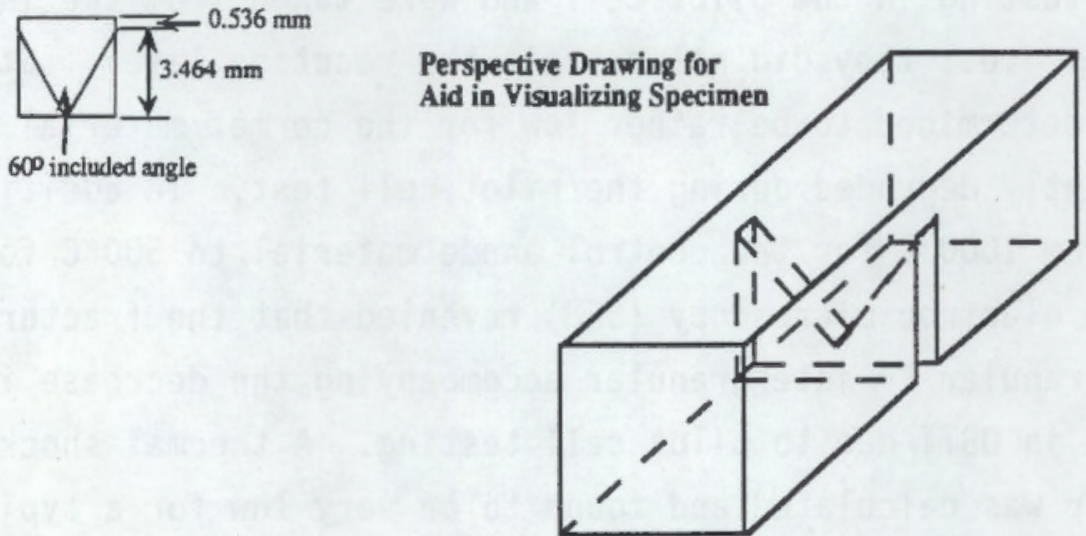

FIGURE 5.48. Chevron-Notch Bars

\section{Results of Mechanical Properties Testing}

Four-point bend fracture strength (modulus of rupture) was calculated from the fracture load using the standard expression for four-point bending

$$
\sigma=(3 L P) /\left(4 B W^{2}\right)
$$

where $L$ is the lower bending span, $P$ is the fracture load, $B$ is the specimen width, and $W$ is the specimen height between the loading points. Bending strain was calculated from specimen mid-point deflection using

$$
\epsilon=(48 W \delta) /\left(11 L^{2}\right)
$$

where $\delta$ is the measured deflection of the specimen mid-point on the tensile face. Stress-strain curves were plotted for each specimen tested and some typical curves are shown in Figure 5.49. For those specimens that exhibited significant plastic deformation, the offset yield strength at a strain of 0.002 was reported. 
IABLE 5.3. Test Matrix for Mechanical Properties Testing

\begin{tabular}{|c|c|c|c|c|}
\hline Specimen & $\begin{array}{c}\text { Test Tem- } \\
\text { perature, }{ }^{\circ} \mathrm{C}\end{array}$ & $\begin{array}{l}\text { Number } \\
\text { Tested }\end{array}$ & $\begin{array}{c}\text { Strength, } \\
\quad \mathrm{MPa} \\
\end{array}$ & $\begin{array}{l}\text { Toughness, } \\
\mathrm{MPa} \cdot \mathrm{m}^{8.5}\end{array}$ \\
\hline \multicolumn{5}{|l|}{ Control Anode } \\
\hline Bend Bar (CBB) & 21 & 1 & 112.4 & \\
\hline CBB & 800 & 1 & 116.7 & \\
\hline $\mathrm{CBB}$ & 900 & 2 & 101.8 & \\
\hline CBB & 950 & 3 & $98.8^{(a)}$ & \\
\hline CBB & 1000 & 3 & $117.4^{(a)}$ & \\
\hline CBB & 1050 & 1 & 85.5 & \\
\hline \multicolumn{5}{|l|}{ Control Anode } \\
\hline \multicolumn{5}{|l|}{ Chevron-notched } \\
\hline Bar (CCN) & 21 & 1 & & 2.78 \\
\hline CNN & 800 & 1 & & 2.88 \\
\hline $\mathrm{CCN}$ & 900 & 1 & & 2.73 \\
\hline $\mathrm{CCN}$ & 950 & 2 & & 2.42 \\
\hline $\mathrm{CCN}$ & 1000 & 2 & & 2.56 \\
\hline $\mathrm{CCN}$ & 1050 & 2 & & 3.73 \\
\hline \multicolumn{5}{|l|}{ Anode F1 Bend } \\
\hline Bar (F1B8) & 21 & 1 & 49.2 & \\
\hline F1BB & 350 & 1 & 63.3 & \\
\hline F1BB & 400 & 1 & 44.1 & \\
\hline F1BB & 450 & 1 & 57.6 & \\
\hline F1BB & 500 & 2 & 57.61 & \\
\hline $\mathrm{F} 1 \mathrm{BB}$ & 550 & 1 & 49.0 & \\
\hline F1BB & 600 & 1 & 37.2 & \\
\hline F1BB & 800 & 1 & 18.3 & . \\
\hline
\end{tabular}


TABLE 5.3. (contd)

\begin{tabular}{|c|c|c|c|c|}
\hline Specimen & $\begin{array}{c}\text { Test Tem- } \\
\text { perature, }{ }^{\circ} \mathrm{C} \\
\end{array}$ & $\begin{array}{l}\text { Number } \\
\text { Tested } \\
\end{array}$ & $\begin{array}{c}\text { Strength, } \\
\mathrm{MPa} \\
\end{array}$ & $\begin{array}{c}\text { Toughness, } \\
\mathrm{MPa} \cdot \mathrm{m}^{6.5}\end{array}$ \\
\hline Anode Fl Chevron- & & & & \\
\hline notched $\mathrm{Bar}$ ( $\mathrm{F} 1 \mathrm{CN})$ & 21 & 1 & & 1.66 \\
\hline $\mathrm{FICN}$ & 350 & 1 & & 2.37 \\
\hline $\mathrm{F} 1 \mathrm{CN}$ & 400 & 1 & & 1.71 \\
\hline $\mathrm{F} 1 \mathrm{CN}$ & 450 & 1 & & 2.14 \\
\hline FICN & 500 & 2 & & 2.59 \\
\hline FICN & 550 & 2 & & 2.47 \\
\hline $\mathrm{F} 1 \mathrm{CN}$ & 600 & 1 & & 1.89 \\
\hline
\end{tabular}

(a) The estimated standard deviations where 3 measurements were taken were $7.8\left(950^{\circ} \mathrm{C}\right)$ and $16.9\left(1000^{\circ} \mathrm{C}\right)$. These values are significantly less than the differences between the Control and the Fl Samples indicating the differences are real and result from the pilot cell testing.

The control anode exhibits brittle fracture behavior up to $1000^{\circ} \mathrm{C}$ with a fracture strength ranging from $100 \mathrm{MPa}$ to $120 \mathrm{MPa}$ (14.5 ksi to $17.4 \mathrm{ksi}$ ) over that temperature range (Figure 5.50). Measured strength increases slightly from ambient up to $1000^{\circ} \mathrm{C}$ with a dip at about $900^{\circ} \mathrm{C}$. The strength drops off rapidly above $1000^{\circ} \mathrm{C}$ as the material deforms plastically (see Figure 5.49a). Anode Fl exhibits similar behavior, but the strength is lower and the DBTT is about $500^{\circ} \mathrm{C}$. Bend strengths range from $50 \mathrm{MPa}$ to $63 \mathrm{MPa}(7.2 \mathrm{ksi}$ to $9.2 \mathrm{ksi})$ and decrease rapidly above the DBTT (see Figure 5.49b).

Fracture toughness measurements (Figures 5.51 and 5.52) are quite low for a cermet material; the fracture toughness of these materials is typically greater than $10 \mathrm{MPa} \cdot \mathrm{m}^{0.5}$. These measurements are made from load-deflection curves of chevron-notched bend bars and are referred to as chevron-notch $\mathrm{K}_{\mathrm{c}}$ measurements. The analysis for these measurements gives (Whithey and Bowen 1990) 


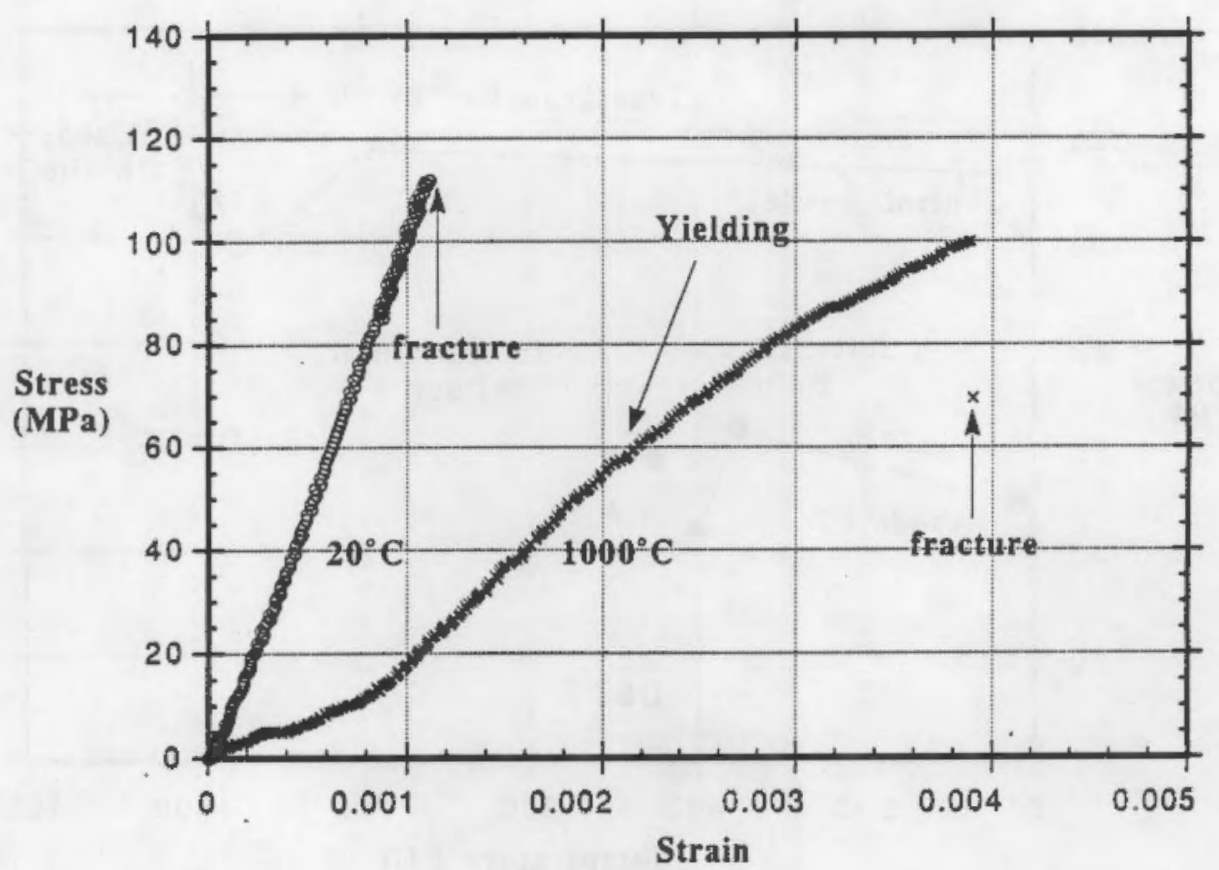

(a) Stress-Strain Curve for Control Anode

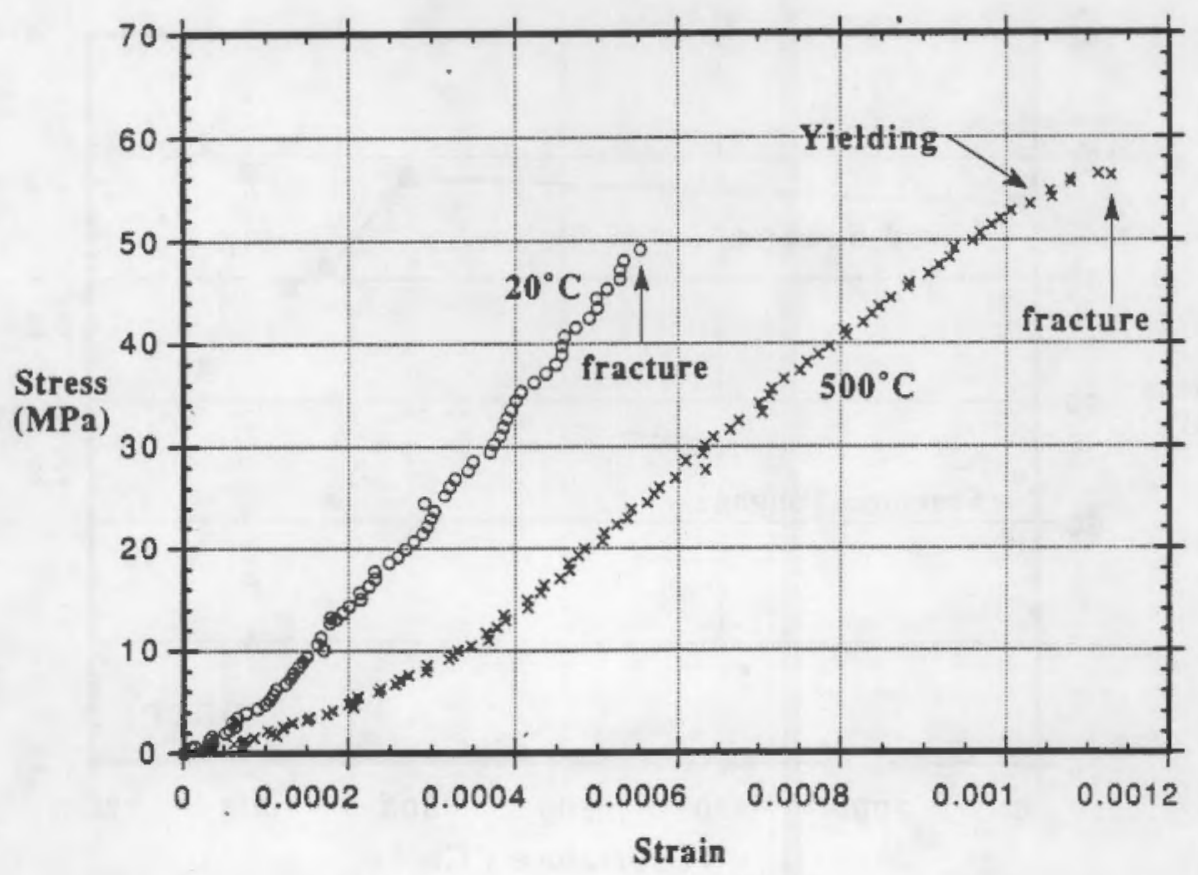

(b) Stress-Strain Curve for Anode F1

FIGURE 5.49. 


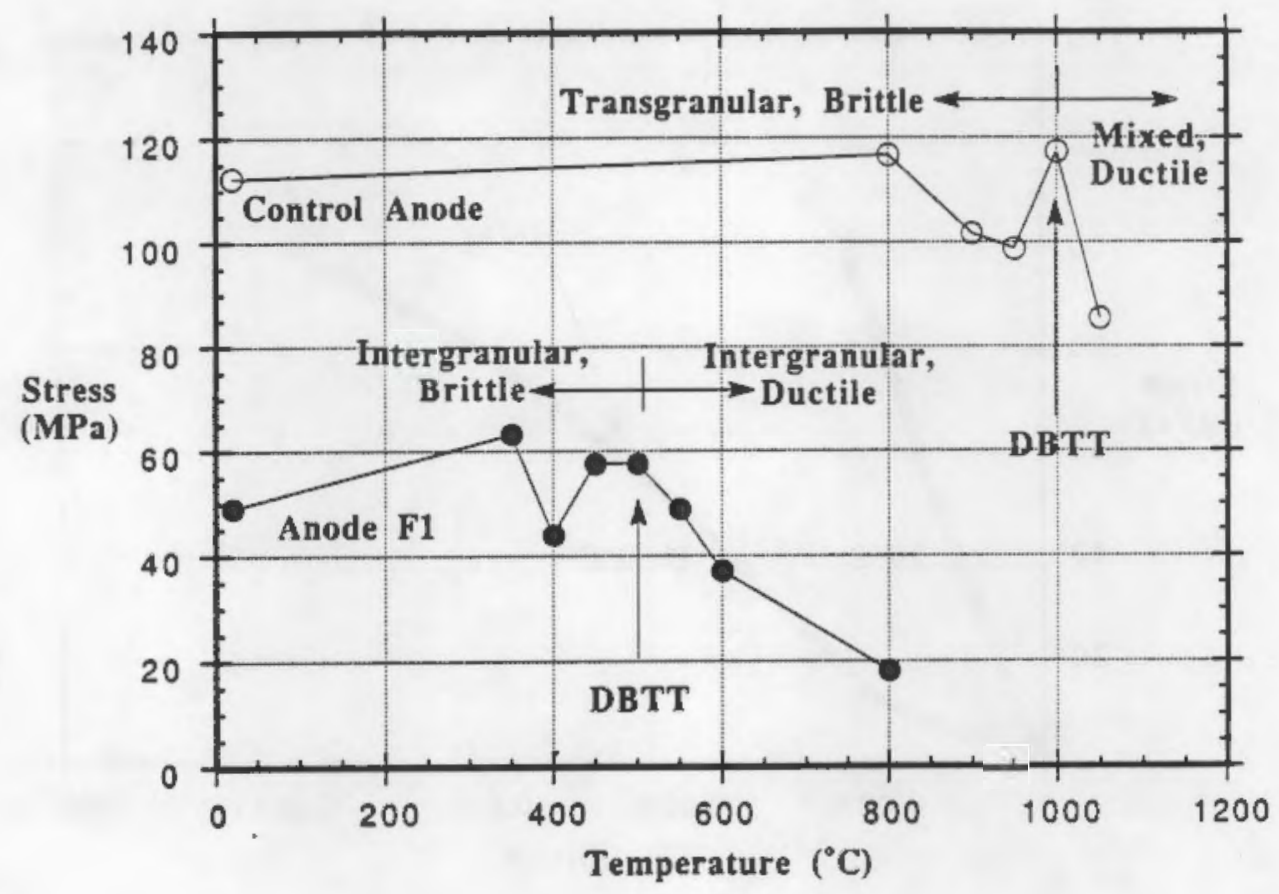

FIGURE 5.50. Variation of Fracture Stress as a Function of Temperature

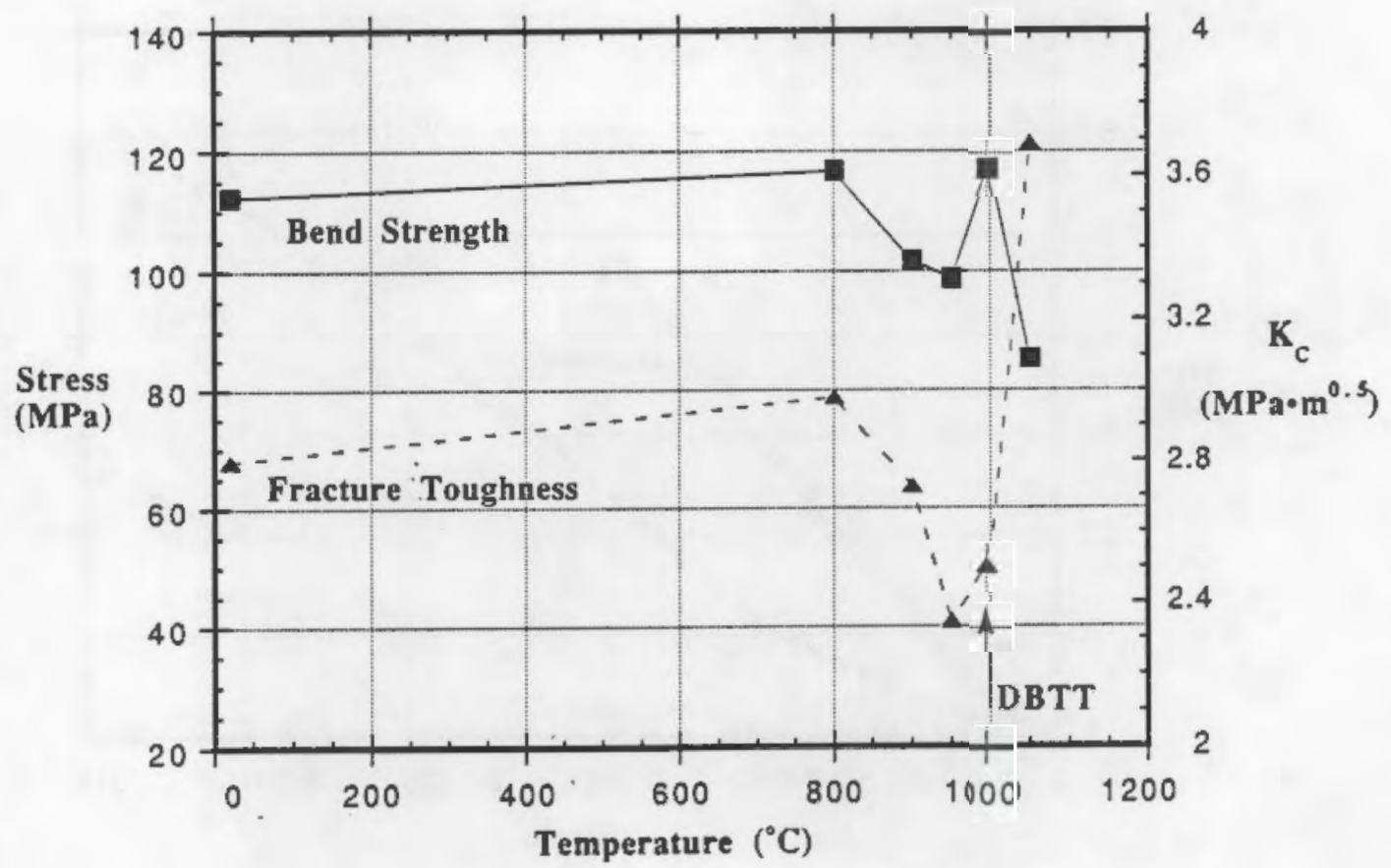

FIGURE 5.51. Toughness and Strength for Control Anode as a Function of Temperature 


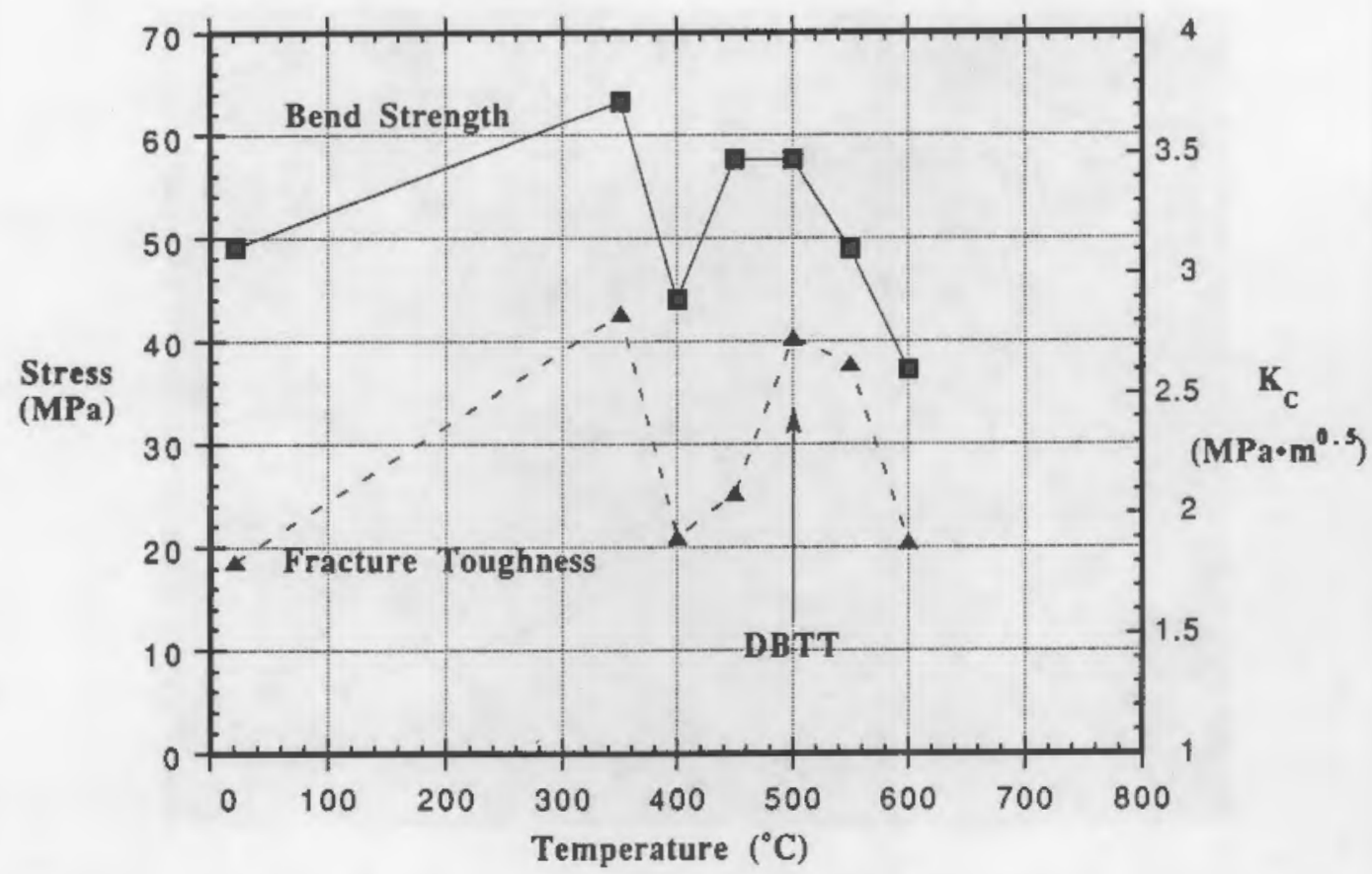

FIGURE 5.52. Toughness and Strength for Anode F1 as a Function of Temperature

$$
K_{C}=\left(P_{\max } Y *{ }_{\min }\right) /\left(B W^{1 / 2}\right)
$$

where $K_{c}$ is the mode I fracture toughness, $P_{\max }$ is the maximum load from the load-deflection curve, and $Y^{*}{ }_{\min }$ is the minimum in the chevron-notch compliance function (Whithey and Bowen 1990). A nominal value of ${ }^{*}{ }_{\min }$ was calculated to be 16 for the specific chevron-notch geometry used in these tests (Figure 5.48).

Toughness values range from $2.4 \mathrm{MPa} \cdot \mathrm{m}^{0.5}$ to $3.7 \mathrm{MPa} \cdot \mathrm{m}^{0.5}$ for the control anode material and from $1.8 \mathrm{MPa} \cdot \mathrm{m}^{0.5}$ to $2.7 \mathrm{MPa} \cdot \mathrm{m}^{0.5}$ for Anode F1 material. The toughness increases above the DBTT, as expected, for the control anode material, but does not increase for Anode F1 material. There is an excellent correspondence between the measured toughness and the measured fracture strength (Figures 5.51 and 5.52). Below the DBTT, all the features of the fracture toughness curves are replicated in the strength curves.

Fracture surface morphologies below and at the DBTT were examined using the SEM and are shown in Figures 5.53 and 5.54. The control anode exhibited 


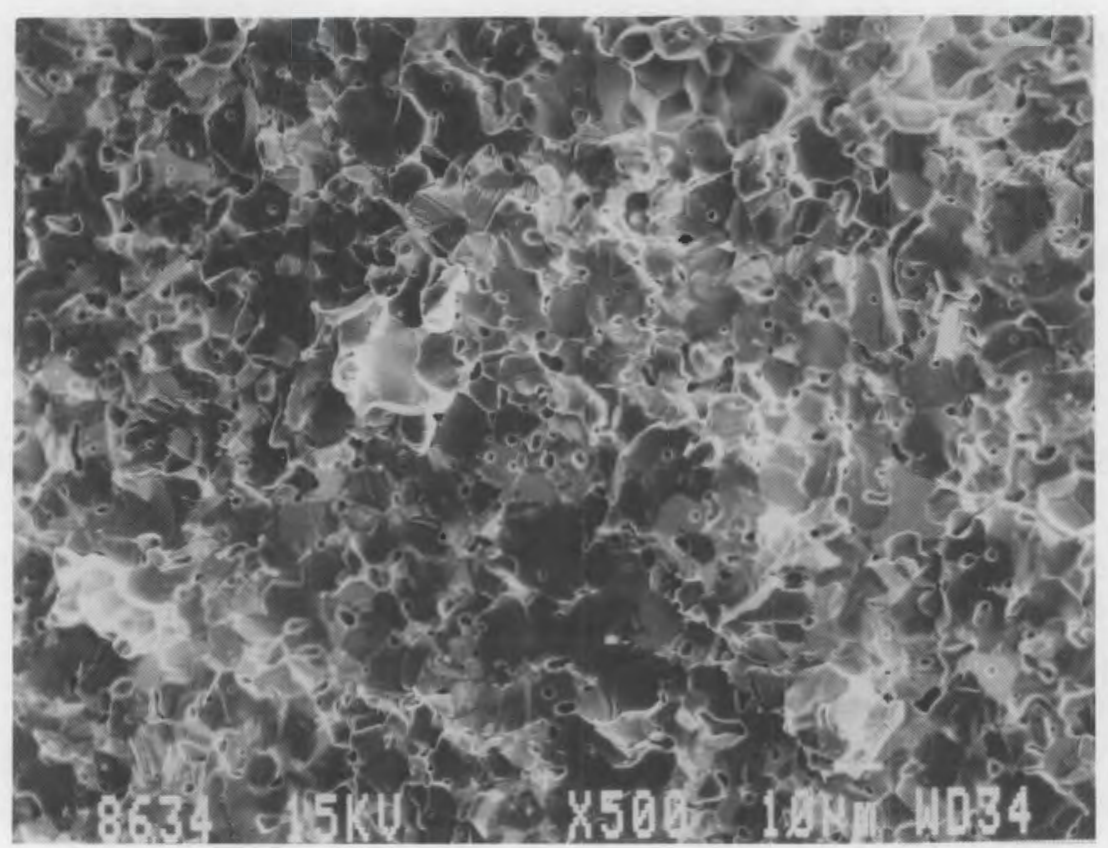

(a) Control Anode Showing Transgranular Fracture

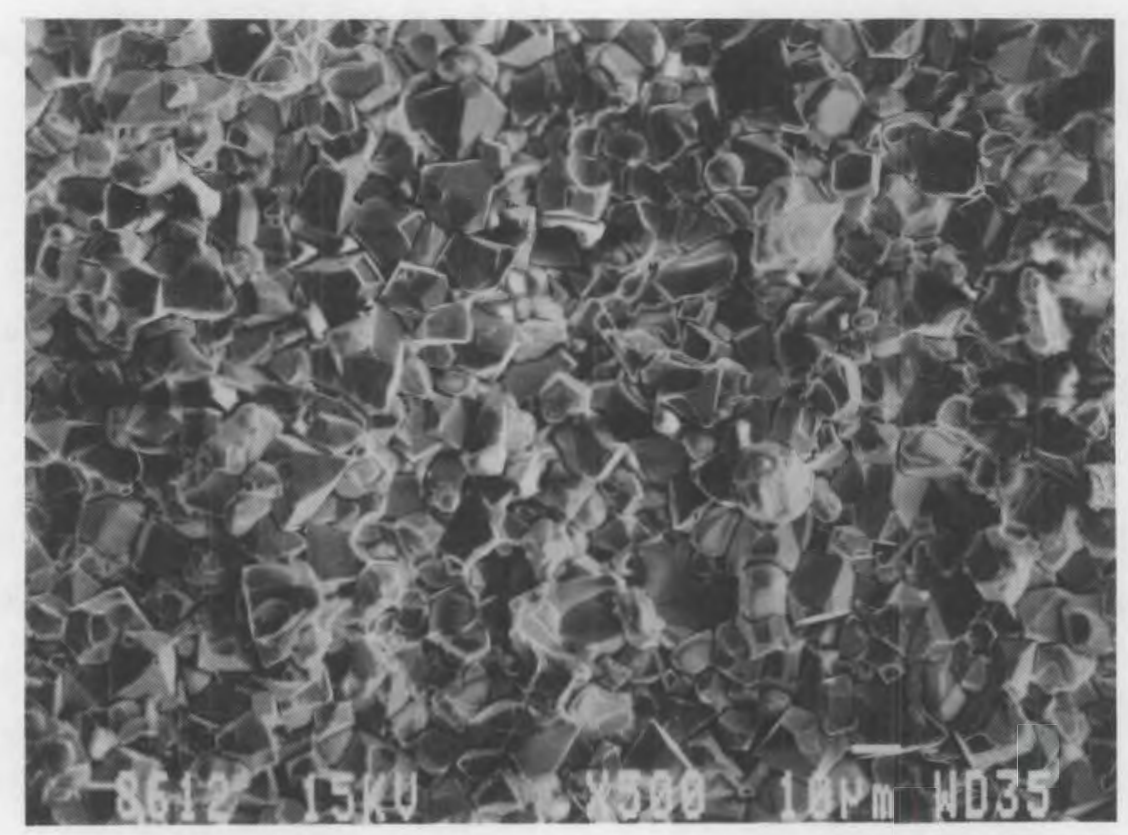

(b) Anode F1 Showing Intergranular Fracture

FIGURE 5.53. Fracture Morphology below the DBTT $\left(20^{\circ} \mathrm{C}\right)$ 


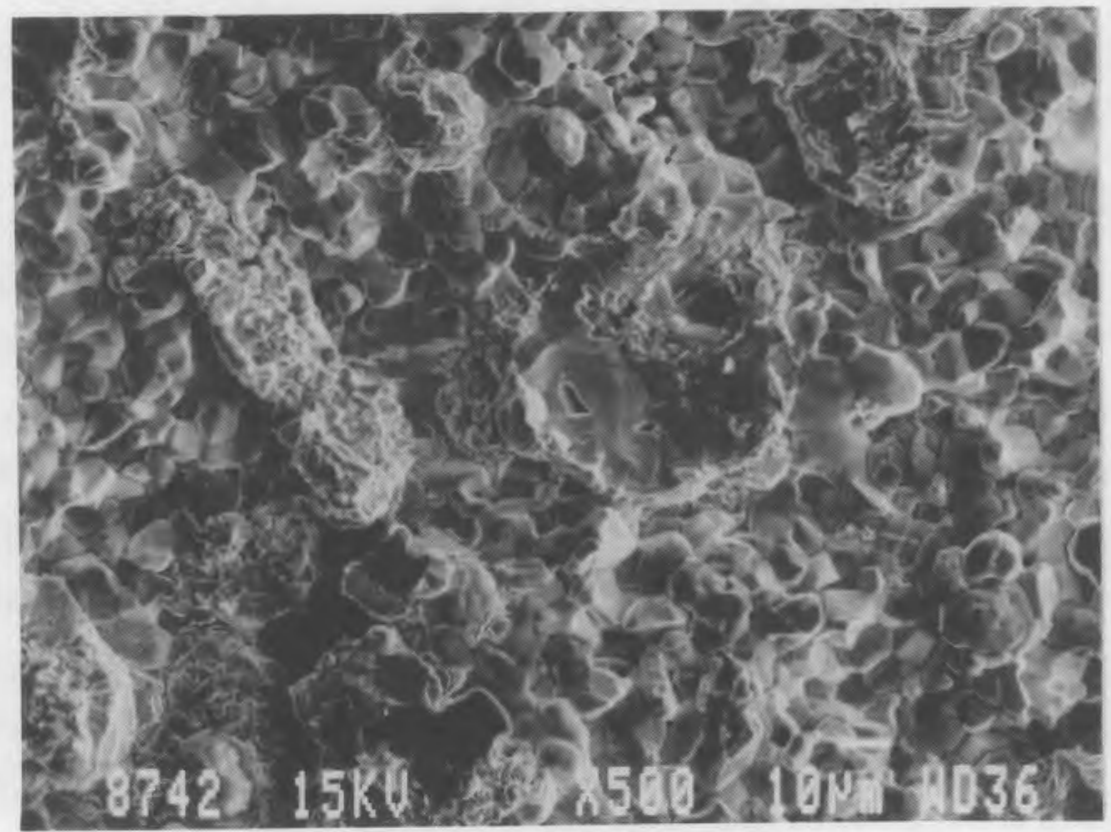

(a) Control Anode at $1000^{\circ} \mathrm{C}$ Showing Mixed Transgranular-Intergranular Fracture

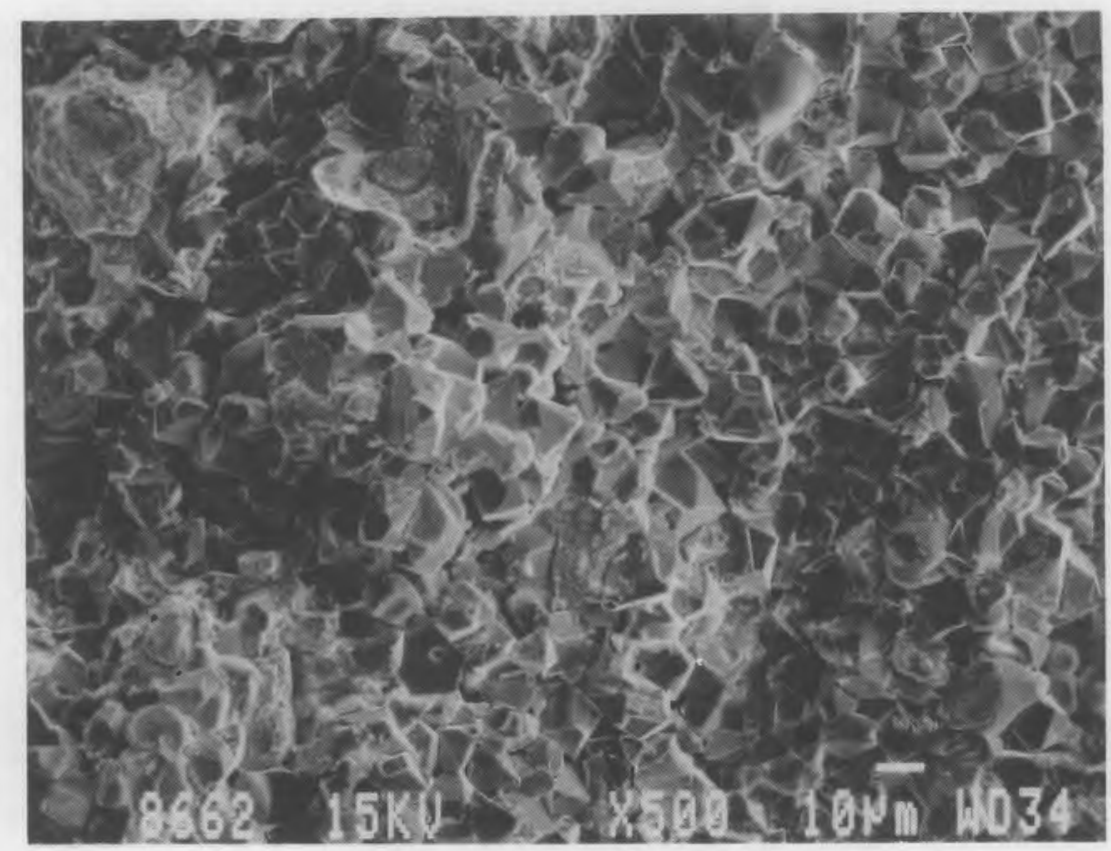

(b) Anode $\mathrm{Fl}$ at $500^{\circ} \mathrm{C}$ Showing Intergranular Fracture

FIGURE 5.54. Fracture Morphology at the DBTT 
mainly transgranular, brittle fracture below the DBTT and a mixture of transgranular-intergranular fracture at the DBTT. Anode F1 exhibited intergranular fracture both below and above the DBTT.

\section{Discussion of Results of Mechanical Properties Tests}

Measured fracture toughness of the two anode materials, control anode and Anode F1, are quite low, even in comparison to other ceramic materials (Table 5.4 and Figure 5.55). Thus, the measured fracture toughness of 2.8 $\mathrm{MPa} \cdot \mathrm{m}^{0.5}$ is consistent with a sintered oxide ceramic, but not with a material containing dispersed copper metal. The two anode materials do not compare favorably with WC, a typical cemented carbide cermet, in terms of fracture toughness, for example (Table 5.4 and Figure 5.55). Apparently, this is due to the distribution of the metallic phase in the anode material. A discontinuous distribution of metallic phase or a very small size of the metallic phase regions could account for the brittle behavior of these two anode materials.

\section{TABLE 5.4. Materials Parameters for Various Ceramics and Cermets}

\begin{tabular}{|c|c|c|c|c|c|c|c|}
\hline Material & $\begin{array}{c}\text { Fracture } \\
\text { Strength, } \\
\mathrm{MPa} \\
\end{array}$ & $\begin{array}{l}\text { Young's } \\
\text { Modulus, } \\
\text { GPA }\end{array}$ & $\begin{array}{c}\text { Poisson's } \\
\text { Ratio } \\
\end{array}$ & $\begin{array}{c}\text { Therma 1 } \\
\text { Expansion } \\
\text { Coefficient, } \\
10^{-6} \mathrm{~K}^{-1} \\
\end{array}$ & $\begin{array}{l}\text { Thermal Con- } \\
\text { duct ivity } \\
W \cdot m^{-1} \cdot K \\
\end{array}$ & $\begin{array}{c}\text { Therma } 1 \\
\text { Shock } \\
\text { Parameter } \\
\mathrm{kW} \cdot \mathrm{m} \\
\end{array}$ & $\begin{array}{l}\text { Fracture } \\
\text { Toughngs\$, } \\
\mathrm{MPa} \cdot \mathrm{m} .5 \\
\end{array}$ \\
\hline Pyrex Glass & 70 & 70 & ø. 24 & 4.6 & 1.7 & 0.28 & 0.75 \\
\hline $\mathrm{Si}_{3} \mathrm{~N}_{4}$ & $79 \emptyset$ & 300 & 0.24 & 3.0 & 17.0 & 10.65 & 6.0 \\
\hline $\mathrm{SiC}$ & $50 \emptyset$ & 400 & 0.19 & 5.0 & 85.0 & 17.2 & 15.6 \\
\hline $\mathrm{Al}_{2} \mathrm{O}_{3}$ & 500 & 380 & 0.26 & 9.0 & 8.0 & 0.87 & 3.0 \\
\hline WC $(6 \% \mathrm{Co})$ & 1400 & 600 & 0.26 & 4.9 & 85.0 & 29.95 & $15 . \emptyset$ \\
\hline $\begin{array}{l}\text { Anode } \\
\text { Cermet }\end{array}$ & 110 & 110 & 9.25 & 12.0 & $10.0^{(a)}$ & 0.63 & 2.8 \\
\hline
\end{tabular}

(a) Anode thermal conductivity estimated from measured thermal diffusivity of $\emptyset .0155 \mathrm{~cm}^{2} \mathrm{~s}^{-1}$ at $500^{\circ} \mathrm{C}$. 


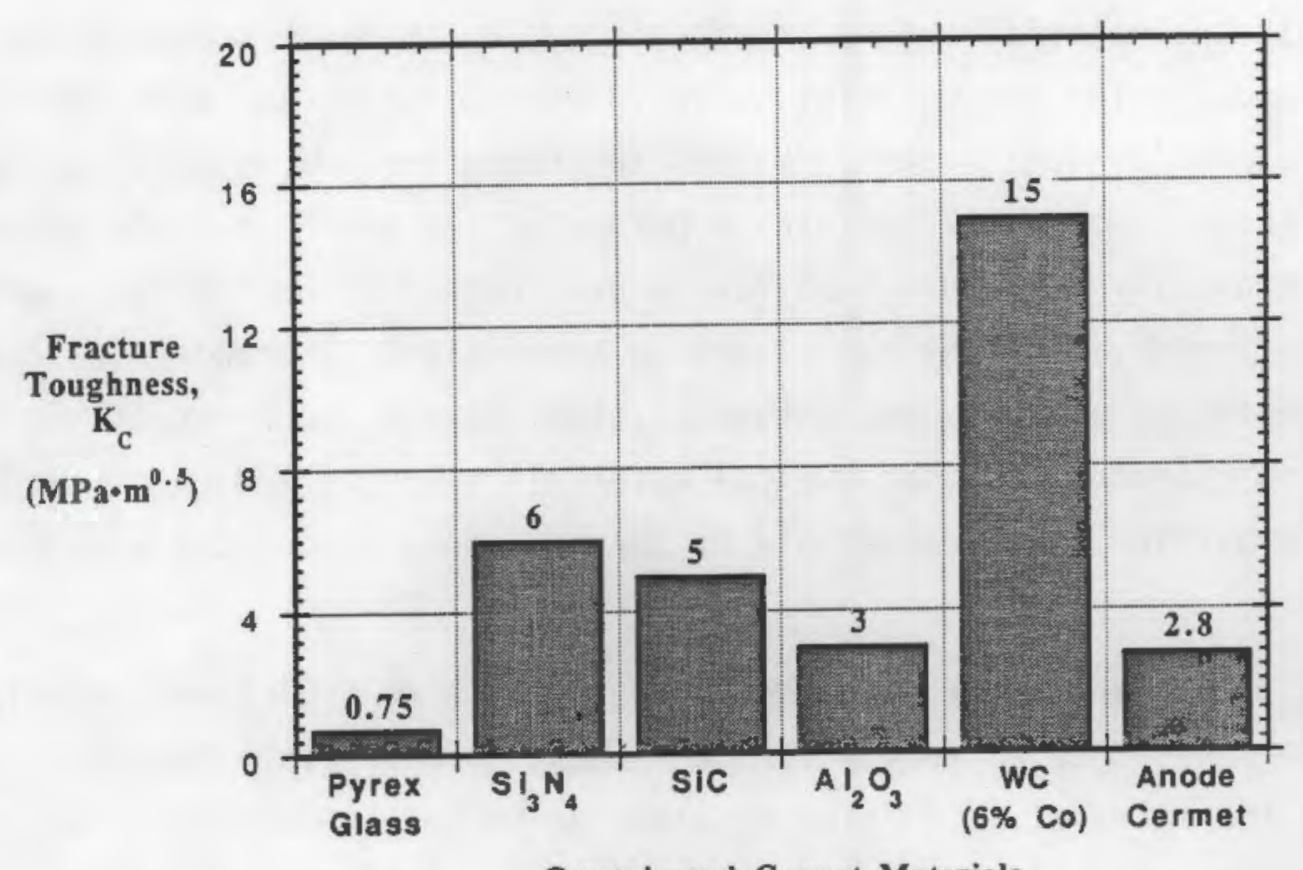

Ceramic and Cermet Materials

FIGURE 5.55. Comparison of Fraction Toughness Values

Given that they exhibit brittle behavior at low temperatures, the measured mechanical properties do provide some useful information. The excellent correspondence between the fracture toughness curves and the fracture strength curves below the DBTT suggests that the fracture strength is controlled by the fracture toughness below the DBTT. That is, strength increases and decreases correspond to toughness increases and decreases below the DBTT where brittle failure occurs. The strength is limited by the largest flaw size in the anode material. Using the standard fracture toughness design criterion, $\sigma=K(\pi c)^{-0.5}$, where $c$ is the half crack length, a critical flaw size of $\sim 480 \mu \mathrm{m}$ is calculated for the control anode material.

The measured fracture strength and Young's modulus were also used to calculate a thermal shock resistance of the anode materials from (Hasselman 1970)

$$
R^{\cdot}=k \sigma_{f}(1-v) /\left(E_{y} \alpha\right)
$$


where $k$ is the material thermal conductivity, $\sigma_{f}$ is the fracture stress, $E_{y}$ is Young's modulus for the material, $v$ is Poisson's ratio, and $\alpha$ is the material thermal expansion coefficient. Values for these various material parameters and for the thermal shock resistance parameter are given in Table 5.4 and compared graphically in Figure 5.56 for several ceramics and cermets. Because of the low strength, high thermal expansion coefficient, and moderately low thermal conductivity of the anode materials, the thermal shock resistance parameter is low compared to other typical materials. This makes these anode materials particularly susceptible to thermal shock associated with use in the pilot cell.

The transgranular fracture morphology of the control anode material below the DBTT is consistent with the measured low fracture toughness. In general, the material is failing by cleavage of the oxide grains, but some copper phase pullout is observed on the fracture surface. Examination of stereo SEM photomicrographs and use of energy dispersive $x$-ray (EDS) analysis does indicate that copper particles are present and are about $20 \mu \mathrm{m}$ in diameter dispersed throughout the control anode material with a spacing of about

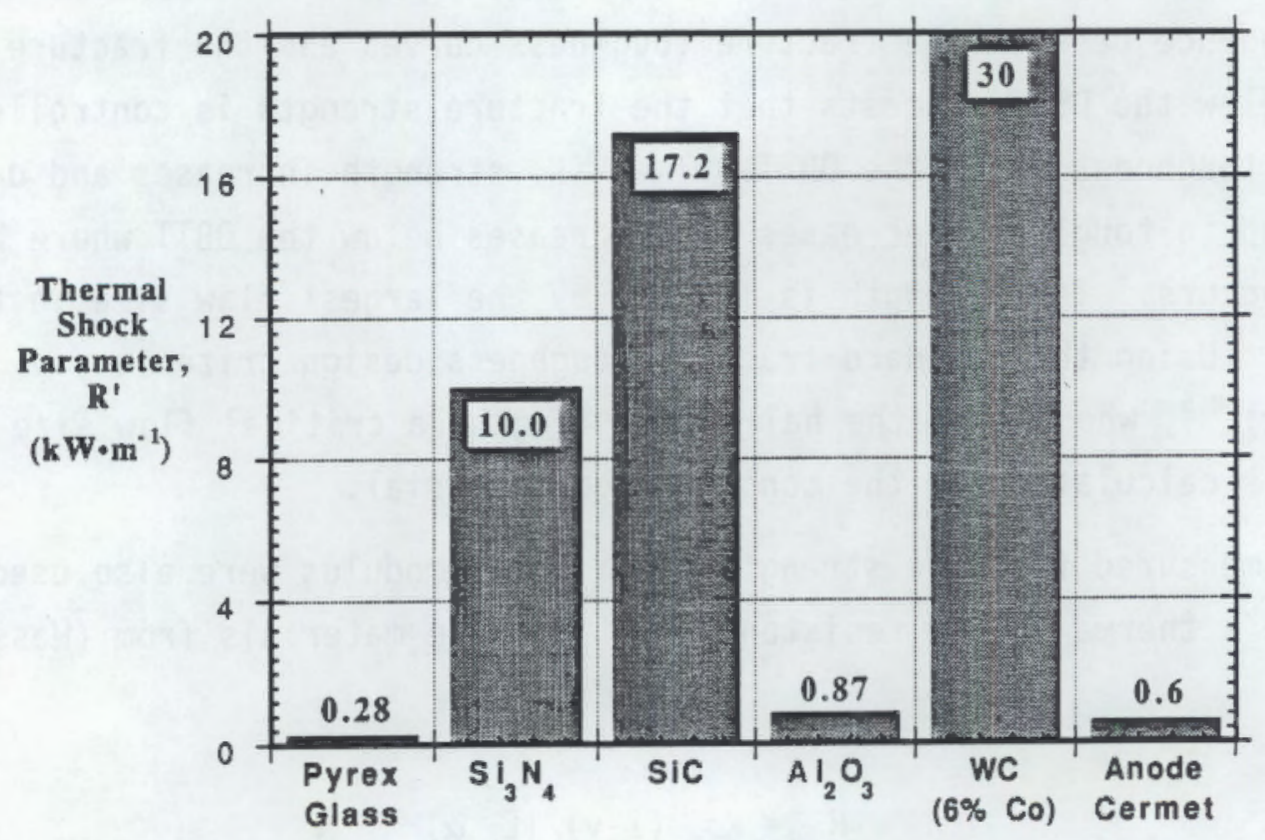

Ceramic and Cermet Materials

FIGURE 5.56. Comparison of Thermal Shock Values 
$100 \mu \mathrm{m}$ on the fracture surface. The oxide grain size is about $10 \mu \mathrm{m}$, so the copper particles are spaced about every 10 oxide grains. The copper particles appear to be deformed plastically at ambient temperature, and evidence of chisel-point failures of the particles can be seen on the fracture surface. This suggests that the copper particles are indeed contributing to the measured fracture toughness of the anode material, but, only very slightly. It may be that a monolithic oxide material without any dispersed metallic phase would have a lower fracture toughness (much like the Anode F1 material) and that a portion of the measured toughness $\left(3 \mathrm{MPa} \cdot \mathrm{m}^{0.5}\right)$ could be attributed to the metallic phase in the cermet.

The transition from transgranular cleavage to a mixed transgranularintergranular morphology above the DBTT is accompanied by oxidation of the copper phase (Figure 5.54a). Apparently, the material ductility is due to this transition and suggests that there is a thin, ductile layer at the grain boundaries, probably copper or a copper alloy, that softens enough at the DBTT to allow some limited plasticity. Indeed, EDS examinations indicate that the fracture surface of the specimens tested at or above the DBTT is covered with copper. In fact, it is rather amazing that the control anode material retains its brittle fracture behavior to such high temperatures. This behavior aiso suggests that the dispersed metallic phase is unable to provide any toughening until temperatures near its melting point, which is estimated to be about $1200^{\circ} \mathrm{C}$ from the $\mathrm{Cu}-\mathrm{Ni}$ phase diagram.

The degradation of strength and toughness in Anode Fl materials tested in the pilot cell is accompanied by a change in the fracture morphology from transgranular (control anode) to completely intergranular failure above and below the DBTT (Figures 5.53b and 5.54b). As discussed in Section 5.2, this transition is accompanied by reactions involving the metallic phase and the uptake from the electrolyte of an $\mathrm{Al}$-containing fluoride phase $\left(\mathrm{AlF}_{3}\right.$, aluminum fluoride or oxyfluoride species) at the grain boundaries (Figure 5.57). The reduction in fracture toughness follows from the reactions involving the metallic phase since they remove a toughening mechanism from the material. The reduction in strength follows from the reduction in fracture toughness. Using the room temperature value of $\mathrm{K}_{\mathrm{c}}$ of $1.8 \mathrm{MPa} \cdot \mathrm{m}^{6.5}$ and strength of $50 \mathrm{MPa}$ 


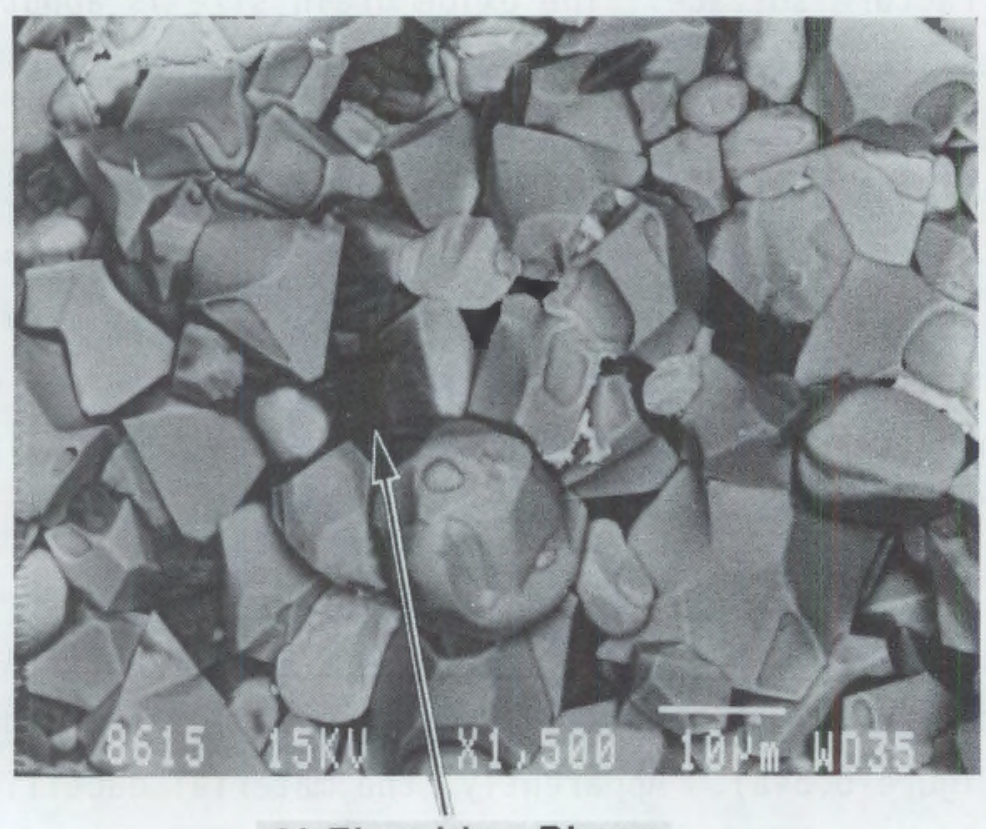

Al-Fluoride Phase

FIGURE 5.57. Micrograph of Fracture Surface Showing Presence of Aluminum Fluoride Phase at the Grain Boundaries

for Anode Fl gives a critical flaw size of $\sim 820 \mu \mathrm{m}$, which is approximately twice the critical flaw size of the control anode material. Therefore, the compositional changes not only alter the fracture toughness, but also increase the critical $\mathrm{flaw}$ size as well. The shift in DBTT from $1000^{\circ} \mathrm{C}$ to $500^{\circ} \mathrm{C}$ can be attributed to the softening of the fluoride phase at the grain boundaries.

Interestingly, both anode materials show a toughness and strength decrease prior to the onset of ductility, just below the DBTT. Since this decrease appears in both materials and appears in both the toughness measurements and the strength measurements, it is not an artifact or error in measurement. However, there is no simple explanation for these results. Perhaps, since the testing was done in air, there is an environmental effect on the material toughness.

\section{Summary of the Mechanical Properties Tests}

Four-point bend fracture strength and fracture toughness were measured for two inert anode materials, a control anode and Anode Fl from the pilot 
cell test. Measured strength and toughness of the control anode are low for cermet materials. Room temperature strength of $110 \mathrm{MPa}$ (16 ksi) and toughness of $2.8 \mathrm{MPa} \cdot \mathrm{m}^{6.5}$ were measured for the control anode. Strength increased to $117 \mathrm{MPa}(17 \mathrm{ksi})$ at $1000^{\circ} \mathrm{C}$ and then decreased above this temperature, the DBTT of the control anode material. Fracture toughness was $2.5 \mathrm{MPa} \cdot \mathrm{m}^{0.5}$ at $1000^{\circ} \mathrm{C}$ and increased to $3.7 \mathrm{MPa} \cdot \mathrm{m}^{9.5}$ at $1050^{\circ} \mathrm{C}$.

Both fracture strength and toughness of these cermet anodes were degraded by exposure to the cryolite bath. Anode Fl fracture strength ranged from $50 \mathrm{Mpa}(7.3 \mathrm{ksi})$ at room temperature to a high of $63.3 \mathrm{MPa}$ (9.2 ksi) at $350^{\circ} \mathrm{C}$. Fracture toughness was $1.7 \mathrm{MPa} \cdot \mathrm{m}^{0.5}$ at room temperature and 2.6 $\mathrm{MPa} \cdot \mathrm{m}^{6.5}$ at $500^{\circ} \mathrm{C}$. The DBTT for Anode $\mathrm{Fl}$ material was determined to be $500^{\circ} \mathrm{C}$, shifted down from the control anode by $500^{\circ} \mathrm{C}$.

Fracture mode changed from transgranular for the control anode materia? tested below the DBTT to intergranular for Anode F1 below the DBTT. Fracture mode changed from transgranular below the DBTT to mixed transgranularintergranular above DBTT for the control anode. Anode Fl exhibited an intergranular fracture morphology at ail test temperatures.

The material plastic deformation at elevated temperatures is controlled by the weakest phase, probably the distributed metallic or grain boundary phase. It is expected that the material DBTT is determined by the composition and distribution of this phase. The fracture morphology change for the control anode at the DBTT is consistent with this conclusion. It is rather remarkable that the control anode can maintain brittle behavior up to $1000^{\circ} \mathrm{C}$ given that the metallic phase is $\mathrm{Cu}-\mathrm{Ni}$ with a melting point of $\sim 1200^{\circ} \mathrm{C}$. The low toughness value implies that the ductile metallic copper phase is not distributed optimally for mechanical properties benefit. Apparently, the metallic phase is too widely distributed and distributed in a size too small to impact the toughness of the cermet material. Fracture toughness for cemented carbides can be as high as $18 \mathrm{MPa} \cdot \mathrm{m}^{\emptyset .5}$. The fracture behavior seems to be controlled by the cleavage strength of the oxide grains. In general, the fracture strength is controlled by fracture toughness below DBTT for these materials. The excellent correspondence between strength and toughness for the anode materials supports this conclusion. 
The observed strength reduction and DBTT shift on exposure to the cryolite bath for Anode F1 points to degradation of the intergranular phase during anode operation, perhaps due to etectromigration. The material no longer fails by cleavage of the oxide grains, but instead deforms at boundaries resulting in a completely intergranutar fracture morphology. The change in the fracture morphology of Anode $\mathrm{Fl}$ compared to the control anode supports this conclusion. The presence of an Al-containing fluoride phase at the oxide grain boundaries in Anode Fl material suggests that this material is essentially very different from the control anode material.

A low fracture toughness, high thermal expansion coefficient, and moderately low thermal conductivity for these cermet anodes makes them very susceptible to thermal shock. Observed cracking during operation is consistent with this. A calculated thermal shock parameter is very low for a cermet material as shown in Figure 5.56. This suggests that use of these materials for inert anodes will entail very delicate handling procedures, which is not desirable. 


\subsection{DISCUSSIDN OF RESULTS}

\subsection{MATERIALS INTERACTIONS ISSUES}

The following discussion concerns primarily the materials interactions of the cermet anodes in the pilot cell test. The discussion focuses on the observations (Sections 5.1 and 5.2) of the type and nature of reactions between the electrolyte and the cermet anode material. These results were of primary concern in this study on the inertness of the cermet material under the pilot cell testing. Issues related to anode cracking were considered less important in this study but will have to be addressed in further research if the cermet material is ever to be used commercially. Nevertheless, it is worthwhile to note at this point that the cracking phenomena resulted from the poor mechanical properties of the material (Section 5.3) and were aggravated by the less-than-ideal anode electrical connection/support scheme. As discussed in Section 3.2, attempts to reduce thermal expansion mismatches with a graded core were unsuccessful because the large anode pieces cracked during fabrication. Clearly, the thermal shock sensitivity of the cermet anodes must be reduced by 1) developing a better strategy for an electrical connection, and 2) determining ways to toughen the material through microstructure and/or compositional changes as discussed in Section 5.3.2.

The cermet material did not appear to behave adequately as an "inert" anode. As indicated in Section 5.1, despite no significant dimensional changes in most cases, the anodes exhibited reaction layers of varying thicknesses. Moreover, as discussed in Section 5.2, evidence for electrolyte penetration was found deep within the anode material. The mode of ingress of the electrolyte appeared to be along grain boundaries and possibiy through pores. Electroiyte in contact with the external and internal surfaces of the anode and along grain boundary surfaces resulted in a multitude of chemical reactions. The results of these reactions were very complicated but some trends were observed and these were reported in Section 5.2 and summarized in Section 5.2.7. While it is impossible to explain all of the observed chemical changes, some of the trends can be rationalized by considering the thermodynamics of two classes of chemical reactions. 
Both classes of chemical reactions that can be used to explain some of the observed chemical changes involve the three components of the alloy phase of the cermet: $\mathrm{Fe}, \mathrm{Ni}$, and $\mathrm{Cu}$. Since the metallic phase of the cermet is the most likely to oxidize or corrode under anodic polarization conditions, and since some of the changes clearly involve this phase, e.g., selective oxidation of $\mathrm{Ni}$ from the alloy in certain regions, it seemed reasonable to attempt an explanation of the chemical changes by first considering the behavior of these elements. As it turns out, the chemistry of these elements is consistent with some of the more obvious compositional changes in the anode and is the focus of the discussion in this section.

The two classes of reactions involving $\mathrm{Fe}, \mathrm{Ni}$, and $\mathrm{Cu}$ are the reactions with $\mathrm{Al}_{2} \mathrm{O}_{3}$ and $\mathrm{AlF}_{3}$. While $\mathrm{Al}_{2} \mathrm{O}_{3}$ and $\mathrm{AlF}_{3}$ do not exist as such in either the molten salt nor its vapor, (a) they provide a good basis for comparing the reactivities of the metals in the cryolitic medium and, as it happens, are two of the few electrolyte species for which thermodynamic data are available. Numerous other workers (Weyand et al. 1986; McLeod et al. 1987) have shown that calculations on this very same basis are also useful as a tool for selecting inert anode materials.

Tables 6.1 and 6.2 show data for the reactions of $\mathrm{Fe}, \mathrm{Ni}$, and $\mathrm{Cu}$ with $\mathrm{Af}_{2} \mathrm{O}_{3}$ and $\mathrm{AlF}_{3}$, respectively (McLeod et al. 1987). In each case, the reactions are written for the formation of oxides or fluorides containing all the common oxidation states of the metals. For each reaction, the standard free energy change at $1300 \mathrm{~K}$ and the standard cell potentials are given. In addition, the cell potentials are given in Table 6.1 for the case where the concentration of alumina is $10 \%$ of its value at saturation giving an activity

(a) For example, $\mathrm{Al}_{2} \mathrm{O}_{3}$ exists as aluminum oxyfluoride ions, and $\mathrm{ATF}_{3}$ as the tetra- and hexaffuoride ions in the melt (Grjotheim et al. 1982). 
TABLE 6.1. Reactions with $\mathrm{Al}_{2} \mathrm{O}_{3}$ at $1300 \mathrm{~K}$

$\begin{array}{lcrl}\text { Reaction } & \Delta G^{\circ}, \mathrm{kJ} & \epsilon^{\circ}, V & \epsilon_{\mathrm{a}=9.901} \\ \mathrm{Al}_{2} \mathrm{O}_{3}+3 \mathrm{Fe}=2 \mathrm{Al}+3 \mathrm{FeO} & 699 & -1.21 & -1.34 \\ \mathrm{Al}_{2} \mathrm{O}_{3}+2 \mathrm{Fe}=2 \mathrm{Al}+\mathrm{Fe}_{2} \mathrm{O}_{3} & 768 & -1.33 & -1.46 \\ \mathrm{Al}_{2} \mathrm{O}_{3}+3 \mathrm{Ni}=2 \mathrm{Al}+3 \mathrm{NiO} & 903 & -1.56 & -1.69 \\ \mathrm{Al}_{2} \mathrm{O}_{3}+6 \mathrm{Cu}=2 \mathrm{Al}+3 \mathrm{Cu}_{2} \mathrm{O} & 1104 & -1.91 & -2.04 \\ \mathrm{Al}_{2} \mathrm{O}_{3}+3 \mathrm{Cu}=2 \mathrm{Al}+3 \mathrm{CuO} & 1155 & -1.99 & -2.12\end{array}$

TABLE 6.2. Reactions with $\mathrm{AlF}_{3}$ at $1300 \mathrm{~K}$

$\begin{array}{lccc}\text { Reaction } & \Delta G^{\circ}, \mathrm{kJ} & \epsilon^{\circ}, V & \epsilon_{\mathrm{a}=\varnothing .61} \\ 2 \mathrm{AlF}_{3}+3 \mathrm{Fe}=2 \mathrm{Al}+3 \mathrm{FeF}_{2} & 771 & -1.33 & -1.50 \\ \mathrm{AlF}_{3}+\mathrm{Fe}=\mathrm{Al}+\mathrm{FeF}_{3} & 422 & -1.46 & -1.63 \\ 2 \mathrm{AlF}_{3}+3 \mathrm{Ni}=2 \mathrm{~A} 1+3 \mathrm{NiF}_{2} & 987 & -1.70 & -1.87 \\ 2 \mathrm{AlF}_{3}+3 \mathrm{Cu}=2 \mathrm{~A} 1+3 \mathrm{CuF}_{2} & 1290 & -2.23 & -2.40 \\ \mathrm{AlF}_{3}+3 \mathrm{Cu}=\mathrm{Al}+3 \mathrm{CuF} & 1155 & -3.52 & -3.69\end{array}$

"a" $=0.001$ according to Grotheim et a1. (1982) and for the case where the fluoride activity is approximately its value at the actual bath ratio 1.35 (Table 6.2). (a)

The reactions in Tables 6.1 and 6.2 may be viewed as follows. Each reaction consists of an anodic half-reaction involving the oxidation of one of the three metals, for example $3 \mathrm{Ni}+\mathrm{Al}_{2} \mathrm{O}_{3}->3 \mathrm{NiO}+2 \mathrm{Al}^{3+}+6 \mathrm{e}^{-}$for oxide for mation and $3 \mathrm{Ni}+2 \mathrm{AlF}_{3}->3 \mathrm{NiF}_{2}+2 \mathrm{Al}^{3+}+6 \mathrm{e}^{-}$for fluoride formation. Both types of reactions couple with the cathodic half-reaction $2 A 1^{3+}+6 \mathrm{e}^{-} \rightarrow>2 \mathrm{Al}$ to give the overall cell reactions 1 isted in Tables 6.1 and 6.2. Again, while the $\mathrm{Al}^{3+}$ does not really exist (unfluorinated) in the cryolite, its use in the half-reaction provides a convenient reference. In any event, the ion does not

(a) In addition to the effects of varying activities of $\mathrm{Al}_{2} \mathrm{O}_{3}$ and $\mathrm{AlF}_{3}$, the equilibria will be affected by the activities of $\mathrm{Fe}, \mathrm{N}^{2}, \mathrm{Cu}$, and $\mathrm{Al}$ within the various phases. A more complete analysis of all of these possible equilibria which would include the effects of metal ion activities is beyond the scope of this work but should be attempted in any future work on the subject. 
enter into any of the overall equations, so its role (or the role of a more realistic aluminum fluoride ion) is inconsequential in these comparisons. Viewed in this way, the reactions in Tables 6.1 and 6.2 are all anodic halfreactions or corrosion half-reactions referenced to the same "reference" halfreaction, j.e., the $\mathrm{Al} / \mathrm{Al}_{2} \mathrm{O}_{3}$ half-cell reduction reaction against which electrode potentials are routinely measured in this system. Consequentiy, the values calculated from the thermodynamic data base should give a good indication of what reactions are favored under the various applied electrode potential conditions.

A11 of the potentials for the reactions in Tables 6.1 and 6.2 are negative. Consequently, under open-circuit conditions, all of the reactions are disfavored and the metals are predicted to be stable with respect to these reactions. However, at $2.2 \mathrm{~V}$ relative to the same half-cell reaction, or the minimum potential required to generate oxygen at unit activity according to $2 \mathrm{Al}_{2} \mathrm{O}_{3} \rightarrow 4 \mathrm{Al}+3 \mathrm{O}_{2}$, some of these reactions are favored. The favored reactions are those with potentials less negative than $-2.2 \mathrm{~V}$.

All of the oxide formation and fluoridation reactions involving $\mathrm{Fe}$ and $\mathrm{Ni}$ are predicted to be strongly favored at $2.2 \mathrm{~V}$. In contrast, the fluoridation of $\mathrm{Cu}$ is disfavored because the potentials are more negative than $-2.2 V$ and the oxide formation reactions are only slightiy favored under conditions of lower oxide ion activities as might exist near the anode. This is consistent with the preferential oxidation of $\mathrm{Fe}$ and $\mathrm{Ni}$ from the alloy phase or, equivalentiy, the refinement of $\mathrm{Cu}$ in these phases.

The reactions that did occur for $\mathrm{Cu}$ were, furthermore, observed to be very complex. In the reaction layer, for example, Cu was found in regions or bands, sometimes with $\mathrm{Ni}$ as an oxide, and was depleted in other areas that were similar to the ferrite in composition. While it is impossible to explain the details of this varied chemical reactivity with any certainty (the layering may have to do with the variation in cell operating conditions), the complexity of the chemistry suggests that $C u$ has open to it a number of possible reaction pathways. This is consistent with the thermodynamic data in Tables 6.1 and 6.2. These data indicate that the reactions involving Cu are 
much closer to the "2.2 V criterion" than those for Fe or Ni. Slight variations in cell conditions could, therefore, shift one or more of these equilibria from "favored" to "disfavored" status or visa versa. For example, at exactiy $2.2 \vee$ the oxidation of $\mathrm{Cu}$ to form copper oxides is predicted by Table 6.1 as long as alumina is at saturation. At lower alumina concentrations, the formation of the oxides becomes more and more disfavored (as indicated by the values for potential for the arbitrarily chosen $10 \%$ saturation). If low alumina is coupled with high fluoride concentrations, or if significant voltage drops develop at the anode surface resulting in a voltage higher than $2.2 V$ within the anode (i.e., right under a resistive layer), or if power supply fluctuations result in slightly higher applied voltages at the anode, the formation of copper fluorides (particularly $\mathrm{CuF}_{2}$ ) would be predicted from Table 6.2.

Weyand et al. (1986) suggested that some of the oxides might be passivating. Given that the copper fluorides are probably more soluble than the oxides, fluctuations of the sort discussed above could significantly have altered the corrosion susceptibility of the $\mathrm{Cu}$ component of the alloy phase. Consequently, one might expect layers of reaction products with some containing copper oxides formed under conditions when the fluorides were disfavored and others containing very little $\mathrm{Cu}$ formed under conditions when the fluoridation of $\mathrm{Cu}$ was favored. If the scenario developed in this paragraph is accurate, clearly the best way to minimize the reactions involving the $\mathrm{Cu}$ component is to maintain operating conditions as constant as possible in "regimes" where copper oxidation and particularly the formation of fluorides is least favored. These conditions appear to include maintaining as close to alumina saturation as possible and a reasonably constant voltage profile uninfluenced by any reaction layers or external voltage fluctuations.

Another type of reaction that was observed in the reaction layer was the apparent substitution of $A 1$ for $F e$ in the ferrite phase. This type of reaction was observed in numerous other studies (Weyand et al. 1986; Windisch and Stice 1991) and it is unlikely that it can be completely eliminated. Previous work (Windisch and Stice 1991) indicated that the substitution might involve (at least initially) the small number of excess Fe ions that exist in 
the ferrite phase. These $\mathrm{Fe}$ ions probably exist as $\mathrm{Fe}^{2+}$ and are more likely to be oxidized or react under anodic polarization (because, unlike the other cations in the ferrite, the divalent $\mathrm{Fe}$ has a higher oxidation state available). Under ideal conditions, i.e., when less-than-significant amounts of metal-phase reactions and very $1 j$ ttle penetration of electrolyte deep into the anode body occur, the substitution reaction probably does not occur to a significant extent. Some studies (McLeod et al. 1987) have even indicated that a similar Al-containing solid solution phase may protect underlying ferrite as a diffusion barrier, as in the case of single crystals. Accompanied by other reactions that erode the integrity of the ceramic matrix, however, the substitution reaction could conceivably accelerate the degradation processes by occurring over much wider regions and in such a way that the formation of an intact, protective layer is hindered. The presence of ferrite-like phases with extremely different morphologies, e.g., the consolidated ferrite regions, indicates that the substitution reaction may produce very different results depending on the circumstances.

In addition to the reactions at the anode surface, the penetration of an Al-containing fluoride species into the body of the cermet anode and evidence for subsequent reactions inside the anode were also reported in Section 5.0. One of the reaction products formed as a result of reactions within the anode was $\mathrm{NiF}_{2}$ or a composite $\mathrm{Ni} / \mathrm{Fe}$ fluoride. As shown in Figure 5.40 , the amount of $\mathrm{Fe}$ in the fluoride phase increases relative to $\mathrm{Ni}$ as a function of distance from the bottom of the anode. Assuming the reactions in the anode can be modelled with the reactions shown in Table 6.2 , this result is not surprising. At the surface of the anode, the activity of fluoride is close to 0.01 , resulting in the potentials shown in Table 6.2. Deep within the anode, the activity of aluminum fluoride should be much less than near the surface. The lower fluoride activities would result in more negative potentials, meaning that fluoridation of the $\mathrm{Fe}$ and $\mathrm{Ni}$ would be less favored deeper within the anode. But, the fluoridation of $\mathrm{Ni}$ is less favored than that of $\mathrm{Fe}$ to both oxidation states at any given fluoride concentration because the potential is more negative for $\mathrm{Ni}$. Near the surface of the anode the differences are inconsequential because both reactions are highly favored and because the amount of $\mathrm{Fe}$ relative to $\mathrm{Ni}$ is too small to notice any differences between 
them. At positions deeper in the anode, the differences between $\mathrm{Fe}$ and $\mathrm{Ni}$ may be more important. With decreased fluoride content the potential for $\mathrm{Ni}$ fluoridation may fall to values close to or below $-2.2 \mathrm{~V}$. Hence the $\mathrm{Ni}$ reaction may become significantly less favored than the Fe reactions whose potentials are significantly less negative than $\mathrm{Ni}$. As a consequence, one would expect the product fluoride phase to contain more $\mathrm{Fe}$ than $\mathrm{Ni}$ at positions deeper in the anode. As discussed above, this was observed. Since very little $\mathrm{Fe}$ is in the alloy phase to begin with, its accumulation to measurable amounts in the fluoride phase is significant and implies that, provided the thermodynamic arguments made here are at least qualitatively correct, the variations in electrochemical potential across the anodes in the pilot cell test may have been significant. This result is clearly an undesired consequence of penetration of the electrolyte into the anode. It is obvious that for this anode material to be successful in commercial applications, the issue of electrolyte penetration must be addressed. Significant work is still required to understand this transport and to inhibit it. In particular, the effects of cermet anode composition and microstructure, as well as cell operating conditions, on this mode of attack are not certain. Solutions to the problem may involve fabricating anodes with a "tighter" microstructure and higher density, adding components to inhibit transport along grain boundaries or other compositional changes, working with a completely different anode composition, or running cells under more uniform and "benign" conditions. Which of these or any alternative approaches gives the best results is unclear at this time. Further work in this area is clearly warranted.

\subsection{OPERATIONAL ISSUES}

The following discussion concerns operational issues related to the pilot cell test of the cermet anodes. The comments were provided by RMC personnel who supervised the operation of the pilot cell and who are in the best position to recommend action concerning the operational efficiency of aluminum reduction cells. 
The operation of the pilot cell with the cermet anodes in a six-pack cluster arrangement was successful in that individual anodes remained in continuous operation for as long as $314 \mathrm{~h}$ (13.1 days). However, the corrosion rate of the anodes, as determined by the rate of increase in the metal impurities, was inadequate for Al reduction cells, with impurity levels exceeding that normally desired for primary metal production ( $<0.5 \%$ total impurities). Major problems that occurred during the pilot cell operation indicate the need and the directions for further development of the cermet anode technology.

\subsubsection{Cermet Anode Cracking and Stem Breakage}

The cracking of the cermet anodes and breaking of the stems indicate that significant design and material selection considerations must be addressed. The anode stem material breakage appears to be manageable with the proper selection of materials and the use of ceramic barriers to protect against electrolyte/vapors attack. The more difficult technical problem appears to be centered around the stem-to-anode connection and the therma1 stress cracking that occurred in the cermet anodes. Regardless of the anode design, it is recommended that additional physical and mechanical properties testing and modelling of therma? stresses be performed prior to future largescale electrolysis testing. The controlled heat-up requirements for the anodes requires specialized start-up and operating techniques. These procedures will have to be determined in sufficient and certain detail or the materials problems solved to allow more flexibility.

\subsubsection{Operation at Low Anode Current Density}

The apparent need to operate at low anode current density will require the design of a reduction cell with significantly increased surface area and with sufficient current conduction to achieve the thermal stability of the aluminum reduction cell. This revised design must exhibit uniform current distribution and also meet the necessary requirements for thermal stress considerations. It appears the most likely success for such a cell design would be in conjunction with refractory hard metal cathodes, such as the $\mathrm{TiB}_{2}-\mathrm{G}$ type currently under development. 


\subsubsection{Operation at Alumina Saturation}

Although the test was inconclusive with respect to the operation of the cermet anodes at reduced alumina concentrations, the corrosion rate did increase significantly with operation at reduced alumina. It is essentially impossible to operate a conventional reduction cell for long periods of time at saturated $\mathrm{AT}_{2} \mathrm{O}_{3}$ conditions due to increasing muck build-up. This muck results in a greater cathode voltage drop and a reduced liquid volume in the cell. The development of innovative cell designs will be required to address these problems. Additional testing is required to determine more precisely the effects of reduced alumina concentrations on cell operation with cermet anodes.

\subsubsection{Cermet Anode Corrosion Rate}

Despite showing significant corrosion rates for the cermet anodes, results from the pilot cell test were inconclusive with respect to the "inertness" of the cermet anodes. This was because there was 1) poor current distribution among the anodes as well as on the individual anodes, and 2) cracking and breaking of the anodes, possibly causing contamination of the metal pad. Many fundamental and applied questions remain concerning the cermet anodes. Significant additional testing would appear to remain concerning both materials development and fabrication techniques.

Further development work on the cermet anodes needs to continue using both small bench cells and larger prototypes. Studies need to continue in the characterization of the material as well as toward innovative cell designs and scaled-up anode designs. Significant tests could be conducted in both small bench cells $(<30 \mathrm{~A})$ as well as larger lab cells (200-500 A) prior to additional pirot cell operations. 
. 


\subsection{CONCLUSIONS AND RECOMMENDATIONS}

The pilot cell test suffered from a number of limitations. Optimal operating conditions were not maintained, including alumina concentration at saturation, constant current and voltage conditions and $A C D$, and constant temperature. In addition, mechanical fracture problems occurred in both the anode connections and the cermet anodes themselves. Despite these limitations, however, the pilot cell test was successful in that certain important and relevant information was learned about the cermet anodes under scaled-up conditions. These conclusions and the recommendations with regard to each are summarized below:

The Cermet Material. Significant amounts of electrolyte penetrated into the cermet anodes in the pilot cell test. The migrating species appeared to be an Al-containing fluoride phase, and at least one mode of access was along grain boundaries. Clearly, this access of electrolyte to the interior of the anode is unacceptable. Further research is recommended to understand the mechanisms of this transport and how cermet composition, microstructure, density, and cell operating conditions influence it. Since some of these issues involve or are impacted by fabrication, it is recommended that this testing proceed to the pilot-scale expeditiously. Further experimental research and theoretical studies should also be performed on the different phases in the cermet and how they react under various redox and chemical conditions. The arguments made in Section 6.1 are preiminary in scope, yet, despite this, suggest the advantage of more fundamental studies. If successful, this work would suggest ways to alter the reactivities of the cermet components via compositional or operational changes.

It is still unclear whether the cermet material evaluated in this work is the best choice for an "inert" anode. Significant corrosion of these anodes was observed in the pilot cell test. If DOE and the aluminum industry intend to develop a nonconsumable anode material, it is recommended that additiona bench-scale and pilot-cell evaluations be performed. However, major 
emphasis in these studies should be given to the material from which the anodes are constructed. The analyses presented here could serve as the basis for a focussed program of materials development.

Chemical Transformations. Certain chemical interactions were identified in this work and should be kept in mind when designing or testing future anodes made from the cermet material. These interactions were 1) the transformation of $\mathrm{Cu}$ to oxides in a layered structure at the surface of the anode, 2) the replacement of $\mathrm{Al}$ for $\mathrm{Fe}$ in the ferrite phase and accompanying changes in grain structure for the ferrite phase, 3) the preferential reaction of $\mathrm{Fe}$ and $\mathrm{Ni}$ relative to $\mathrm{Cu}$ in the alloy phase, and 4) coupled with these transformations, the penetration and reactions of an Al-containing fluoride species into the cermet with the resulting formation of $\mathrm{NiF}_{2}$ and $\mathrm{Ni}-\mathrm{Fe}$ fluoride compounds.

Mechanical Properties. The cermet anodes tested in the pilot cell were extremely brittle and sensitive to thermal shock. If such anodes are to be successfully used in industry, it appears that significant work remains to toughen the material by compositional or microstructural modifications, to develop new operating conditions that impose less thermal stresses on the material, or to engineer a more durable electrode configuration. The mechanical properties testing performed in this work should serve as a procedural guide for evaluating improved materials.

Anode Connection. A new strategy for an electrical connection to the anode needs to be developed. A metal rod screwed directly into the cermet as used in the pilot cell will not work because of the severe thermal expansion mismatch. Clearly, this rod cannot be constructed of $\mathrm{Ni}$. A less expensive material is needed, the properties of which are compatible with it being used as an anode stem. Use of a graded core in the cermet may be successful but the procedures have to be developed further since the sintering of large anodes with these cores has resulted in cracks in previous fabrication efforts.

pilot Cell operating Conditions. During the pilot cell test, significant fluctuation in operating conditions occurred. Those portions of anodes exposed "mostly" to "normal" conditions of less than $0.5 \mathrm{~A} / \mathrm{cm}^{2}$ and close to 
alumina saturation exhibited very little "dimensional loss," but did show the growth of a reaction layer of significant thickness. Anodes exposed to severe conditions of higher current density and low alumina concentration exhibited severe dimensional and compositional changes. The observed changes in the anodes were accompanied by the increase of significant amounts of anodederived impurities in the Al metal. The corrosion processes observed in this work can probably be attributed to one or more of the following factors: 1) the inherent limitations of the cermet material tested, 2) the differences between the composition and microstructure of the cermet material tested in the pilot cell and previous cermet material tested in the laboratory, 3) the fluctuations in cell operating conditions and, in the case of alumina saturation and current, their variance from "optimal" conditions, 4) the influence of the large carbon anode on the voltages in the cell and possibiy on anode reactions, and 5) the failure of the connector rods and the cracking of the anodes, which necessitated a significant amount of electrode manipulation. Which of the above factors was most important is still unclear at this time. Clearly, additional pilot-scale testing is required to determine, without ambiguity, whether the cermet material itself is in some way deficient.

In any future pilot cell test on this materiai, it is recommended that only cermet anodes be employed (no carbon), anodes be fabricated that have microstructure and physical properties as close as possible to the anodes previously tested in the laboratory, the pilot cell test be performed using a design and procedure that minimizes fluctuations in operating conditions and more easily permits operation near alumina saturation, the pilot cell be modelled extensively before testing particularly in regards to its current and voltage characteristics, and a more durable anode design or effective heat-up strategy be used to minimize thermal shock. 


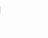

,

. 


\subsection{REFERENCES}

Grjotheim, K., C. Krohn, M. Malinovsky, K. Matiasovsky, and J. Thonstad. 1982. Aluminum Electrolysis, Second Edition. Aluminium-Verlag, Dusseldorf, FRG.

Hart, P. E., B. B. Brenden, N. C. Davis, 0. H. Koski, S. C. Marschman, K. H. Pool, C. H. Schilling, C. F. Windisch Jr., and B. J. Wrona. 1987. Inert Anode/Cathode Program Fiscal Year 1986 Annual Report. PNL-6247, Pacific Northwest Laboratory, Richland, Washington.

Hasselman, D.P.H. 1970. "Thermal Stress Resistance Parameters for Brittle Refractory Ceramics: A Compendium." American Ceramic Society Bulletin, Vol. 49, pp. 1033-1037.

Haupin, W. E. 1971. "A Scanning Reference Electrode for Voltage Contours in Aluminum Smelting Cells." Journal of Metals, Vol. 23, pp. 46-49.

McLeod, A. D., J. Lihrmann, J. S. Haggerty, and D. R. Sadoway. 1987. "Selection and Testing of Inert Anode Materials for Hall Cells." Light Metals 1987, The Metallurgical Society, Warrendale, Pennsylvania, pp. 357-365.

Skybakmoen, E., A. Sotheim, and A. Sterten. 1990. "Phase Diagram Data in the System $\mathrm{Na}_{3} \mathrm{~A} 1 \mathrm{~F}_{6}-\mathrm{Li}_{3} \mathrm{~A} 1 \mathrm{~F}_{6}-\mathrm{AlF}_{3}-\mathrm{Al}_{2} \mathrm{O}_{3}$ Part II: Alumina Solubility." Light Metals 1990, The Minerals, Metal's and Materials Society, Warrendale, Pennsyivania, pp. 317-324.

Strachan, D. M., S. C. Marschman, N. C. Davis, J. R. Friley, and C. H. Schilling. 1989. Fiscal Year 1988 Annual Report for the Inert Electrodes Program. PNL-7106, Pacific Northwest Laboratory, Richland, Washington.

Strachan, D. M., C. F. Windisch Jr., 0. H. Koski, L. G. Morgan, R. D. Pederson, N. E. Richards, and A. T. Tabereaux. 1990. Results from Electrolysis Test of a Prototype Inert Anode. PNL-7345, Pacific Northwest Laboratory, Richland, Washington.

Tabereaux, A. T., and N. E. Richards. 1983. "An Improved ATumina Concentration Meter." Light Metals 1983, The Metallurgical Society, Warrendale, Pennsylvania, pp. 495-506.

Weyand, J. D., D. H. DeYoung, S. P. Ray, G. P. Tarcy, and F. W. Baker. 1986. Inert Anodes for Aluminum Smelting: Final Technical Report for the Period 1980 September 29 - 1985 September 30. DOE-CONS-40158-20, Alcoa Laboratories, ATcoa Center, Pennsylvania.

Whithey, P. A., and P. Bowen. 1990. "Analysis of Chevron Notches in Pure Bending." International Journal of Fracture, Vol. 46, pp. R55-R59. 
Williford, R. E., and C. F. Windisch Jr. 1992. Final Report on the Application of Chaos Theory to an Alumina Sensor for Aluminum Reduction Cel]s.

PNL-8042, Pacific Northwest Laboratory, Richland, Washington.

Windisch, C. F., Jr., and N. D. Stice. 1991. Final Report on the Characterization of the Film on Inert Anodes. PNL-7589, Pacific Northwest Laboratory, Richland, Washington.

Windisch, C. F., Jr., T. R. Alcorn, and A. T. Tabereaux. 1991a. Test Plan for the Pilot Cell Test of Inert Anodes: Report on the June 1991 Meeting at the Reynolds Metals Company Facility. PNL-7802, Pacific Northwest Laboratory, Richland, Washington.

Windisch, C. F., Jr., D. M. Strachan, N. C. Davis, L. G. Morgan, J. W. Shade, N. D. Stice, and R. E. Westerman. 1991b. Inert Electrodes Program Fiscal Year 1990 Annual Report. PNL-7777, Pacific Northwest Laboratory, Richland, Washington.

Windisch, C. F., Jr., L. A. Chick, G. D. Maupin, and N. D. Stice. 199lC. The Effects of Microstructure on the Corrosion of Glycine/Nitrate Processed Cermet Inert Anodes: A Preliminary Study. PNL-7733, Pacific Northwest Laboratory, Richland, Washington.

Windisch, C. F., Jr. 1992. Final Report on DSA Methods for Monitoring A] umina in Aluminum Reduction Cells with Cermet Anodes. PNL-8076, Pacific Northwest Laboratory, Richland, Washington. 
APPENDIX A

BATH CONCENTRATION DATA 
PNL BATH ANALYSIS

\begin{tabular}{|c|c|c|c|c|c|c|c|c|c|c|}
\hline SAMPLE ID & DATE & TIME & RATIO & $\begin{array}{c}\text { CaF2 } \\
\%\end{array}$ & $\begin{array}{c}\text { Al2O3 } \\
\%\end{array}$ & $\begin{array}{c}\text { EXCESS AIF3 } \\
\%\end{array}$ & $\begin{array}{c}\text { BATH TEMP } \\
\text { DEG C }\end{array}$ & $\begin{array}{c}\text { ALUMINA } \\
\text { SAT \% }\end{array}$ & $\underset{\%}{\mathrm{MgF2}}$ & $\begin{array}{l}\mathrm{LiF} \\
\%\end{array}$ \\
\hline $2683-15 A$ & AUG 3 & 1400 & 1.75 & 0.45 & 0.38 & -5.98 & 993 & 3.3 & & \\
\hline $2683-15 A$ & & 1400 & 1.77 & 0.27 & 0.24 & -6.43 & 993 & 2.0 & & \\
\hline $2683+16 A$ & & 1800 & 1.74 & 0.27 & 0.6 & -5.76 & 993 & 5.1 & & \\
\hline $2683-16 B$ & & 2200 & 1.68 & 0.27 & 1.26 & -4.39 & 981 & 11.7 & & \\
\hline $2683-17 B$ & AUG 4 & 200 & 1.75 & 0.45 & 0.9 & -5.95 & 990 & 7.9 & & \\
\hline $2683-18 A$ & & 600 & 1.6 & 0.45 & 1.49 & -2.50 & 972 & 14.7 & & \\
\hline $2683-18 B$ & & 1000 & 1.49 & 0.36 & 5.81 & 0.25 & 969 & 58.8 & & \\
\hline $2683-18 C$ & & 1400 & 1.48 & 0.45 & 4.64 & 0.51 & 978 & 44.9 & & \\
\hline $2683-19 A$ & & 1800 & 1.42 & 1.72 & 8.67 & 1.96 & 981 & 86.7 & & \\
\hline $2683-19 C$ & & 2200 & 1.4 & 1.45 & 9.37 & 2.46 & 970 & 98.4 & & \\
\hline $2683-20 B$ & AUa 5 & 200 & 1.43 & 1.36 & 7.75 & 1.74 & 973 & 79.7 & & \\
\hline $2683-20 \mathrm{C}$ & & 600 & 1.43 & 1.27 & 7.72 & 1.74 & 982 & 75.7 & & \\
\hline $2683-20 \mathrm{E}$ & & 1000 & 1.42 & 1.36 & 8.08 & 1.98 & 981 & 79.9 & 0.22 & 0.63 \\
\hline $26 R 3-20 G$ & & 1400 & 1.4 & 1.36 & 10.1 & 2.45 & 985 & 98.2 & 0.21 & 0.64 \\
\hline $2683-22 A$ & & 1800 & 132 & 1.44 & 9.43 & 4.58 & 966 & 101.8 & 0.23 & 0.63 \\
\hline $2683-22 \mathrm{C}$ & & 2200 & 1.28 & 1.72 & 9.52 & 5.68 & 973 & 100.8 & 0.26 & $0.64^{\circ}$ \\
\hline $26 B 3-23 B$ & AUG 6 & 200 & 1.28 & 2.08 & 8.63 & 5.71 & 972 & 92.9 & 0.26 & 0.62 \\
\hline $2683-230$ & & 600 & 1.22 & 2.26 & 8.44 & 7.47 & 967 & 94.3 & 0.23 & 0.68 \\
\hline $2683-23 E$ & & 1000 & 1.22 & 2.35 & 8.28 & 7.47 & 969 & 92.0 & 0.16 & 0.52 \\
\hline $26 \mathrm{B3}-24 \mathrm{~A}$ & & 1400 & 1.18 & 235 & 8.29 & 8.70 & 964 & 94.8 & 0.16 & 0.53 \\
\hline $2683-24 C$ & & 1800 & 1.16 & 235 & 9.16 & 9.23 & 971 & 102.0 & 0.16 & 0.53 \\
\hline $2683-24 \mathrm{E}$ & & 2200 & 1.14 & & 8.5 & 10.21 & 979 & 85.5 & 0.17 & 0.51 \\
\hline $2683-25 B$ & AUG 7 & 200 & 1.16 & 3.62 & 8.59 & 9.16 & 984 & 94.3 & 0.17 & 0.53 \\
\hline $2683-25 \mathrm{C}$ & & 600 & 1.15 & 3.52 & 8.24 & 9.52 & 985 & 90.0 & 0.17 & 0.53 \\
\hline $2683-26 \mathrm{~B}$ & & 1000 & 1.14 & 3.62 & 8.4 & 9.81 & 986 & 91.9 & 0.17 & 0.55 \\
\hline $2683-26 D$ & & 1400 & 1.11 & 3.62 & 8.28 & 10.79 & 988 & 90.7 & 0.15 & 0.51 \\
\hline $2683-27 A$ & & 1800 & 1.02 & 5.25 & 7.58 & 13.73 & 969 & 97.1 & 0.16 & 0.46 \\
\hline $2683-27 \mathrm{C}$ & & 2200 & 0.99 & 4.8 & 8.06 & 14.80 & 984 & 97.4 & 0.16 & 0.49 \\
\hline $2683-28 \wedge$ & AUG 8 & 0 & 0.98 & 5.06 & 7.96 & 15.14 & 986 & 96.8 & 0.16 & 0.49 \\
\hline $2683-28 \mathrm{C}$ & & 400 & 0.96 & 4.98 & 6.92 & 16.09 & 987 & 84.7 & 0.16 & 0.49 \\
\hline $2683-28 E$ & & 1000 & 0.95 & 4.62 & 7.09 & 1651 & 994 & 84.3 & & \\
\hline $2683-29 B$ & & 1400 & 0.91 & 5.06 & 8.07 & 17.79 & 981 & 103.8 & & \\
\hline $2683-30 A$ & & 1800 & 1.02 & 4.79 & 7.84 & 13.76 & 971 & 98.2 & & \\
\hline $2683-31 B$ & & 2200 & 1.02 & 4.88 & 8.5 & 13.64 & 983 & 101.9 & & \\
\hline $26883-31 D$ & AUG 9 & 200 & 1.02 & 4.71 & 7.8 & 13.78 & 995 & 89.1 & & \\
\hline $2683-32 B$ & & 600 & 1.01 & 4.69 & 8.17 & 14.08 & 993 & 94.4 & 0.17 & 0.46 \\
\hline $2683-33 A$ & & 1000 & 1.02 & 4.59 & 9.14 & 13.59 & 984 & 108.1 & & \\
\hline $2683-34 A$ & & 1400 & 1.09 & $4.6 \mathrm{~B}$ & 8.45 & 11.30 & 966 & 105.1 & & \\
\hline $2683-34 A$ & & 1800 & 1.09 & 6.41 & 7.73 & 11.16 & 955 & 106.3 & & \\
\hline $2683-35 A$ & & 2200 & 1.09 & 6.22 & 9.9 & 10.90 & 962 & 131.1 & & \\
\hline $2683-36 \wedge$ & AUG 10 & 200 & 1.1 & 6.31 & 6.48 & 11.01 & 965 & 85.1 & & \\
\hline $2683-36 C$ & & 600 & 1.1 & 6.14 & 5.28 & 11.18 & 965 & 69.0 & 0.11 & 034 \\
\hline $2683-37 A$ & & 1000 & 1.12 & 5.79 & 8.71 & 10.16 & $\$ 61$ & 113.7 & & \\
\hline $2683-38 A$ & & 1400 & 1.12 & $5.5 i$ & 9.24 & 10.13 & 956 & 122.1 & & \\
\hline
\end{tabular}




\section{PNL BATH ANALYSIS}

\begin{tabular}{|c|c|c|c|c|c|c|c|c|c|c|}
\hline SAMPLEID & DATE & T1ME & RATIO & $\begin{array}{c}\mathrm{CaF2} \\
\%\end{array}$ & $\begin{array}{c}\mathrm{A} 12 \mathrm{O} 3 \\
\%\end{array}$ & $\begin{array}{c}\text { EXCESS AlF3 } \\
\%\end{array}$ & $\begin{array}{c}\text { BATH TEMP } \\
\text { DEG C }\end{array}$ & $\begin{array}{l}\text { ALUMINA } \\
\text { SAT \% }\end{array}$ & $\begin{array}{c}\mathrm{MgF}_{\mathrm{g}} \\
\end{array}$ & $\underset{\%}{\text { LiF }}$ \\
\hline $2683-39 A$ & & 1800 & 1.13 & 5.51 & 8.21 & 9.93 & 959 & 107.0 & & \\
\hline $2683-40 \mathrm{~A}$ & & 2200 & 1.13 & 6.41 & 7.61 & 9.90 & 965 & 99.4 & & \\
\hline $2683-41 A$ & AUG 11 & 200 & 1.13 & 6.44 & 7.99 & 9.85 & 964 & 104.9 & & \\
\hline $2683-42 A$ & & 600 & 1.17 & 6.42 & 9.03 & 8.52 & 970 & 1145 & 0.11 & 0.15 \\
\hline $2683-43 A$ & & 1000 & 1.2 & 6.3 & 7.39 & 7.80 & 972 & 92.1 & & \\
\hline $2683-43 \mathrm{C}$ & & 1400 & 1.22 & 6.39 & 7.66 & 7.18 & 983 & 90.9 & & \\
\hline $2683-44 A$ & & 1800 & 1.19 & 6.3 & 7.79 & 8.06 & 981 & 93.5 & & \\
\hline $2683-45 A$ & & 2200 & 1.2 & 6.38 & 6.25 & 7.90 & 982 & 74.8 & & \\
\hline $2683-46 B$ & AUG 12 & 200 & 1.21 & 6.32 & 7.46 & 7.50 & 979 & 90.0 & & \\
\hline $2683-46 D$ & & 600 & 1.16 & 6.41 & 7.94 & 8.94 & 988 & 93.5 & 0.11 & 0.35 \\
\hline $2683-478$ & & 1000 & 1.11 & 6.3 & 8.16 & 10.48 & 982 & 99.5 & & \\
\hline $26833-48 B$ & & 1400 & 1.1 & 6.3 & 8.16 & 10.80 & 976 & 102.2 & & \\
\hline $2683 \sim 48 \mathrm{~A}$ & & 1800 & 1.06 & 6.33 & 6.27 & 12.37 & 978 & 79.1 & & \\
\hline $2683-49 \Lambda$ & & 2200 & 1.06 & 5.94 & 8.7 & 12.08 & 977 & 108.6 & & \\
\hline $2683-49 C$ & AUG 13 & 200 & 1.07 & 5.77 & 7.55 & 11.93 & 967 & 97.4 & & \\
\hline $2683-50 A$ & & 600 & 1.11 & 5.69 & 7.29 & 10.66 & 981 & 87.6 & 0.12 & 0.36 \\
\hline $2683-50 D$ & & 1000 & 1.14 & 5.69 & 7.63 & 9.67 & 974 & 93.6 & & \\
\hline $2683 \rightarrow 50 F$ & & 1400 & 1.18 & 5.76 & 6.19 & 8.57 & 972 & 76.2 & & \\
\hline $20 A 3-52 A$ & & 1800 & 1.24 & 5.67 & 5.86 & 6.81 & 962 & 74.5 & & \\
\hline $2683-52 D$ & & 2200 & 1.26 & 5.58 & 6.52 & 6.19 & 981 & 75.5 & & \\
\hline $2683-53 A$ & AUG 14 & 200 & 1.28 & 5.69 & 6.88 & 5.59 & 989 & 76.9 & & \\
\hline $2583-53 D$ & & 600 & 1.3 & 5.57 & 8.09 & 4.98 & 990 & 89.2 & 0.12 & 0.37 \\
\hline $2683-53 \mathrm{E}$ & & 1000 & 1.24 & 5.69 & 6.54 & 6.75 & 984 & 75.3 & & \\
\hline $2683-54 \mathrm{~A}$ & & 1400 & 1.24 & 5.76 & 5.31 & 6.84 & 974 & 64.1 & & \\
\hline $2683-55 A$ & & 1800 & 1.21 & 5.87 & 5.14 & 7.74 & 963 & 65.8 & & \\
\hline $2683-55 C$ & & 2200 & 1.21 & 5.77 & 5.32 & 7.73 & 984 & 61.8 & & \\
\hline $2683-56 \mathrm{~B}$ & AUG 15 & 200 & 1.2 & 5.79 & 5.64 & 8.01 & 980 & 66.9 & & \\
\hline $2683-56 \mathrm{D}$ & & 600 & 1.21 & 5.87 & 7.21 & 7.56 & 981 & 85.1 & & \\
\hline $2683-57 \AA$ & & 1000 & 1.21 & 5.78 & 6.46 & 7.63 & 971 & 79.5 & & \\
\hline $2683-57 \mathrm{C}$ & & 1400 & 1.25 & 5.78 & 5.62 & 6.53 & 972 & 68.4 & & \\
\hline $2683-58 A$ & & 1800 & 1.2 & 5.77 & 4.67 & 8.10 & 958 & 61.0 & & \\
\hline $2683-58 C$ & & 2200 & 1.14 & 5.78 & 4.38 & 10.02 & 953 & 59.1 & & \\
\hline $2683-59 B$ & AUG 16 & 200 & 1.12 & 5.68 & 4.43 & 10.68 & 955 & 59.3 & & \\
\hline $2683-59 D$ & & 600 & 1.13 & 5.59 & 4.84 & 10.31 & 963 & 62.3 & & \\
\hline $2683-60 A$ & & 1000 & 1.13 & 5.43 & 5.97 & 10.20 & 967 & 75.1 & & \\
\hline $2683-60 \mathrm{C}$ & & 1400 & 1.12 & 5.12 & 3.88 & 10.81 & 954 & 51.3 & & \\
\hline $2683-618$ & & 1800 & 1.12 & 5.11 & 8.59 & 10.25 & 961 & 109.8 & & \\
\hline $268.3-61 \mathrm{D}$ & & 2200 & 1.12 & 5.43 & 3.78 & 10.79 & 962 & 48.8 & & \\
\hline $2683-62 \mathrm{~A}$ & AUG 17 & 200 & 1.13 & 5.43 & 1.76 & 10.69 & 957 & 23.2 & & \\
\hline $2683-62 D$ & & 600 & 1.13 & 5.52 & 5.12 & 10.29 & 963 & 65.8 & & \\
\hline $2683-63 A$ & & 1000 & 1.14 & 5.42 & 6.71 & 9.80 & 965 & 84.9 & & \\
\hline $2683-63 C$ & & 1400 & 1.17 & 5.24 & 11.76 & 836 & 968 & 144.7 & & \\
\hline $2683-64 A$ & & 1800 & 1.21 & 5.16 & 13.1 & 7.11 & 968 & 159.6 & & \\
\hline $2683-64 C$ & & 2200 & 1,3 & 5.14 & 7.93 & 5.01 & 971 & 94.3 & & \\
\hline
\end{tabular}


PNL BATH ANALYSIS

SAMPLE ID DATE TIME RATIO CaF2 AIZO3 EXCESS AIF3 BATH TEMP ALUMINA MgF2 LiF \% \% DEOC SAT \% \% $\%$

\begin{tabular}{|c|c|c|c|c|c|c|c|c|c|c|}
\hline $2683-65 B$ & AUG 18 & 200 & 1.36 & 5.15 & 7.7 & 3.43 & 966 & 93.2 & & \\
\hline $2683-65 \mathrm{C}$ & & 600 & 1.38 & 5.15 & 7.24 & 2.93 & 975 & 83.6 & & \\
\hline $2683-66 \hat{A}$ & & 1000 & 1.33 & 5.32 & 7.7 & 4.21 & 976 & 89.6 & & \\
\hline $2683-66 D$ & & 1400 & 133 & 5.31 & 10.25 & 4.08 & 968 & 123.8 & & \\
\hline $2683-67 A$ & & 1800 & 1.34 & 5.32 & 10.85 & 3.80 & 978 & 124.7 & & \\
\hline $2683-68 \mathrm{~A}$ & & 2200 & 1.34 & 5.06 & 11.35 & 3.79 & 983 & 126.3 & 0.13 & 0.33 \\
\hline $2683-69 A$ & AUG 19 & 200 & 1.34 & 4.95 & 10.09 & 3.85 & 975 & 116.3 & & \\
\hline $2683-70 A$ & & 600 & 1.34 & 4.68 & 12.24 & 3.76 & 971 & 142.6 & & \\
\hline $2683-70 \mathrm{C}$ & & 1000 & 1.34 & 4.7 & 7.62 & 3.97 & 977 & 86.4 & & \\
\hline $2683-71 \mathrm{~B}$ & & 1400 & 1.33 & 4.52 & 6.18 & 4.32 & 978 & 69.4 & & \\
\hline $2683-72 B$ & & 1800 & 1.33 & 4.24 & 8.09 & 4.24 & 968 & 94.5 & & \\
\hline $2683-72 D$ & & 2200 & 1.27 & 4.15 & 7.78 & 5.92 & 964 & 93.0 & 0.11 & 0.38 \\
\hline $2683-73 B$ & AUG 20 & 200 & 1.26 & 4.06 & 6.21 & 6.32 & 969 & 72.4 & & \\
\hline $2683-73 D$ & & 600 & 1.24 & 4.06 & 4.89 & 7.01 & 970 & 57.0 & & \\
\hline $2683 \div 73 \mathrm{E}$ & & 1000 & 1.22 & 3.89 & 6.62 & 7.48 & 971 & 76.6 & & \\
\hline $2683-74 A$ & & 1400 & 1.18 & 3.98 & 6.29 & 8.73 & 963 & 76.2 & & \\
\hline $2683-74 B$ & & 1800 & 1.18 & 3.89 & 6.22 & 8.75 & 964 & 74.8 & & \\
\hline $2683-74 C$ & & 2200 & 1.24 & 4.16 & 8.24 & 6.74 & 981 & 91.5 & & \\
\hline $2683-75 B$ & AUG 21 & 200 & 1.31 & 4.07 & 6.82 & 4.86 & 971 & 78.3 & & \\
\hline $2683-76 B$ & & 600 & 1.33 & 4.16 & 7.75 & 4.26 & 970 & 89.4 & & \\
\hline $2683-76 \mathrm{D}$ & & 1000 & 1.31 & 4.07 & 7.74 & 4.8: & 975 & 87.2 & & \\
\hline $2683-76 E$ & & 1400 & 1.3 & 4.16 & 7.84 & 5.07 & 971 & 90.3 & & \\
\hline $2687-1 A$ & & 1800 & 1.33 & 4.25 & 8.43 & 4.22 & 979 & 93.4 & & \\
\hline $2687-t c$ & & 2200 & 1.33 & 4.25 & 8.08 & 4.24 & 982 & 88.3 & & \\
\hline $2687-1 F$ & AUG 22 & 200 & 1.34 & 4.43 & 7.24 & 4.00 & 976 & 81.8 & & \\
\hline $2687-28$ & & 600 & 1.32 & 4.52 & 7.42 & 4.53 & 973 & 85.5 & & \\
\hline $2687-2 C$ & & 1000 & 1.26 & 4.52 & 8.16 & 6.15 & 983 & 90.5 & & \\
\hline $2687-2 F$ & & 1400 & 1.27 & 4.34 & 8.35 & 5.86 & 978 & 94.1 & & \\
\hline $2687-3 B$ & & 1800 & 1.35 & 3.8 & 10.06 & 3.64 & 969 & 115.0 & & \\
\hline $2687-3 D$ & & 2200 & 1.35 & 3.8 & 1152 & 3.58 & 966 & 133.6 & & \\
\hline $2687-4 B$ & AUG 23 & 200 & 1.32 & 3.71 & 7.3 & 4.58 & 974 & 81.6 & & \\
\hline $2687-4 D$ & & 600 & 1.29 & 3.79 & 8,04 & 5.36 & 968 & 93.0 & & \\
\hline $2687-4 E$ & & 1000 & 1.27 & 3.61 & 7.6 & 5.96 & 998 & 76.5 & & \\
\hline $2687-5 A$ & & 1400 & 1.2 & 3.61 & 6.96 & 8.08 & 972 & 79.7 & & \\
\hline $2687-6 A$ & & 1800 & 1.2 & 3.61 & 6.65 & 8.11 & 973 & 75.9 & & \\
\hline $2687-6 C$ & & 2200 & 1.17 & 3.7 & 7.51 & 8.95 & 983 & 82.8 & & \\
\hline $2687-7 B$ & AUG 24 & 200 & 1.23 & 3.71 & 8.23 & 7.07 & 982 & 89.9 & & \\
\hline $2687-7 D$ & & 600 & 1.25 & 3.88 & 7.51 & 6.53 & 980 & 82.9 & & \\
\hline $2687-8 B$ & & 1000 & 1.28 & 4.6 & 7.41 & 5.63 & 975 & 85.2 & & \\
\hline $2687-8 C$ & & 1400 & 1.27 & 4.97 & 7.12 & 5.90 & 970 & 84.9 & & \\
\hline $2687-8 \mathrm{~F}$ & & 1800 & 1.31 & 4.98 & 6.79 & 4.81 & 981 & 76.5 & & \\
\hline $2687-86$ & & 2200 & 1.33 & 4.79 & 6.55 & 4.29 & 985 & 71.8 & & \\
\hline $2687-9 B$ & AUO 25 & 200 & 1.33 & 4.79 & 7.26 & 4.25 & 984 & 79.9 & & \\
\hline $2687-9 D$ & & 600 & 1.29 & 4.79 & 7.23 & 5.35 & 985 & 79.8 & & \\
\hline
\end{tabular}


PNL BATH ANALYSIS

\begin{tabular}{|c|c|c|c|c|c|c|c|c|c|}
\hline SAMPLE ID & DATE & TIME & RATIO & $\begin{array}{c}\mathrm{CaF2} \\
\text { \% }\end{array}$ & $\begin{array}{c}\mathrm{A} / 2 O 3 \\
\%\end{array}$ & $\begin{array}{c}\text { EXCESS AIF3 } \\
\%\end{array}$ & $\begin{array}{c}\text { BATH TEMP } \\
\text { DEG C }\end{array}$ & $\begin{array}{c}\text { ALUMINA } \\
\text { SAT \% }\end{array}$ & $\underset{\%}{\mathrm{MgF2}}$ \\
\hline $2687-96$ & & 1000 & 1.25 & 4.61 & 6.89 & 6.52 & 981 & 77.5 & \\
\hline $26287-9 \mathrm{~J}$ & & 1400 & 1.23 & 4.52 & 7.46 & 7.06 & 977 & 85.5 & \\
\hline $2687-10 \mathrm{~A}$ & & 1800 & 1.24 & 4.61 & 7.52 & 6.76 & 985 & 83.3 & \\
\hline $2687-10 C$ & & 2200 & 1.24 & 4.51 & 7.62 & 6.76 & 985 & 84.1 & \\
\hline $2687-10 \mathrm{~F}$ & AUG 26 & 200 & 1.21 & 4.7 & 7.63 & 7.63 & 990 & 83.5 & \\
\hline $2687-11 B$ & & 600 & 1.24 & 4.7 & 7.18 & 6.78 & 981 & 81.2 & \\
\hline $2687-11 \mathrm{D}$ & & 1000 & 1.21 & 4.36 & 7.26 & 7.69 & 973 & 84.6 & \\
\hline $2687-15 A$ & & 1400 & 1.26 & 4.36 & 6.65 & 6.26 & 970 & 77.9 & \\
\hline $26887-15 C$ & & 1800 & 1.28 & 4 & 6.53 & 5.72 & 952 & 82.2 & \\
\hline $2687 \rightarrow 15 F$ & & 2200 & 1.28 & 4.19 & 6.19 & 5.73 & 956 & 76.9 & \\
\hline $2687-16 \mathrm{~B}$ & AUG 27 & 200 & 1.31 & 4.19 & 6.36 & 4.88 & 967 & 74.7 & \\
\hline $2687-16 \mathrm{D}$ & & 600 & 1.31 & 4.19 & 5.22 & 4.94 & 975 & 59.0 & \\
\hline $2687-16 \mathrm{E}$ & & 700 & 131 & 4.19 & 4.72 & 4.97 & 986 & 50.7 & \\
\hline $2687-16 \mathrm{H}$ & & 1000 & 1.36 & 4.18 & 4.44 & 3.59 & 981 & 48.5 & \\
\hline $2687-17 A$ & & 1200 & 1.35 & 4.28 & 3.91 & 3.89 & 976 & 43.9 & \\
\hline $2687-17 B$ & & 1400 & 1.34 & 4.37 & 4.61 & 4.13 & 975 & 52.2 & \\
\hline $2687-18 A$ & & 1600 & 1.36 & 4.32 & 3.55 & 3.62 & 973 & 40.5 & \\
\hline $2687-18 B$ & & 1800 & 1.37 & 4.28 & 4.59 & 3.31 & 967 & 53.7 & \\
\hline $2687-180$ & & 2000 & 1.4 & 4.28 & 4.39 & 2.52 & 969 & 50.7 & \\
\hline $2687-18 F$ & & 2200 & 1.43 & 4.27 & 4.14 & 1.75 & 970 & 47.5 & \\
\hline $2687-18 G$ & AUO 28 & 0 & 1.46 & 4.32 & 3.75 & 0.99 & 967 & 43.6 & \\
\hline $2687-19 B$ & & 200 & 1.49 & 4.37 & 3.28 & 0.25 & 971 & 37.3 & \\
\hline $2687-19 C$ & & 400 & 1.49 & 4.32 & 3.9 & 0.24 & 972 & 44.1 & \\
\hline $2687-19 E$ & & 600 & 15 & 4.27 & 3.12 & 0.00 & 973 & 35.0 & \\
\hline $2687-20 A$ & & 1000 & 1.52 & 4.09 & 2.83 & -0.49 & 971 & 31.8 & \\
\hline $2687-20 \mathrm{C}$ & & 1400 & 1.55 & 3.91 & 2.12 & -1.22 & 976 & 23.0 & \\
\hline $2687-21 B$ & & 1800 & 1.56 & 4.45 & 1.97 & -1.45 & 981 & 21.1 & \\
\hline $2687-21 D$ & & 2200 & 1.61 & 4.37 & 1.41 & -2.63 & 983 & 14.8 & \\
\hline $2687-22 B$ & AUG 29 & 200 & 1.6 & 3.55 & 1.43 & -2.42 & 983 & 14.7 & \\
\hline $2687-22 C$ & & 600 & 1.57 & 3.55 & 1.54 & -1.71 & 983 & 15.9 & \\
\hline $2687-23 A$ & & 1000 & 1.55 & 3.12 & 3.44 & -1.21 & 976 & 36.4 & \\
\hline $2687-23 B$ & & 1400 & 1.56 & 3.18 & 2.79 & -1.46 & 996 & 26.6 & \\
\hline $2687-23 D$ & & 1800 & 1.5 & 3.21 & 2.08 & 0.00 & 980 & 21.7 & \\
\hline $2687-24 B$ & & 2200 & 1.58 & 3.12 & 2.51 & -1.94 & 989 & 24.7 & \\
\hline $2687-24 \mathrm{D}$ & AUG 30 & 200 & 1.62 & 3.29 & 2.26 & -2.87 & 979 & 23.5 & \\
\hline $2687-24 \mathrm{E}$ & & 600 & 1.64 & 3.38 & 2.26 & -3.32 & 976 & 23.9 & \\
\hline $2687-25 B$ & & 1000 & & 3.46 & & & 984 & & \\
\hline $2687-30 \mathrm{~A}$ & & 1400 & & 3.47 & & & & & \\
\hline
\end{tabular}




\section{APPENDIX B}

LETTER FROM W. E. HAUPIN ON CALCULATING CURRENT DENSITIES 
2820 Seventh Street Road Lower Burrel1, PA 15068

Phone: (412) 337-4021

Fax: (412)339-6871

Aug 16,1991

Dr. Charles F. Windisch Jr.

Battelle, PNL

Battelle Boulevard

P.O. Box 999

Mail stop R2-48

RIChland WA 99352

Dear Dr. Windisch:

RE: Voltage Measurements on Pilot Cell Test of Inert Anodes

I visited the Reynolds Metals Research Facility Aug. 10 through Aug. 14 to observe the pllot cell testing of Battelle inert anodes. My overall impression was that the inert anodes were performing well. The cell was cunning smoothly. The anodeg were withstanding well the normal mechanical abuse that occurs with pot working and breaking crust around them.

While there I assisted in making potential scans under and at the sides of inert anodes to determine the current distribution. The quartz voltage probes with tungsten tips functloned well. Although they slowly dissolved, they retained adequate wall thickness and strength even after 20 to 25 minutes in the bath. presently the lnert anodes are operating with about 0.2 $A / \mathrm{cm}^{2}$ on the anode bottomg, about $0.4 \mathrm{~A} / \mathrm{cm}^{2}$ on the 81 des facing bare walla with very little current leaving sides facing the carbon anode or other inert anodes. These figures are slightly different than I quoted to you over the phone. Upon returning home I discovered an error in the calculations I made at the Reynolds laboratory. The above indicates that you could gafely increase the lnert anode current at leat $25 \%$. 


\section{Voltage Probe Work}

The probe was kept connected to the cathode of the cell through a $15 \mathrm{ohm}$ resistor except when taking a reading. For readings, a switch connected the probe to a high resistance digital voltmeter referenced to the inert anode under study. We found frequently, when measuring close to an Inert anode, less than the expected $2.217 \mathrm{~V}$ between the probe tip and the inert anode. It appears that either the nearly constant cathoding of the probe tip did not matntain unit activity of aluminum on the tungsten or the low currents on the 1nert anodes did not establish unit activity of oxygen on them. Also $I$ observed that the probe's potential would start to drift positive after 3 to 4 seconds following cathoding. Since it took only about 3 seconde to make a reading, this did not seem to be a problem, but it ig poorer stablitty than we experienced in the past in a conventional Hall Cell.

\section{Preliminary Analysis of Probe Data}

The optimum way to analyse the probe data is by computer with a 3D plotting program. I made the following quick analysis of data from anode $A$ to determine that we were getting valid data. From 3 vertical scans at varying distance between the inert anode and the north wall I determined that the average potential. gradtent to the wall was $0.063 \mathrm{~V} / \mathrm{cm}$. From geometry, the bath area at this location was $15 \mathrm{~cm} \times 18 \mathrm{~cm}$ or $270 \mathrm{~cm}^{2}$. Bath analyois for the day was not yet available so I assumed, based upon prior days, that it was $1.25 \mathrm{R}, 58 \mathrm{CaF}_{2}, 0.58 \mathrm{MgF}_{2}, 0.68$ LiF, and 7 \& $\mathrm{Al}_{2} \mathrm{O}_{3}$. This bath would have an electrical conductivity of $2.068 \mathrm{ohm}^{-1} \mathrm{~cm}^{-1}$. Therfore, $0.063 \mathrm{~V} / \mathrm{cm}+2.068$ $\mathrm{ohm}^{-1} \mathrm{~cm}^{-1}=0.130 \mathrm{~A} / \mathrm{cm}^{2}$ current density in the bath. Hence, 270 $\mathrm{cm}^{2} \star 0.130 \mathrm{~A} / \mathrm{cm}=35$ ampe from this quadrant of side area.

Dividing by the gubmerged side area for the quadrant $\left(87 \mathrm{~cm}^{2}\right.$ for 1.9 " submerged) we get a current density of $0.41 \mathrm{~A} / \mathrm{cm}^{2}$ for this side of anode $A$.

A scan under anode A gave $0.058 \mathrm{~V} / \mathrm{cm}$. Voltage scang between anode $B$ and the carbon anode and anode $C$ and the carbon anode showed a negative potential gradient indicating that current was fanning out from the carbon anode (operating at a more positive 
potential than the inert anodeg) preventing current escape from the sides of the inert anodes facing the carbon anode. This was confirmed by lowering the voltage (and current) on the carbon anode and noting the rise in currents from anodes $\mathrm{A}, \mathrm{B}$, and $\mathrm{C}$. From this information and the geonetry I assumed that current fanning from the bottom under anode A was $2.54 \mathrm{~cm}$ east $1.27 \mathrm{~cm}$ south, 0 west, and approxlmately $2.54 \mathrm{~cm}$ north. Based upon this, I calculated the effectlve bath cross section under anode A to be $270 \mathrm{~cm}^{2}$. The current then $1 \mathrm{~s} 0.058 \mathrm{~V} / \mathrm{cm} * 2.068 \mathrm{ohm}^{-1}$ $\mathrm{cm}^{-1} * 270 \mathrm{~cm}^{2}=32 \mathrm{~A}$. Dividing by the anode bottom area of 182 $\mathrm{cm}^{2}$ glveg a current density of $0.1 \mathrm{~B} \mathrm{~A} / \mathrm{cm}^{2}$. Thls agrees well with the $0.19 \mathrm{~A} / \mathrm{cm}^{2}$ current density on the bottom of anode $\mathrm{B}$ calculated by dividing the measured current into it by its bottom area (since essentially no current leaves the sides of anode B).

Suming the calculated currents from the side and bottom of anode $A$ gives 67 amps vo the 68 amps measured. The additional ampere for even slightly more, considering the error of measurement and in assumptions made) may be leaving the anode from the sides facing other 1nert anodes.

Most sincerely,

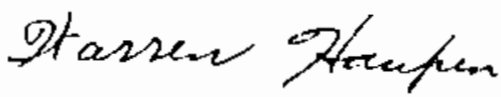

Warren Haupin

CC: Dr. Pat Hart

Dr. Denis strachan 
1

$+$

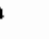




\section{APPENDIX C}

ANALYSIS OF NI ROD FRACTURE 
Manufacturing Technology Laboratory

Analytical Department

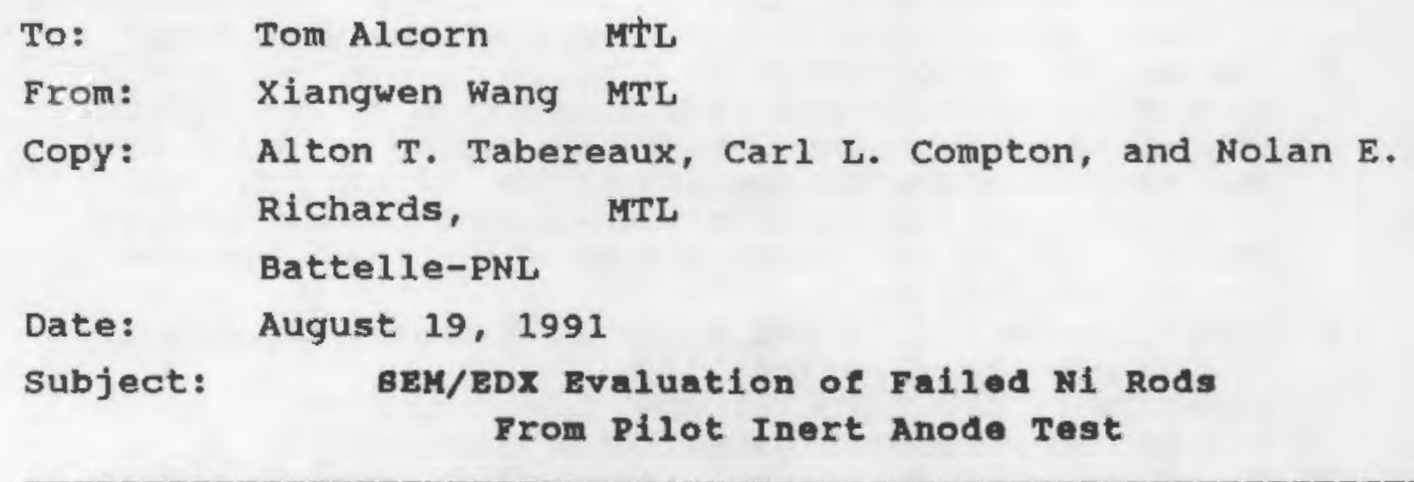

\section{Background:}

Battelle-PNL uses nickel rods (grade type: Nickel 200) as holder and conductor for the inert anodes in the inert anode pilot test at MTL of Reynolds Metals Co. These $\mathrm{Ni}$ rods experienced self-broken failure at the section above the inert anode after a period of service. Two of those Ni rod samples were brought to the Analytical Lab for SEM/EDX evaluations of possible causes for the failure.

visual observation of the samples indicates that a layer of greenish $\mathrm{film}$ was over the broken section of one $\mathrm{Ni}$ rod while the other sample had extraordinary sizes of grains/crystals in the failed section which was surrounded with about $2 \mathrm{~mm}$ thick greenish layer. SEM/EDX analysis was performed on these broken sections of the $\mathrm{Ni}$ rods.

\section{Bummaries:}

1. The greenish layer/film was analyzed to be primarily composed of $\mathrm{NiO}$ and some of cryolite component such as $\mathrm{NaF}$ and $\mathrm{AlF}_{3}$.

2. Abnormal high content $s$ was found over the $\mathrm{Ni}$ grains/crystals in the failed section of one Ni rod, which was associated with either $M n$ and $T 1$ or $N 1$ as non-metallic phases.

3. Some high $S$ content areas were also found in a freshly fractured section opposite the failed site.

4. Sizes of grains/crystals in the fallure section of one Ni rod sample were found to be at least 10 times greater than the freshly fractured section opposite the failed site.

5. No graphite precipitate phases were found in the failed sections. 
Conclusions and Recommendations:

The results of SEM/EDX analysis in this report are only preliminary and it is therefore not conclusive. Further evaluations are needed for, the $\mathrm{N} i$ rod failure. Nevertheless, the following conclusions and recommendations were made:

1. The oxygen was observed on SEM/EDX to diffuse into the $\mathrm{Ni}$ rod and form layers of porous oxide at the site of the harsh environment during the course of pilot test.

2 . The recrystallization/growth of the Ni grains, and precipitation/formation of non-nickel phases such as $\mathrm{Mn}, \mathrm{Ti}$, and $\mathrm{Ni}$ sulfides, may be the primary reasons for the Ni rod failure.

3. Nickel grade 200 is not suitable for service above 315 ${ }^{\circ} \mathrm{C}$ for prolonged period $[1]$.

4. Impurity of the $\mathrm{Ni}$ metal and microstructure of the $\mathrm{Ni}$ rod should be investigated for the sources of $\mathrm{s}$.

5. Ni alloys such as Inconel rather than pure $\mathrm{N} 1$ rod is recommended to be used in the inert anode test. The $\mathrm{Ni}$ alloys have both high corrosion resistance and mechanical strength at the high temperature corrosive environment.

\section{BEM/EDX EValuation:}

\section{Ni Rod Sample \#1}

The falled section of the sample was covered with greenish film. Figure 1 shows a typical morphology of the surface. The bright area on the secondary electron image is due to the presence of fluoride. Figure 2 (a) and (b) are the EDS respectively for the whole field of the sample surface shown in Figure 1 and bright area. Figure 3 (a) and (b) present the structure change of the $\mathrm{Ni}$ rod. Figure 4 gives the EDS of the whole field of Figure 3 (b). The presence of $S$ in the freshly fractured section opposite the failed site as shown in Figure 3 (b) was identified to be from over the Ni grains. Figure 5 shows dark eye/round areas which was enriched with S. An EDS for the window area was presented in Figure 6 (b).

\section{N1 Rod Sample \#2}

This sample has extraordinary sizes of grains/crystal in the whole broken section which was surrounded with about $2 \mathrm{~mm}$ thick greenish layer. Figure 7 (a) shows the surface on which one can easily identify greenish film and recrystallization region. Figure 7 (b) is a close look at the greenish film which is composed of layers of Nio showing the oxygen diffusion into the rod. Figure 8 is the EDS obtained over the $11 \mathrm{~m}$ region. Figure 9 is a general microstructure of the broken section showing the sizes of these grains. Bright dots around the grains or on the distinct 
crystal surface were identified to be non-metallic sulfide phases. Figure 10 (a) shows the non-metallic sulfide phases on one (100) plane and Figure 10 (b) shows how the phase was formed on the surface. Figure 11 gives an EDS obtained on one of the non-metallic phases. Formation of the sulfide precipitate phases and recrystallization of the grains will cause embrittlement of the $\mathrm{Ni}$ rod.

References:

1. Metal Handbook: 9 th ed. Vol.3 Propertles and Selections: stainless steel, Tool Materials, and special-Purpose Metals, ASM, p128, 1980.

Submitted by:

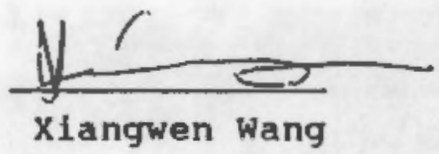

Approved by:

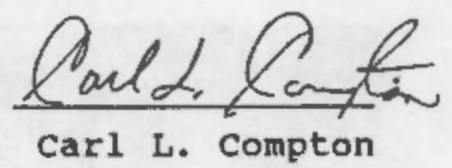




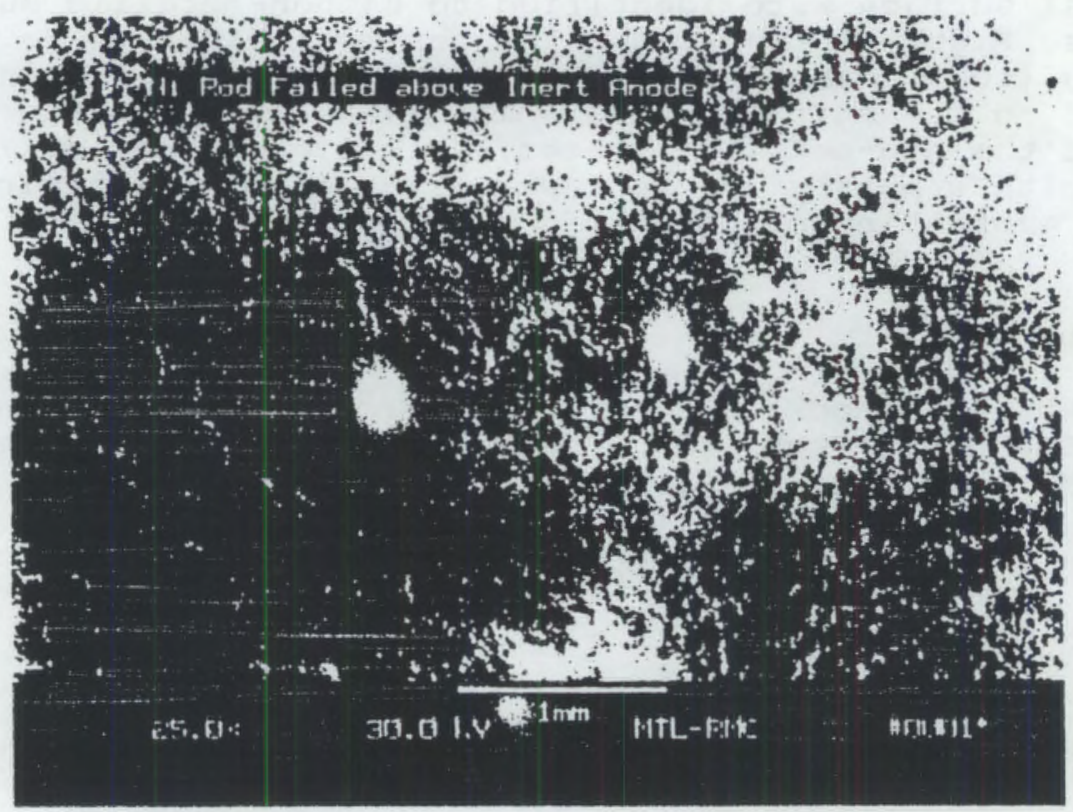

(a)

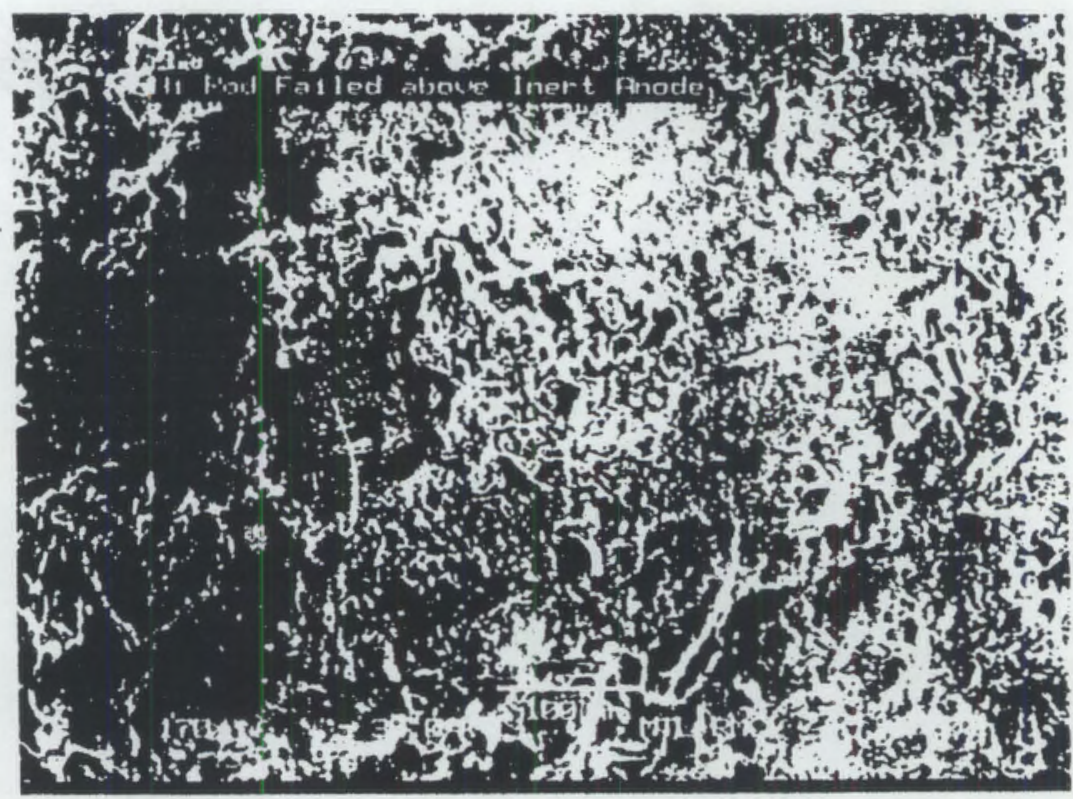

(b)

Figure 1 Video prints of the SEM secondary electron images for (a) failed section of $\mathrm{Ni}$ rod $\# 1$ and (b) a close look of bright area in Figure 1 (a). 


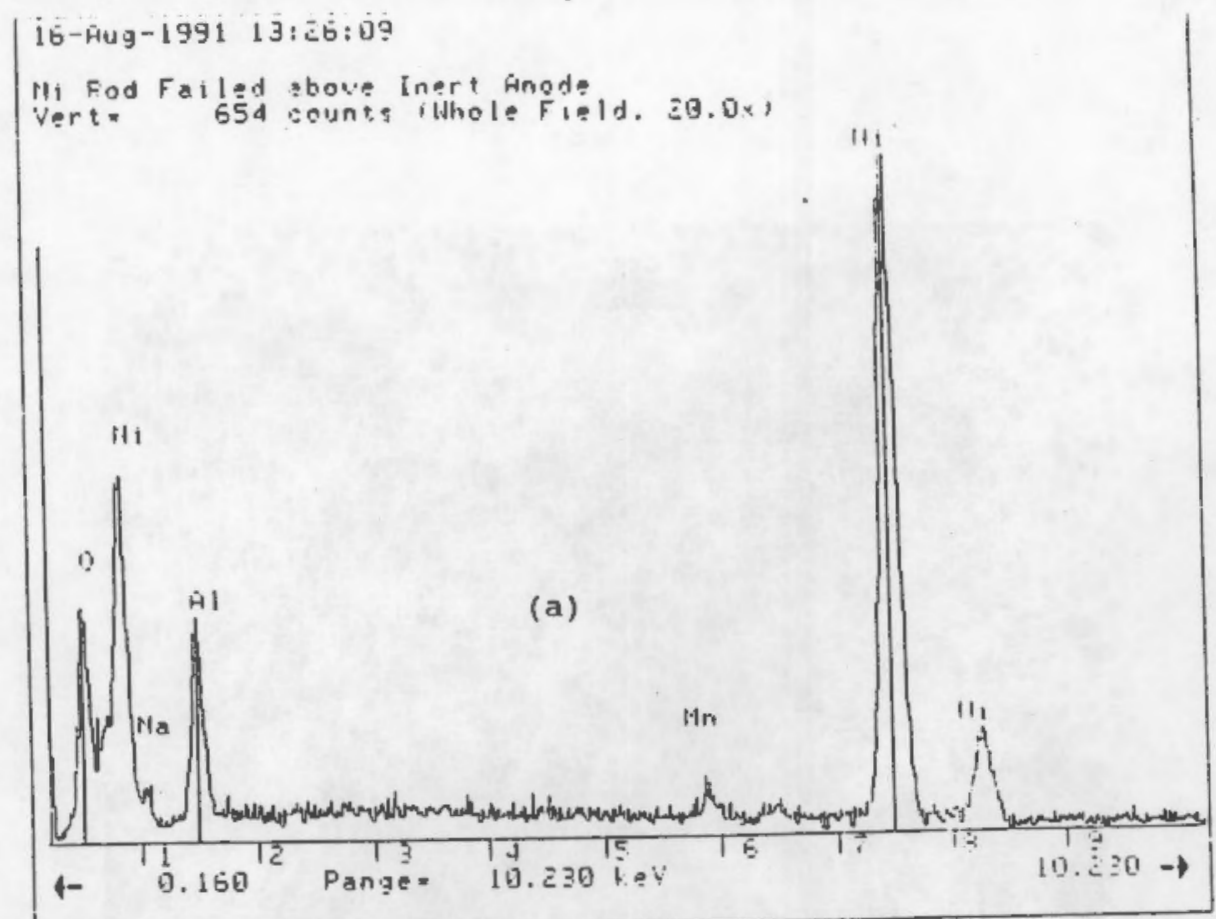

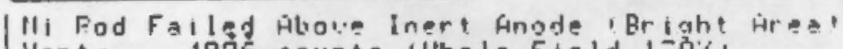

Vert = 4995 counts (Whole Field, 1 . B':

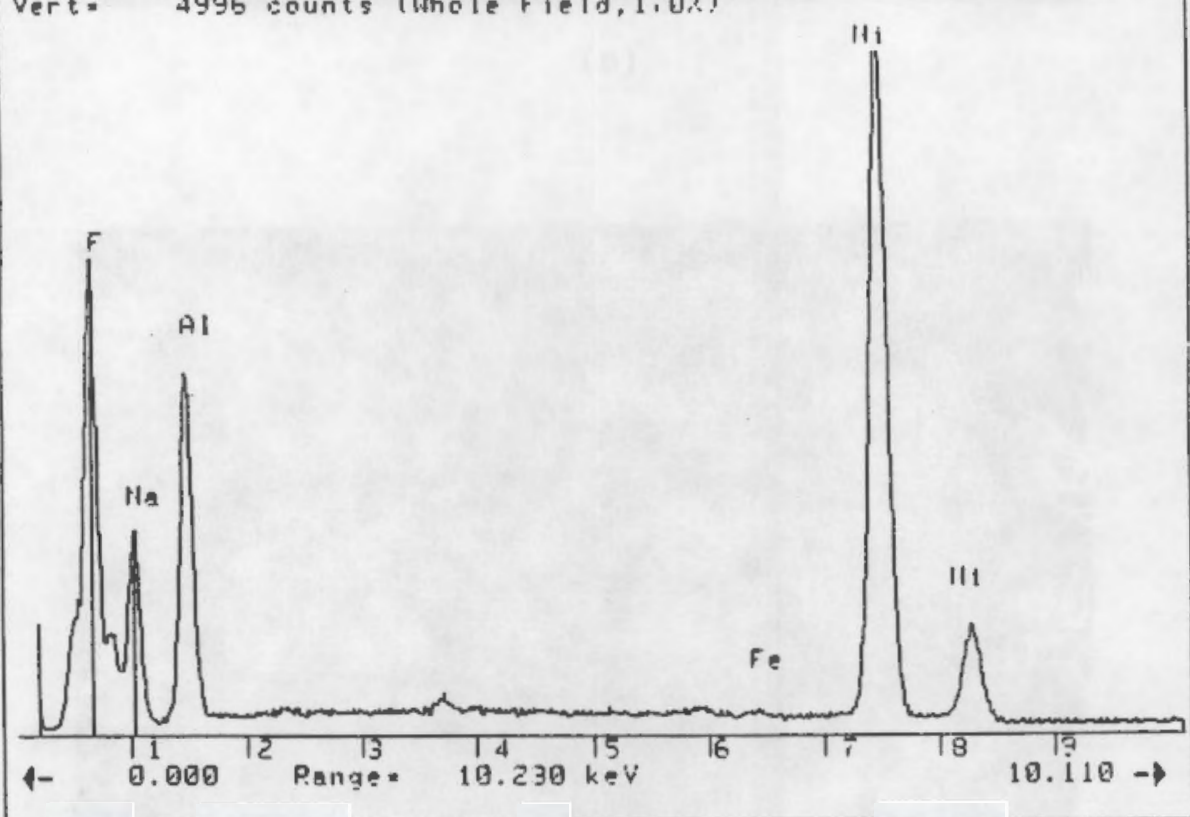

(b)

Figure 2 EDS obtained for (a) the whole field of failed surface in Flgure 1 (a), and (b) the whole fleld of the surface in Figure 1 (b). 


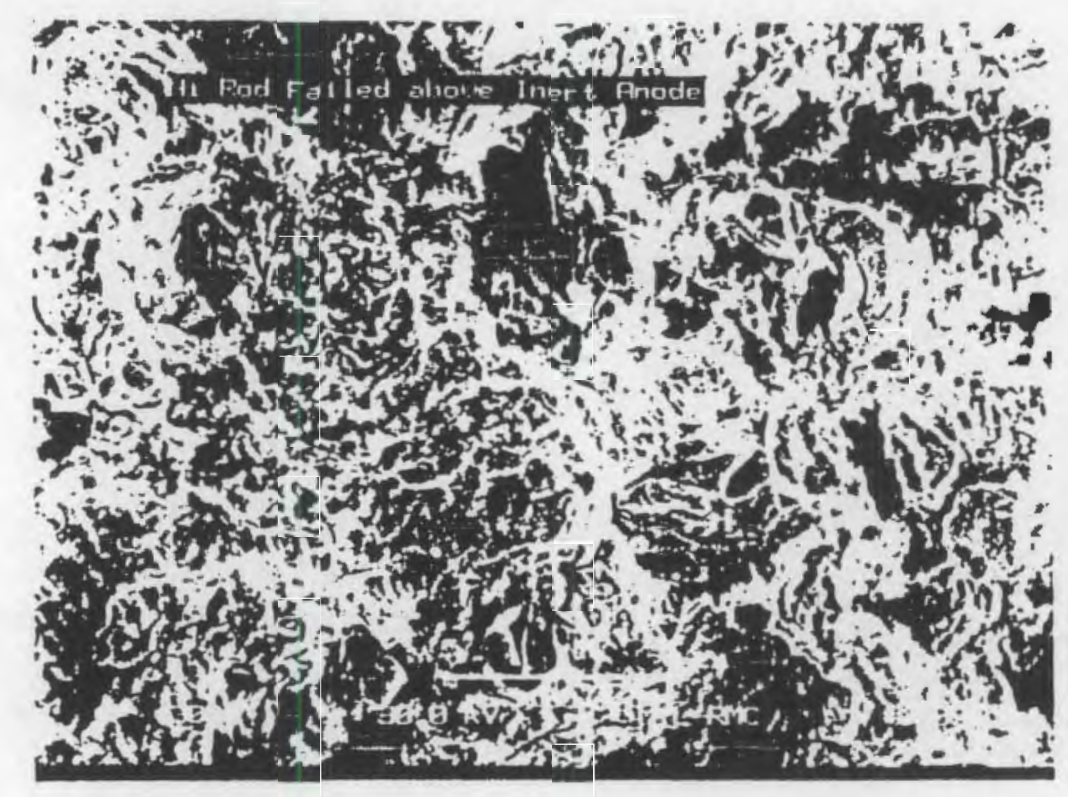

(a)

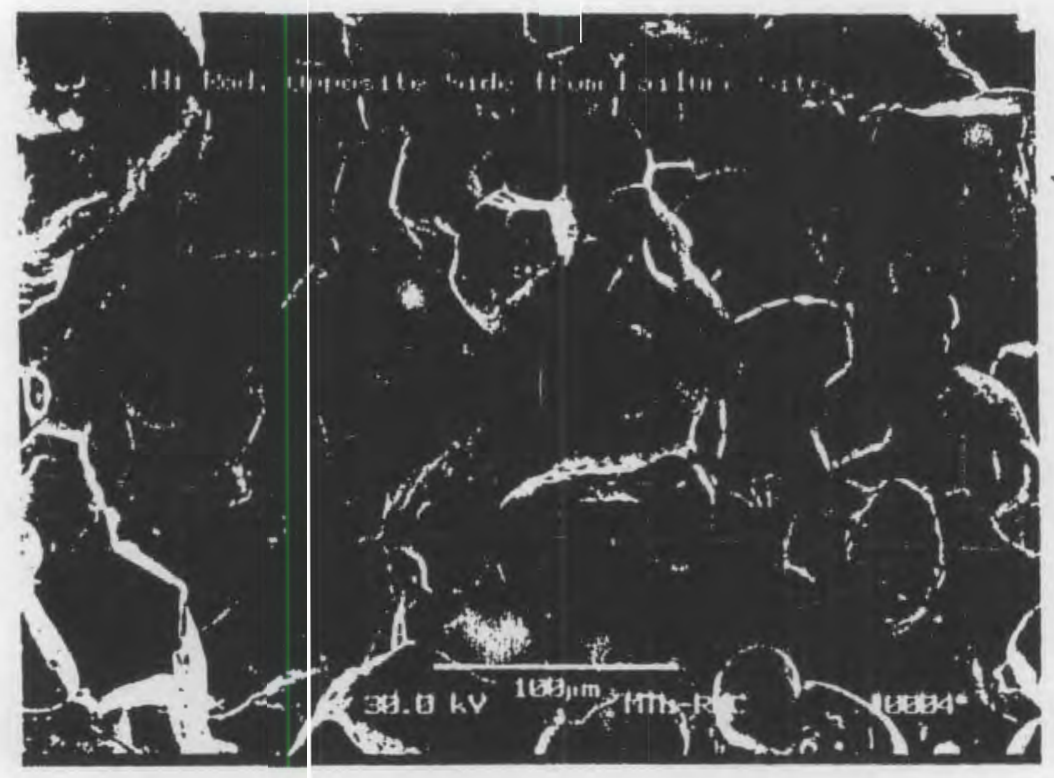

(b)

Figure 3 Video prints of the SEM secondary electron images for (a) a typical surface of the failed section of sample $\# 1$, and (b) fractured structure opposite the failed site at the sample scale. 


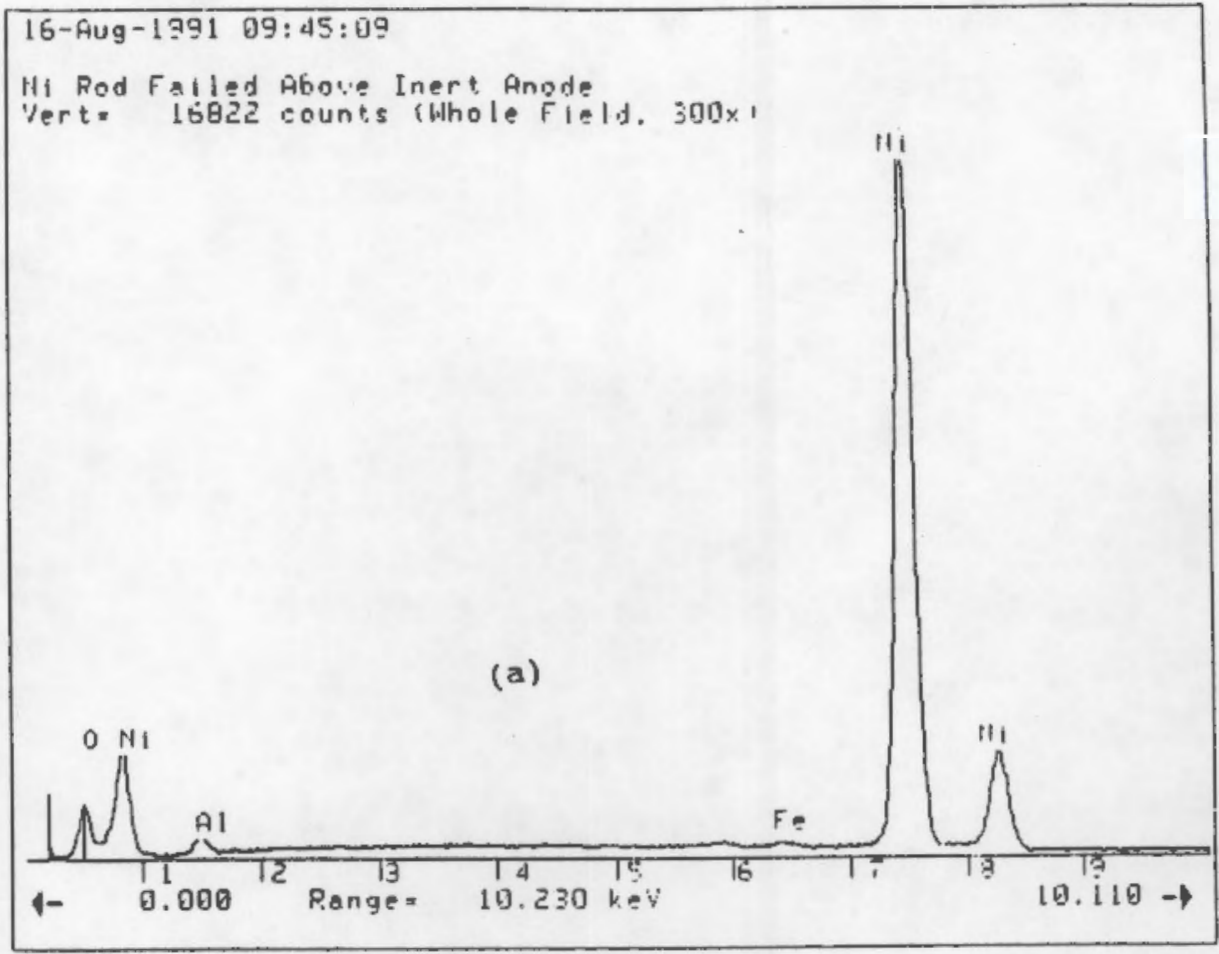

Ni Pod, Coposite side from Filure Site

Vert. 10.479 counts (lhole field, $300 x$ )

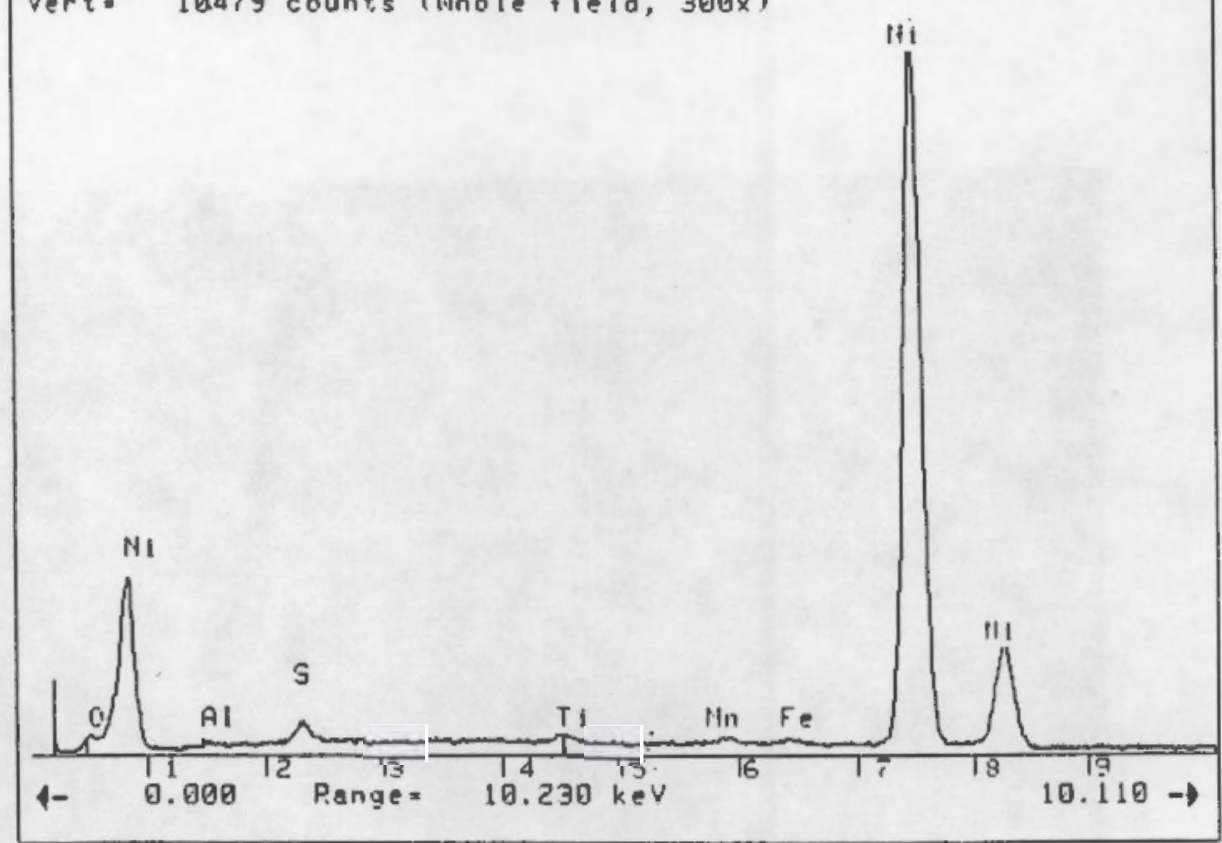

(b)

Flgure 4 EDS obtained for (a) the whole field of failed surface in Figure 3 (a), and (b) the whole fleld of the surface in Figure 3 (b). 


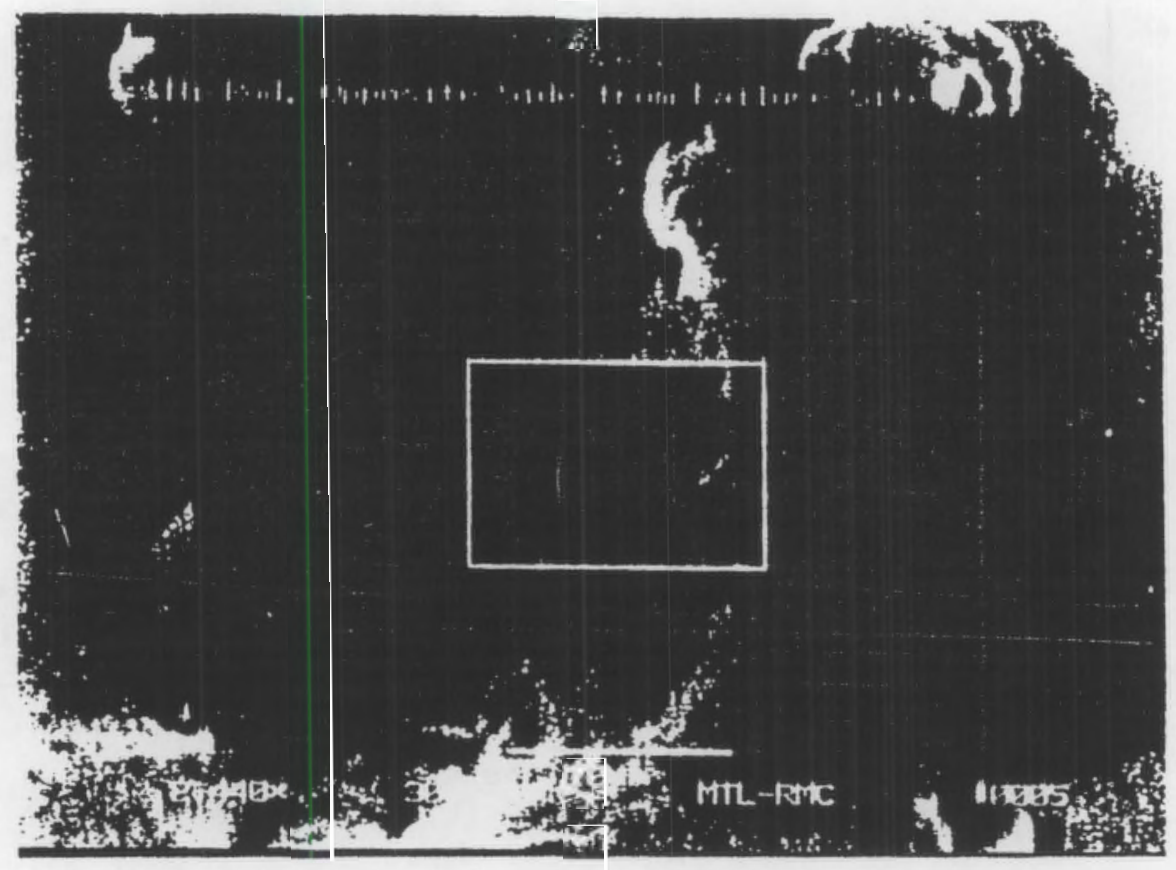

Figure 5 Video print of the SEM image showing forms of $S$ (dark eye areas) on one $\mathrm{Ni}$ grain. 


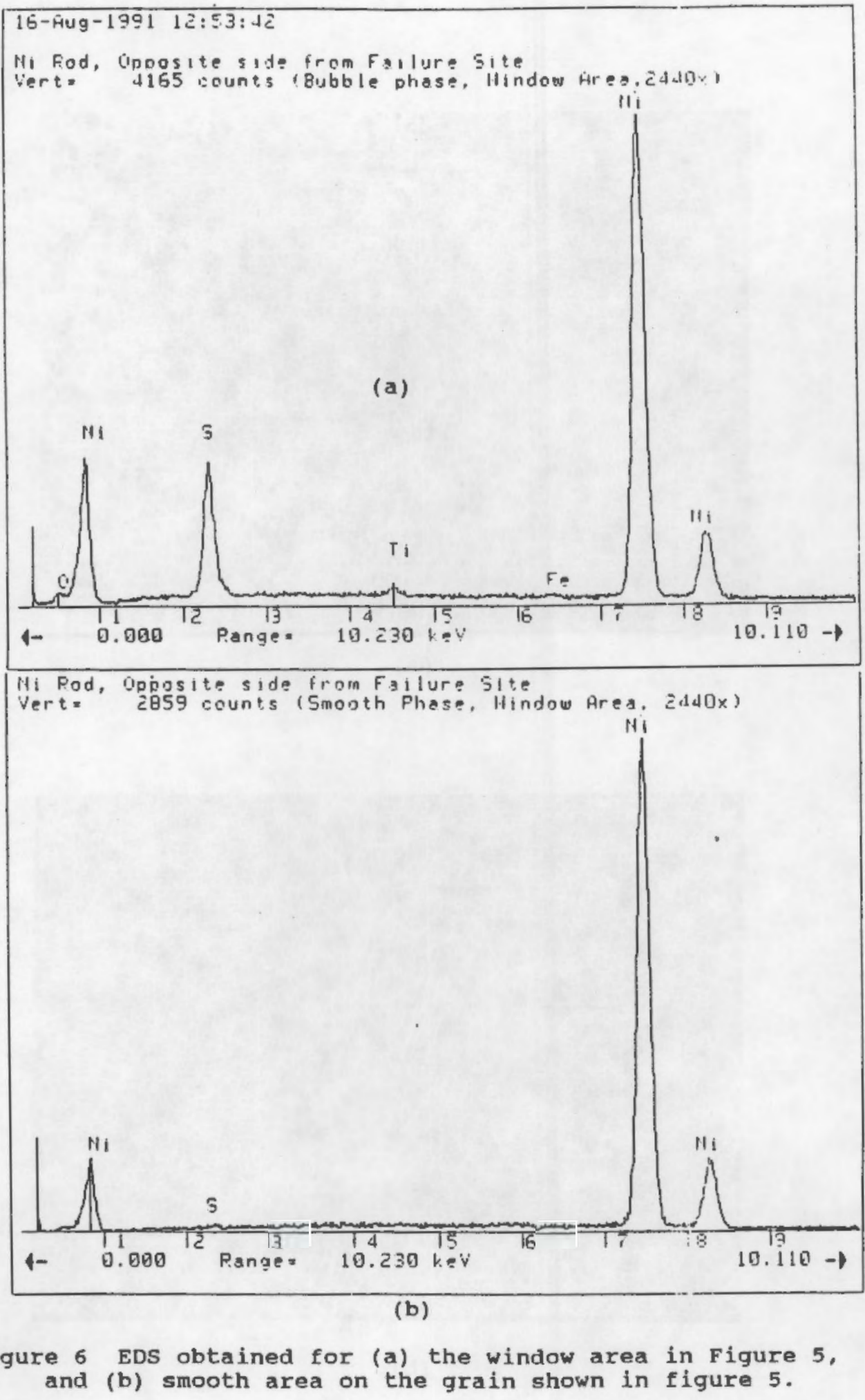




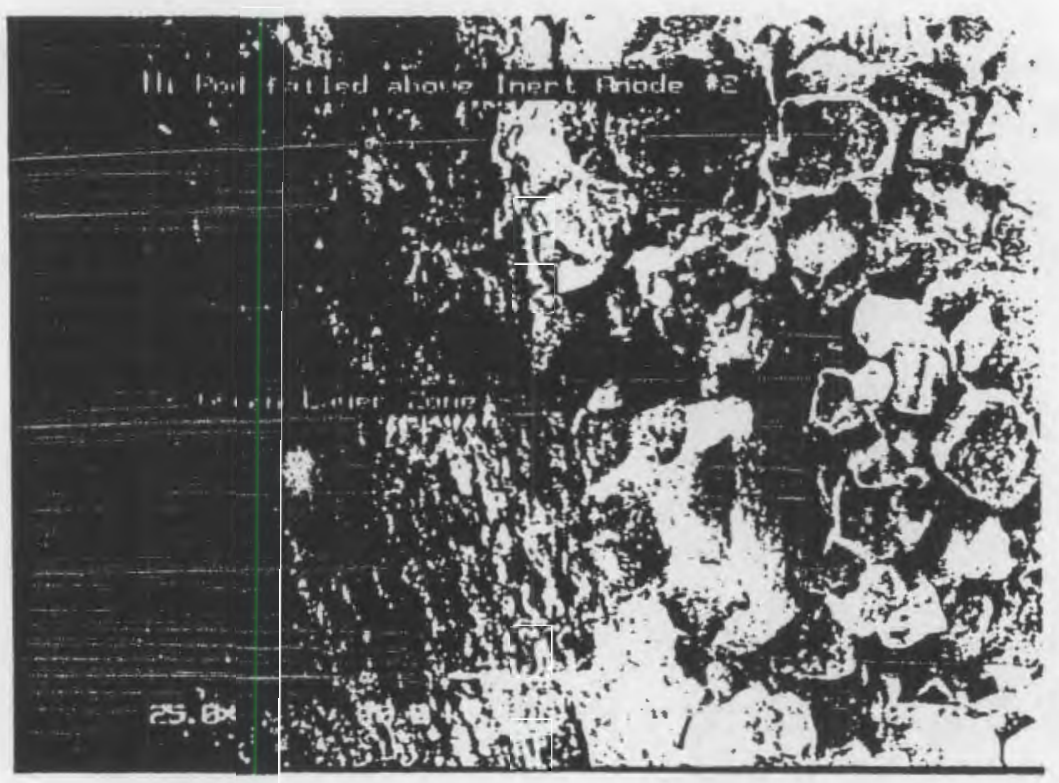

(a)

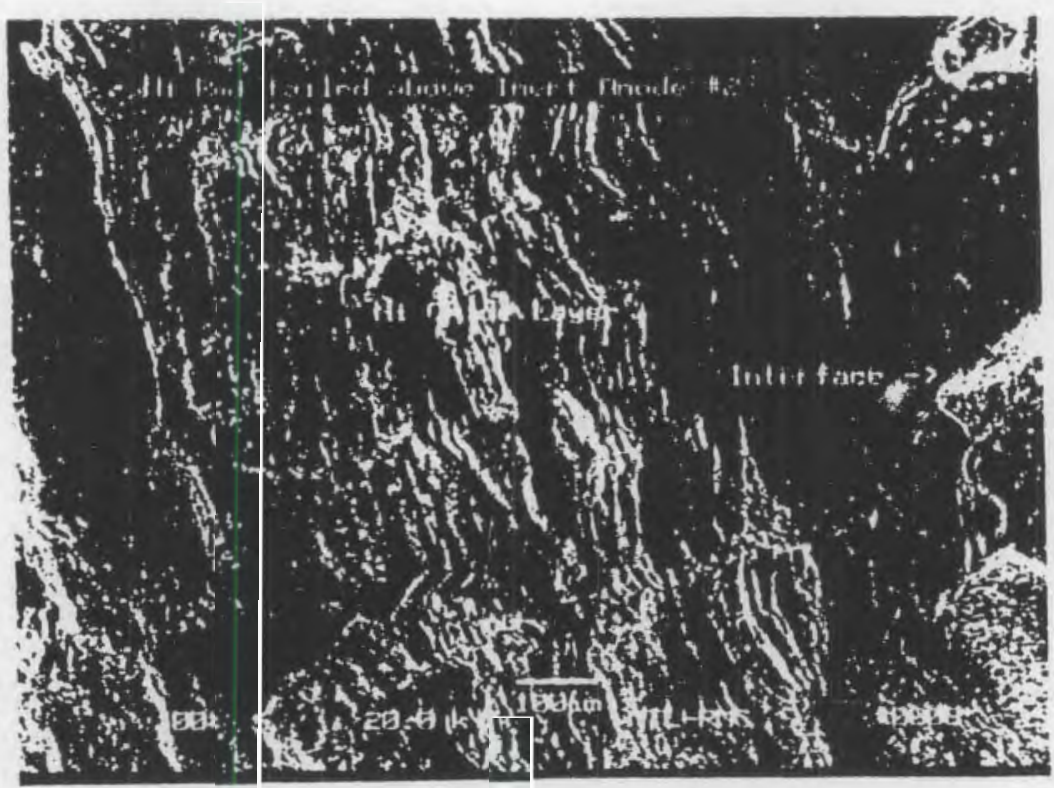

(b)

Figure 7 video prints of the SEM secondary electron images for (a) green layer zone in failed $\mathrm{Ni}$ rod $\# 2$, and a close look at the green layer. 


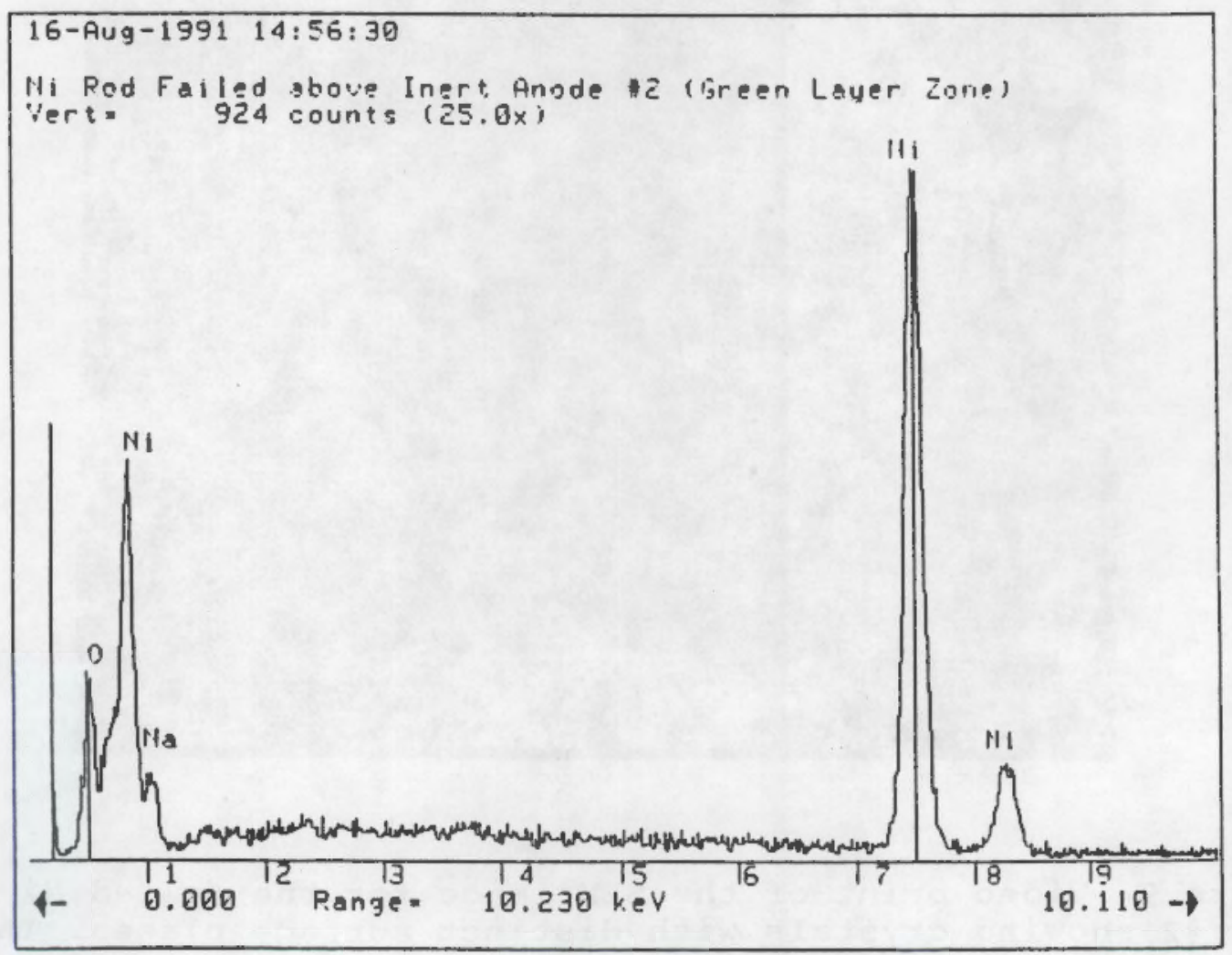

Figure 8 EDS obtained for the green layer zone shown in Figure 7 (a). 


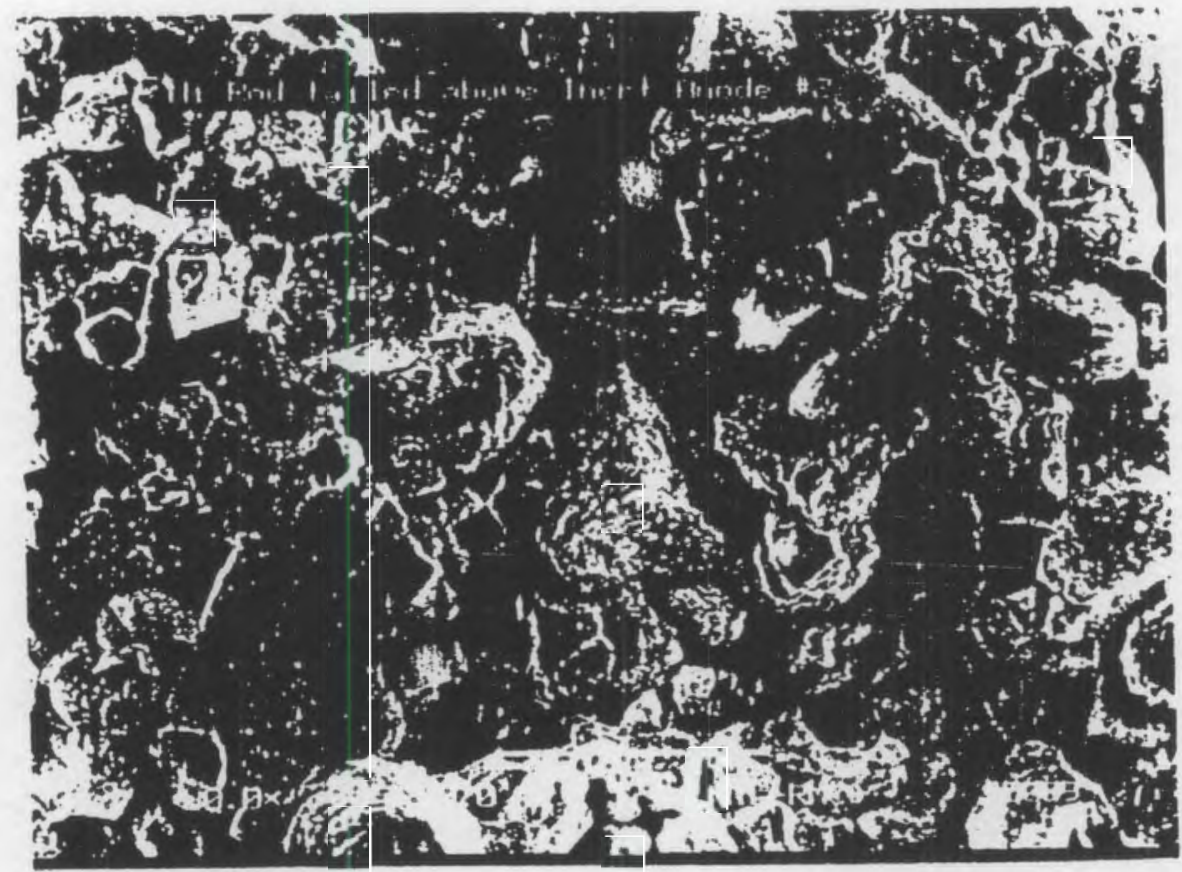

Figure 9 Video print of the SEM image for the failed $\mathrm{Ni}$ rod \#2 showing crystals with distinct surface planes. The bright dots on the surface were identified as nonmetallic sulfide precipitate phases. 


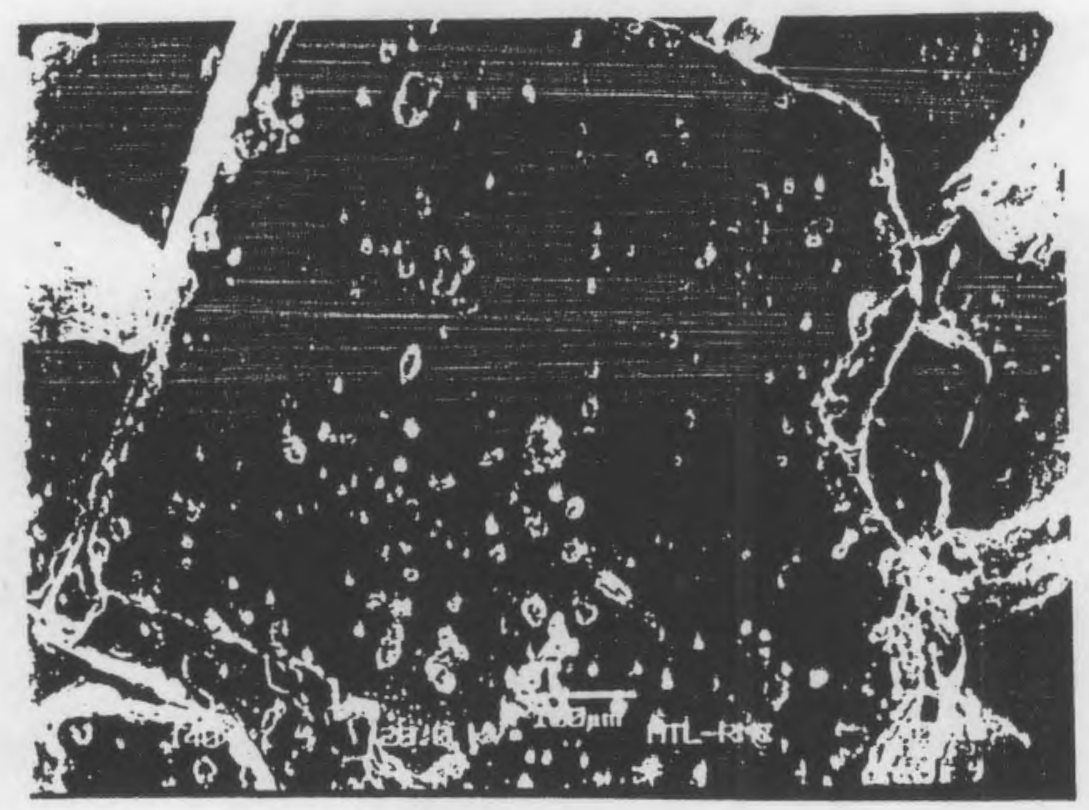

(a)

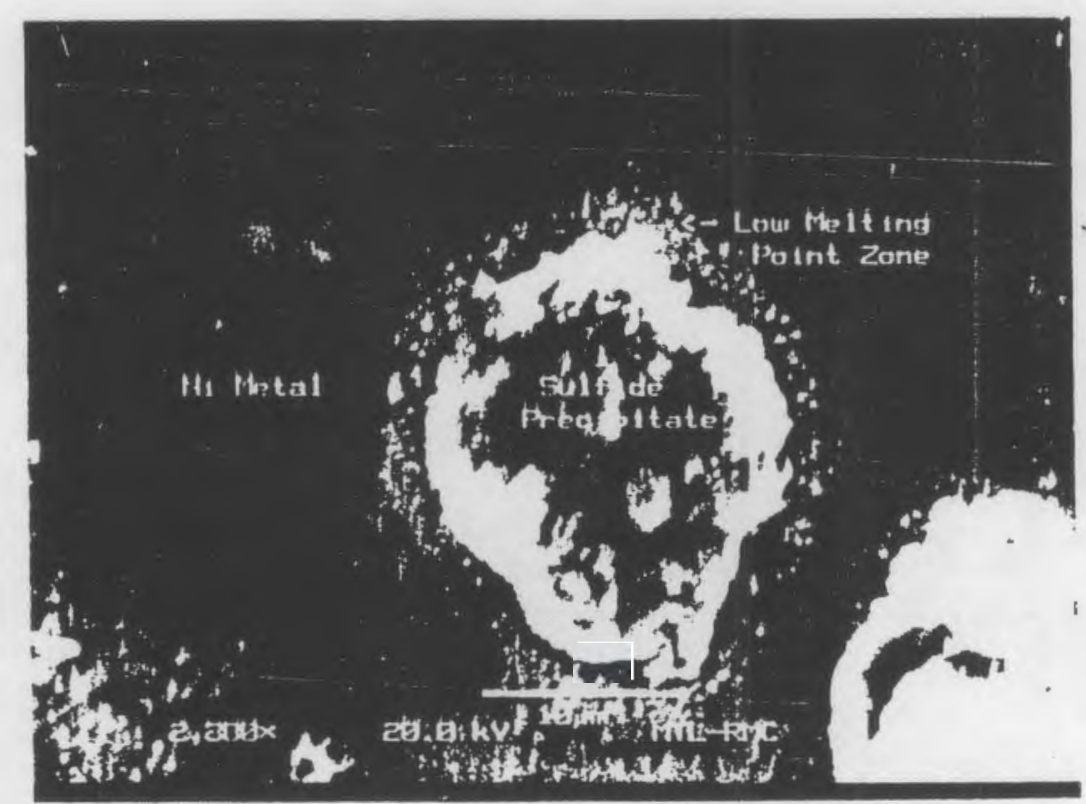

(b)

Figure 10 Video prints of the SEM secondary electron images showing (a) a plane (100) of $\mathrm{Ni}$ crystal and precipitate phases, and (b) a close look at one typical precipitate. 


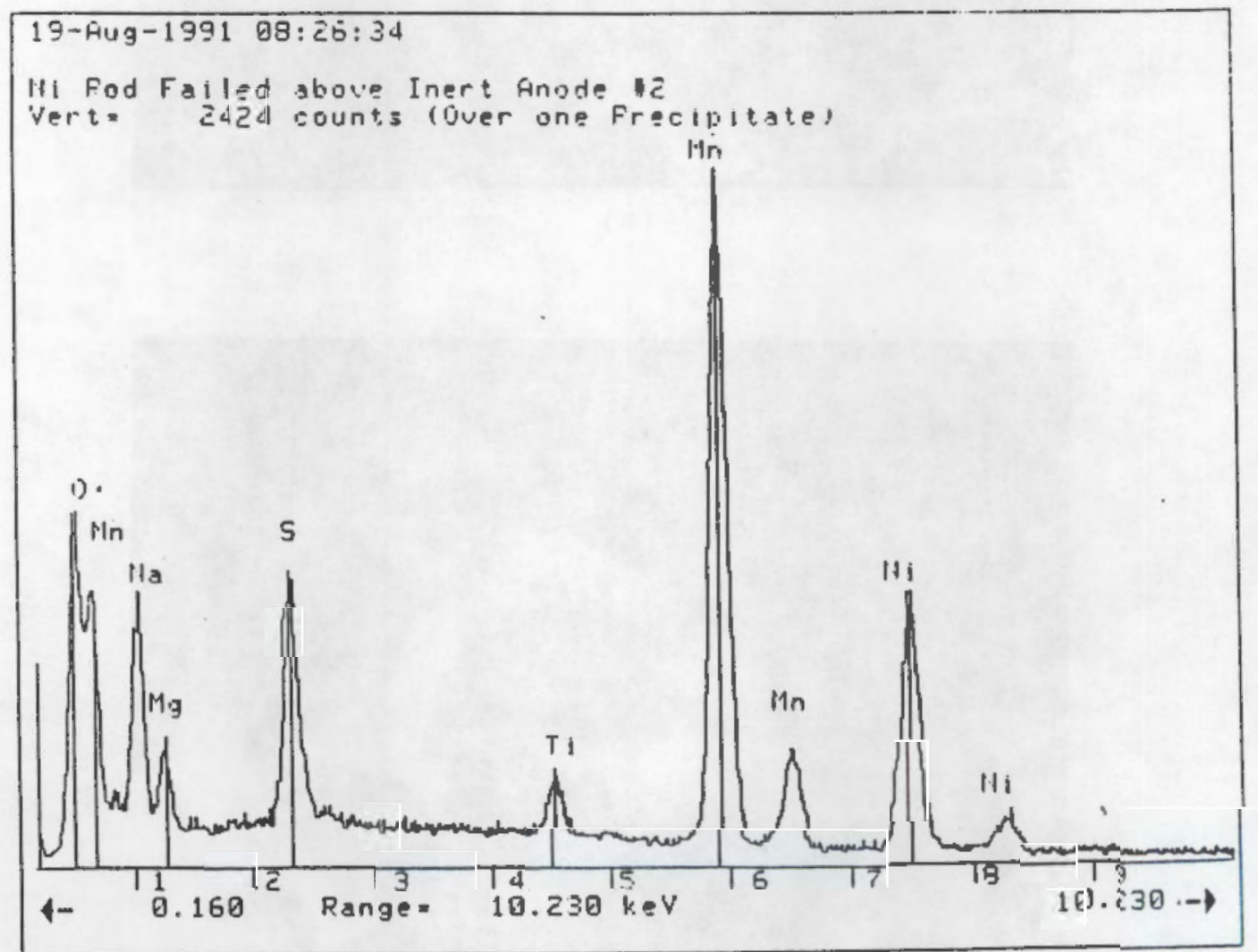

Figure 11 EDS obtained on the precipitate shown in Figure 10 (b). 
APPENDIX D

METAL ANALYSIS RESULTS 
METAL ANALYSIS

\begin{tabular}{|c|c|c|c|c|c|}
\hline Sample ID & Date & Time & $\mathrm{Ni}, \%$ & $F \theta, \%$ & $\mathrm{Cu}, \%$ \\
\hline $2683-13$ & AUG 3 & 700 & 0.004 & 0.42 & 0.120 \\
\hline $2683-158$ & & 1400 & 0.004 & 0.46 & 0.110 \\
\hline $2683-17 B$ & AUG 4 & 200 & 0.004 & 0.48 & 0.110 \\
\hline $2683-19 B$ & & 1800 & 0.005 & 0.50 & 0.093 \\
\hline $2683-19 D$ & & 2200 & 0.005 & 0.51 & 0.093 \\
\hline $2683-20 \mathrm{D}$ & AUG 5 & 200 & 0.004 & 0.49 & 0.086 \\
\hline $2683-20 A$ & & 600 & 0.004 & 0.50 & 0.092 \\
\hline $2683-20 \mathrm{~F}$ & & 1000 & 0.004 & 0.48 & 0.086 \\
\hline $2683-20 \mathrm{H}$ & & 1400 & 0.004 & 0.49 & 0.085 \\
\hline $2683-228$ & & 1800 & 0.004 & 0.46 & 0.082 \\
\hline $2683-220$ & & 2200 & 0.008 & 0.48 & 0.080 \\
\hline $2683-23 A$ & AUG 6 & 200 & 0.004 & 0.48 & 0.081 \\
\hline $2683-23 C$ & & 600 & 0.004 & 0.43 & 0.074 \\
\hline $2683-23 F$ & & 1000 & 0.004 & 0.44 & 0.077 \\
\hline $2683-24 B$ & & 1400 & 0.004 & 0.41 & 0.071 \\
\hline $2683-24 D$ & & 1800 & 0.004 & 0.42 & 0.072 \\
\hline $2683-24 F$ & & 2200 & 0.004 & 0.43 & 0.072 \\
\hline $2683-25 A$ & AUG 7 & 200 & 0.004 & 0.44 & 0.076 \\
\hline $2683-25 D$ & & 600 & 0.004 & 0.42 & 0.069 \\
\hline $2683-26 A$ & & 1000 & 0.003 & 0.42 & 0.089 \\
\hline $2683-26 C$ & & 1400 & 0.003 & 0.40 & 0.065 \\
\hline $2683-278$ & & 1800 & 0.003 & 0.42 & 0.068 \\
\hline $2683-270$ & & 2200 & 0.003 & 0.39 & 0.085 \\
\hline $2683-288$ & AUG 8 & 0 & 0.003 & 0.42 & 0.068 \\
\hline $2683-28 D$ & & 400 & 0.003 & 0.41 & 0.064 \\
\hline $2683-28 F$ & & 1000 & 0.003 & 0.35 & 0.053 \\
\hline $2683-29 A$ & & 1400 & 0.004 & 0.42 & 0.062 \\
\hline $2683-308$ & & 1800 & 0.004 & 0.41 & 0.058 \\
\hline $2683-31 A$ & & 2200 & 0.003 & 0.37 & 0.052 \\
\hline $2683-31 C$ & AUG 9 & 200 & 0.004 & 0.39 & 0.056 \\
\hline $2683-32 A$ & & 600 & 0.003 & 0.37 & 0.053 \\
\hline $2683-338$ & & 1000 & 0.003 & 0.32 & 0.045 \\
\hline $2683-34 B$ & & 1400 & 0.003 & 0.37 & 0.055 \\
\hline $2683-35 B$ & & 2200 & 0.003 & 0.37 & 0.052 \\
\hline $2683-368$ & AUG 10 & 600 & 0.003 & 0.35 & 0.050 \\
\hline $2683-378$ & & 1100 & 0.004 & 0.37 & 0.050 \\
\hline $2683-388$ & & 1400 & 0.004 & 0.38 & 0.050 \\
\hline $2683-39 B$ & & 1700 & 0.003 & 0.33 & 0.046 \\
\hline $2683-40 B$ & & 2200 & 0.004 & 0.32 & 0.045 \\
\hline $2683-41 B$ & AUG 11 & 200 & 0.006 & 0.37 & 0.050 \\
\hline $2683-42 B$ & & 600 & 0.006 & 0.34 & 0.047 \\
\hline $2683-438$ & & 1000 & 0.006 & 0.35 & 0.048 \\
\hline $2683-43 D$ & & 1400 & 0.008 & 0.36 & 0.051 \\
\hline $2683-44 B$ & & 1800 & 0.022 & 0.42 & 0.058 \\
\hline $2683-45 B$ & & 2200 & 0.039 & 0.37 & 0.060 \\
\hline
\end{tabular}


METAL ANALYSIS

\begin{tabular}{|c|c|c|c|c|c|}
\hline Sample ID & Date & Time & $\mathrm{Ni}, \%$ & $\mathrm{Fe}, \%$ & $\mathrm{Cu}, \%$ \\
\hline $2683-46 A$ & AUG 12 & 200 & 0.018 & 0.35 & 0.052 \\
\hline $2683-46 C$ & & 600 & 0.034 & 0.35 & 0.059 \\
\hline $2683-47 A$ & & 1000 & 0.023 & 0.37 & 0.057 \\
\hline $2683-48 A$ & & 1400 & 0.02 & 0.33 & 0.050 \\
\hline $2683-48 B$ & & 1800 & 0.018 & 0.33 & 0.049 \\
\hline $2683-49 B$ & & 2200 & 0.022 & 0.34 & 0.054 \\
\hline $2683-49 D$ & AUG 13 & 200 & 0.023 & 0.32 & 0.053 \\
\hline $2683-50 B$ & & 600 & 0.024 & 0.33 & 0.051 \\
\hline $2683-50 C$ & & 800 & 0.044 & 0.33 & 0.061 \\
\hline $2683-50 E$ & & 1000 & 0.055 & 0.38 & 0.071 \\
\hline $2683-50 G$ & & 1400 & 0.044 & 0.36 & 0.064 \\
\hline $2683-52 B$ & & 1800 & 0.056 & 0.37 & 0.068 \\
\hline $2683-520$ & & 2200 & 0.081 & 0.64 & 0.081 \\
\hline $2683-53 B$ & AUG 14 & 200 & 0.055 & 0.38 & 0.069 \\
\hline $2683-53 C$ & & 600 & 0.062 & 0.39 & 0.072 \\
\hline $2683-53 F$ & & 1000 & 0.07 & 0.40 & 0.072 \\
\hline $2683-54 B$ & & 1400 & 0.12 & 0.44 & 0.100 \\
\hline $2683-55 B$ & & 1800 & 0.14 & 0.44 & 0.120 \\
\hline $2683-55 D$ & & 2200 & 0.14 & 0.46 & 0.120 \\
\hline $2683-56 A$ & AUG 15 & 200 & 0.34 & 0.56 & 0.220 \\
\hline $2683-56 C$ & & 600 & 0.37 & 0.69 & 0.280 \\
\hline $2683-57 B$ & & 1000 & 0.19 & 0.47 & 0.160 \\
\hline $2683-57 D$ & & 1400 & 0.14 & 0.45 & 0.130 \\
\hline $2683-58 B$ & & 1800 & 0.1 & 0.39 & 0.100 \\
\hline $2683-580$ & & 2200 & 0.09 & 0.37 & 0.100 \\
\hline $2683-59 A$ & AUG 16 & 200 & 0.09 & 0.37 & 0.090 \\
\hline $2683-59 C$ & & 600 & 0.1 & 0.37 & 0.100 \\
\hline $2683-608$ & & 1000 & 0.14 & 0.38 & 0.110 \\
\hline $2683-600$ & & 1400 & 0.11 & 0.36 & 0.100 \\
\hline $2683-61 A$ & & 1800 & 0.11 & 0.34 & 0.100 \\
\hline $2683-61 C$ & & 2200 & 0.12 & 0.38 & 0.100 \\
\hline $2683-62 B$ & AUG 17 & 200 & 0.11 & 0.38 & 0.100 \\
\hline $2683-62 C$ & & 600 & 0.12 & 0.37 & 0.100 \\
\hline $2683-63 B$ & & 1000 & 0.12 & 0.37 & 0.100 \\
\hline $2683-63 D$ & & 1400 & 0.13 & 0.38 & 0.100 \\
\hline $2683-64 B$ & & 1800 & 0.14 & 0.40 & 0.110 \\
\hline $2683 \rightarrow 640$ & & 2200 & 0.14 & 0.36 & 0.110 \\
\hline $2683-65 A$ & AUG 18 & 200 & 0.55 & 0.48 & 0.360 \\
\hline $2683-65 D$ & & 800 & 0.98 & 0.61 & 0.700 \\
\hline $2683-66 \mathrm{~B}$ & & 1000 & 0.59 & 0.51 & 0.380 \\
\hline $2683-66 C$ & & 1400 & 0.2 & 0.44 & 0.130 \\
\hline $2683-67 B$ & & 1800 & 0.15 & 0.39 & 0.110 \\
\hline $2683-68 B$ & & 2200 & 0.16 & 0.39 & 0.110 \\
\hline $2683-698$ & AUG 19 & 200 & 0.18 & 0.44 & 0.120 \\
\hline $2683-70 B$ & & 600 & 0.17 & 0.40 & 0.120 \\
\hline
\end{tabular}


METAL ANALYSIS

\begin{tabular}{rrrrrr} 
Sample ID & Date & Time & Ni, $\%$ & Fe, $\%$ & CU, $\%$ \\
\hline $2683-70 D$ & & 1000 & 0.2 & 0.44 & 0.120 \\
$2683-71 A$ & & 1400 & 0.2 & 0.43 & 0.120 \\
$2683-72 A$ & & 1800 & 0.29 & 0.71 & 0.170 \\
$2683-72 C$ & & 2200 & 0.34 & 0.48 & 0.200 \\
$2683-73 A$ & AUG 20 & 200 & 0.27 & 0.44 & 0.160 \\
$2683-73 D$ & & 600 & 0.56 & 0.74 & 0.310 \\
$2683-73 F$ & & 1000 & 0.29 & 0.50 & 0.180 \\
$2683-74 A$ & & 1400 & 0.22 & 0.44 & 0.130 \\
$2683-74 B$ & & 1800 & 0.22 & 0.45 & 0.140 \\
$2683-74 D$ & & 2200 & 0.22 & 0.44 & 0.140 \\
$2683-75 A$ & AUG 21 & 200 & 0.22 & 0.44 & 0.130 \\
$2683-76 A$ & & 600 & 0.21 & 0.42 & 0.130 \\
$2683-76 C$ & & 1000 & 0.24 & 0.44 & 0.140 \\
$2683-76 F$ & & 1400 & 0.24 & 0.44 & 0.140 \\
$2687-1 B$ & & 1800 & 0.25 & 0.44 & 0.140 \\
$2687-1 D$ & & 2200 & 0.26 & 0.48 & 0.160 \\
$2687-1 E$ & AUG 22 & 200 & 0.25 & 0.44 & 0.150 \\
$2687-2 A$ & & 600 & 0.25 & 0.42 & 0.140 \\
$2687-2 D$ & & 1000 & 0.26 & 0.46 & 0.150 \\
$2687-2 E$ & & 1400 & 0.27 & 0.46 & 0.160 \\
$2687-3 A$ & & 1800 & 0.72 & 3.07 & 0.430 \\
$2687-3 C$ & & 2200 & 0.42 & 1.63 & 0.220 \\
$2687-4 A$ & AUG 23 & 200 & 0.31 & 0.51 & 0.180 \\
$2687-4 C$ & & 600 & 0.33 & 0.60 & 0.180 \\
$2687-4 F$ & & 1000 & 0.3 & 0.52 & 0.180 \\
$2687-5 B$ & & 1400 & 0.27 & 0.45 & 0.160 \\
$2687-6 B$ & & 1800 & 0.29 & 0.48 & 0.160 \\
$2687-6 D$ & & 2200 & 0.28 & 0.48 & 0.160 \\
$2687-7 A$ & AUG 24 & 200 & 0.3 & 0.49 & 0.170 \\
$2687-7 C$ & & 600 & 0.28 & 0.46 & 0.150 \\
$2687-8 A$ & & 1000 & 0.3 & 0.52 & 0.170 \\
$2687-8 D$ & & 1400 & 0.3 & 0.51 & 0.170 \\
$2687-8 E$ & & 1800 & 0.3 & 0.51 & 0.170 \\
$2687-8 H$ & & 2200 & 0.31 & 0.52 & 0.180 \\
$2687-9 A$ & AUG 25 & 200 & 0.32 & 0.52 & 0.180 \\
$2687-9 C$ & & 600 & 0.32 & 0.52 & 0.180 \\
$2687-9 F$ & & 1000 & 0.32 & 0.52 & 0.190 \\
$2687-9 H$ & & 1400 & 0.32 & 0.54 & 0.180 \\
$2687-10 B$ & & 1800 & 0.31 & 0.53 & 0.170 \\
$2687-10 D$ & & 2200 & 0.32 & 0.54 & 0.180 \\
$2687-10 E$ & AUG 26 & 200 & 0.32 & 0.52 & 0.180 \\
$2687-11 A$ & & 600 & 0.32 & 0.54 & 0.180 \\
$2687-11 C$ & & 1000 & 0.36 & 0.66 & 0.220 \\
$2687-15 B$ & & 1400 & 0.3 & 0.55 & 0.170 \\
$2687-15 D$ & & 1800 & 0.3 & 0.56 & 0.170
\end{tabular}


METAL ANALYSIS

\begin{tabular}{crrrrr} 
Sample ID & Date & Time & Ni, \% & Fe, \% & Cu, \% \\
\hline $2687-15 E$ & & 2200 & 0.29 & 0.54 & 0.160 \\
$2687-16 B$ & AUG 27 & 200 & 0.29 & 0.53 & 0.170 \\
$2687-16$ C & & 600 & 0.29 & 0.54 & 0.160 \\
$2687-16$ F & & 730 & 0.3 & 0.54 & 0.170 \\
$2687-16 G$ & & 1000 & 0.32 & 0.56 & 0.190 \\
$2687-17 C$ & & 1400 & 0.33 & 0.57 & 0.190 \\
$2687-18 C$ & & 1800 & 0.33 & 0.56 & 0.190 \\
$2687-18 F$ & & 2200 & 0.33 & 0.56 & 0.190 \\
$2687-19 A$ & AUG 28 & 200 & 0.34 & 0.56 & 0.210 \\
$2687-19 D$ & & 600 & 0.35 & 0.57 & 0.210 \\
$2687-20 B$ & & 1000 & 0.34 & 0.56 & 0.200 \\
$2687-20 D$ & & 1400 & 0.36 & 0.57 & 0.220 \\
$2687-21 A$ & & 1800 & 0.41 & 0.61 & 0.250 \\
$2687-21 C$ & & 2200 & 0.41 & 0.62 & 0.250 \\
$2687-22 A$ & AUG 29 & 600 & 0.46 & 0.63 & 0.300 \\
$2687-23 A$ & & 1000 & 0.62 & 0.80 & 0.520 \\
$2687-238$ & & 1400 & 0.48 & 0.68 & 0.360 \\
$2687-23 C$ & & 1800 & 0.49 & 0.69 & 0.380 \\
$2687-24 A$ & & 2200 & 0.53 & 0.71 & 0.420 \\
$2687-24 C$ & AUG 30 & 200 & 0.53 & 0.72 & 0.430 \\
$2687-24 F$ & & 600 & 0.56 & 0.77 & 0.460 \\
$2687-25 A$ & & 1000 & 0.56 & 0.74 & 0.460 \\
$2687-30 B$ & & 1400 & 0.58 & 0.76 & 0.480
\end{tabular}


APPENDIX E

METAL IMPURITIES IN THE BATH 
BATH IMPUAITIES

\begin{tabular}{|c|c|c|c|c|c|}
\hline Sample ID & Date & Time & Cu, \% & $\mathrm{Ni}, \%$ & $\mathrm{Fe}, \%$ \\
\hline $2683-15 A$ & AUG 3 & 1400 & 0.002 & 0.005 & 0.066 \\
\hline $2683-15 A$ & & 1400 & 0.002 & 0.005 & 0.066 \\
\hline $2683-16 A$ & & 1800 & 0.002 & 0.006 & 0.077 \\
\hline $2683-16 B$ & & 2200 & 0.002 & 0.006 & 0.096 \\
\hline $2683-178$ & AUG 4 & 200 & 0.001 & 0.006 & 0.067 \\
\hline $2683-18 A$ & & 600 & 0.001 & 0.006 & 0.057 \\
\hline $2683-18 B$ & & 1000 & 0.001 & 0.007 & 0.078 \\
\hline $2683-18 C$ & & 1400 & 0.001 & 0.007 & 0.089 \\
\hline $2683-19 A$ & & 1800 & 0.001 & 0.006 & 0.081 \\
\hline $2683-19 C$ & & 2200 & 0.001 & 0.006 & 0.076 \\
\hline $2683-208$ & AUG 5 & 200 & 0.001 & 0.007 & 0.280 \\
\hline $2683-20 C$ & & 600 & 0.001 & 0.006 & 0.100 \\
\hline $2683-20 E$ & & 1000 & 0.001 & 0.007 & 0.044 \\
\hline $2683-20 G$ & & 1400 & 0.001 & 0.008 & 0.040 \\
\hline $2683-22 A$ & & 1800 & 0.001 & 0.006 & 0.083 \\
\hline $2683-22 C$ & & 2200 & 0.001 & 0.006 & 0.170 \\
\hline $2683-238$ & AUG 6 & 200 & 0.001 & 0.006 & 0.055 \\
\hline $2683-23 D$ & & 600 & 0.001 & 0.005 & 0.054 \\
\hline $2683-23 E$ & & 1000 & $<.001$ & 0.006 & 0.024 \\
\hline $2683-24 A$ & & 1400 & $<.001$ & 0.006 & 0.022 \\
\hline $2683-24 C$ & & 1800 & $<.001$ & 0.005 & 0.025 \\
\hline $2683-24 E$ & & 2200 & $<.001$ & 0.008 & 0.037 \\
\hline $2683-25 B$ & AUG 7 & 200 & $<.001$ & 0.006 & 0.024 \\
\hline $2683-25 C$ & & 600 & $<.001$ & 0.006 & 0.034 \\
\hline $2683-26 \mathrm{~B}$ & & 1000 & $<.001$ & 0.005 & 0.023 \\
\hline $2683-26 D$ & & 1400 & $<.001$ & 0.005 & 0.021 \\
\hline $2683-27 \mathrm{~A}$ & & 1800 & $<.001$ & 0.005 & 0.025 \\
\hline $2683-27 C$ & & 2200 & $<.001$ & 0.005 & 0.027 \\
\hline $2683-28 A$ & AUG 8 & 0 & $<.00 t$ & 0.004 & 0.020 \\
\hline $2683-28 C$ & & 400 & $<.001$ & 0.004 & 0.020 \\
\hline $2683-28 E$ & & 1000 & $<.001$ & 0.006 & 0.018 \\
\hline $2683-29 B$ & & 1400 & $<.001$ & 0.006 & 0.021 \\
\hline $2683-30 A$ & & 1800 & $<.001$ & 0.006 & 0.020 \\
\hline $2683-31 B$ & & 2200 & $<.001$ & 0.005 & 0.016 \\
\hline $2683-31 D$ & AUG 9 & 200 & $<.001$ & 0.006 & 0.019 \\
\hline $2683-32 B$ & & 600 & $<.001$ & 0.006 & 0.016 \\
\hline $2683-33 A$ & & 1000 & $<.001$ & 0.006 & 0.019 \\
\hline $2683-34 A$ & & 1400 & $<.001$ & 0.006 & 0.022 \\
\hline $2683-34 A$ & & 1800 & $<.001$ & 0.006 & 0.023 \\
\hline $2683-35 A$ & & 2200 & $<.001$ & 0.005 & 0.015 \\
\hline $2683-36 A$ & AUG 10 & 200 & $<.001$ & 0.006 & 0.019 \\
\hline $2683-36 \mathrm{C}$ & & 600 & $<.001$ & 0.006 & 0.021 \\
\hline $2683-37 \mathrm{~A}$ & & 1000 & $<.001$ & 0.006 & 0.021 \\
\hline $2683-38 A$ & & 1400 & $<.001$ & 0.006 & 0.023 \\
\hline $2683-39 A$ & & 1800 & 0.005 & 0.009 & 0.025 \\
\hline $2683-40 A$ & & 2200 & 0.003 & 0.009 & 0.024 \\
\hline
\end{tabular}


BATH IMPURITIES

\begin{tabular}{|c|c|c|c|c|c|}
\hline Sample ID & Date & Time & $\mathrm{Cu}, \%$ & $\mathrm{Ni}, \%$ & $\mathrm{Fe}, \%$ \\
\hline $2683-41 A$ & AUG 11 & 200 & 0.002 & 0.008 & 0.026 \\
\hline $2683-42 A$ & & 600 & 0.002 & 0.007 & 0.031 \\
\hline $2683-43 A$ & & 1000 & 0.005 & 0.012 & 0.044 \\
\hline $2683-43 C$ & & 1400 & 0.003 & 0.009 & 0.033 \\
\hline $2683-44 A$ & & 1800 & 0.008 & 0.018 & 0.030 \\
\hline $2683-45 A$ & & 2200 & 0.002 & 0.018 & 0.017 \\
\hline $2683-46 B$ & AUG 12 & 200 & 0.001 & 0.006 & 0.027 \\
\hline $2683-46 D$ & & 600 & 0.001 & 0.006 & 0.022 \\
\hline $2683-478$ & & 1000 & 0.002 & 0.007 & 0.025 \\
\hline $2683-488$ & & 1400 & 0.002 & 0.007 & 0.027 \\
\hline $2683-48 A$ & & 1800 & 0.001 & 0.006 & 0.024 \\
\hline $2683-49 A$ & & 2200 & 0.001 & 0.006 & 0.019 \\
\hline $2683-49 C$ & AUG 13 & 200 & 0.002 & 0.007 & 0.028 \\
\hline $2683-50 A$ & & 600 & 0.001 & 0.006 & 0.029 \\
\hline $2683-50 \mathrm{D}$ & & 1000 & 0.001 & 0.007 & 0.025 \\
\hline $2683-50 F$ & & 1400 & 0.001 & 0.006 & 0.024 \\
\hline $2683-52 A$ & & 1800 & 0.001 & 0.006 & 0.027 \\
\hline $2683-520$ & & 2200 & 0.001 & 0.006 & 0.024 \\
\hline $2683-53 A$ & AUG 14 & 200 & 0.003 & 0.009 & 0.021 \\
\hline 2683-53D & & 600 & 0.001 & 0.006 & 0.019 \\
\hline $2683-53 E$ & & 1000 & 0.001 & 0.005 & 0.017 \\
\hline $2683-54 A$ & & 1400 & 0.001 & 0.006 & 0.018 \\
\hline $2683-55 A$ & & 1800 & 0.002 & 0.007 & 0.018 \\
\hline $2683-55 C$ & & 2200 & 0.001 & 0.005 & 0.015 \\
\hline $2683-56 B$ & AUG 15 & 200 & 0.001 & 0.006 & 0.018 \\
\hline $2683-56 D$ & & 600 & 0.001 & 0.006 & 0.018 \\
\hline $2683-57 A$ & & 1000 & 0.001 & 0.007 & 0.019 \\
\hline $2683-57 C$ & & 1400 & 0.001 & 0.006 & 0.023 \\
\hline $2683-58 A$ & & 1800 & 0.001 & 0.007 & 0.028 \\
\hline $2683-58 \mathrm{C}$ & & 2200 & 0.001 & 0.006 & 0.023 \\
\hline $2683-59 B$ & AUG 16 & 200 & 0.001 & 0.006 & 0.026 \\
\hline $2683-59 D$ & & 600 & 0.001 & 0.006 & 0.024 \\
\hline $2683-60 A$ & & 1000 & 0.001 & 0.006 & 0.019 \\
\hline $2683-60 \mathrm{C}$ & & 1400 & 0.002 & 0.007 & 0.017 \\
\hline $2683-61 B$ & & 1800 & 0.001 & 0.006 & 0.024 \\
\hline $2683-61 D$ & & 2200 & 0.002 & 0.005 & 0.014 \\
\hline $2683-62 A$ & AUG 17 & 200 & 0.001 & 0.007 & 0.018 \\
\hline $2683-62 D$ & & 600 & 0.001 & 0.006 & 0.019 \\
\hline $2683-63 A$ & & 1000 & 0.001 & 0.006 & 0.017 \\
\hline $2683-63 C$ & & 1400 & 0.005 & 0.013 & 0.020 \\
\hline $2683-64 A$ & & 1800 & 0.002 & 0.006 & 0.020 \\
\hline $2683-64 C$ & & 2200 & 0.002 & 0.006 & 0.018 \\
\hline $2683-65 B$ & AUG 18 & 200 & 0.002 & 0.008 & 0.028 \\
\hline $2683-65 C$ & & 600 & 0.002 & 0.007 & 0.030 \\
\hline $2683-66 A$ & & 1000 & 0.002 & 0.009 & 0.028 \\
\hline $2683-66 D$ & & 1400 & 0.001 & 0.008 & 0.024 \\
\hline
\end{tabular}


BATH IMPURITIES

\begin{tabular}{llrrrr} 
Sample ID & Date & Time & Cu, \% & Ni, \% & Fe, \% \\
\hline $2683-67 A$ & & 1800 & 0.002 & 0.010 & 0.029 \\
$2683-68 A$ & & 2200 & 0.002 & 0.009 & 0.025 \\
$2683-69 A$ & AUG 19 & 200 & 0.002 & 0.009 & 0.026 \\
$2683-70 A$ & & 600 & 0.002 & 0.008 & 0.026 \\
$2683-70 C$ & & 1000 & 0.002 & 0.009 & 0.027 \\
$2683-71 B$ & & 1400 & 0.002 & 0.009 & 0.027 \\
$2683-72 B$ & & 1800 & 0.002 & 0.008 & 0.032 \\
$2683-72 D$ & & 2200 & 0.001 & 0.007 & 0.028 \\
$2683-73 B$ & AUG 20 & 200 & 0.001 & 0.007 & 0.020 \\
$2683-73 D$ & & 600 & 0.002 & 0.008 & 0.026 \\
$2683-73 E$ & & 1000 & 0.002 & 0.006 & 0.022 \\
$2683-74 A$ & & 1400 & 0.002 & 0.006 & 0.028 \\
$2683-74 B$ & & 1800 & 0.001 & 0.006 & 0.023 \\
$2683-74 C$ & & 2200 & 0.002 & 0.005 & 0.014 \\
$2683-75 B$ & AUG 21 & 200 & 0.002 & 0.005 & 0.021 \\
$2683-76 B$ & & 600 & 0.001 & 0.005 & 0.029 \\
$2683-76 D$ & & 1000 & 0.002 & 0.005 & 0.019 \\
$2683-76 E$ & & 1400 & 0.002 & 0.005 & 0.020 \\
$2687-1 A$ & & 1800 & 0.002 & 0.006 & 0.026 \\
$2687-1 C$ & & 2200 & 0.002 & 0.008 & 0.025 \\
$2687-1 F$ & AUG 22 & 200 & 0.002 & 0.008 & 0.022 \\
$2687-2 B$ & & 600 & 0.002 & 0.006 & 0.022 \\
$2687-2 C$ & & 1000 & 0.002 & 0.008 & 0.023 \\
$2687-2 F$ & & 1400 & 0.002 & 0.009 & 0.022 \\
$2687-3 B$ & & 1800 & 0.002 & 0.013 & 0.051 \\
$2687-3 D$ & & 2200 & 0.002 & 0.006 & 0.023 \\
$2687-4 B$ & AUG 23 & 200 & 0.001 & 0.007 & 0.020 \\
$2687-4 D$ & & 600 & 0.002 & 0.007 & 0.024 \\
$2687-4 E$ & & 1000 & 0.002 & 0.006 & 0.033 \\
$2687-5 A$ & & 1400 & 0.002 & 0.007 & 0.032 \\
$2687-6 A$ & & 1800 & 0.002 & 0.006 & 0.028 \\
$2687-6 C$ & & 2200 & 0.002 & 0.006 & 0.029 \\
$2687-78$ & AUG 24 & 200 & 0.002 & 0.006 & 0.025 \\
$2687-7 D$ & & 600 & 0.002 & 0.006 & 0.023 \\
$2687-8 B$ & & 1000 & 0.002 & 0.012 & 0.080 \\
$2687-8 C$ & & 1400 & 0.002 & 0.008 & 0.060 \\
$2687-8 F$ & & 1800 & 0.002 & 0.009 & 0.052 \\
$2687-8 G$ & & 2200 & 0.003 & 0.009 & 0.043 \\
$2687-9 B$ & AUG 25 & 200 & 0.002 & 0.007 & 0.036 \\
$2687-9 D$ & & 600 & 0.002 & 0.007 & 0.041 \\
$2687-9 G$ & & 1000 & 0.002 & 0.006 & 0.026 \\
$2687-9 J$ & & 1400 & 0.002 & 0.006 & 0.024 \\
$2687-10 A$ & & 1800 & 0.002 & 0.007 & 0.032 \\
$2687-10 C$ & & 2200 & 0.002 & 0.006 & 0.031 \\
$2687-10 F$ & AUG 26 & 200 & 0.002 & 0.008 & 0.028 \\
$2687-11 B$ & & 600 & 0.002 & 0.008 & 0.027
\end{tabular}


BATH IMPURITIES

\begin{tabular}{|c|c|c|c|c|c|}
\hline Sample ID & Date & Time & $\mathrm{Cu}, \%$ & $\mathrm{Ni}, \%$ & $\mathrm{Fe}, \%$ \\
\hline $2687-11 D$ & & 1000 & 0.002 & 0.008 & 0.034 \\
\hline $2687-15 A$ & & 1400 & 0.003 & 0.007 & 0.031 \\
\hline $2687-15 \mathrm{C}$ & & 1800 & 0.002 & 0.006 & 0.040 \\
\hline $2687-15 F$ & & 2200 & 0.002 & 0.005 & 0.024 \\
\hline $2687-16 B$ & AUG 27 & 200 & 0.002 & 0.005 & 0.030 \\
\hline $2687-16 D$ & & 600 & 0.005 & 0.011 & 0.036 \\
\hline $2687-16 E$ & & 700 & 0.003 & 0.008 & 0.036 \\
\hline $2687-16 \mathrm{H}$ & & 1000 & 0.003 & 0.009 & 0.040 \\
\hline $2687-17 A$ & & 1200 & & & \\
\hline $2687-178$ & & 1400 & 0.003 & 0.008 & 0.040 \\
\hline $2687-18 A$ & & 1600 & & & \\
\hline $\begin{array}{l}2687-18 \mathrm{~B} \\
2687-180\end{array}$ & & 1800 & 0.003 & 0.009 & 0.049 \\
\hline $2687-18 F$ & & $\begin{array}{l}2000 \\
2200\end{array}$ & 0.003 & 0.009 & 0.057 \\
\hline $2687-18 G$ & AUG 28 & 0 & & & \\
\hline $2687-19 B$ & & 200 & 0.003 & 0.009 & 0.047 \\
\hline $2687-19 C$ & & 400 & & & \\
\hline $2687-19 E$ & & 600 & 0.004 & 0.010 & 0.038 \\
\hline $2687-20 A$ & & 1000 & 0.003 & 0.009 & 0.056 \\
\hline $2687-20 C$ & & 1400 & 0.002 & 0.008 & 0.060 \\
\hline $2687-21 B$ & & 1800 & 0.003 & 0.009 & 0.049 \\
\hline $2687-21 D$ & & 2200 & 0.003 & 0.009 & 0.052 \\
\hline $2687-228$ & AUG 29 & 200 & 0.011 & 0.017 & 0.073 \\
\hline $2687-22 C$ & & 600 & 0.007 & 0.014 & 0.078 \\
\hline $2687-23 A$ & & 1000 & 0.006 & 0.013 & 0.112 \\
\hline $2687-23 B$ & & 1400 & 0.005 & 0.013 & 0.079 \\
\hline $2687-23 D$ & & 1800 & 0.012 & 0.021 & $0.1+0$ \\
\hline $2687-24 B$ & & 2200 & 0.013 & 0.020 & 0.174 \\
\hline $2687-24 D$ & AUG 30 & 200 & 0.007 & 0.013 & 0.079 \\
\hline $2687-24 E$ & & 600 & 0.003 & 0.009 & 0.054 \\
\hline $2687-25 B$ & & 1000 & 0.006 & 0.013 & 0.042 \\
\hline $2687-30 A$ & & 1400 & 0.005 & 0.017 & 0.060 \\
\hline
\end{tabular}




\section{DISTRIBUTION}

No. of

Copies

\section{OFFSITE}

M. J. McMonigle

U.S. Department of Energy

Office of Industrial Programs

Forrestal Building

Washington, DC 20585

P. H. Salmon-Cox

U.S. Department of Energy

Office of Industrial Programs

Forrestal Building

Washington, DC 20585

12 DOE Office of Scientific and

Technical Information

Dr. T. Alcorn

Manufacturing Technology Laboratory

Reynolds Metals Co.

3326 East 2nd Street

Muscle Shoals, AL 35661-1258

C. Anderson

Columbia Aluminum Co.

85 John Day Dam Road

Goldendale, WA 98620

J. V. Anderson

WCVE3

EG\&G Idaho, Inc.

Idaho Falls, ID 83415

D. Auburg

Bonnevilie Power Administration

P.0. Box 3621, PDX 97208

Portland, OR 97208

F. W. Baker

Ceramics Division

Alcoa Laboratories

Alcoa Center, PA 15069
No, of

Copies

M. Baltzell

Eastalco Aluminum Company

Alumax, Inc.

5601 Manor Woods

Frederick, MD 21701

J. A. Barclay

U.S. Bureau of Mines

2401 "E" Street N.W.

Washington, DC 20241

H. Robert Baungartner

Ceramics Division

ATcoa Laboratories

Alcoa Center, PA 15069

T. R. Beck

Electrochemical Technology Corp.

1601 Dexter Avenue

Seattle, WA 98109

S. Berwagan

Bonneville Power Administration

P.0. Box $3621 \mathrm{~K}$

Portland, OR 97208

T. M. Besmann

Metals and Ceramics Division

Oak Ridge National Laboratory

P.0. Box X, Bldg. 4515

Oak Ridge, TN 37831-6063

K. A. Blakely

President

Advanced Refractory

Technologies, Inc.

699 Hertel Ave.

Buffalo, NY 14207

M. H. Blenk

Du Pont

P.0. Box 787

Niagara Falls, NY 14302 
No. of

Copies

L. G. Boxall

Martin Marietta Laboratories 1450 South Rolling

Baltimore, MD 21227

J. Bracher

Kaiser Aluminum and Chemical Corp.

825 N.E. Multnomah St., Suite 960

Portland, OR 97232-2150

R. Brandt

Department of Materials Science and Engineering University of Washington FB-10 Seattle, WA 98195

J. J. Brown, Jr.

Materials Engineering

Virginia Polytechnic Institute B1acksburg, VA 24061

A. J. Caputo

Development Division

0ak Ridge $Y-12$ Plant

Building 9202 MS-B095

0ak Ridge, TN 37831-8095

N. Clark

Bonneville Power Administration Industrial Conservation

P.0. Box 3621

Portland, OR 97208

A. Cooke

Martin Marietta Laboratories

1450 South Rolling

Baltimore, MD 21227

J. A. Coppola

Standard 0il Engineered

Materiais Company

P.0. Box 156

Niagara Falls, NY 14302
No. of

Copies

R. Curtis

Materials Development

Corporation

81 Hicks Avenue

Medford, MA 02155

J. V. Day

Kaiser Aluminum and Chemica]

Corp.

E 2111 Hawthorne Road

Mead, WA 99021

D. H. DeYoung

Alcoa Technical Center

Alcoa Center, PA 15069

T. Dwonch

Snake River District BPA

101 W. Poplar

Walla Walla, WA 99362

G. L. Eitel

Stone \& Webster Engineering Corp Greenwood P7aza Box 5406

Denver, C0 80217

R. Engdahl

Deposits and Composites, Inc.

318 Victory Drive

Herndon, VA 22070

B. G. Epstein

A. D. Little, Inc.

955 Lenfant Plaza SW 4200

Washington; DC 20024-2119

J. W. Evans

University of California

Dept of Mat?. Sci. and Mineral Eng.

Berkeley, CA 94720

R. A. Fenimore

ICI Advanced Materials

Rollins Building, Eighth Floor

Wilmington, DE 19897 
No. of

Copies

D. A. Figgins

ARCO Petroleum Products Co.

P.0. Box 61004

Anaheim, CA 92803-6104

P. Foster

Alcoa Laboratories

P.0. Box 772

New Kensington, PA 15068

J. Gee

Great Lakes Research Corp

P.0. Box 1031

Elizabethton, TN 37643

T. Gilligan

E]tech Systems Corp.

625 East Street

Fairport Harbor, $\mathrm{OH} \quad 44077$

W. M. Goldberger

Superior Graphite Co.

120 S. Riverside Plaza

Chicago, IL 60606

J. Goodwel1

Center for Metals Production

Mellon Institute

4400 Fifth Avenue

Pittsburgh, PA 15213

Dr. Janet Gregg

Eltech Research Corporation

625 East Street

Fairport Harbor, $\mathrm{OH} \quad 44077$

J. A. S. Green

Martin Marietta Laboratories

1450 South Rolling

Baltimore, MD 21227

C. Griffin

Ceramatec Inc.

2425 S. 900 West

Salt Lake City, UT 84119
No, of

Copies

\author{
L. I. Grindstaff \\ Great Lakes Research Corp. \\ P.0. Box 1031 \\ Elizabethton, TN 37643 \\ J. Haggerty \\ MIT \\ Building 12, Room 009 \\ 77 Massachusetts Avenue \\ Cambridge, MA 02139 \\ I. L. Harry \\ Electric Power Research \\ Institute \\ P.0. Box 10412 \\ Palo Alto, CA 94303 \\ W. E. Haupin \\ 28207 th Street Road \\ Lower Burre11, PA 15068
}

R. Hill

Union Carbide Corp.

P. 0. Box 94637

Cleveland, $\mathrm{OH} \quad 44101$

H. F. Hillegass

A]coa Wenatchee Works

P.0. Box 221

Wenatchee, WA 98807

D. G. Howitt

College of Engineering

University of Cal ifornia, Davis

Davis, CA 95616

F. R. Huettig

Advanced Magnetics, Inc.

45 Corey Lane

Medham, NJ 07945

G. R. Hyde

U.S. Bureau of Mines

2401 "E" Street N.W.

Washington, DC 20241 
No. of

Copies

S. C. Jacobs

Primary Processing

Aluminum Company of America

Alcoa Technical Center

Alcoa Center, PA 15069

S. H. Jan

Tennessee Valley Authority

R\&D Division - MR $3 A$

Chattanooga, TN 37401

N. Jarrett

149 Jefferson Avenue

New Kinsington, PA 15068

J. Johnson

Intalco Aluminum Company

P.0. Box 937

Ferndale, WA 98248

L. Joo

Great Lakes Research Corp.

P.0. Box 1031

Elizabethton, TN 37643

M. Karmous

Oregon State Department of Energy

625 Marion Street, N.E.

Sa]en, OR 97310

R. Keller

RD 3 Roundtop Road

Export, PA 15632

C. W. Koerr

The Stackpole Corporation

Cermag Division

201 Stackpole Street

St. Marys, PA 15847

K. Krupinski

Aristech Research

I000 Tech Center Dr.

Monroeville, PA 15146
No. of

Copies

G. Y. Lai

Cabot Corporation

P.0. Box 9013

Kokomo, IN 46902-9013

R. A. Landy

Director of Research

North American Refractories Co.

3127 Research Dr.

State College, PA 16801

J. E. Lane

Ceramic Research and

Development Center

Westinghouse Electric Corp.

1310 Beulah Road

Pittsburgh, PA 15235

Sai-Kwing Lau

Standard 0il Engineered

Materials Company

Niagara Falls R\&D Center

P.0. Box 832

Niagara Falls, NY 14302

J. J. Leddy

Dow Chemical U.S.A.

1776 Building

Midl and, MI 48640

W. W. Liang

Gas Research Institute

8600 West Bryne Mawr Avenue

Chicago, IL 60631

W. H. Link

Columbia Aluminum Corp.

85 John Day Dam Road

Goldendale, WA 98620

S. Loftness

Washington State Energy Office

$400 \mathrm{E}$. Union

01 ympia, WA 98504 
No. of

Copies

A. G. Longmuir

Kaiser Aluminum and Chemical Corp.

P.0. Box 877

Pleasanton, CA 94566

R. A. Lowden

Metals and Ceramics Division

0ak Ridge National Laboratory

P.0. Box X, B1dg, 4515

0ak Ridge, TN 37831-6063

W. N. Maclay

Koppers Company, Inc.

1005 William Pitt Way

Pittsburgh, PA 15238-1336

J. C. McCloskey

Ten Mile River Associates

$296 \mathrm{Mt}$. Hope Street

North Attleboro, MA 02760

Prof. G. Mamantov

University of Tennessee

Knoxville, TN 97996

S. C. Manaktala

Manager of Technology

Reduction Division

Kaiser Aluminum and Chemical

Corp.

300 Lakeside Drive

0akland, CA 94643

V. H. Markant

Du Pont

P.0. 80x 787

Niagara Falls, NY 14302

C. J. McMinn

Manufacturing Technology Laboratory

Reynolds Metals Co.

3326 East 2nd Street

Muscle Shoals, AL 35661-1258
No. of

Copies

C. H. McMurtry

Standard 0i1 Engineered

Materials Company

Niagara Falls R\&D Center

P.0. Box 832

Niagara Falls, NY 14302

M. A. Mitnick

Avco Specialty Materials

Subsidiary of Textron Inc.

2 Industria] Avenue

Lowe11, MA 01851

H. Mortensen

R. Palika

Cercom, Inc.

P.0. Box 70

Vista, CA 92083

P. Ness

Washington State Dept of Trade and Economic Development

2001 6th Avenue $\$ 2600$

Seattle, WA 98121-2522

C. L. Nikias

30010 Via Borica

Rancho Palos Verdes, CA 90274

J. R. Payne

Kaiser Aluminum and Chemica] Corp.

P.0. Box 877

Pleasanton, CA 94566

T. Payne

Columbia Falls Aluminum Co.

Columbia Falis, MT

W. Pebley

Oregon Freeze Dry Corp.

525 25th Avenue SW

P.0. Box 1048

Albany, OR 97321 
No. of

Copies

R. D. Peterson

Manufacturing Technology Laboratory

Reynolds Metals Co.

3326 East 2nd Street

Muscle Shoals, AL 35661-1258

T. R. Pritchett

Kaiser Aluminum and Chemical Corp.

P.0. Box 877

Pleasanton, CA 94566

W. W. Pritsky

Aluminum Association

900 19th St. N.W.

Washington, DC 20006

S. P. Ray

Alcoa Technical Center

Alcoa Center, PA 15069

Resource Center

Washington State Dept of Trade and Economic Development

20016 th Avenue \#2700

Seattle, WA 98121-2522

J. F. Rhodes

Advanced Composite Materials Corp.

1525 S. Buncomb Rd.

Greer, SC 29651

N. E. Richards

Manufacturing Technology Laboratory

Reynolds Metals Co.

3326 East 2nd Street

Muscle Shoals, AL 35661-1258

J. J. Ritter

Ceramics Division

National Bureau of Standards

Gaithersburg, MD 20899
No. of

Copies

R. C. Rohwedder

3028 0hio Street Longview, WAD.

R. Sadoway MIT Room 8-109

77 Massachusetts Avenue

Cambridge, MA 02139

W. Scott

Department of Materials

Science \& Engineering

Wilcox Hall FB-10

University of Washington

Seattle, WA 98195

D. R. Secrist

Great Lakes Research Corp.

P.0. Box 1031

Elizabethton, TN 37643

A. B. Shah

Noranda Aluminum, Inc.

P.0. Box 70

New Madras, MO 36869

N. Shelton

Intalco

1300 S.W. 5th, Suite 3508

Portland, OR 97201

Brian Spector

Pace Consultants

4848 Loop Central Drive

Houston, TX 77081

F. W. Spillers

Dow Chemical U.S.A.

B-1210 Building

Freeport, TX 77541

Dr. Richard M. Spriggs

Office of the Director

Center for Advanced

Ceramic Technology

Alfred University

Aifred, NY 14802 
No. of

Copies

D. V. Stewart

Manufacturing Technology Laboratory

Reynolds Metals Co.

3326 East 2nd St.

Muscle Shoals, AL 35661-1258

D. Strahan

Reynolds Metals Company

P.0. Box 27003

Richmond, VA 23261

A. T. Tabereaux

Manufacturing Technology Laboratory

Reynolds Metals Co.

3326 East 2nd Street

Muscle Shoals, AL 35661-1258

G. P. Tarcy

Aluminum Company of America

Alcoa Technical Center

ATcoa Center, PA 15069

$P$. Thaure

A1umax, Inc.

5655 Peachtree Parkway

Norcross, GA 30092

W. H. Thielbahr

Conservative Technology

Division

DOE-Idaho Operations Office

785 DoE Place

Idaho Falls, IO 83402

S. Thomson

General Manager

Klickitat PUD

1313 S. Columbus

Goldendale, WA 98620

R. Unger

Merner Research

P.0. Box 248

Ridgewood, NJ 07451
No. of

Copies

A. Vinnard

Bonneville Power

Administration (KWI)

P.0. Box 362l

Portland, OR 97208

T. Von Muller-KWI

Bonneville Power Administration

P.0. Box 3621

Portland, OR 9720B

D. H. Weinblatt

AIMCOR

One Parkway North

Deerfield, IL 60015

J. D. Weyand

EG\&G Idaho, Inc.

Idaho Falls, ID 83415

B. Wi1cox

Northwest Aluminum $\mathrm{Co}$.

$3313 \mathrm{~W}$. Second St.

The Dalles, OR 97058

C. B. Wilson

Dow Chemical U.S.A.

Texas Operations

B-101 Building

Freeport, TX 77541

\section{FOREIGN}

D. Brodie

Comalco Ltd.

55 Collins St.

Melbourne,

AUSTRALIA

H. Connor

Group Licensing Controller

Johnson Matthey, plc

New Garden House

78 Hatton Garden

London ECIN 8JP

ENGLAND 
No. of

Copies

T. Kjar

Comalco Ltd.

55 Collins St.

Melbourne,

AUSTRALIA

E. W. Dewing

A]can International

P.0. Box 8400

Kingston, Ontario

CANADA K7L $4 Z 4$

D. N. MacMillan

Alcan International

C.P. 1250

Jonquieve, Quebec

CANADA G7S $4 \mathrm{~K} 8$

A. Oye

Institute of Inorganic Chemistry

Norwegian Institute of Technology

University of Trondheim

N-7034 Trondheim-NTH, NORWAY

J. Thonstad

Laboratories of Industrial

Electrochemistry

Norwegian Institute of

Technology

University of Trondheim

$\mathrm{N}-7034$ Trondheim-NTH, NORWAY
No. of

Copies

K. 0 . Vee

ASV Arda1 Verk

N-5875 Ardalstargen,

NORWAY

Dr. Eric Frazer

CSIRO Australia

Division of Mineral Products

339 Williamstown Road

P.0. Box 124

Port Me]bourne, Vic 3207

ONSITE

DOE Richland Field Office

D. R. Segna

24 Pacific Northwest Laboratory

M. Clement

D. K. Hilliard

G. L. McVay

N. L. Moore

L. G. Morgan

D. M. Strachan

R. W. Westerman

R. E. Williford

C. F. Windisch (10)

Publishing Coordination

Technical Report Files (5) 